\title{
AN ANALYSIS OF RESTORATIVE JUSTICE AND INTIMATE PARTNER VIOLENCE POLICY AND PRACTICE: PROFESSIONALS' PERSPECTIVES AND PERCEPTIONS
}

\author{
BY \\ MELISSA L. GARBER
}

\begin{abstract}
A thesis
Submitted to the Victoria University of Wellington in fulfilment of the requirements for the degree of Doctor of Philosophy
\end{abstract}

Victoria University of Wellington

2016 
Copyright (C) 2016 Melissa L. Garber 


\section{ABSTRACT}

This qualitative research project endeavoured to open up the conversation around RJ and IPV and highlight gaps in policy in order to give voice to an area in the RJ process that has, up to this point, been virtually silent. There were two overarching aims. The first was to identify the underlying practice assumptions and values evident in the New Zealand Ministry of Justice (MOJ) restorative justice (RJ) standards for family violence (FV) cases (MOJ, 2013). These would be viewed from the perspective of working with intimate partner violence (IPV) cases in particular. The intention was to compare these assumptions and values with RJ and IPV international theory and New Zealand practice. The second aim was to clarify the processes and criteria used to determine/assess IPV offender suitability and readiness for RJ, ascertain the ways in which these practices were theoretically justified, and to compare the implementation of practice to the explicit and implicit guidelines present in New Zealand policy. To these ends, a collection of 30 criminal justice professionals (judges, lawyers, police officers) and restorative justice facilitators involved in the referral and assessment process of IPV offenders participated in interviews in person, over the phone, or via Skype, which were recorded, transcribed verbatim, and then subject to analysis in order to create a conceptual framework. The analysis identified 18 main themes that were grouped into four main categories: RJ IPV conceptualization, effective RJ IPV assessor qualities, IPV offender assessment for RJ suitability/readiness, and RJ IPV practice issues. These results were compared with policy and with the international literature in order to identify consistencies and inconsistencies and to discover where gaps in policy may become clarified. Results showed that a great deal of the policy was supported by the international literature, however there were several gaps and inconsistencies. Several issues were of interest - namely the lack of clarity in the framework of RJ for IPV (i.e. where does it sit in relation to the traditional criminal justice system, intervention vs. pathway vs. overarching framework), the timing of $\mathrm{RJ}$ assessment in terms of treatment and interventions, siloing of agencies, and funding/resourcing issues. A final question that arose for me during analysis was regarding the purpose and value of assessment in these cases. Rather than making a decision regarding suitability in order to exclude an IPV case from the RJ process, if the process was truly restorative, perhaps the outcome of an assessment of IPV offender/case suitability should, instead, be to determine what resources are necessary in order to support any IPV case through the RJ process. 


\section{ACKNOWLEDGEMENTS}

It is hard to know where to begin when writing this section. There have been so many people along this adventure that have been instrumental and invaluable. I will start by thanking my supervisor, Professor Tony Ward, for all of his patience, guidance, knowledge, counselling, and for believing in me and my ideas... and for allowing me to change my topic three months into this! I am so very grateful that I could take this journey with you!

Thank you to Chris Marshall for his support and for helping me attend the restorative justice conference in Vermont - your input throughout this project has been hugely appreciated. I would also like to thank Gabrielle Maxwell who was one of my first points of contact in the world of RJ and who spent many hours sharing her wealth of knowledge.

To my mother, Myrna Garber, who has supported me with encouragement and with her endless "guten toogies" and "carpe diems" - Thank you for modelling for me from an early age that a woman can do anything she sets her mind to. You are an incredible person.

I want to thank my amazing daughter Ayla Garber, who has had to deal with a mother who has been in school since she was five years old - I can only hope that my degree of distraction can somehow be compensated for by showing you that you too can do ANYTHING you set your mind and heart to. Thank you for being the incredible person you are and for enabling me to do this. You are a joy and an inspiration to me.

A huge thank you to my family and friends, near and far, who have been with me through all of this... a special thanks to Kaz, who supports me daily with cups of green tea, decaf coffee, hugs, love, and who patiently listens to endless conversations that begin with "I wonder..."

Thank you to my dear friend Jennifer Garvey Berger, who spent endless hours walking the hills of Paekakariki and Wellington with me, and who supported me with her thoughts, ideas, love, and gluten free goodies - who also failed to stop me from taking this $\mathrm{PhD}$ journey despite telling her after completing my Masters thesis to, "never let me study or do research 
again." Thank you to Michael Berger for your time and effort when most needed, and for the hugs you always had available.

Thank you to Nicola Morgan who spent valuable hours of her life combing through the pages of this thesis to find my annoyingly repetitive grammar and spelling errors... and for keeping my ego in check by continuously beating me on the tennis court.

This research would not exist if it were not for the participants. I am humbled by the generosity and openness of all of the individuals who consented to be interviewed. The knowledge and time that you shared with me is greatly appreciated. The passion that you all have for the work you do is truly amazing, heart-warming, and inspiring. 


\section{Table of contents}

$\begin{array}{lr}\text { Introduction } & 8\end{array}$

$\begin{array}{ll}\text { Chapter 1: Traditional criminal justice background } & 11\end{array}$

Chapter 2: Intimate partner violence (IPV) 28

Chapter 3: Restorative justice (RJ) 42

Chapter 4: Methods $\quad 57$

Chapter 5: Component 1 - Theoretical Analysis - New Zealand Policy 63

Chapter 6: Component 2 - Empirical Analysis $\quad 80$

- RJ IPV conceptualization $\quad 81$

- Effective RJ IPV assessor qualities 106

- IPV offender RJ assessment 120

- RJ IPV practice issues 149

$\begin{array}{ll}\text { Chapter 7: Discussion } & 166\end{array}$

Appendix A. Sample introductory letters, information sheets, consent forms 194

Appendix B. Semi-structured interview framework 200

Appendix C. Sentencing amendment act $2014 \quad 203$

Appendix D. Domestic Violence Act (1995) 204

$\begin{array}{ll}\text { References } & 207\end{array}$ 


\section{LIST OF TABLES}

1 Restorative justice core values in IPV 46

2 Restorative justice core values in IPV - implicit assumptions 


\section{LIST OF FIGURES}

1 Conceptualization and practice map of the assessment of RJ in IPV cases 80

$\begin{array}{lll}2 & \text { RJ IPV conceptualization } & 81\end{array}$

3 RJ IPV conceptualization: Relationship focus $\quad 81$

4 RJ IPV conceptualization: Practice aims 91

5 RJ IPV conceptualization: Role in justice process 95

6 RJ IPV conceptualization: MOJ RJ FV standards, laws, and RJ IPV case assessment 102

$7 \quad$ Effective RJ IPV assessor qualities 106

$8 \quad$ Effective RJ IPV assessor qualities: Knowledge/experience 107

9 Effective RJ IPV assessor qualities: Skill set 111

10 Effective RJ IPV assessor qualities: Capacity to create a safe environment 117

11 Effective RJ IPV assessor qualities: Risk assessment expertise 119

$\begin{array}{lll}12 & \text { IPV offender RJ assessment } & 121\end{array}$

13 IPV offender RJ assessment: Initially offender driven 122

14 IPV offender RJ assessment: Context of assessment 124

15 IPV offender RJ assessment: Sources of information 126

16 IPV offender RJ assessment: Green/yellow/red flag search 130

17 IPV offender RJ assessment: Judgment practices 143

18 RJ IPV practice issues 149

19 RJ IPV practice issues: New and evolving practice 150

20 RJ IPV practice issues: Pre-conference/conference configuration 156

21 RJ IPV practice issues: Relationship to external DV agencies 158

22 RJ IPV practice issues: Post conference monitoring 162

$\begin{array}{lll}23 & \text { RJ IPV practice issues: Politics } & 164\end{array}$ 


\section{INTRODUCTION}

Restorative justice is commonly acknowledged to be a grassroots movement that is often practice rather than theory-driven (Ward \& Langlands, 2008). According to Walgrave (2008), restorative justice is "an option for doing justice after the occurrence of an offence, that is primarily oriented towards repairing the individual, relational, and social harm caused by that offence" (p. 21). Historically, its primary focus has been on transforming the way justice is implemented in communities more than on formulating a coherent theory and set of norms to guide a response to crime. As Workman (2012b) puts it:

Pre - occupation with the question of whether an initiative "qualifies" as a Restorative Justice programme encourages purism. Restorative Justice does not exist in a pure state - it does not have that sort of pedigree. Restorative Justice is a mongrel - it was conceived not in the ivory towers of the state, but in the dusty streets of guilt and despair. It will sleep with anyone who wants it. (p. 3)

In other words, it could be said that RJ programmes constitute a patchwork of loosely connected ideas and practices rather than a tightly knitted set of principles and institutions. However, in relatively recent years there are government policies that have been instituted after consultation with restorative justice providers in order to "reflect an internal consistency about the values and principles that should inform RJ practice [while] allowing flexibility of practice within cultural and contextual variation"(MOJ, 2011, p. 5). In 2002, reference to RJ was incorporated into the New Zealand Sentencing Act of 2002 (MOJ, 2015b), and in 2004, the New Zealand Ministry of Justice (MOJ) released restorative justice principles of best practice, subsequently updated in 2011(MOJ, 2011). This was initially guided by consultation with the New Zealand restorative justice network (i.e. RJ providers, non-government organisations, judges, and other individuals working in the sector) (MOJ, 2013) and also partly in response to urging from the United Nations in 2002 that "states adopt guidelines and standards to govern the use of restorative justice programmes [in order to ensure that] the fundamental principles of RJ are upheld" (MOJ, 2011, p. 5). More recently, in July 2013, the MOJ released Restorative Justice Standards For Family Violence Cases (MOJ, 2013) because it considered that though the generic RJ best practice standards "provide a sound basis for the practice of restorative justice, additional safeguards are necessary when dealing with harm which has had complex or chronic impacts, such as family or sexual violence” (MOJ, 2013, p. 4). Additionally, in 2014 section 24a was added to the Sentencing Act (The Parliament of New Zealand, 2014), requiring judges to adjourn cases for restorative justice assessement 
when various fairly generic criteria are met - making restorative justice for adult offenders, far more mainstream than it ever has been in New Zealand. This thesis explores the literature on $\mathrm{RJ}$, the conventional criminal justice system, IPV, the policy that is in effect locally, and aimed to identify how this policy was put into practice and how this compares to international literature.

Chapter 1 begins by providing a background to the traditional criminal justice system and clarification of the terminology and concepts used throughout the thesis. Chapter 2 provides an in depth discussion of the international literature on intimate partner violence and the various treatment and intervention programmes used. The background, core values, and theoretical framework of restorative justice are explored in chapter 3. Additionally, the literature on understanding the appropriateness of restorative justice in IPV cases is examined. In chapter 4 the methodology used in the two components of this thesis is discussed. The first component is a theoretical analysis of the New Zealand policy and is presented in chapter 5 . This chapter systematically explores the current NZ policy on RJ and IPV, compares this to international literature from North America and Europe, and considers the following questions: what assumptions do these policies make regarding RJ values, processes and readiness; what procedures are found to best assess readiness, risk, and suitability to participate in RJ programmes; and is it possible to have programmes and procedures that reflect the values and principles of RJ while also addressing the complexities of IPV cases? This is followed by component 2 - the empirical analysis, in chapter 6 . This component utilizes grounded theory to understand the perspectives of 30 professionals (judges, lawyers, police, RJ facilitators, court coordinators) from the RJ IPV field. This component of this research explores: how the individuals understand/define RJ principles; what procedures for assessment and evaluation of readiness/appropriateness of and IPV offender to participate in $\mathrm{RJ}$ are used; do these practices reflect the principles of RJ; what model of RJ is implicated by these practices; and how are conferences implemented? The final chapter discusses specific points of tension that were found in both policy and practice and where this converged or diverged from the international literature.

This research found consistencies and inconsistencies between international literature, local policy, and local practice. Many of the findings clarify the gaps in the NZ policy and highlight areas in need of further attention. In particular, the question of whether RJ for IPV is a theoretical framework for addressing crime, part of the traditional criminal justice system, or an intervention. Another primary area of inquiry focused on the assessment of IPV offenders' suitability and readiness to participate in the RJ process. After analysis, the 
question arose of whether the point of the assessment should be suitability for participation in $\mathrm{RJ}$, or rather, a process in which to determine what safeguards, interventions, treatments, and support is required in order to have an effective $\mathrm{RJ}$ process.

Once we have greater clarity about the procedures currently in practice, future studies could explore the overall effectiveness of RJ practice for IPV. This is valuable information for judges and other criminal justice professionals as clarify RJ policy and practice facilitates the optimum use of resources (both financial and time) and validates interventions and policy. If RJ practices in the IPV domain lack adequate theoretical justification, are inconsistently applied, idiosyncratic, and poorly thought through, the integrity and ethical defensibility of this type of intervention are seriously undermined. The major goal of this research project was to shed light on these issues. 


\section{CHAPTER 1}

\section{TRADITIONAL CRIMINAL JUSTICE BACKGROUND}

The New Zealand Domestic Violence (DV) Act 1995 defines domestic violence as: "violence against that person by any other person with whom that person is, or has been in a domestic relationship.” (MOJ, 2014, p. 14). Domestic relationships refer to a heterosexual, homosexual, transgender, or bisexual present or past intimate partner, spouse, (MOJ, 2013), family member, or someone who shares a household with (not tenant or employee) or someone who has a close personal relationship with the other person (MOJ, 2014). Violence refers to physical, sexual, and psychological abuse which includes but is not limited to intimidation, harassment, damage of property, threats of physical, sexual or psychological abuse, and financial or economic abuse (MOJ, 2014). Abuse also includes spiritual violence that is thought to threaten an individual's mauri-ora (wellbeing) by robbing them of following their spiritual or religious beliefs and practices (National Collective of Independent Women's Refuges (NCIWR), 2013). Psychological and emotional abuse may take on many forms but at its core, it is thought to primarily be about manipulation and coercion (NCIWR, 2013). There are sections in the DV Act 1995 (MOJ, 2014) that define abuse towards children, however as this thesis is not focused directly on that particular area, definitions will not be provided.

At times, the terms domestic violence, spousal violence, family violence, and intimate partner violence (IPV) are used interchangeably in the literature (Hayden, 2010; Office of Women's Health, U.S. Department of Health and Human Services, 2015). The term IPV will be used throughout this thesis in order to clarify that this research focuses on abusive partners (present or past) rather than abuse involving children or other family members. However, there are some cases where the abbreviation FV or DV may be used if part of official legislation or a text title.

The use of the term victim is often contested in the context of IPV and DV as it is said that while it "makes clear the power relationship in which abuse occurs and while it acknowledges the violation and oppression experienced, it can obscure the agency [that other terms can imply]" (Laing \& Humphreys, 2013, p. 6). When referring to domestic violence and sexual violence, the term victim is often replaced with victim-survivor (Jülich, Buttle, Cummins, \& Freeborn, 2010; NCIWR, 2013). The combination of the terms victim and survivor, is said to "retain the empowerment conveyed by the word "survivor" and the outrage implied by the word "victim" (Koss \& Achilles, 2008, p. 1). The term offence victim was often used throughout the interviews, as was the term victim. However, the term victim- 
survivor will be used throughout this thesis in order to acknowledge the "complex coexistence of both agency and oppression" (Laing \& Humphreys, 2013, p. 6) unless quoting someone who uses different terminology. The terms offender, batterer, perpetrator, and abuser all refer to the individual who is responsible for committing violence (physical, sexual or psychological), without implying that charges or arrests have been made (Koss \& Achilles, 2008). The term offender is used across a lot of the literature (including the Ministry of Justice RJ standards and guidelines) (MOJ, 2013) and in the majority of the interviews; therefore offender will be used throughout this thesis for continuity. A final point - research shows that IPV abuse can be experienced by both men and women and perpetrated by both men and women. It is commonly thought that a majority of IPV is experienced as abuse to women perpetrated by men on women (Black, et al., 2011; Dennis, 2014), however, as will be discussed later, this is a contested point. Throughout the interviews, and in a lot of the literature, the offender was referred to using male pronouns; therefore, throughout this research the offender may often be referred to using male pronouns. This is not to discount the abuse that occurs to men, it is more for ease of reading and consistency. A final clarification, because this thesis is concerned with offences that are referred through the criminal justice system, and imprisonment is a form of punishment used by the criminal justice system, the term imprisonment may be used interchangably when referring to punishment.

It is important to not only clarify which individual terms are used throughout this thesis, but also to define broader terms that form the foundation of this research. Before introducing the two main components that explore New Zealand RJ IPV policy and practice, it is important to understand some of the underlying concepts that will be discussed such as justice, punishment, apologies, and readiness to change. Some of these concepts could warrant a lot more discussion time than is available in this thesis, however it is important to introduce them in order to begin to gain some insight into the intricacies that underlie the policy and practice of RJ and IPV.

\section{Justice}

"The wellbeing of a nation is measured not by the absence of disorder, but the presence of justice" (Workman, 2012a, p. 1).

The Oxford English Dictionary defines justice as, "the quality of being fair and reasonable; the administration of the law or authority in maintaining this" (Oxford Dictionaries Pro, 2013). Interestingly, it has been observed that many people, rather than defining what justice $i$, they focus on what justice is not (e.g. oppression, violation, 
segregation, inequality, bias, abuse) (Workman, 2012b). Consequently, it is suggested that “our criminal justice systems reflects society's negative or punitive response to crime and injustice, much more than being a positive and pro-active process of developing a more just society" (Nikkel, 2011, p. 2). In addition, it has been suggested that in forensic psychology, "justice is addressed pragmatically in debates on the causes of crime and their correction, without concern for the fundamental moral issues" (Taylor, 2006, p. 6). Thinking about this, Sawatsky (2008) poses the question, "if injustice is about excluding, breaking, and being shamed, then shouldn't justice be more about embracing, giving back, and connecting?" (p. 2).

Justice can be viewed as dynamic, and relational (Sawatsky, 2008) and is not simply about our response to offending or how we treat offenders - it is a reflection of the "moral character of society and it is comprehensively about advancing and protecting the wellbeing and peace of all people in that society" (Nikkel, 2011, p. 2). Justice is not "a detached exercise involving breaches of law, judgment and punishment. It embraces the whole fabric of social relationships and inter-relationships - individuals, families, communities, nations [and] is about us living with one another in nourishing and supporting the individual and social well-being of all people" (Workman, 2012a, p. 8). In fact, justice is considered to be a basic human need (Tolman, 2006) and morality and social justice are considered to be central to offender rehabilitation (Eccleston \& Ward, 2006).

\section{Punishment}

There is no relationship anywhere in the world between the imprisonment rate and the crime rate. The imprisonment rate is not a measure of crime. It is a measure of the consumption of punishment (Workman, 2012a, p.4).

What is punishment? A psychological definition of punishment is, "a consequence to a behaviour that decreases the likelihood of the behaviour from reoccurring" (Andrews \& Bonta, 2010, p. 442). Others would define it as "the deliberate infliction of harm by duly authorised agents of the state that involves the imposition of sanctions that would be considered morally wrong were they not within the law, such as deprivation of the right of offenders to freedom" (Eccleston \& Ward, 2006, p. 51).

Punishment is thought to be effective in suppressing undesirable behaviour because the individual will try to avoid the painful consequences (physical, emotional or psychological) of their actions. However, there are other known side effects to punishment that are undesirable in a broader sense (Andrews \& Bonta, 2010). Punishment may inhibit 
desirable behaviours (like socializing or going to work) and may increase the risk of developing learned helplessness if the situation is perceived as inescapable - which can increase depression and lower self esteem (Abramson, Seligman, \& Teasdale, 1978). If viewed as unfair or unjust by the individual being punished, punishment may also increase anger, hate, or feelings of rejection (Andrews \& Bonta, 2010). The effects and impact of punishment on those who are punished and their families and communities, vary depending on the sentence, the conditions in which the punishment is administered, and the offender's previous experience and character (Duff, 2001). Offender punishment (including those who are found not guilty) begins prior to trial and may include loss of money, freedom, shame, embarrassment, public scrutiny and the "forceful disciplinary power of the state" (Duff, 2001, p. viii).

New Zealand's rate of recorded crime in 2012 was at its lowest rate since 1979 (Workman, 2012a, p. 1) and the 2015 Global Peace Index ranked New Zealand forth highest worldwide in its state of peace (Institute for Economics and Peace (IEP), 2015). However, the number of individuals imprisoned was at a rate of 194 per 100,00 people, which is above England, Australia, and Germany (Workman, 2012a). The United States, with an incarceration rate of 756 per 100,000 in 2007, accounts for nearly half of the world's incarcerated individuals (Andrews \& Bonta, 2010) and while the population of the US grew $40 \%$ between 1970 and 2000, the incarceration rate increased by more than 500\% (King, Mauer, \& Young, 2005). Meanwhile, the US Department of Justice makes the claim that “tough sentencing means less crime” (King et al., 2005, p. 1).

Incarceration is a common and costly form of punishment. In the United States punishment not only involves the loss of freedom, but also the deprivation of various items that are thought to be "perks" such as cigarettes, television, and exercise facilities (Andrews $\&$ Bonta, 2010) and in some states capital punishment is still sanctioned. According to Workman (2012a), in New Zealand, prisons are secure - ensuring public safety from escape, and prisoners are looked at as "risks to be carefully managed [rather than] clients in need of support"(p. 7). In other words, there seems to be a greater focus by The Department of Corrections, on managing risk rather than managing relationships or supporting individual offender needs (Workman, 2012a).

Costs of punishment are not only associated with the burdens placed on the offender and his/her family, but also the financial burden on the penal system and community, the fear that may exist in the community regarding release of the offender following punishment, and the negative effect of being imprisoned and punished (Duff, 2001). Duff (2001) suggests that 
if alternative means that would bring greater benefit at a lower (or equivalent) cost are available, they should be considered. Implementation of this perspective requires identification of risk factors (both dynamic and static) in order to predict an offender's risk to the community, as well as the gains that would be achieved through punitive action (Duff, 2001; Ward, 2009).

There are five necessary elements when discussing punishment in the criminal justice context (Ward, 2009, p. 219). Punishment is:

1. Authorised by the state

2. Intentional

3. Retrobative (shows disapproval)

4. Retributive (follows a wrongful act committed by the offender)

5. Harmful (results in suffering, a burden or deprivation to the offender)

However, Bennett (2008) suggests that it is not clear, to victim-survivors and offenders, what the penal system is meant to accomplish, or whether "the officially given purposes are really compelling ones" (p. 13). There is a question of whether the harm that is inflicted on the offender, and the hardship that may also be experienced by family, friends and the wider community is justified. Outside of the criminal justice context, deliberately inflicting harm is considered morally wrong - so why is it justified in this context? There are several theories that provide possible justification.

\section{The Consequential (Ward, 2009) or instrumentalist theory (Bennett, 2008)}

The consequential or instrumentalist theory is a forward focused theory where punishment is justified because it will prevent future offending or initial offending because the individual wants to avoid suffering (Ward, 2009), and looks at the positive outcomes that will result from the punishment (i.e. reduced threat, rehabilitation, reduced offending) (Bennett, 2008). It posits that if good outweighs the harm, then punishment is justifiable (Duff, 2001) - in other words, inflicting suffering on an offender and his/her family is thought to be outweighed by the avoidance or reduction of suffering to their victim, potential victims, and the broader community. Instrumentalists think of punishment as a technique with which to solve social problems (Bennett, 2008).

The consequentialist theory, in itself, does not justify why punishment is the best means by which to reduce offending because rather than punishment being the deterrent that reduces recidivism, it is more a case that punishment can incapacitate potential offenders (through imprisonment or capital punishment), therefore reducing recidivism potential (Andrews \& Bonta, 2010). However, this is (except in the case of the death penalty) 
temporary and only partial as they will be released eventually and can also commit offences while imprisoned (Duff, 2001). The theory really does not answer the question of whether imprisonment reduces crime in the community nor does it highlight the cost of imprisonment on the community (Andrews \& Bonta, 2010).

In actual fact, it was found that states (in the United States) that had below average incarceration rates experienced a greater decline in crime rates than states with greater incarceration rates (King et al., 2005, p. 3). In a meta-analysis done by Smith, Goggin and Gendreau (2002), they found that not only were incarceration and intermediate sanctions (e.g. intensive supervision programmes, boot camps, electronic monitoring) not associated with decreased recidivism, those imprisoned had rates of recidivism that were $7 \%$ higher than offenders based in the community. The studies in their meta-analysis found there was no difference between prison or community sanction and offender risk level, and "excessive use of incarceration may have substantial cost implications" (Smith et al., 2002, p. ii). However, it is also important to assess the effects of prison on recidivism from the inside so to speak changes in prisoner behaviours and cognitions, situational factors within the prison that affect the adjustment of inmates, and how specific inmate characteristics interact with environmental factors in the prison (Smith et al., 2002).

Punishment, from the consequentialist perspective, would help to modify people's motivation and respect for the law which could in turn assist offenders in understanding that crime is wrong, leading to a reduced tendency to reoffend. Punishment can deter reoffending through shame as it is thought that individuals who "acknowledge shame and accept personal responsibility will refrain from further wrongdoing because they have considered the harmful consequences and [will want to] avoid them in the future" (Ahmed \& Braithwaite, 2005, p. 303). However, blaming others and dismissing shame can increase antisocial behaviour, therefore, there is no guarantee that punishment alone will create a scenario of personal responsibility (Ahmed \& Braithwaite, 2005).

\section{The Retribution theory}

The retribution theory of punishment is a past focused theory that justifies punishment as a response to a crime (Ward, 2009). This is grounded in the premise that "the guilty deserve to suffer" (Duff, 2003, p. 340) and that it is society's obligation to punish the guilty and that punishment is meant to fit the crime ("just deserts") (Andrews \& Bonta, 2010, p. 427). This perspective can be seen as harsh by some, and for others, offender suffering feels like the "intrinsically good" response to a crime (Honderich, 2006). This perspective has a very emotive and symbolically charged view of punishment (Bennett, 2008). 
Retribution theory justifies the idea of punishment as a means to restoring balance and justice in society, or some say as retaliation and vindication for the victim-survivor (Gerber \& Jackson, 2013). By not imposing punishment, violation of laws or public norms and the effect this has on the victim-survivors is not being adequately acknowledged (Ward, 2009). Communication of censure or condemnation to the offender, his victim and the wider community is achieved through punishment (Duff, 2003). This perspective does not justify punishment in terms of the consequences of punishment, but rather in terms of "its intrinsic justice as a response to crime" (Duff, 2001, p. 27). Punishment expresses blame and acknowledges that the offender is a "responsible moral agent" (Duff, 2001, p. 29) whose violation of social norms needs to be taken seriously and who should be held accountable (Ward, 2009). From a retribution perspective, "accountability encourages offenders to face up to the nature of the harm inflicted and to make amends by accepting the burdens associated with [criminal sanctions]" (Ward, 2009, p. 223).

A major problem with this perspective is that rehabilitation, therapeutic intervention and reintegration is given less attention than the placement of blame and accountability thereby focusing on moral accountability while psychological and social needs may be overlooked (Ward, 2009). In addition, retribution does not empower offenders in their own change process or satisfy the needs of victim-survivors (Eccleston \& Ward, 2006) and does not truly answer the questions of "why should they suffer?" and "how should they suffer?" (King et al., 2005). Additionally, it does not take into account the research that shows that punishment does not reduce crime (Andrews \& Bonta, 2010).

\section{Abolition theories}

The contingent abolitionist perspective argues that while state punishment, in some systems (which would be different from ours), might be justified, "punishment as practiced in our own societies cannot be justified, since it cannot be what it would need to be to be justified" (Duff, 2001, p. 31). This perspective posits that there is no system of state punishment that would ever be justifiable, no matter what kind of society we lived in. In terms of IPV, the abolitionist theories do not take into account the needs of the victimsurvivor and do not answer the question of how to protect the women and children (Lewis, Dobash, Dobash, \& Cavanagh, 2000).

\section{Communication theories}

Communication theories justify punishment as a way to communicate society's censure of crime to the offender. Additionally, the aim is for the offender to acknowledge that this disapproval is justified and in a sense can "see the wrong [he/she] has done", can 
understand why it was wrong, the act's impact on the victim-survivor (and community), and also the relationship between themselves and the victim-survivor(s) (Duff, 2003, p. 345). In a sense, this perspective is focused on the offender developing empathy or in other words, "feeling a congruent emotion with another person, in virtue of perceiving her emotion with some mental process such as imitation, simulation, projection, or imagination" (Oxley, 2011, p.32). Through this, the offender's attention and perspective are brought to the perspective and experience of others, potentially transforming his/her (the offender's) beliefs and values (Oxley, 2011).

In addition, the offender must then repent, look for ways to make reparation to the victim-survivor and commit to avoidance of future wrongdoing. This reparation refers to both material and moral reparation (i.e. in the form of an apology) and acknowledges that in some cases, it is impossible to materially replace what has been harmed (Duff, 2003). This perspective focuses on relationships and views offenders as responsible moral agents who should not be coerced into taking responsibility for his/her crime. The communication of wrongdoing is an opportunity for them to "redeem themselves and ultimately be reconciled to the community" (Ward, 2009, p. 224).

This is a form of retributionism in that punishment is justified as a response to the crime committed as well as having a future oriented perspective in that repenting for the crime will hopefully lead to reparation and reform (Duff, 2003). However, this is not a combined theory because rather than an instrumental connection existing between means and ends (as in the consequential theory), the desire to repent becomes internalized (Duff, 2003) and is done because it is the right thing to do rather than doing it to avoid punishment.

It is said that the development of empathy and the ability to internalize the desire to repent is "necessary for morality and complex social functioning" (Ward \& Durrant, 2013, p. 7). This internal reflection relies on perspective taking that is both self and other focused, which arguably reflects a particular stage of adult developmental (Berger, 2012). I question whether individuals who have not reached that stage of adult development would struggle to understand and achieve this perspective taking and requiring them to do so (without facilitator understanding of developmental limitations) could be doing them an injustice. In addition, empirical research suggests empathy for one situation does not necessarily generalise to future situations (Mann \& Barnett, 2012) and that in itself, "does not reliably result in moral and pro-social behaviour" (Ward \& Durrant, 2013, p. 7). However, Mann \& Barnett (2012) note that there are many limitations to the studies on the connection between offender empathy and 
recidivism and to conclude that empathy for the victim-survivor and offender recidivism are unrelated may be "overly hasty" (p. 289).

This variation in punitive theories and the role of empathy in reparation begins to illustrate the complexities that exist in the area of criminal justice. Knowing whether the aim of punishment is to illustrate society's censure of offending behaviour and/or to prevent future offending is unclear, however, it is clear that the expectation of society is that punishment will change an offender's behaviour (Eccleston \& Ward, 2006).

It would be remiss to discuss punishment (within the criminal justice context) without also discussing apologies and remorse. Within this context, assessment (for referral to RJ) and sentencing, both have components that consider offender apologies and genuineness of remorse when deciding the level of punishment warranted. For example, Section 10 (1d.ii) of the Sentencing Act 2002 (Ministry of Justice, 2015) stipulates that when sentencing, the court must take into account an apology and the genuineness of this apology that is made to the victim-survivor, whanau, or family of the victim-survivor.

\title{
Apology and remorse
}

\begin{abstract}
Although money can be useful in many ways, no amount of cash could provide the sorts of meaning that you might receive if the offender apologized, accepted blame, took moral as well as fiscal responsibility for the loss, and then honoured a commitment never to cause such harm (Smith, 2008, p. 2).
\end{abstract}

Moral reparation, in the form of an apology, is an important area to explore further as it is an integral part of the restorative justice policy that will be discussed later. In the traditional criminal justice system, the presence of remorse and apologies can significantly affect the level of punishment faced by an offender. In the United States, the Bureau of Justice Statistics reported that in 2011, there were close to 7 million offenders that were supervised by adult correctional authorities (Glaze \& Parks, 2012). In the majority of these cases, the level of punishment was mediated by the degree in which an offender appeared apologetic or remorseful (Smith, 2014). A defendant showing remorse can be interpreted as being "less bad and need[ing] less deterrence, incapacitation or retribution" (Bibas \& Bierschbach, 2004, p. 88).

The Federal Sentencing Guidelines (United States Sentencing Commission, 2011) include a stipulation that if an offender "clearly demonstrates acceptance of responsibility for his offence [the sentence should be decreased]” (§3E1.1). In addition, by taking responsibility 
in a timely manner and assisting the prosecution or authorities, the offender's behaviour has "permit[ted] the government and the court to allocate their resources efficiently", and qualifies for a reduction in sentencing (United States Sentencing Commission, 2011, §3E1.1). Some of the factors that are considered before reducing the sentence are: admitting responsibility for the offence in a timely manner, voluntarily stopping association with antisocial associates and criminal behaviour, voluntary restitution before being found guilty, promptly surrendering to authorities, and rehabilitation efforts following the offence (United States Sentencing Commission, 2011). This raises the question of: a. how is genuineness of offender remorse, apologies, and responsibility taking for the offence determined; and $b$. should being remorseful, apologizing, taking responsibility for the offence, and admitting that they were wrong, all be considered in the same way? Additionally, there is no stipulation in the guidelines that states the moral position of the offender or that they understand that they were not justified in committing the offence - because admitting guilt is not the same as being accountable.

There may be other drivers (e.g. reduction of sentence) that motivate someone to take the steps to apologize. In other words, "in practice accepting responsibility has come to mean agreeing to a plea even while denying guilt"(emphasis in text) (Smith, 2014, p.3). Therefore, it is important to acknowledge that there is a difference between accepting responsibility by apologizing for an act, and apologizing because an offender knows they were wrong and that the victim-survivor is not to blame. Victim-survivors could face further harm if an apology is assumed to hold more merit than it does in reality. Smith (2014) maintains that "distinguishing the truly repentant from the disingenuous, requires considerable theoretical nuance as well as sophisticated institutional procedures" (p. 4).

In order for an apology to be genuine, it is suggested that the offender should: indicate to the victim-survivor that the particular offence was wrong and accept responsibility for the specific offence; indicate why the offence was wrong (accepting blame and recognizing that this is deserved); indicate how he intends to actively commit to repairing the harm; and indicate desistance by offering reasons and evidence why the harm will not occur again to the victim-survivor (Corlett, 2006; Smith, 2014). Therefore an apology is more complex than saying "I'm sorry."

On the other hand, remorse, as defined by the Oxford English Dictionary (Oxford University Press, 2014), is “a feeling of deep regret or guilt for a wrong committed." In a sense, it seems that remorse is actually part of an apology - the feeling part. An apology is more multifaceted and contains not only the emotional component, but also a behavioural 
component. Some go as far as to say that apologies are a form of treatment and are a transformative procedure for offenders to work through (Smith, 2014). This points to a fine line between the concepts of remorse and an apology that is often blurred in the literature and in policy. Whether this is just a semantic blurring or a lack of understanding of the depths of a genuine apology is unclear.

According to Bibas and Bierschbach (2014), the reason judges consider remorse and genuine apologies when reducing sentences is because in their eyes this indicates, "the offender is not 'lost', that he has some self-transformative capacity that justifies a lesser punishment" (p. 94). Other judges believe that being remorseful is a reflection of good character, is an indication that rehabilitation is more likely, shows that the offender is less "hardened" (Bibas \& Bierschbach, 2004, p. 95), and that the remorse and guilt will be motivating to make changes (ten Brinke, MacDonald, Porter, \& O'Connor, 2012).

Considering that an apology and remorse carry so much weight in sentencing and in policy, it follows that understanding and having clear procedures on how a genuine apology or remorse is assessed is vital. Smith (2014) notes that reliance on gut feelings, evaluations of emotional cues, and instincts, that are influenced by explicit and implicit biases, are used to make decisions about an offender's character and genuineness of an apology. Additionally, it has been said that a defendant's demeanour is a significant factor that is consulted when making this decision (ten Brinke et al., 2012). There is a strong subjective component to these assessments, which leaves a lot of room for error and, as Smith (2014) said, biases.

\section{Readiness and motivation to change}

Clinical research suggests that the readiness of the individual to undergo therapy is perhaps more important than either the therapist or therapeutic technique (Avolia \& Hannah, 2008, p. 332).

What makes an individual change thoughts and behaviours? What determines if an individual is ready for change or ready to change? How are motivation to change and readiness to change different? What is the readiness - empathy connection?

Thinking back to the earlier discussion about punishment, in the past it has been thought that change is motivated by avoiding discomfort, feeling shame, guilt, threat, fear or humiliation - "if you make people feel bad enough, they will change" (Miller \& Rollnick, 2002, p. 11). However, research shows that programmes that aim to do this (e.g. boot camps, 
"Scared Straight") are not effective in reducing offending or motivating change (Andrews \& Bonta, 2010). In addition, it has been thought that as long as someone is motivated to change, then change can occur - this has also been proven incorrect (Miller \& Rollnick, 2002). In fact, if we consider not only offenders, but also every day situations that we all encounter, there are many situations where people say, "I want to "x" (i.e. quit smoking, lose weight, exercise daily)", but do not actually do so.

Walker (2004) argues that for change to be transformative, the individuals "need to change the way they think about things (including change itself) not merely the way they act" (p. 28). Inadequate motivation, defensiveness and resistance to therapy (Prochaska, DiClemente, \& Norcross, 1992), inappropriate matching of risk and needs of offenders, and treatment readiness (Day, Casey, Ward, Howells, \& Vess, 2010) are variables often associated with lack of positive outcomes to interventions. According to Prochaska et al. (1992), there are five stages of change readiness (motivation to change): pre-contemplation, contemplation, preparation, action, and maintenance. It is important to note that their model somewhat blurs the line between motivation and readiness which, I argue, are not interchangeable. They seem to define readiness by the willingness to act or not to act. However, consider the possibility that an offender can be motivated to change and participate in intervention(s), but is not cognitively, emotionally or developmentally able to engage in the program in order to have the desired outcome. This may indicate that the individual is motivated but not ready to change.

Treatment readiness is considered by some to be "the willingness to engage in the treatment process" (Serin, Kennedy, Mailloux, \& Hanby, 2010, p. 19) (which seems to grey the line between motivation and treatment readiness), others suggest it is, "the presence of characteristics (states or dispositions) within either the client or the therapeutic situation, which are likely to promote engagement in the therapy and which, thereby, are likely to enhance therapeutic change" (Day et al., 2010, p. 6). Within the domain of readiness, Serin et al. (2010) suggest eight significant factors to be assessed: problem recognition (acknowledge that there is a need for change); benefits of treatment (long and short term outcome expectancy that treatment will reduce abusive behaviour and increased other desired outcomes such as relationships, employment, fewer release conditions); treatment interest (both internal and external value); treatment distress (distress about current situation increases involvement in change); treatment goals (keep realistic and identify and acknowledge

\footnotetext{
${ }^{1}$ A scheme that took young offenders into prisons to meet "lifers" in an attempt to "scare them straight" (Shapiro, 1978)
} 
challenges); treatment behaviour (historical behaviour in treatment and motivation for treatment); motivational consistency (looks at verbal and behavioural responses regarding treatment - and inconsistencies/consistencies between them); and treatment support (support for change by significant others).

One model of readiness is the Multifactor Offender Readiness Model (MORM), which "proposes that impediments or barriers to offender treatment can reside within the person, the context, or within the therapy or therapeutic environment"(Day et al., 2010, p. 6). Miller and Rollnick (2002) note that motivation is a product of an interaction between individuals which moves the focus of motivation from internal to external to the individual. It has been said that individuals are in fact dependent on each other in order to establish a "sense of who they are [and] acts of caring are most reliably motivated by social or moral emotions such as empathic concern, sympathy, and compassion" (Ward \& Salmon, 2011, p. 405). It is important to acknowledge the familial/relationship imbalances that often occur and to "address the moral issues arising in relations among the unequal...and noticing how often these attributes apply not only in the household but in the wider society" (Held, 2006, p. 13). Taking into account these possible imbalances within relationships - a possible barrier to readiness could be viewed through the relationships that motivate/or do not motivate an individual to want to change or to care about another individual.

Internal readiness factors in the MORM are cognitive (beliefs, thinking style, thoughts of self efficacy), affective (emotional control - access to emotional state, ability to express this in a therapeutic environment), behavioural (strengths, skills), or volition (intention to pursue goals, wants, desires, motivation to change) (Day et al., 2010). Thinking in terms of the cognitive factors, in the Liverpool Desistance Study, it was noted that when comparing offenders who persisted and those who desisted, they both had "scripts" about themselves (Maruna, 2001). The persisters had "condemnation scripts" which portrayed them as "helpless, dependent on circumstances and victim-survivors of society" (Ward \& Laws, 2010, p. 16) while conversely, those who desisted had "redemption scripts" which had a more optimistic perspective regarding their ability to control their lives, to be "productive, and to give something back to society" (Ward \& Laws, 2010, p. 16). In cases of IPV, in addition to condemnation scripts, perhaps offenders have "power scripts" where they view themselves as needing to control their partners and that society supports this position.

Another cognitive aspect is that of an awareness of discrepancy (Miller \& Rollnick, 2002). Basically, this means that the individual is aware of the difference between the perception of the present situation and way of being, and the perception of the desired goal. In 
other words, "when a behaviour comes into conflict with a deeply held value, it is usually the behaviour that changes" (Miller \& Rollnick, 2002, p. 23). However, there is an assumption that the offender is able to identify this discrepancy. This is where the literature between motivation and readiness overlaps and at times appears to confuse the two concepts. In motivation, the individual may be able to identify the conflict and want to change, but their state of readiness may not allow this to occur.

The volition factor can be examined through The Good Lives Model (GLM) (Ward, Mann, \& Gannon, 2007) offender rehabilitation theory (discussed in depth later) which proposes that focusing on the primary goods (individual goals and values) is likely to improve an offender's engagement with treatment and positive programme outcomes (Day et al., 2010; Ward et al., 2007). Rather than focusing on why a person does not change, focus on what the individual wants/needs thereby providing a context for change (Miller \& Rollnick, 2002).

After thinking about the individual components of the criminal justice context that are relevant to this thesis (justice, punishment, apologies, remorse, readiness, and motivation), the next level of understanding needs to be the justice system as a whole. As this research aims to understand the overarching framework of RJ for IPV in New Zealand, it is important to think about criminal justice in general, how it has evolved over time, how IPV is viewed and addressed within that system, and how and where RJ sits in relation to the traditional criminal justice system.

\section{Criminal Justice Historical Background}

It could be said that the modern state legal system was established to provide an alternative to "blood feuds when restorative justice failed, by depersonalizing conflict through submission to a higher authority" (Lui, 2007, p. 31). Braithwaite (2007) commented, "until the nineteenth century, criminal justice in the most developed nations such as Britain and United States was mostly a victim initiated process" (p. 146). Following this, state based justice placed the right to take action in the hands of the state, not the victim-survivor. This is thought to "curb the danger of vendettas and sets limits on arbitrary, cruel and excessive punishment" (Herman, 2005, p. 576). Supposedly, the punishment ordered by the state was more appropriate and humane than that of the individual. In 1829, Prime Minister Robert Peel established the London Metropolitan Police model, and it is said that following this, paramilitary police regimes became prevalent globally (Braithwaite, 2007). The 1970s saw the retributive movement also known as the "Nothing works" movement. Focus was on punitive reactions to crime, victim-survivor advocacy, and was thought to be anti rehabilitation. It was said that during this period of time the focus was on imprisonment as 
punishment rather than the "effects of prevention and rehabilitation" (Andrews \& Bonta, 2010, p. 348). In the 1980's, in an effort to give the victim-survivor a voice, courts used victim impact statements to influence proceedings before sentencing.

\section{Conventional criminal justice approach to retribution}

The conventional justice system's approach to retribution positions the government authority as central and the interests of the governing body are of primary concern (Maxwell $\&$ Lui, 2007). The primary focus is on guilt, law breaking, risk management, recidivism (Andrews \& Bonta, 2010), and punishment (Zehr, 2008) and some suggest that the criminal courts are predominantly concerned with "accountability to social norms rather than individual needs" (MacDowell, 2011, p. 98). In other words, the conventional criminal justice system believes that crime violates laws and aims to answer: What laws have been broken? Who broke the law (Blame focus)? What do they deserve (What amount of punishment/pain should be administered)? (Zehr, 2002 in Umbreit \& Armour, 2010). It is a case of the offender versus the governing body where the government rules outweigh the outcome of punishment and "justice is sought through a conflict between adversaries" (Zehr, 1989, p. 10) - a win/lose scenario. Through the trial process, if a guilty plea has not already happened, accountability is determined and the court then determines an appropriate sentence. It is often the case that little responsibility of rehabilitation is taken by the courts (Maxwell \& Lui, 2007).

Punishment in the conventional criminal justice system is seen by some restorative justice theorists, as a way to condemn criminal activity as well as a form of reparation for the offending (Maxwell \& Lui, 2007). The offender is threatened with sanctions that will disrupt his life, and disempower him - which could potentially discourage him from being involved in his own change process (Eccleston \& Ward, 2006), potentially isolate him both physically and emotionally from the community (Jackson, 2009), and gives him less access to the victim-survivor in order to express remorse.

In terms of the victim-survivor, some groups working with IPV cases (i.e. RJ agencies) view the conventional criminal justice system as "grounded in the idea of the social contract and crimes against the state - [which] severely limits if not completely eliminates the role of the victim" (Jackson, 2009, p. 2). The concern of the state is to ascertain whether something has been done that requires punishment, rather than trying to repair the situation between the stakeholders (Bennett, 2008). This ignores the needs of the victim-survivor and could at times create further harm as a result of the process of acquiring evidence to prove 
offender guilt beyond reasonable doubt. This can leave the victim-survivor feeling less satisfaction from a conviction (Bennett, 2008) rather than feeling a sense of closure or repair.

It is important to note that the criminal justice system is not all about prison sentences for IPV offenders. It is also possible the offender may have to pay restitution to the victimsurvivor, or be referred to batterer programmes, alcohol and drug dependency treatment programmes, or have limits placed on contact allowed (although this is often violated, and therefore does not guarantee victim-survivor safety) (MacDowell, 2011). However, it is thought that in cases of domestic and sexual violence, the needs and desires of victimsurvivors for support, social acknowledgement, and validation is often completely in opposition to legal proceedings that publically challenge a victim-survivor's credibility (Herman, 2005). Rather than having a voice, victim-survivors were viewed as passive recipients of the criminal justice system and the impact of the process on them was not acknowledged (Lewis et al., 2000). Many victim-survivors, who use the criminal justice system feel marginalized, often feel renewed humiliation and are "shocked to discover just how little they mattered" (Herman, 2005, p. 582). Some feminists view the conventional criminal justice system as "saturated in patriarchal beliefs, structures and methods" (Lewis et al., 2000, p. 182) and because of this, would be unable to address the power and control imbalances of IPV cases. However, the increased and improved enforcement of laws regarding IPV has been "credited with removing violence against intimates from the realm of conduct outside the purview of the state and recasting it as a social problem and conduct subject to state sanction" (MacDowell, 2011, p. 103).

Presently, there is a powerful social message coming from the state saying that domestic violence is unacceptable and safety must be ensured for the victim-survivors. However, the best way in which to implement this is what is in question. Some argue that the state is providing a service by taking control of the decision to prosecute - by not forcing the victim-survivor to decide to prosecute or to have to feel pressured by family to drop the charges, the state alleviates the need for the victim-survivor to feel pressure or to feel as if they are betraying the offender or family unit (MacDowell, 2011). Others note that in the United States, the implementation of mandatory police and prosecution policies (i.e. mandatory arrest and no drop prosecution) in domestic violence cases can actually further traumatize victim-survivors who do not want to prosecute or appear in court. This is due to the fact that victim-survivors can be jailed for failure to appear in court or be charged with perjury if they change their statements regarding a domestic violence episode (Goodmark, 2015). A policy that was implemented to supposedly protect those that were seen as 
vulnerable (the victim-survivors) may actually disempower and further harm them. A final point to address is that the state system charges for singular events of abuse - in other words, "the legal process takes the assault out of the context of the larger abusive relationship" (Hartley \& Ryan, 2002, p. 4). This means that the historical nature of abuse is therefore not taken into account and could be doing all stakeholders a disservice by not acknowledging the extent of abuse. 


\section{CHAPTER 2}

\section{INTIMATE PARTNER VIOLENCE}

\section{Intimate partner violence (IPV)}

When people think of domestic violence they often think about acts that happen behind closed doors. They think about the immediacy of domestic violence - the black eyes, the broken vase, the verbal abuse, and children watching from the corner (Henare \& Hannifin, 2011, p. 75).

There is a lot of information in the media and in policy that states that IPV is "heavily gendered with victim-survivors of partner violence being predominantly women" (MOJ, 2013 , p. 6). For example, in 2008 , it was reported that approximately $85 \%$ of the reported serious IPV offences were against women (MOJ, 2013). Between 2009 and 2012, 24\% of the IPV related deaths were perpetrated by women while $76 \%$ were perpetrated by men (Family Violence Death Review Committee, 2014). Globally, it has been reported that between 10$69 \%$ of women worldwide have experienced IPV (Fanslow \& Robinson, 2010). However, these figures often do not mention the incidence of violence that men experience, and critics say that the perspective that IPV is predominantly a social problem of men being violent towards women, has "arisen from ideological motives" (Dixon \& Graham-Kevan, 2011, p. 1146) and propagates "assertions that are not supported by the evidence" (Esquivel-Santovena \& Dixon, 2012, p. 209). Esquivel-Santovena and Dixon (2012) reviewed IPV studies and found that there were significant methodological differences between these studies. Some methodologies resulted in situations that were not conducive to participants, particularly men, reporting being a victim-survivor of IPV. Other studies did not ask both partners about their victimization - only females were asked. This perpetuates the view that women's violence as a result of men's violence towards them is "a symptom of men's IPV" (Dixon \& GrahamKevan, 2011, p. 1146). Archer (2000a) did a meta analysis of 81 studies and found that the rate of violence perpetrated by women against their male partners was at least equal to the violence perpetrated by men towards women. Archer's (2000b) review of his meta-analysis (Archer, 2000a) suggests that there are limitations with the data base used in several of the studies - in particular that extreme examples such as data from women refuges and crime statistics - suggesting that some outcomes cannot be generalise d. Laroche (2008) noted that data from the 2004 General Social Survey in Canada revealed that men and women reported 
aggression from their partners in similar proportions ( 1 in 18 men were victims versus 1 in 16 women).

Johnson (2014) suggests that different results from different studies could be due to them comparing different types of IPV. Rather than being a singular category, Johnson suggests that IPV can be divided into different types of violence: intimate terrorism (violence to gain power and control), violent resistance (a response to violence from one's partner), and situational couple violence (situationally provoked violence with no pattern of coercive control; also known as common couple violence). Each type of IPV is thought to have different gender balances. Johnson (2014) suggests that "intimate terrorism is perpetrated largely by men, violent resistance by women, and situational couple violence roughly equally by men and women" (Johnson, 2014, p. 9). However, Hamel (2009) found that Johnson's findings in earlier studies ignored contradictions in data and "reached its conclusions from biased samples" (p. 44). Laroche (2008) points out that by using clinical studies that recruited women victim-survivors from shelters and emergency wards, Johnson "presupposes that intimate terrorism is perpetrated almost exclusively by men" (p. 32) and found that the 2004 GSS data did not support that contention. In fact, the 2004 GSS data showed that men comprised $37 \%$ of a total of 583,700 victim-survivors of intimate terrorism (Laroche, 2008). In addition, when Laroche (2008) used Johnson's typology to categorize the 2004 Canadian GSS data, the gender balance was virtually equal for both intimate terrorism and situational violence. These findings begin to highlight the contention and lack of agreement that exists in the area of IPV gender balance. There is a general public perception that more men abuse women than vice versa; however it soon becomes apparent that this is not as clear cut an argument as it may appear on the surface.

In the western world, New Zealand has one of the highest incidents of IPV (Herbert \& Mackenzie, 2014). Within New Zealand, the 2014 NZ crime and safety survey (NZCASS) (MOJ, 2014a) reports that of all of the violent interpersonal violence offences that were reported to police in 2013 (781,000), IPV accounted for the greatest numbers $(491,000)$. It is important to note that the NZCASS only reflect what is reported and IPV is known to be highly under-reported (MOJ, 2014a). IPV has been found to be correlated to high rates of youth suicide, bullying, sexual violence, mental illness, drug abuse, educational and employment difficulties to name a few (Herbert \& Mackenzie, 2014). In addition, it is important to realize that intimate partner violence does not only affect adults - it also affects the children involved, whether through physical contact or through observation. According to data collected by the Hamilton Abuse Intervention Pilot Project (HAIPP) and analysed by 
Maxwell (1994), of 528 reported incidents of domestic violence in New Zealand between 1991 and 1994, victim-survivors had children under 17 years of age in their care in at least $62 \%$ of the cases and in $79 \%$ of the reported incidents where children were in the victimsurvivor's care, children were present at the time of the violent event (Maxwell, 1994). The Ministry of Justice reports that in 2010/2011, of the family violence incidents attended by police, 96,627 children between the ages 0-16 were present during the incidents or residing with the victim-survivor and research suggests, "in up to $75 \%$ of the families where IPV occurs, child abuse will also be occurring" (MOJ, 2013, p. 7). Long term exposure to traumatic events (such as IPV and DV) is known to have a great impact on an individual's cognitive, emotional, and behavioural functioning (Henare \& Hannifin, 2011) and evidence suggests that the negative outcomes of children who experience maltreatment are similar to those outcomes of children who are exposed to violence at home but who are not directly maltreated (MOJ, 2013).

As young people develop, the behaviours of their families and their environment is often reflected in their own behaviours (Becroft \& Thompson, 2006) and youth that live in a community and home environment that have high levels of violence are at a greater risk of offending (Becroft \& Thompson, 2006). "The quality of children's relationships with those who care for them provides the framework for the exponential development and learning that occurs in the early years" (Kiro, 2009, p. 18) and youth and adults who display persistent patterns of offending have often been found to have problem behaviours that have been present from early childhood (Kiro, 2009; Moffitt \& Caspi, 2001). It has been said that, "if children grow up on a diet of violence, the result is likely to be a violent adult [and] for this reason, effective interventions start early and start with the family" (Becroft \& Thompson, 2006, p. 1). IPV is a problem then, for the entire family. It is important to note, however, that not all children exposed to violence will actually commit crimes and there is little support for the view that "violence inevitably begets violence" (Polaschek, 2006, p. 119). Nonetheless, it is clear that IPV has both immediate and potentially long-term consequences that affect the entire family. It has been said that, "the history of a man who batters is often a history of childhood abuse; exposure to male role models who have shown hostile attitudes toward women; [substance abuse]; and the denial of love and nurturing as a child" (Pence \& Paymar, 1993, p. 4).

A serious concern regarding IPV is the level of violence that goes unreported to police. Fanslow \& Robinson (2010) report that more than $75 \%$ of the 956 women in their study reported telling someone about the violence, however more than $40 \%$ reported that they 
received no help and as few as 5.6\% reported the violence to the police (Hayden, 2010). The New Zealand Crime and Safety Survey (NZCASS) (Justice Sector Strategy Group, 2009) found that $50 \%$ of the victim-survivors of IPV did not report to the police because they thought it was either too trivial, not worth reporting, or made an unsuccessful attempt at reporting. $45 \%$ felt that it was a private matter to be dealt with on their own. Further reasons for not reporting include fear of partner, fear of retribution, a view that the behaviour was not considered real violence, shame, denial and self blame (Hayden, 2010). When reporting does occur, and individuals do use services that are available, they are less satisfied with services that are offender focused (e.g. criminal courts and batterer interventions) versus services that focused more directly on victim-survivor needs (e.g. shelters) (Fernandez, 2010). Jülich (2001) found that when victim-survivors were asked what process would give them a sense of justice, they described restorative processes; however, they still did not think that attending a restorative justice conference would meet their needs and would not encourage them to report offending.

Part of the fear that exists and the resulting non-reporting, is said to be a manifestation of the power and control aspect of IPV. Power and control are key issues when discussing IPV - in particular, “a batterer's quest for control” (Mahoney, 1991, p. 5). IPV is characterized by an imbalance in power and inequality where one partner is controlling, coercing, dominating and manipulating of the other (Elizabeth, 2003). Dominance is established through physical, sexual, emotional, financial and spiritual abuse, shaming and degradation (Herman, 2005). Some refer to this type of IPV as "intimate terrorism" (Johnson, 2014). This power struggle exists not only during the relationship, but can be an ongoing concern, as seen through assaults that occur after separation has occurred (Mahoney, 1991). There are also thought to be cognitive distortions, long-standing beliefs and behaviours of the offender (as well as members of the community and extended family) that support the perpetuation of IPV (MOJ, 2013). The ability of a victim-survivor to leave a situation, and have access to a good exit strategy, is mediated by social and cultural practices (Elizabeth, 2003 ) and it is not a simple solution (or even a possibility) for some to 'just leave.' It is important to be aware of the hierarchical nature of the society in which we live and that we live in a culture that places value on power and in order to challenge these norms, as facilitators and practitioners, the "norm requires challenging ourselves" (Pence \& Paymar, 1993, p. 1). Practitioners, restorative justice facilitators, as well as all stakeholders in IPV cases should be aware of the presence and impact of these challenges and of biases that may 
exist such as, "she asked for it because she..." or "if it was that bad, she would have left..." (MOJ, 2013, p. 21).

As previously mentioned, there is a suggestion that though coercive power and control is the most obvious and recognized form of IPV (i.e. intimate terrorism), there are other types that exist - i.e. violent resistance and situational couple violence (Johnson, 2014).

Historically, there has been an interpretation of IPV that assumed that men are violent towards women in order to gain power and control over them (Hamel, 2009). Additionally, it has also been presumed that the violence that women show towards men is in self defense and therefore its consequences are not as important to consider (Pence \& Paymar, 1993).

However, it has been suggested that this point of view is not grounded in empirical evidence and does not help in the understanding of intimate partner violence (Dixon \& Graham-Kevan, 2010). Violent resistance IPV is considered to be violence that is in response to violence that has been inflicted upon the victim-survivor. This violence may be a result of an "instinctive reaction to being attacked" (Dow \& Wood, 2006, p. 75), feelings of revenge, self-defence, or a desire to end the violence and feeling that there is no other way to escape (Johnson, 2014). However, due to the size and strength difference between most men and women, it is thought that this violent retaliation does not help and may make the situation worse. At times, it is said, that killing their partner is the only way out of the situation (Dow \& Wood, 2006). The difference in this violence and intimate terrorism, is that in violent resistance, the violence does not come from a place of control.

Using large scale community samples Johnson and Leone (2005) studied both intimate terrorism and situational couple violence. The latter is generally thought to be a form of violence that is not intended to gain power or control over but rather it is triggered within the context/situation (Johnson, 2014). This situational IPV distinction was replicated in several studies where individuals and couples were found to have aggressive or violent behavior but lower or more reciprocal controlling behaviors than those in the intimate terrorist (power and control) groups (Olson, 2002; Graham-Kevan \& Archer, 2003). As previously mentioned, there is contention regarding the IPV gender balance rates in terms of who perpetrates and who is the victim-survivor; however, there seems to be agreement that the data samples can be viewed from the perspective of different IPV subtypes. However, there are questions regarding the relevance of violence severity within Johnson's classifications. Johnson focuses predominantly on the level of power and control (Johnson \& Leone, 2005; Johnson, 2014) where as other researchers have found significance in deliniating the levels of violence (Holtzworth-Munroe \& Stuart, 1994; Laroche, 2008). These perspectives are mentioned here 
in order to acknowledge the idea that the dynamics of IPV are far more complex than merely assuming that power and control are the only issues to be focused on during assessment and treatment.

There is great heterogeneity of behaviour and treatment needs with IPV offenders. As mentioned, Johnson's (2014) subtypes for IPV are not the only suggested way to categorize IPV offending. Others have suggested that there are four subtypes of IPV offending that focus on the level of violence: Family-only (FO), Low-level antisocial (LLA) (Holtzworth-Munroe, Meehan, Herron, Rehman, \& Stuart, 2000), Dysphoric/Borderline (DB) and Generally Violent and Antisocial (GVA) (Holtzworth-Munroe \& Stuart, 1994). The FO offending is considered to be less severe or frequent, the offenders are less likely to engage in psychological or sexual abuse, and violence generally happens only towards members of the immediate family so he is less likely to have problems with violence or the law outside of the home. This group reported having lower levels of anger, but similar levels of depression and jealousy as the other subtypes (Saunders, 1992). However, it is noted that this lower level of reported anger may reflect anger suppression that is released by alcohol or stress (Saunders, 1992). Alcohol and drug abuse was found to be low-moderate and the FO subtype accounts for approximately $50 \%$ of all IPV offenders (Holtzworth-Munroe \& Stuart, 1994). These individuals reported having more compatible relationships and less marital conflict than the other subtypes (Saunders, 1992).

The LLA subtype exhibits partner violence levels between FO and the other subtypes, however they were found to exhibit similar levels of antisociality on the Millon Clinical Multiaxial Inventory III (MCMI-III) scale (Millon \& Grossman, 2006) as the other more severe subtypes (Holtzworth-Munroe et al., 2000). The DB subtype accounts for $25 \%$ of the IPV offenders and these individuals engage in moderate-severe violence that includes psychological and sexual abuse. The violence was predominantly towards their partner, however there is some evidence of low-moderate violence and criminal activity outside of the family (Holtzworth-Munroe \& Stuart, 1994). There is evidence that the members of this group display more psychological distress than those in FO subtype, have a higher incidence of drug and alcohol use and reported less marital satisfaction (Saunders, 1992).

Jacobson and Gottman (1998) identified the abuser type "pit bull" which is closely associated with the DB group (McMaster, 2012). Their behaviour is learned through observing/experiencing inter-generational domestic violence and offenders with these traits are said to be motivated by a fear of abandonment - They "sink their teeth into you, it is hard to get them to let go" (Jacobson and Gottman, 1998, p. 39) implying that leaving an abuser 
with "pit bull" characteristics is difficult and can be dangerous in the long run. They are said to exhibit behaviours such as stalking and jealous rages (Brody, 1998).

The third subtype, GVA offenders, are considered to be "emotionally volatile aggressors" (Saunders, 1992, p. 270) who engage in severe forms of violence both at home and outside of the home, including sexual and psychological abuse. Jacobson and Gottman (1998) used the term "cobra" to describe this GVA type of abuser. The "cobra" type is said to be motivated by "immediate gratification and strike swiftly and with great lethality when they feel threatened" (Jacobson \& Gottman, 1998, p. 38). This type has a greater likelihood of showing psychopathic traits, such as lack of empathy, the inability to form intimate relationships, and may at first seem charming but soon can become cold and calculating (Brody, 1998), physically abusive and psychologically manipulative (McMaster, 2012). It was found that those men who were labelled the "cobra" and antisocial type, had a decrease in their heart rates during a conflict, while the men labelled as "pit bulls" had in increase in their heart rate during conflict (Johnson, 2007).

A meta-analysis by Stith, Smith, Penn, Ward and Tritt (2004) found that negative emotionality predicted serious IPV. In addition, they found that attitudes supporting violence and traditional sex roles, marital dissatisfaction, anger, stress, depression, alcohol and illicit drug use were all dynamic risks factors significantly associated with IPV (Stith et al., 2004). Some research suggests that men's abusive behaviour, attitudes and responses to stressful or distressing cues with anger, has not only been learned through childhood and other life experiences but has also been reinforced and rewarded over time (Walker, 2009). In order for the abuse to stop, it has been suggested "deeply entrenched behaviours of the offender need to change, the abusive relationship needs to be transformed, and significant and often longstanding harms need to be repaired" (MOJ, 2013, p. 21).

It has also been found that the relationship between the victim-survivor and the offender can take on a cyclical pattern where the violence can in turn influence the development of a learned helplessness also known as the "battered-woman syndrome" (Karmen, 2007, p. 215). The learned helplessness can be both on the personal level and the universal level in that the woman may start to feel that no matter what she does, the situation will not improve (personal) or no matter what others do, the situation will not change (universal) (Abramson, Seligman, \& Teasdale, 1978). The cycle that is thought to form is one where there is initially the tension-building period, abuse occurs, and then reconciliation and a period of relatively peaceful aftermath, and then the pattern is repeated (Karmen, 2007). The violence can escalate in frequency until something is done to change the cycle and break the 
pattern. This seems to apply more to physical and sexual abuse than some of the other forms of abuse that would tend to be more ongoing and may not require a build up period but are actually present most of the time in order to control the victim-survivor.

There is a strong focus on separation in many professional agencies and communities around the world, however, some claim that this focus not only devalues the relationship (Coker, 2002), but also assumes that separation will result in safety (Mahoney, 1991). There are many reasons why victim-survivors of IPV stay in abusive relationships or want to return to them. The National Collective of Independent Women's Refuges (NCIWR) (NCIWR, 2015) suggests ten common reasons why women choose to stay in abusive relationships: First, leaving can be the most dangerous time. Mahoney (1991) suggests that separation often increased the risk of violence for some women, as the batterer may attempt to block her from leaving, force her return using violence, or retaliate violently in response to her leaving; Secondly, without adequate resources available, many women do not have the financial stability to support themselves and their children if they leave and can feel dependent (Karmen, 2007); Third, there may be no where to go or no one to turn to (Karmen, 2007) and if social agencies do not recognize the legitimacy of her needs and her children's needs for their wellbeing are not met, staying/returning may become the "preferred" option (Elizabeth, 2003, p. 73); Forth, women may also be concerned about losing their children or the safety of their children if they leave (Fanslow \& Robinson, 2010; Karmen, 2007) as well as concerned because the children may not want to lose their father (NCIWR, 2015); Fifth, there may be a strong belief in family values or there may be cultural/religious/family pressure to honour marriage at least until the children have grown up (Elizabeth, 2003); Sixth the woman may not be believed (NCIWR, 2015); Seventh, the women still love their partner and/or have an emotional investment in the relationship (Fanslow \& Robinson, 2010); Eighth is social isolation. Offence victim-survivors of IPV are at a great risk of social exclusion and isolation (Henare \& Hannifin, 2011) from the community and in particular, from their family/whanau (MOJ, 2013); Ninth, they do not want to be judged by others (NCIWR, 2013); Tenth, is that abuse/violence becomes normalized or is not considered serious (Fanslow \& Robinson, 2010).

When victim-survivors do seek help, this is influenced by a variety of factors such as the characteristics of the relationship, the victim-survivor's personal perspective, their "appraisal of the violence" (Fanslow \& Robinson, 2010, p. 931) and the response of others to the situation. In addition, victim-survivors are motivated to leave abusive situations for a variety of reasons: violence has increased in severity; children are being abused; the ability to 
be financially independent is viable; realizing the situation is violent and not acceptable (Elizabeth, 2003). Following the violence and leaving the situation, there are thought to be many unresolved issues. Themes that stood out during research was that of closure and healing, a continued emotional link to the abusers, a need for vindication, empowerment, restitution, and truth, and the connection of children (Fernandez, 2010).

Rehabilitation is thought to be a more effective and cost efficient way of reducing recidivism than through punishment and imprisonment alone (Andrews \& Bonta, 2010). In terms of IPV, it is known that the offence is rarely a 'one off' event and that there exist deeply entrenched cognitive distortions, beliefs and behaviours (MOJ, 2013). A variety of programmes exist, from those that try to change the cognitive distortions and psychopathologies which lead to violence while others take a feminist perspective and address the issues of power and control and gender inequality in order to protect women and children. Most programmes are hybrids of sorts (Lewis et al., 2000) and regardless of which intervention is used, the central issues of minimized risk and increased safety are a common thread (Bograd \& Mederos, 1999).

\section{Batterer programmes}

Just because violence occurs within the privacy of the home, does not mean that it's not a crime or that the community has no role to play in trying to stop it from happening again. U.S. Attorney General Mike Fisher (U.S. Attorney General's Task Force on Family Violence, 1998, p. 4)

The batterer program approach, also thought of as a systems or institutional advocacy approach, focuses a great deal of its' attention on establishing systems and services that are needed in order to restore women's safety, freedom and autonomy (Frederick \& Lizdas, 2010). In the 1950s and 1960s, IPV was handled globally, from the perspective of preserving the family unit through re-building the relationship, healing damage done and encouraging a potentially nurturing union and also presuming that the women were partly responsible for the resulting abuse (perhaps provoking their husbands) (Karmen, 2007). This approach has been criticized for assuming mutual blame, trivializing the danger and impact of the violence and for ignoring the power imbalances that were present (Karmen, 2007). Prior to the 1980s, the issues of privacy versus the best interests of society were at the forefront of the domestic violence picture. IPV was often thought of as something that was "best left behind drawn curtains" (Babcock, Green, \& Robie, 2004, p. 1024) and to be dealt with through mediation with only the offender and victim-survivor involved. Following those early responses to IPV (after 1980s), responses have relied upon the legal system to criminalize abuse, support 
separation, protection of the victim-survivor(s), and the punishment and rehabilitation of offenders (Karmen, 2007). It has been said that historically, the responses to IPV, rather than being data driven, were based on identified needs (e.g. development of shelters in the 1970s) and advocacy and policy work (e.g. development of restraining /protection orders, pro-arrest policies) (Fanslow \& Robinson, 2010, p. 930).

Following these early beginnings, batter intervention programmes (BIPs) have developed into the most prevalent intervention for men, in an attempt to reduce IPV (Lehmann \& Simmons, 2009). Generally speaking, IPV interventions are a combination of punishment (arrest) and rehabilitation (court-ordered treatment). Given that there is a high attrition rate for counselling programmes, it was thought that court-ordered programmes were a way to ensure a higher rate of compliance as well as providing an alternative to prison (Feder \& Dugan, 2002). Many of the programmes use cognitive-behavioural techniques with a mixture of approaches that have been seen as ranging from confrontational (gender issue focused) or too naïve without a clear message that change is necessary (skill building focused) (Gondolf, 2004). Regardless of which intervention is used, the central issues of minimized risk and increased safety are a common thread (Bograd \& Mederos, 1999).

\section{The Duluth model}

A hybrid model that utilizes both feminist theory and cognitive-behavioural interventions is the Duluth Model (Lehmann \& Simmons, 2009). This is a psycho-education model that focuses on the misuse of power and control, and is the underlying theory of more IPV programmes than any other current theory (Polaschek, 2006). This intervention is based on the Duluth Domestic Abuse Intervention Project (DAIP) developed in 1989 in Duluth Minnesota (Babcock et al., 2004) as a way to make IPV a public rather than a private issue, increase victim-survivor safety in the community, and to hold offenders accountable for their actions (Lehmann \& Simmons, 2009). The theory behind the Duluth model is that violence is used in order to control another person's behaviour (Pence \& Paymar, 1993) and is based on the belief that criminal justice practices (arrest and prosecution) in conjunction with courtmandated intervention (predominantly group work) is "crucial for change" (Lehmann \& Simmons, 2009, p. 5).

The Duluth model considers IPV a learned behaviour and does not consider interventions to be therapy (Lehmann \& Simmons, 2009) nor does it address serious mental health or substance abuse issues (Corvo, Dutton, \& Chen, 2009). The purpose of the group work is to address society biases that sanction patriarchal beliefs, the use of power and control over women (Babcock et al., 2004), and to learn more gender sensitive and non-aggressive 
behaviours (Lehmann \& Simmons, 2009). Two fundamental tools, developed by DAIP for use in treatment, are the "Power and Control Wheel" and the "Equality Wheel"(Domestic Abuse Intervention Programmes, 2011). The Power and Control wheel contains the principle tactics used by abusers to dominate women and the Equality wheel contains skills, concepts and strategies that are thought to be required in order for offenders to change their behaviour from abusive to non-abusive (Pence \& Paymar, 1993).

The U.S Attorney General's Task Force on Family Violence (1984) made the claim that these programmes offered "great hope and potential for breaking the destructive cycle of violence" (in Babcock et al., 2004, p. 1024), however studies have found little evidence of program effectiveness (Babcock et al., 2004; Feder \& Dugan, 2002). Labriola, Rempel, and Davis (2005) found that offenders that participated in court-mandated group batterer programmes did not show lower rates of re-abuse than judicial monitoring groups and Murphy and Eckhardt (2005) note that beyond the effect of probation monitoring and prosecution, there is little effect on recidivism of group counselling. In fact, "no specific type of intervention for partner violence has been found to be consistently more effective than any other intervention" (Murphy \& Eckhardt, 2005, p. 2).

Another issue to be aware of is that victim-survivors whose abuser had participated in batterer programmes reported feeling safer (Labriola et al., 2005). Victim-survivor satisfaction is considered to be a positive outcome; however, looking closer at this particular issue, this perception of safety is a concern as this may create a false sense of security, which could then put victim-survivors at further risk of abuse (Babcock et al., 2004).

Despite these findings, the Duluth model continues to be the most prevalent form of intervention used in the western world, for domestic violence (Gondolf, 2004). Corvo et al. (2009) suggest that the use of practices based on the Duluth model pose an ethical threat due to the lack of empirical evidence to support its effectiveness, "failure to utilize best practice protocols, inadequate assessment/diagnosis, failure to connect assessment to treatment, failure to develop individual treatment plans, and failure to provide treatment appropriate to the client's needs" (p. 323).

\section{Cognitive behavioural therapy (CBT)}

The CBT model views IPV as a result of cognitive distortions, beliefs and assumptions that can result in violence in order to "reduce [an offender's] inner tension, to achieve victim-survivor compliance, to end an uncomfortable situation, and/or give the batterer a feeling of power and control of a situation" (Lehmann \& Simmons, 2009, p. 7). The CBT approach is a skill-based approach that is based on the idea that past behaviours do not 
create a static path, that offenders have the control to change beliefs to create a more positive future, and these beliefs are not "shameful examples of patriarchal socialisation that must be reprogrammed" (Eckhardt \& Schram, 2009, p. 149).

Negative emotion regulation, in particular - anger regulation, has been suggested to have a high correlation to IPV (Eckhardt \& Schram, 2009). In particular, two of the subtypes previously mentioned - GVA (generally violent and antisocial) and DB (borderline dysregulation) were found to have significantly high levels of anger (Holtzworth-Munroe \& Stuart, 1994) and studies show that men with high levels of anger, with little control of this anger, which was then expressed externally, perpetrated the most IPV of all groups measured (Eckhardt, Samper, \& Murphy, 2008).

A suggested model for CBT therapy for IPV abusers includes four phases: 1. Motivation to change (establish alliance, motivational interviewing techniques, develop personal goals for change), 2. Safety (eliminate abusive behaviour, increase stability of circumstances, and identify obstacles to treatment), 3. Development of functional relationships (reduce negative cognitions, effective parenting skills, increase positive partner attributions), 4. Trauma recovery and relapse prevention (process traumatic events, develop coping skills and self directed change) (Murphy \& Eckhardt, 2005, p. 8). Interestingly, there is little evidence to show that change in cognitions of IPV offenders during treatment can independently predict a significant reduction in violent behaviour (Eckhardt \& Schram, 2009). There is controversy among many women's advocacy groups over the concept of mental health problems and negative emotion regulation as being risk factors for IPV. This is due in part to their concern that this could lead to a focus on the medical model of intervention and draw attention away from important concepts such as patriarchal society views, covert or overt community support of violence towards women, and the need for men to be accountable and responsible for their behaviour (Eckhardt \& Schram, 2009). In addition, anger management as an intervention for IPV, is thought by some to imply that the victimsurvivor provokes anger and triggers the abuse, does not address the control and power imbalances, and can be thought of as a "quick fix" that could potentially endanger women (Gondolf, 2002, p.14).

\section{Couples approach}

There is significant opposition to couples therapy in cases involving IPV. Two of the key areas of contention are the mutual responsibility that is implied for the violence and the victim-survivor's safety (Schacht, Dimidjian, George, \& Berns, 2009). Others suggest that couples therapy is appropriate in IPV cases after the offender has attended rehabilitation and 
education programmes that target issues associated with IPV and where there has not been any instances of violence for at least six months after completing the program (Jacobson \& Gottman, 1998). Bograd and Mederos (1999) raise the question: "how can therapists make decisions about the appropriateness of couples therapy in a way that minimizes risk for all participants?” (p. 291). It is thought that couples sessions can expose the tactics used to control and dominate and the interpersonal relationship can be explored (Bograd \& Mederos, 1999) however, addressing safety issues and violence is imperative (Schacht et al.; 2009).

The effectiveness of programmes was significantly dependent on the particular intervention system used (Gondolf, 2004). There are problems with assessing outcomes of programmes cited throughout the literature. The question of what, how and when to asses the outcomes, program definitions, and when to start the evaluation are not clearly defined or consistent throughout studies and the enmeshing of the criminal justice system with rehabilitation - can vary tremendously. It has also been found that, after controlling for prior criminality and "stakes in conformity", the offenders who were considered less likely to have reoffended (even without attending a court-mandated program) were the offenders who completed programmes (Feder \& Dugan, 2002, p. 371). It is also suggested that offenders who are likely to change, will do so early on in the treatment program, whereas those that might have found a beneficial effect from a longer program, tend to drop out of the programmes (Gondolf, 2004, p. 619).

It is evident that though there are a variety of conventional approaches, there is little empirical evidence to support the effectiveness of any one commonly utilized IPV program (Babcock et al., 2004). Additionally, it is apparent that there are a variety of perspectives on how the traditional criminal justice system addresses the needs of the stakeholders - the victim-survivor in particular. With the many (and at times conflicting) viewpoints on IPV, punishment, readiness, and the use and effectiveness of an apology, there is a lot of room for speculation as to the most effective approach to dealing with IPV. Restorative justice is an approach, which, in terms of the traditional criminal justice system, is a relative new comer to IPV. Though RJ has long been utilized at the grassroots or indigenous level (Umbreit \& Armour, 2010), due to the amendments to the Sentencing Act 2002 (Ministry of Justice, 2015b), far more IPV cases will be adjourned for assessment of suitability for RJ. This opens up an entirely new set of issues and challenges to be addressed. Some studies suggest that restorative justice may be an effective way to address the needs of the individuals involved in crime while also addressing the traditional criminal justice goal of reducing recidivism 
(Johnstone \& Van Ness, 2007); however, the latter point alludes to the confusion that exists as to where RJ sits relative to the traditional criminal justice system and the goal of recidivism. 


\section{CHAPTER 3 \\ RESTORATIVE JUSTICE}

What is restorative justice? According to Zehr (2008), restorative justice is "a process to involve, to the extent possible, those who have a stake in a specific offence, and to collectively identify and address harms, needs, and obligations in order to heal and put things as right as possible" (p. 4). The principles and practices of restorative justice have origins in many cultures worldwide and have been utilized for centuries (Umbreit \& Armour, 2010). The Brehon laws in $7^{\text {th }}$ century AD used in Celtic practices, focused on restitution rather than punishment (The Courts Service Dublin, 2013). In Pakistan and Afghanistan there is the tradition of jirgah - an assembly of respected community elders and the individuals involved in the dispute, where stories are heard and amicable settlement to the dispute is sought (Taizi, 2007). The Arab tradition of Sulh is a practice of reconciliation, cooperation, forgiveness and mediation that works along side the state justice system to address conflict between families of a murder victim and the offender (Lang, 2002). The Canadian First Nation Peacemaking circles and Navajo peacemaker courts bring together offenders, victim-survivors and families by a respected leader of the community in order to settle disputes (Zehr, 2008; Umbreit \& Armour, 2010). In 1989, Navajo Nation Peacemaker Courts were established in the United States in order to "reassert a traditional form of problem solving within the Anglo justice system (Ptacek, 2009, p. 9). The Truth and Reconciliation Commission (TRC) was a restorative justice body established in South Africa in 1995 by the Government of National Unity, in order to help address the harms that resulted from the violence and violations of human rights that occurred under apartheid. The former Minister of Justice, Mr. Dullah Omar, said that, "a commission is a necessary exercise to enable South Africans to come to terms with their past on a morally accepted basis and to advance the cause of reconciliation" (DOJ\&CD, 2009).

Reconciliation programmes that were faith-based were the first programmes to use the term restorative justice. In 1974, two probation officers in Ontario, Mark Yantzi and Dave Worth, facilitated the first documented case of what was then called a Victim Offender Reconciliation Program (VORP) (Zehr, 2008). The success of this intervention encouraged the Mennonite Central Committee to create a victim-survivor and offender reconciliation program in both the United States and Canada (Ptacek, 2009). Victim offender mediation (VOM) was a more secular based version of the original faith-based programmes that were led by trained facilitators and allowed the victim-survivor and the offender to question each other, share stories and feelings, and negotiate restitution contracts (Zehr, 2008). In the 1990's 
restorative justice emerged to re-empower victim-survivors and was said to "give victimsurvivors a direct voice in the course of proceedings as opposed to voice only through legal mouthpieces" (Braithwaite, 2007, p. 148). It was thought that an apology from the offender and reparation would have more emotional benefits to a victim-survivor than longer prison sentences and could reduce post-traumatic stress effects of crime (Angel, 2005).

As this thesis is focused on restorative justice in New Zealand, the principles and philosophies of tikanga Maori ${ }^{2}$ are particularly relevant. Prior to colonization, there was a collectivist approach in New Zealand where the group, rather than the individual, was the central focus of the culture and relationships were the central focus of Maori customs (Bowen, Boyack, \& Calder-Watson, 2011). When an offence occurred, in order to resolve conflict, social order and mana (authority, power, influence, status, spiritual power) (Moorfield, 2015) of all involved (the victim-survivor, the offender, the whanau (extended family), hapu (kinship group/sub-tribe) and iwi (tribe)), a meeting would occur where all parties had a voice, reciprocity in order to restore utu (balance) would occur (Workman, 2012b), and a consensus decision (kotahitanga) was sought (Bowen et al., 2011). Utu is not the same as punishment and is not necessarily unpleasant or unwelcome (Workman, 2012b). The restorative process was viewed as valuable in its self, and was thought to be both therapeutic and cathartic for the family, the offender, and the victim-survivor (Workman, 2012b). However, if utu/ restorative justice could not be established or failed, then violence, death or exile as a result of a personal/family vendetta could occur (Lui, 2007, p. 30). When colonization occurred, individualistic, state driven, rule bound behaviour was implemented and despite the Maori understanding that the Treaty of Waitangi would maintain Maori autonomy over their affairs, this was not necessarily the case in practice.

In 1989, family group conferences (FGC) were introduced in New Zealand through the Children, Young Persons, and Their Families Act 1989 (MOJ, 2013). Ptacek (2009) suggests that when FGCs were established, they were based on principles of tikanga Maori and they endeavoured to reduce the number of young Maori in the court system. It is more a case that the process is culturally sensitive and addresses the fact that Maori children and young people "comprise around half of all youth apprehended by police, have an FGC, or are being prosecuted in court" (Ferguson \& Becroft, 2013). The FGC addresses the needs of the youth offender while also holding him/her accountable (Ferguson \& Becroft, 2013). FGCs have an approach that is grounded in the restorative justice ideology stipulating that a wider

\footnotetext{
2 "The customary system of values and practices that have developed over time and are deeply embedded in the social context." (Moorfield, 2015)
} 
breadth must be taken than just the victim-survivor and offender, and that members of the families and the community need to be present in order to "collectively identify and address harms, needs and obligations in order to heal and put things as right as possible" (Zehr, 2008, p. 4). During the 1990s, similar restorative principles and practices were applied in cases of adult offending, however, this was not an official practice. Restorative justice was given legitimacy and recognition through the passing of the Sentencing Act 2002, the Parole Act 2002, and the Victims Rights Act 2002 (MOJ, 2013). These three Acts encourage the use and consideration of restorative justice processes during sentencing and parole wherever appropriate (MOJ, 2013). Restorative justice was further integrated into the system with the passing of section 24a of the Sentencing Amendment Act 2014 (The Parliament of New Zealand, 2014) where all cases that are pre-sentence that come before the District Court are considered for adjournment for restorative justice assessment if certain criteria are met. New Zealanders referred through the District Court and the Police Adult Diversion Scheme predominantly experience restorative justice conferencing during pre-sentencing, however, the restorative justice process can "occur in a variety of ways at different stages in the criminal justice system" (MOJ, 2011, p. 7).

Restorative justice is not only a way of thinking about crime, but is also a process in which to respond to crime (Ministry of Justice, 2013). From the RJ perspective, crime is viewed as a "violation of people and interpersonal relationships" (Zehr \& Mika, 2003). Aziz (2010) challenges that view and suggests this is too narrow a view of crime (especially in the case of IPV) and does not take into account gender and race biases and the "impact of crime on the political, social, moral and cultural fabric of society" (p. 6). This will be further discussed in the following section on RJ and IPV issues.

\section{Restorative justice approach}

As stated earlier, restorative justice is a process that identifies and endeavours to address harms, obligations, and needs that have resulted from offending. RJ aims to involve, whenever possible, all stakeholders who have been affected - i.e. the victim-survivor, the offender, the family, whanau, and community (Zehr, 2008). The processes in restorative justice are considered flexible and value driven in that it is the "values that determine the process, and the process that makes visible the values" (MOJ, 2011, p. 30). Core values of RJ are said to be: Participation, respect, interconnectedness, accountability, empowerment, empathy, and mutual understanding (Zehr \& Toews, 2004). At a more fundamental level, the values are viewed by some to acknowledge the value and dignity of all human beings, the 
concept that power is less important than relationships, and the personal is political in the sense that personal harms and social harms are considered (and repair of this harm) (Pranis, 2007). Braithwaite (2003) suggests that these values can be further categorized into constraining values that must be enforced (e.g. empowerment, respect, accountability, equality of concern for all stakeholders, social support), maximizing values that should actively be encouraged (e.g. restoration and healing), and emergent values that may be a result of a successful RJ process but should not be forced as that would make them coercive (e.g. remorse, forgiveness, an apology).

From the restorative perspective the questions asked are: Who has been hurt, what are the needs of the victim-survivor and what are the paths to empower and restore them? (Umbreit \& Amour, 2010; Zehr, 2008). Zehr and Mika (2003) outline three core principles that underpin restorative justice initiatives that resonate with the core ideas in this definition. First, criminal conduct violates individuals and their relationships with one another. Such violation harms all of the key stakeholders in crime-victim-survivors, offenders, and communities-whose needs therefore ought to be actively addressed through a restorative process of some kind. The role of each of these stakeholders will vary depending on their individual capacities and inclinations as well as the nature of the offence (Zehr \& Mika, 2003). Whether the practices of RJ promote victim-survivor restoration (especially in the cases of IPV) is thought to depend on the program, the community support, the victim-survivor, the offender, how much each stakeholder is invested in the restorative aspect of RJ, how much the problem presented by the offence is understood, and whether the autonomy of the victimsurvivor is respected (Frederick \& Lizdas, 2010). The government may have a stake in this process, but is no longer considered the central force with all of the power (Maxwell \& Lui, 2007).

Secondly, crime results in obligations and liabilities for offenders. The offender is obliged to take responsibility for the crime and attempt to repair the harm caused. RJ literature that discusses the harm inflicted by the conventional criminal justice system (Jackson, 2009; Maxwell \& Lui, 2007) seems to imply that the harm inflicted by the restorative justice process is not comparable to that of the conventional system. However, this is not strictly the case. For example, the offender is still required to fulfil restitution obligations to the victimsurvivor (and potentially the community), which may cause harm of some sort as well as the potentially emotionally challenging experience of meeting the victim-survivor and other stakeholders who were affected by the crime. In addition, there may still be a prison sentence involved depending on the particular crime committed. However, the intention behind holding 
offenders accountable in the RJ process is to achieve reparation of the relationships and the individuals, rather than to cause suffering (Ward \& Salmon, 2009). Additionally, the community is obliged (or at least encouraged) to support both the victim-survivor and the offender in dealing with the effects of the crime and though there is emphasis on the needs of the victim-survivor, this does not pose their rights and needs over or in opposition to those of the offender or the community (Bazemore, 1998). It is a process of balance.

Third, the purpose of restorative justice is to facilitate community healing by repairing the harm that results from crime, more specifically, the fractures within relationships between victim-survivors, offenders, and the community that inevitably occur following offending. Restorative values such as participation, respect, interconnectedness, accountability, empowerment, empathy, and mutual understanding form the foundation of, and subsequently guide, practice (Zehr, 2008; Zehr \& Toews, 2004). Table 1 summarizes the core values of RJ in IPV that are reflected across the literature.

Table 1. RJ core values in IPV: Normative components (reflected values)

Repair of personal and social harms: attention is focused on victim-survivor (and community) needs and harms suffered, and how to best address and repair these

Accountability: offender acknowledges personal responsibility for the offence

Participation: RJ is an informal process where ALL stakeholders are given the opportunity to be involved in discussion of event(s), harm that occurred, and what steps should be taken in order to repair harm.

Voluntariness: participation must be voluntary and informed for all stakeholders and outcomes should be agreed upon by all participants without coercion

Interconnectedness/communities of care: emphasis on repairing relationships between stakeholders. This includes reintegration into the community

Respect/Dignity of all human beings: rather than a focus on stigmatization and punishment, the focus is on responsibility, making amends, repairing harm, and reintegration into a pro-social community. All stakeholders are moral agents

Empowerment: an ability to move beyond the trauma and expand their perspective, acknowledge humanity in each other and an increased sense of closure.

Needs of victim-survivor/victim-survivor driven: process motivated by victim-survivor and not due to external pressures from families, communities, or the criminal justice system Safety: emotional and physical safety for all stakeholders must be managed at all times Flexibility: one static process for RJ does not exist - situation and stakeholder dependent

It is important to note at this point, that a "single accepted conception of restorative is deeply contested [and it is important] to acknowledge the differing and indeed competing ideas about its nature" (Johnstone \& Van Ness, 2007, p. 9). It has been suggested that this can 
be attributed to the fact that restorative justice, rather than being developed through research and theory, is a grassroots movement that has "predominantly developed through practice and experience" (Aziz, 2013, p. 3; Ward \& Langlands, 2008). Its primary focus is on transforming the way justice is implemented in communities rather than on formulating a coherent theory and set of norms to guide a response to crime. What this means is that RJ programmes constitute a patchwork of loosely connected ideas and practices rather than a tightly knitted set of principles and institutions.

Two schools of thought are evident in the literature, and seem to define the outer limits of the RJ spectrum: 1. Encounter/process-focused 2. Reparation/outcome-focused. The encounter concept of restorative justice views the meeting of the stakeholders in an informal context (RJ conferences) outside of the professional and formal government settings (e.g. courtrooms) as central (Johnstone \& Van Ness, 2007). From the encounter perspective, conferences can produce beneficial results such as: rehabilitation, deterrence and reinforcement of norms, possibility of restitution, active involvement in decision process, possibly a sense of increased safety, and an understanding of other's perspective and life circumstances, if used in "appropriate cases and properly conducted" (Johnstone \& Van Ness, 2007, p. 10).

A more 'purist' RJ paradigm at this end of the spectrum is the process-focused paradigm from McCold (2000). This focuses on bringing the stakeholders together in an "empowering co-operative problem-solving process" (Zernova \& Wright, 2007, p. 92) and in this model participation is completely voluntary - without judicial involvement, with the goal that all cases would eventually use RJ rather than the "formal justice system" (Zernova \& Wright, 2007, p. 92). From this perspective, "the goals of restorative justice are to meet the real needs of victim-survivors, offenders, and their communities created by the criminal act" (McCold, 2008, p. 14). Including any "coercive judicial sanctions (such as community service)... or obligations to obedience, are equal to punishment" and should not be considered in the RJ process (McCold (1999) in Walgrave, 2001, p. 18).

Some claim that McCold's perspective is too narrow because it only focuses on scenarios where it is possible for stakeholder to meet face-to-face and excludes those cases where meeting is either undesirable or not possible. In addition, it is important to consider that the conference process, in itself, may not be enough to guarantee the desired beneficial results, and rehabilitation and reintegration need to be considered as well. As is stated in the New Zealand Ministry of Justice restorative justice standards for family violence cases (MOJ, 2013) - "a one-off RJ service is unlikely to achieve the change of deeply entrenched offender 
behaviours, transformation of the abusive relationship, and repairing of long-standing harms and will be one step only in a much longer process" (p. 21).

The other RJ perspective is that of reparation and outcome-focus (often referred to as "maximalist") (Walgrave, 2001). From this perspective, it is thought that a serious wrong has been committed, an injustice has occurred, and the wrong needs to be put right through repairing the harm done to the relationship between individuals (Johnstone \& Van Ness, 2007). Reparation can be both material (e.g. restitution or compensation) which addresses the tangible or intangible specific harm or symbolic (e.g. an apology) which addresses the wrongness of the act (Sharpe, 2007). From this perspective it is thought that the encounter (conference) is only one way for the reparation process to occur and that sanctions, guided by RJ principles, can be administered by the criminal justice system outside of the RJ conference (e.g. in cases where a stakeholder does not consent to participation). These principles include: healing the stakeholders, active involvement of all stakeholders in the process of justice (as much as possible), and balancing the roles of government (promoting and preserving a "just order”) and the community (promoting “just peace”) (Johnstone \& Van Ness, 2007, p. 15). The distinction between RJ and the formal criminal justice system rests in whether the aim is to repair or to punish and cause pain. From an RJ perspective, the idea is to "transform the criminal justice system by reorienting [its] goals away from retributive and towards restorative ones" (Zernova \& Wright, 2007, p. 93). Duff (2011) suggests offenders should be punished for their wrong doing, but when coming from the RJ perspective, the fundamental purpose of this punishment should be restorative and that in fact, RJ programmes should not be alternatives to retribution but rather act as "paradigms of punishment, and thus as models for the criminal justice system" (p. 368).

There appears to be considerable overlap between the perspectives. Perhaps it is more a case of a continuum where in practice some RJ programmes are, for example, more (or less) focused on reparation or repair of harm, while others are more focused on rebuilding relationships or empowering the individuals. It has been suggested that how the process of RJ occurs varies, and a fundamental principle of restorative justice is not that one static form or another needs to be adopted, but rather that whatever form is adopted reflects the values of restorative justice (MOJ, 2011). The processes in RJ are considered flexible and value driven and it is said that it is the RJ "values that determine the process, and the process that makes visible the values" (MOJ, 2011, p. 30). With the new legislations for RJ in family violence cases that were released by the Ministry of Justice (MOJ, 2013), there is a lot to consider in terms of what perspective restorative justice practice in New Zealand is coming from and how 
the values and flexibility of RJ work within (or beside) the traditional criminal justice framework for IPV cases. This issue will be explored in both the analytical and the empirical components of this thesis.

\section{Restorative justice and intimate partner violence}

In 1995, restorative justice protocols were being drafted by Waikato Mediation Services for a pilot program, and a debate began regarding whether the program should include domestic violence cases (Hooper \& Busch, 1996). A large portion of that debate was centred around the mediation process and how, from one perspective, it can be imbalanced and potentially unsafe, and the other perspective suggested mediation was more empowering than court proceedings (Hooper \& Busch, 1996). It is important to note that restorative justice is not the same as mediation. In mediation, stakeholders are "assumed to be on a level moral playing field" and there is a sense of shared blame (Zehr, 2002, p. 5). Within the RJ context, there is an identified offender (person who is accountable) and victim-survivor. Though the term mediation was used in the early days of $\mathrm{RJ}$, this term is now replaced with conferencing (Zehr, 2002).

Bazemore and Earle (2002) suggest that many of the earlier restorative justice models that have been used (i.e. victim-offender mediation or family group conferencing), were not formulated with the complexities of IPV in mind. RJ and IPV present unique challenges that are not present in most other cases of offending in terms of power imbalances between the victim-survivor and the offender, the historical relationship between the victim-survivor and the offender, threat of future harm, entrenched attitudes and the cyclical nature of IPV. Additionally, it is suggested that RJ standards are under-developed or vague and that there is a lack of information on offender assessment/suitability, victim-survivor reintegration, longterm effects of RJ, and the consistent definitions of constructs such as victim-survivor satisfaction (Hudson, 2002; Stubbs, 2007). Others suggest RJ in IPV cases do not take into account victim-survivor learned helplessness and passivity, power and control, and cultural biases (Aziz, 2010). As a result, amongst many feminists, victim-survivor advocates, and policy makers, it is thought that RJ is not an appropriate intervention in cases of IPV and as a result, "this area of practice is under-researched" (Gavrielides \& Artinopoulou, 2013, p. 26). The United Nations Handbook for legislation on violence against women section 3.9.1 (Department of Economic and Social Affairs/Division for the Advancement of Women (DAW/DESA), 2009), recommends that legislation should "explicitly prohibit mediation in all cases of violence against women, both before and during legal proceedings" (p. 38) because there is a risk of assuming during mediation that there is equal fault for the violence, 
reduced offender accountability, and that there is a balance of power to negotiate (DAW/DESA, 2009). As previously mentioned, the term mediation was used in the early days of RJ, but is now not considered to be the same as RJ - however the line can at times be blurred or confused due to lack of education or awareness.

Other issues to consider are stakeholder safety and the fact that research shows that IPV is typically reflective of well established, chronic patterns of behaviour in which a single session intervention like a RJ conference is unlikely to permanently alter these patterns (Bazemore \& Earle, 2002). This last point reflects an assumption that RJ is a one-off intervention, which is an idea that is a point of tension across policy and practice. The New Zealand MOJ standards for FV cases (MOJ, 2013) states, "a one-off restorative justice service is unlikely to achieve this degree of change and will be one step only in a much longer process potentially involv[ing] support and change programmes and services for the victimsurvivors and offenders, together with involvement of a range of other family/whanau and community supports" (p. 22). This idea was quite clearly illustrated in the concern of victimsurvivor 'Alice' (Hayden, 2010, p. 135) who said,

The support's there, but once you leave that controlled situation, what happens when you go home with the person? ... [If restorative justice] was something that was a matter of course ... that if someone [was aggressive] towards someone, they saw [restorative justice] as, "Well, if I'm repentant, this system will see me through without a severe penalty ... All I have to do is make the right noises and I'll come out the other end. (Alice: Interview A)

This quote highlights another area of contention - the emphasis on an apology. There are conflicting views regarding the value an apology and how much emphasis should be given to an apology during the RJ process. It is thought that some offenders may be "quick to apologize, but slow to change" (Coker, 2002, p. 148). Some suggest that it is important that pre-conference processes assess not only the genuineness of an apology, but also the offender's motivation in order to understand the value of that apology. Additionally, postconference monitoring should be in place to ensure that restorative agreements are upheld (MOJ, 2013). However, how this assessment of genuineness and motivation is done and who is meant to monitor conference agreements, is not clear in the MOJ (2013) guidelines. When thinking about the value of apologies or restitution from the perspective of the victimsurvivor, Stubbs (2007) suggests that victim-survivors typically are not as concerned with punishment as they are with protection for themselves and their children, their right to live without violence, the exposure to abuse and validation of their efforts to stop the violence. 
Other research that has analysed victim-survivors experiences found that they, "hunger for information about: "why [the] offence happened and what has happened since, the truth about what happened so that healing can happen, for reclaiming the control they have lost (empowerment), and seeking restitution (real or symbolic) of the losses as a means of vindication" (Fernandez, 2010, p. 139). Smith (2008) comments about an apology - "no amount of [restitution] could provide the sorts of meaning that you might receive if the offender apologized, accepted blame, took moral as well as fiscal responsibility for the loss, and then honoured a commitment never to cause such harm" (p. 2). However, others have noted that an apology in words alone may not be genuine and potentially cannot be trusted as it may be used as a form of deception (deliberate or non-deliberate). As Smith (2014) stated, "An apology is specifically not synonymous with an admission of guilt... attorneys can deploy such apologies as an attitudinal structuring tactic to lubricate settlement discussions and influence an opponent's behaviour. Apology becomes a wolf in sheep's clothing" (p. 10-11).

It is evident that there are conflicting opinions regarding the appropriateness of IPV cases for RJ and that this area is complex and certainly not straightforward. Some of the questions regarding appropriateness of RJ in the area of IPV revolve around whether RJ is effective and how effectiveness is measured. This all highlights a common thread regarding RJ for IPV cases; as Zehr (2002) cautions - DV is "probably the most problematic area of application" of RJ (p.6).

\section{Measuring RJ's effectiveness}

How is effectiveness of RJ measured and what factors need to be present? Kim and Gerber (2010) note that most studies focus on outcome variables such as victim-survivor satisfaction, changes in offender attitudes, and rates of recidivism. Maxwell and Morris (2001) found that a successful youth conference was considered to be one in which the conference was memorable, evoked remorse, and this led to the individual not only meeting his/her victim-survivor, but also apologizing and making steps towards amends. Kingi, Paulin, and Porima (2008) measured success by asking offenders and victim-survivors about their experience and found that regardless of whether there was considered to be a "productive outcome", most victim-survivors still felt angry and could not forget what had happened despite being satisfied with the RJ process (p. 68-69). Offenders, on the other hand seemed to feel less "animosity" and more understanding for the experience of the victimsurvivors (Kingi et al., 2008, p. 69).

Principle B of the MOJ standards (2013) states that healing for victim-survivors should occur in a safe supportive environment where they can discuss the harm experienced, a 
genuine apology is received, and where "they can negotiate for actions or behaviours which they would find restorative" (p. 24). Healing and justice for the offender is thought to take place through the opportunity to "publicly take accountability for wrong-doing, to make appropriate reparations for the harm caused, and to commit to action to prevent any further abuse" (MOJ, 2013, p. 24). Others posit that the achievement of reintegrative shaming is the most important factor in a successful conference (Kim \& Gerber, 2010). Rather than stigmatizing the offender, reintegrative shaming allows the victim-survivor and the community to express disapproval, which is then followed by "gestures of reacceptance into the community of law abiding citizens" (Braithwaite, 1989, p.55). An important question that is not addressed is how offender selection affects the outcome of the RJ process. If certain offenders are thought to be "unsuitable" for the RJ process - what is this based on and where is the evidence to say these are valid reasons to disqualify a case?

There are a number of problems generated by the above practices and theory. It is not clear, in fact, what actually makes something "restorative." Is it the conference, the consequences of the encounter, or something else entirely? Claiming that an offender is going to get help is very different from knowing that an offender has changed his values or the manifestation of his values. The concepts of shame and restoration are also culture specific and can vary depending on the specific crime (Kim \& Gerber, 2010). An offender's knowledge that he had scared his partner and believing that he "needs to change" does not mean that he has an understanding of the core values of dignity or has empathy, understands the power imbalance, the lack of a mutually respectful relationship, or grasps the full impact that his actions and beliefs have on his victim-survivor, whanau, and the wider community. The question still remains - how are success, genuine apologies, and change accurately measured?

\section{RJ values - Implicit assumptions}

Johnstone and Van Ness (2007) note that it is crucial that individuals who practice and adhere to the encounter perspective keep considering the RJ values, where they come from, and how these values are adhered to by stakeholders in the process. It appears that Johnstone and Van Ness (2007) have an underlying assumption that offenders will already, on some level, hold the values of RJ. Pranis (2007) comments that the process values are in place in order to best facilitate stakeholders to access and act upon their best self values (e.g. respect, compassion, patience, truth, personal responsibility). That, again, appears to assume that in order to be involved in an RJ conference, an offender must already hold the values of RJ at some level (perhaps implicitly). With these thoughts in mind, it is apparent that there are 
several implicit assumptions reflected in the literature (see Table 2) that are taken for granted and are considered important factors when assessing the suitability of an RJ offender and for a successful conference. There are still some questions that remain unanswered: how does an offender's capacity to hold these values get assessed? And is it possible that these values can be acquired through the RJ process?

Table 2. RJ core values in IPV: implicit assumptions

Offender empathy: an awareness and understanding of others' experiences prior to, and as a result of the offence - implied that this should exist pre-conference or can occur as a result of conference and this will result in behaviour change

Readiness: capacity to give a meaningful apology and to understand impact on victim-survivor, and reflects an ability to change...

Power of genuine apology/remorse: thought to be an integral part of victim-survivor healing and criteria for appropriate cases...

Offender Insight: Expressions of remorse, offender insight into their own behaviour and a desire to repair harm

Reparation: for some, reparation, rather than the RJ process which enables healing of relationships, is at the source of repair and expression of remorse (outcome focus) (Johnstone and Van Ness, 2007)

Offenders hold the values of $\mathbf{R J}$ before entering into $\mathbf{R J}$ processes: the RJ process is there to best facilitate the expression of person values such as respect, compassion, truth, responsibility

A number of researchers (Hudson, 2002; Stubbs, 2007) have argued that the question of which standards of RJ are appropriate are under-developed or vague and that there is a lack of information on offender assessment/suitability, victim-survivor reintegration, long-term effects of RJ, and consistent definitions of important constructs such as victim-survivor satisfaction. These gaps highlight the importance of determining the perspective of those assessing, referring and facilitating RJ. This is because professional perspectives are central to the purpose of restorative justice, the values to be upheld by restorative justice, and determine how these relate to criteria for eligibility/suitability to participate in RJ. If policy is not anchored by empirical evidence and clearly supported procedures, then the practice can become idiosyncratic and thus less equitable.

\section{When is RJ appropriate in IPV cases?}

Kingi et al. (2008) found that key informants in their study (e.g. facilitators, district court judges, police prosecutor, lawyers, family violence coordinators) used a variety of criteria to determine whether or not RJ was an appropriate process for particular IPV cases. 
Their decision depended on the type of offence, offender characteristics, and the specific relationship between offender and victim-survivor. The relationships in IPV cases present different issues for the restorative justice process than other cases. In other cases, the whanau/family and friends that are present for the offender and victim-survivor are all brought together to provide support, and "explore needs, differences and common ground" (Bazemore \& Earle, 2002, p. 157). However, in the case of IPV, victim-survivors and offenders have been (are) in a relationship, often share friends, their whanau may be connected through the marriage/relationship, and the "power dynamics within the family are typically already significantly inappropriate and entrenched" (Bazemore \& Earle, 2002, p. 157). It is thought that the conference could potentially reinforce this power imbalance. Coker (2002) suggests a conference should not require the victim-survivor to forgive or reconcile, but allow for the possibility - as placing that expectation of the victim-survivor can be coercive and "once again subordinates her own needs to those of the abuser" (p. 148). In addition, when meeting an unknown/stranger offender, part of the process is learning that the offender did not personally target them and that they are safe from future threat. However, in the case of IPV, the offender is not a stranger and there is a question as to whether RJ has an underlying understanding of crime as an isolated event of the past which can be restored, rather than recognizing the potential for ongoing threat (Stubbs, 2007) that exists in IPV cases. Some critics of RJ suggest that "RJ processes may be too informal and outcomes too lenient for the serious offending that constitutes gendered violence" (Curtis-Fawley \& Daly, 2005, p. 618).

Who are the appropriate IPV offenders for RJ practices and how is suitability assessed? Kingi et al. (2008) found that there was a lot of variation within their key informants regarding which FV offences were considered appropriate for RJ. Some suggested that inappropriate cases included: rape and other sexual offences, "extreme violence", repeat offenders, grievous bodily harm, aggravated assault, breaches of protection orders, and the more serious male assaults female offences. However, it was noted that assessment needed to be done in a case-by-case approach. Offenders who showed genuine remorse, accepted responsibility, whose level of violence was not extreme or this offending was a one-off incident, were considered "particularly appropriate for the use of RJ processes" (Kingi et al., 2008, p. 75). Circumstances that were thought to be particularly appropriate were those where "healing is possible for the victim-survivor; where a bond exists between victim-survivor and offender; for couples who need to work through issues; where families want to stay together; where there is no physical violence, if the victim-survivor wants to stay in the relationship; 
and where the victim-survivor and offender have children together" (Kingi et al., 2008, p. 75). However, this appropriate/inappropriate line is blurred - take, for example, where there is learned helplessness and the woman wants/feels she needs to stay with a violent partner, or there is repeat violence (in many cases) and children are involved. No case is simple, straight forward, or cut and dry so to speak. In addition, what is not mentioned in Kingi et al.'s (2008) study, nor in the MOJ standards (2013) (see below), and is not apparent in other relevant RJ literature, is how the key informants came to the conclusions that these factors were significant, how these factors were measured, and how readiness and suitability to participate were assessed. The literature asks who and what is considered appropriate - not how is this appropriateness assessed and what is the particular criterion/methods used for interpreting the information that is gathered for the assessment.

Another issue raised by feminist scholars is the issue of privatization and how restorative justice in IPV cases, may "push domestic violence back into the realm of the private" (Coker, 2002, p. 131), however, IPV is not privatized if these proceedings occur in conferences with community and professionals - especially if they are given the responsibility of future monitoring of offender behaviour. In fact, the RJ process may help a woman to build a stronger connection with her community and as Coker (2002) suggests, this process of justice actually "helps a women build a community that supports her autonomy without forcing women to choose between their ethnic/racial communities and safety (p.148). It is important to be aware that in IPV cases, it has been said that community and whanau cognitions that may reinforce and support forms of patriarchal power should be acknowledged and is difficult to safeguard against if the facilitator also comes with those biases (Lewis et al., 2000). The key is not to merely balance the traditional practices of rehabilitation, risk management, punishment or reintegration while maintaining traditional values, but rather to find a way in which these practices can be in line with the values and principles of RJ while being compatible with each other (Bazemore \& Earle, 2002).

It is thought that restorative justice will need to be adaptable, and perhaps include aspects of traditional criminal justice safeguards when responding to IPV in order to ensure victim-survivor safety. In other words, when addressing IPV, RJ principles will keep the processes on the restorative justice path "even when the path does not resemble typical restorative justice protocols" (Bazemore \& Earle, 2002, p. 158). The processes become very individualized and it becomes apparent that the emphasis should be on a flexible approach that stresses the rigor needed in applying principles rather than on scripts and processes. As previously stated, within that flexible approach, the values and principles of RJ should be 
upheld and in terms of retribution, the fundamental purpose should be that of restoration rather than causing pain (Duff, 2011).

Another issue to consider is the vague definition in the RJ literature of what is actually meant by 'repair' and the most effect form the processes should take. How do we know that all harm is repairable and how do we know if adequate repair has occurred for the victimsurvivor, the offender and other relevant stakeholders, and who determines if the restoration is adequate and appropriate (Aziz, 2010)? How do we know what RJ process is most effective if part of the principle behind RJ is that the processes are flexible and not static? In addition Aziz (2010) notes that it is unclear whether it is "the process of repairing and restoring the harm itself that is important or whether it is in fact the end result” (p. 12). Another question to ask is - what is being restored? Does this not assume that something healthy and positive existed before the harm? Perhaps we are not trying to restore but rather create a new relationship dynamic.

A final point is whether $\mathrm{RJ}$ is considered an entirely separate process from the conventional criminal justice system, does it run parallel to the traditional system, or is it perhaps a refinement of the traditional process? It has been said that punishment and imprisonment, in themselves, do not reduce crime (Andrews \& Bonta, 2010) and the conventional criminal justice system is found to not be restorative for the victim-survivor, community and offender, or to address victim-survivor autonomy in IPV cases. As mentioned, many women find their experience with the criminal justice system to be a negative one to say the least, and often do not seek help for a variety of reasons. Perhaps it would be beneficial for all stakeholders, policy makers, facilitators and other professionals involved in IPV cases to consider that the criminal justice portion is only one part of a much broader intervention and process that should be used when addressing IPV (Bailey, 2010). When approaching the problem of IPV and criminal justice through a restorative justice lens, perhaps, ways of reducing risk, ensuring safety, increasing autonomy, encouraging an interaction with the criminal justice system and communicating justice can happen through, as Zehr (2008) comments, "a process to involve, to the extent possible, those who have a stake in a specific offence, and to collectively identify and address harms, needs, and obligations in order to heal and put things as right as possible" (p. 4). More specifically, what is needed is an integrated system that can address these needs - "involving multiple agencies and individuals, each with differing responsibilities and working on different parts of the problem. An integrated system where all agencies and individuals who are either directly or indirectly involved at all levels operates as one system" (Herbert \& Mackenzie, 2014, p. 4). 


\section{CHAPTER 4}

\section{METHOD}

This study is comprised of two linked components: a theoretical analysis and an empirical analysis. The first component of this research analysed the RJ literature and New Zealand policy in order to detect patterns in convergence and/or divergence with RJ principles, values, assessment practice, and policy, and to detect any underlying assumptions (and their coherence or conflict with RJ assumptions and practices) that may be present. In the empirical component, a grounded theory approach was used in order to develop a theoretical framework or model regarding the phenomenon derived from the text (data) (Charmaz, 1996). In addition, this allowed the researcher to acquire a rich understanding of the perspectives, the assessment procedures used, and the RJ values of RJ facilitators, judges, police officers, and lawyers involved in the intimate partner violence restorative justice process. This particular approach is valuable for this research because it allows a fine grained study of individual meaning making within a flexible framework, opening up the opportunity to gather rich information, to follow the direction of the data and findings, and through rigorous analysis of the data - to develop a theoretical understanding of the phenomenon.

\section{Grounded theory}

Grounded theory, at a fundamental level, brings together theory development with a rigorous research process of inspection, refinement, developing ideas, and making sense of data (Charmaz, 1996). The second component of this study endeavoured to understand and examine the participants' point of view about the assessment of IPV offender readiness and suitability to be referred to RJ. More specifically, participants were asked how they assessed genuine remorse, empathy, and the ability to change. Another aim was to understand what values of RJ were reflected in practice and what framework of RJ was suggested. The collection of data and the analysis of data "inform and shape each other and are conducted in tandem" (Charmaz \& Bryant, 2008, p. 375). With the grounded theory research approach, theories are developed through analysis of the data rather than having categories and themes established before hand (Willig, 2008). It is important to note that "even the research question is no permanent fixture in grounded theory" (Willig, 2008, p. 38) and as a result, some of the research questions in this thesis changed and more questions developed following analysis of the data. This reflects an abductive approach to grounded theory where there is a "creative production of hypotheses based on surprising evidence" (Timmermans \& Tavory, 2012, p. 168). For example, understanding effective RJ IPV assessor qualities was not an initial aim, 
however, after collection and analysis of data, it became apparent that this is an area that was integral in understanding the readiness assessment process. In grounded theory, a researcher endeavours to learn and understand the perspectives of those interviewed, but also "mandates that those interpretations and perspectives become incorporated in our own interpretations (conceptualizations)" (Straus \& Corbin, 1994, p. 280). The primary difference between grounded theory and other qualitative approaches to research is the ongoing interaction of data collection and theoretical analysis and development (Straus and Corbin, 1994).

\section{General structure}

\section{Component 1: Policy Analysis}

In this component there was an analysis of the MOJ (2013) policies on restorative justice and domestic violence, assessment procedures for IPV programmes, and the assessment of readiness, and decision-making literature.

\section{Component 2: Empirical analysis}

In this component, semi-structured interviews were conducted with judges, lawyers, police officers, RJ facilitators, RJ court coordinators, and victim-survivor and offender specialists working with IPV cases in New Zealand (30 combined total in order to provide thematic saturation and sufficient coverage of perspectives). Semi-structured interviews occurred, in order to gather detailed information on the individual understanding of RJ and IPV processes and principles, what procedures occur during the assessment process, attitudes regarding expectations and outcomes of the assessment process, and RJ in general.

The two components are conceptually linked; each component can arguably be thought of a precursor (both conceptually and practically) to the next component. In order to have a practice, we need a set of ideas or policy that we are drawing from. If the practices are clearly RJ, they will reflect the theory and the model in which they come from - which has also been accurately translated into policy.

\section{Participants}

All interviewees were identified through either websites containing information on RJ facilitators and agencies, through government websites listing judges and RJ agencies throughout New Zealand, books or chapters written by various individuals working in RJ, or referrals from other participants in this study who suggested potential participants.

The majority of the district court judges throughout New Zealand were selected from the list of judges that were warranted to work with both family and general cases on the Courts of New Zealand website (MOJ, 2015a). An attempt was made to cover a variety of districts around the country when deciding whom to send letters to. Additionally, some judges were 
contacted after individuals working in the $\mathrm{RJ}$ sector identified potential participants for this study, or judges I was interviewing suggested other judges that might. A total of 20 introductory letters were sent to judges and 5 judges consented to be interviewed. 3 of the judges who consented to participate had been selected from the government website while 2 of the judges were contacted as a result of recommendations from other individuals in the study. There were 2 female and 3 male judges interviewed. An attempt was made to not only speak with judges who supported and worked in RJ, but others who would have differing viewpoints and perspectives. RJ facilitators and court coordinators were selected based on agencies that they worked for (selected from a range of agencies across the North and South Island) and referrals from other facilitators regarding potential participants. An attempt was made to select a variety of facilitators with a variety of experience in both RJ and FV to understand the issues from a broader perspective. 19 facilitators were contacted and 15 agreed to participate. 4 of the interviewed facilitators were initially selected to contact because of their affiliation to a particular RJ agency. Following this, contact was made with 9 facilitators as a result of referrals from interviewees and 2 were following introductions at an RJ conference. 4 lawyers, 4 court coordinators, and 6 individuals working for the police were identified through referrals from interviewees and other individuals working in RJ. 2 lawyers (both male), 3 court coordinators (all female), and 5 individuals working for the police agreed to participate ( 2 male and 3 female). Of the 30 participants, 8 identified as Maori and the remainder were Tauiwi or Pakeha. One participant was from the South Island. All other participants were located in the North Island.

Being a qualitative research study, the numbers of participants is relatively small when compared to a quantitative study. This is generally due to the rich amount of data that is collected in qualitative research and the labour intensive procedures involved in data collection and analysis (Willig, 2008). It is argued that though generalization of results is not considered possible in a qualitative study, if "a given experience is possible, it is also subject to universalisation" and must exist within a given society or culture (Willig, 2008, p. 17). The sample size is considered adequate when "theoretical saturation is reached, that is, no new themes or concepts are generated" (Higginbottom, 2004, p. 10).

\section{Reflexivity}

It is important to recognize the researcher's influence in the process and that an interview is a form of social interaction (Forrester, 2010). In order to have reflexivity, an awareness of a researcher's contribution to meaning making during the research process and the "impossibility of remaining outside of one's subject matter while conducting research," 
(Willig, 2008, p. 10) is necessary. Therefore, it has been important to be aware of how interviews are conducted, the questions asked, the biases that I, or the interviewee may have, and the cultural awareness that is necessary (Forrester, 2010). In a sense, the interviews were 'co-produced' and responses to my questions may depend on how they were asked, what was asked, why I am asking, and the interviewees desire to present a certain perspective or view of themselves or the process. In addition, analysis involves coming from both an empathic perspective and a questioning perspective (Smith \& Osborn, 2003) - not only did I endeavour to understand the interviewees' experience and point of view, but I also analysed the interviews and asked critical questions of this text such as implicit meanings and perhaps have had an insight into meaning that the interviewee was not completely aware of.

\section{Procedure}

\section{Component 1}

Each principle of the NZ standards of RJ for FV cases (MOJ, 2013) was analysed in depth in order to determine the consistencies and inconsistencies with the international literature and theory. In the case of inconsistencies, further analysis occurred in order to illustrate the gaps or tension that existed and present arguments that illustrated a direction for clarification. Additionally, the Sentencing Amendment Act (The Parliament of New Zealand, 2014) was also taken into consideration as this policy now drives the referrals of cases to $\mathrm{RJ}$ in the court system. This robust analysis created further questions and gaps in policy that helped to create the framework for the semi-structured interviews that would occur in Component 2.

\section{Component 2}

All potential interviewees were contacted either via email or post, with an introductory letter explaining the research, and a request to be in touch if they were interested in participating. Once interest was expressed, an information sheet was sent along with a consent form and questions were answered regarding the research (see Appendix A).

Once consent was received, potential interviewees were contacted in order to schedule an interview time. A semi-structured interview protocol was developed (see Appendix B) in order to explore the participant's views on RJ, IPV, how to assess genuineness, empathy and IPV offender suitability for RJ. Single interviews (in all but two cases) were implemented either face-to-face, over the phone, or via Skype. Interview questions were open-ended in order to allow for better understanding of how participants understood the processes and theories and follow-up questions were driven by participant's responses (Creswell, 2013). Some examples of questions from the interview protocol are as follows: "In your opinion, what is RJ?" "What types of IPV offences do you usually work with?" "What are the specific 
characteristics you look for in an offender that lets you know the offender is appropriate for RJ... and how do you know this?" "How do you know if an offender is showing genuine remorse or empathy?" The interviews varied in length between 45 minutes and 75 minutes with an average length of 60 minutes. Debriefing will occur following the completion of the thesis. This will consist of a brief summary of findings that will be emailed to each participant along with the option to receive a pdf copy of the full thesis. Interviews were recorded using the HT Recorder application on an iPhone 5 (Applies Voices LLC, 2014) and were transcribed by this researcher using ExpressScribe Questions software (NCH Software, 2014) on a MacBook Air laptop computer. Data collection occurred over a 9-month period. Ethical approval was received 9/6/2014 from the standing committee of the Victoria University Human Ethics Committee, reference 0000020835

\section{Data analysis}

32 interviews were completed and transcribed (two interviewees were interviewed twice in order to gather further information). Initially, 23 interview transcriptions were actively read through in order to become familiar with the data at a deeper level (Braun \& Clarke, 2006). Following this, two interviewees were contacted again via email in order to clarify questions that arose after reviewing the transcripts. The active reading involved reading individual texts line-by-line, looking for meaning and patterns and summarizing ideas that were both directly observable (manifest content) and implicitly referred to (latent level) (Marks \& Yardley, 2004). Initially, open coding was done by breaking the data down into smaller units (first level categories) of meaning that refer to particular ideas, content, actions, or thoughts. First level categories were then clustered into second level categories in order to establish general themes that reflected properties of each category (Creswell, 2013). Following the general theme clustering, further analysis of the clusters occurred in order to determine if splitting or splicing was required and some subthemes were developed. Ongoing analysis of the interviews (all 32) was done in order to further refine and define the specifics of each category and theme and subtheme (Braun \& Clarke, 2006, Willig, 2008). Detailed definitions of the potential categories and themes were then made (Marks \& Yardley, 2004; Willig, 2008) and a conceptual model was developed in order to illustrate a potential conceptual framework of RJ IPV offender assessment. Transcripts were then revisited and analysed in order to ensure themes were represented in the texts (to determine saturation) (Creswell, 2013), to discover commonalities and differences in themes and clusters between subjects (Smith \& Osborn, 2003) and to gain a more "generalised understanding of the phenomenon" (Willig, 2008, p. 61). Quotes were then extracted from the text and final 
analysis of these extracts was done in order to ensure they related back to the categories and themes. Using the hypothetico-deductive method (Willig, 2008), subthemes were tested in order to understand whether they still existed or whether others needed to be created. At that point subthemes were absorbed into the general theme categories as it was found unnecessary to complicate the model with that level of division.

In order to ensure objectivity and reliability, eight, randomly selected, interviews were coded by an external coder in order to determine the extent to which the categories and themes we each found corresponded to one other (Willig, 2008). Of the 4 categories and 18 themes, there was found to be $91 \%$ agreement between categories and themes found by the external coder and myself (he was in full agreement on 20 of the 22 themes). He questioned whether the last two themes stood alone and whether they could be absorbed into other themes. After consideration of the two themes in question, it was decided that they were necessary because they had particular features that differentiated them from other themes and these features were important in the development and understanding of the category. Therefore, no further adjustments were required. These categories and themes were then compared with the international literature and local policy in order to ascertain how the processes and procedures in practice compare to the principles of RJ and IPV that was represented in both. 


\section{CHAPTER 5 \\ COMPONENT 1: THEORETICAL ANALYSIS THE NEW ZEALAND PERSPECTIVE - RJ FV POLICY}

The aim of Component 1 was to analyse the current New Zealand policy regarding RJ and IPV and explore how it is consistent and inconsistent with the international literature from North America and Europe. The New Zealand Ministry of Justice has a code of best practice for restorative justice cases that was originally published in 2004. It was said that this was produced after consultation with RJ practitioners and was produced at the same time as the statement of restorative justice values and processes that was prepared by the Restorative Justice Network (an association of community providers) (MOJ, 2011). It was noted that there was consistency across these documents in representing the values and principles of RJ and a decision was made to publish these together representing a "collaborative working relationship between the government and community" (MOJ, 2011, p.5) in terms of agreed values, quality criteria, and an acknowledgement of the need for flexibility of practice that considers both contextual and cultural differences. The most recent version is included in part B of the restorative justice standards for family violence cases (MOJ, 2013). I began by exploring the eight principles of Best Practice for Restorative Justice in criminal cases (MOJ, 2013) then covered the two additional principles that specifically pertain to FV/IPV cases. It was found the some principles required more in-depth discussion and analysis than others. This was due to the complexity of the particular principles they addressed, their clarity and comprehensiveness, and how much they were in agreement (or not) with the international literature.

\section{Principle one}

The first principle states that voluntary participation and informed consent of both the offender and the victim-survivor in the restorative justice process is mandatory. This voluntary nature of RJ not only refers to whether they participate or not, but also how the process proceeds. For example, it is said that voluntary acceptance of their obligations occurs for the majority of offenders involved in restorative justice, however, they may be required to fulfil binding commitments agreed to during the conference, as the primary obligation is thought to be to the victim-survivor (Zehr \& Mika, 2003). However, it is important to recognize that harm has been experienced by the victim-survivor, the family, the community, and the offender, so respectful treatment, healing and reintegration into the community of all individuals should also be a focus of the restorative process (Zehr \& Mika, 2003) and 
agreement on an outcome should not be the sole focus (MOJ, 2013). Saying that, once agreements are made, monitoring is necessary to ensure obligations are met and it has been suggested that "healing, recovery, accountability and change are maximized when agreements are kept" (Zehr \& Mika, 2003, p. 42).

Bennett (2008) questions whether, rather than being completely voluntary, there is an aspect of restorative justice that is coercive. For example, Shapland, Robinson, and Sorsby (2011) note that a restorative justice conference could accentuate cultural or social power imbalances, and that there could be pressure on the victim-survivor or the offender to act in a particular way (e.g. angry, apologetic, fearful, forgiving) when they do not naturally feel inclined to do so. In this case, a person may feel obligated, or there may be an implicit requirement, to apologize or forgive the individual(s) perceived as having more power. In this case, rather than feeling forgiveness or apologetic, they are feeling compliant and coerced. Shapland et al. (2011) caution that this should be something to be mindful of prior to and during the conferences, considering the required voluntary nature of the situation. This was alluded to in the MOJ guidelines (2013).

\section{Principle two}

The second principle states, "full participation of the victim-survivor and offender should be encouraged" (MOJ, 2013). Basically, the purpose of restorative justice is to facilitate healing between the victim-survivor, the offender and the community (Zehr \& Mika, 2003 ) and to "restore the balance of relationships within the society" (Maxwell \& Lui, 2007, p. 6). The aim is to create conditions, and focus on practices and processes, that encourage collaboration and reintegration as opposed to isolation, stigmatization, punishment, and coercion (Maxwell \& Lui, 2007; Umbreit \& Amour, 2010). According to the New Zealand Ministry of Justice (2013), though the community (this can vary between cases) and other professionals (police officers, lawyers, probation officers) may be part of the restoration process, the primary participants are the victim-survivor and the offender. Victim-survivors must decide on their level of involvement and will be contacted following the offender agreeing to involvement (MOJ, 2013). Full participation of the victim-survivor is encouraged, however, victim-survivor advocates can represent the victim-survivor in conference, or in the case of the Sycamore Tree Project (Prison Fellowship International, 2009), groups occur where victim-survivors and offenders from unrelated crimes come together for the restorative process (the panel process).

\section{Principle three}


The third best practice principle is that: "Effective participation requires that participants, particularly the victim-survivor and the offender, are well-informed" (MOJ, 2013, p. 13). Pre-conference meetings with the offender, the victim-survivor and other professionals should occur, where they are briefed on the procedure, who will be in attendance, realistic options for addressing the offence, pros and cons of attending, their individual roles, what rights they have and the limitations to confidentiality (MOJ, 2013).

\section{Principle four}

The fourth principle states that: "Restorative justice processes must hold the offender accountable" (MOJ, 2013, p. 14). This is consistent with international literature on RJ which stipulates that prior to being referred to a restorative justice conference, the offender must assume responsibility for the offence (Shapland et al., 2011). The MOJ (2013) guidelines state, "a plea of guilty, which may be accompanied by an agreed Statement of Facts, will provide the clearest indication of an offender's acknowledgement of responsibility" (p. 14). Interestingly, there is also a line in the standards which states that facilitators should be aware of the risks for the victim-survivor and the offender if the "RJ process is undertaken in cases where a guilty plea has not been entered...” (MOJ, 2013, p. 14). This seems contrary to the fourth principle where the offender is meant to be held accountable. Another point to consider is that there is a difference between pleading guilty and feeling accountable. It is possible that an offender could enter a guilty plea for an offence while they may also not feel that they are at fault - or in a sense accountable. Relying on a guilty plea to prove accountability seems like a potentially misinformed assumption.

Not only is it said that (for the most part) the offender should take responsibility, but he should also agree to the commitments made during the conference. These obligations, though possibly challenging, should be fair, realistic, completed within a particular and appropriate time frame, not be overly lenient (MOJ, 2013) or harmful in terms of human rights, and should be achievable by the offender (Umbreit \& Amour, 2010; Zehr, 1989). The fact that offenders are expected to have insight and to understand their obligations starts to hint at the concept of offender empathy and altruism.

There are conflicting definitions of empathy in the research. Oxley (2011) defines it as: "feeling a congruent emotion with another person, in virtue of perceiving her emotion with some mental process such as imitation, simulation, projection, or imagination” (p.32). Barnett and Mann (2013) define empathy as, "cognitive and emotional understanding of another's experience, resulting in an emotional response that is congruent with a view that others are worthy of compassion and respect and have intrinsic worth" (p. 229). Care ethics places 
empathy at its' core with the notion that an action is only wrong if it shows a lack of care for (or empathy for) others by the agent (Ward \& Salmon, 2011, p. 405). It has been suggested by Barnett and Mann (2013) that there are four components of empathy: 1. Perspective taking (imagining oneself in another person's situation and/or imagining what it is like for that person in the situation); 2. Affective or emotional responding (or emotional contagion where they actually can feel what the other person feels). Oxley (2011) contests the idea that emotional contagion is a component of empathy because it does not require an understanding of another's emotions, rather it is more of a trigger response of motor neurons; 3 . A belief that humans are worthy of respect and compassion. In addition, it has been suggested that "empathic responses are mediated partly by compassion and respect for target persons" (Ward \& Durrant, 2013, p. 15). However, is it still possible to believe in the worth and respect of some but not others - and therefore have the ability to be selectively empathetic?; 4 . The ability to manage personal distress and situational factors (Barnett \& Mann, 2013).

Impairment or disruption of these factors and processes can occur for a variety of reasons, resulting in different obstacles to an offender experiencing empathy for a victimsurvivor. Reasons suggested include: underlying or cultural biases and cognitions that support the offence, deficits in theory of mind, intense emotions (e.g. shame) that leads to self rather than other focus, a break down in cognitive functioning, and problems coping (Barnett \& Mann, 2013). Particular deficits are associated with particular impairments in empathic component outcomes. For example, if lacking theory of mind capabilities, the offender will find it difficult to accurately deduce their victim-survivor's cognitive or emotional states (Ward \& Durrant, 2013).

Ward and Durrant (2013) note that, in comparison to Oxley's definition, Barnett and Mann's (2013) definition of empathy seems to go beyond the emotional state of empathy and enters into the realm of the action known as altruism. Kitcher (2010) refers to three varieties of altruism (biological, behavioural, and psychological) and for the purpose of this thesis, psychological altruism will be the main focus and will be the variety referred to. Altruism is thought to be desires or intentional acts that are directed towards the wellbeing of others without self-interest driving the intention or taking priority. Once there is an awareness of your effect on others, your emotions, intentions and desires change from what they were prior to that recognition (Kitcher, 2010).

It is suggested that altruism is a more appropriate concept to be focused on when dealing with offenders as it acknowledges the role of ethical norms and context (Ward \& Durrant, 2013). Context is important when thinking about altruism as it has been suggested 
that an individual will often have certain people (i.e. those closer to them) whose desires and welfare are taken into account, however, there will be those outside of their circle, who do not take priority (Kitcher, 2010; Ward \& Durrant, 2013). In addition, as mentioned in regards to empathy, there may be certain scenarios when an individual's usual sense of altruism is impaired (i.e. when angry or under the influence of alcohol or drugs).

Kitcher (2010) suggests that there are five factors that determine an individual's "altruism profile: intensity of your response to the perceived wishes of the other, the range of people to whom you are willing to respond altruistically, the scope of contexts in which you respond, your discernment in understanding the consequences for others, and your empathic skill in identifying the desires of other (p. 126). Without the ability to cognitively understand the nature of the relationship and the ability to empathize, the best intentions (intensity, scope, and range) may still be misguided.

Batson, O'Quin, Fultz, Vanderplas, and Isen (1983) suggest that those individuals who experience personal distress led to them having a more self oriented egoistic motivation to help others whereas individuals who felt more empathy had a more altruistic motivational response. Thought of in another way, it has also been found that a more egoistic focus predicted less community relatedness and empathy and increased aggression while altruism predicted an increase in empathy, community relatedness while reducing aggression (Park, Jordan, \& Maner, 2011). This all supports the possibility that empathy should be thought of as a component or a criterion of altruism.

\section{How does this relate to IPV and RJ?}

The implication of this perspective of altruism is that in every act of IPV there is a lack of psychological altruism, which may or may not occur in the absence of empathy. In every case, the welfare of the victim-survivor does not take priority but the offender may or may not understand the victim-survivor's experience. If the purpose of RJ is to build relationships, connectedness and to heal, the evidence presented suggests that in order for this to happen, offenders should not only be in a state of readiness, but must be able to exhibit altruistic tendencies.

In addition, it also appears as if the MOJ standards for RJ in DV somewhat greys the line between readiness, motivation, and altruism (for the purposes of this thesis, motivation is thought of as the willingness to change and readiness to change is the ability and skills to change). It appears to make the assumption that an offender who is motivated to change, will have altruistic qualities that will in turn benefit and heal the victim-survivor and himself. I propose that it is possible that a few different scenarios may occur when assessing IPV 
offenders for the RJ process: 1. A person is both ready to change and altruistic, 2. A person is altruistic but not ready to change, 3. A person is ready to change but is not altruistic (changes for their own gain, not that of the victim-survivor), 4. A person is neither ready to change nor altruistic, 5. A person feels empathy and is ready to change, but is not altruistic, 6. A person feels empathy and is not ready to change, and is not altruistic. What happens to those individuals that are not in the first group? What is in place for facilitators to assess these nuances and because someone is not ready, what steps can be taken to prepare him for future readiness? What steps can be taken to increase altruism, and should a case be referred back to $\mathrm{RJ}$ after interventions have occurred in order to give the situation the best possible odds for success?

Principle four also addresses the concept of post conference monitoring of agreed outcomes. It states that agreement on who will take responsibility for post conference monitoring should occur, and a plan should be formulated to address the situation when/if compliance does not occur. In addition, the court may become involved and appoint someone to do the post conference monitoring if no one is named in the conference notes (which have been provided to the court) (MOJ, 2013). Who monitors the outcomes of the conference is not clear in the guidelines, although it does state, "the RJ facilitator does not have a mandate or mechanism to require offenders to complete agreed outcomes. Their role is reserved to a monitoring and reporting role" (MOJ, 2013, p. 31) - although later in the document, it states, "providers will follow up on agreed conference outcomes" (MOJ, 2013, p. 32). This could be a treatment program provider or the restorative justice provider. Either way, it is clear that someone should be monitoring post-conference progress.

According to Ward and Langlands (2009), "it is imperative to give rehabilitation [of the offender] equal weight to restoration and reparation, [as there] is a tendency within restorative justice to respond to need of victim-survivors and their communities first and foremost, even if this conflicts with the needs of offenders"(p. 211). In order to rebuild connections between the victim-survivor, the offender, and the community, the offender must believe that he can build a better life and that he has the skills to do so. Additionally, the community needs to be welcoming or at least open to working on rebuilding this fracture.

There should also be government funded rehabilitation and restorative justice programmes as well as training program opportunities. The application of deterrence and retribution is said to rely on external controls (i.e. courts, arrest) for behaviour change, where as rehabilitation and re-education programmes focus on an individual's internal control of their behaviour (Lewis et al., 2000). In reality, the approaches often overlap as arrest and/or 
court proceedings are often a starting point that leads to re-education and rehabilitation. It is unclear in the policy where exactly treatment fits in - and in many cases, it appears that treatment happens post conference, which is discussed in study two, as an issue that needs addressing.

A coordinated approach to restorative justice that includes a rehabilitation approach, such as the Good Lives Model (GLM) is recommended by Ward and Langland (2009) assuming that research proves that this method would be effective. Several principles of the GLM are complementary to restorative justice. First, ethical theory is at the core of the GLM and holds that human rights and respect of the dignity of others is essential and secondly, that there is a mutual respect between individuals and the norms of the community. An individual will adhere to norms and laws of the community if these laws support the attainment of a good life. Third, people are interdependent and rely on each other in one way or another, for happiness. Fourth, the GLM acknowledges the importance of personal identity and agency. Fifth, in an attempt to provide better lives for offenders, victim-survivors and community, behaviour change is used (Ward \& Langland, 2009). Whatever approach is chosen, it is evident that clarity of direction and intention would be beneficial rather than a vague statement of intent.

In many traumas, violations and conflict, humiliation and shame play a central role (Zehr, 2008). When thinking about post-conference monitoring and reintegration, shame is an area that is important to acknowledge. There are two types of shaming: stigmatizing shaming and reintegrative shaming. The former is condemning and labels the individual as 'bad' and can make the likelihood of recidivism worse. Reintegrative shaming has an aspect of forgiveness and reintegration attached to it that acknowledges a bad act but not labelling the individual as a bad person (Ahmed \& Braithwaite, 2005). It has been suggested that reintegrative shaming also results in offenders developing a better understanding of the victim-survivor's experience (empathy) and a feeling that they could "make up for the offence" (Maxwell \& Hayes, 2006, p. 140). It is also important to address the shame and the victimization feelings of the victim-survivor, as these feelings could result in individuals becoming "stuck in the victim-survivor identity and can lead to offending behaviour" (Zehr, 2008, p. 10).

This thesis initially intended to focus predominantly on the offender, however, it is important to note that within the context of RJ and IPV, both the offender and the victimsurvivor need to be considered. In RJ there is a strong focus on the victim-survivor and that victim-survivor reintegration into life post conference is an important consideration. As part 
of victim-survivor's reintegration, it has been suggested that rather than women being seen as either the provocateur or a victim-survivor incapable of agency, a reframing should occur where she empowered as a "resource in [her] own transformation and in the recovery and healing of others" (Bazemore \& Earle, 2002, p. 172). However, it is important to consider that offending not only violates the victim-survivor and the offender, but also their relationship to the community. The community which was affected by the crime should be involved and empowered through this process and should be assisted to identify and respond to community factors that may have supported the offending (Umbreit \& Amour, 2010). It is important to note that when speaking about empowerment of individuals (i.e. the victim-survivor), that this is not taken to mean that they are being asked to stand on their own in a strong isolation, but rather they are being supported and encouraged to ask for help and to acknowledge the role of others in safety and reintegration (Family Violence, Restorative Justice and the Law Conference Day 1, 2015). The U.S. Attorney General's Task Force on Family Violence (1998) notes that there is a need for a "coordinated community response to family violence... and all the forces of society must actively intervene" (p. 14). The relationships between the community, the victim-survivor and the offender are a vital part of this process, where communities are "seen as having a collective interest and responsibility for the decisions and outcomes" (Maxwell \& Lui, 2007, p. 8). Finding supportive communities that are open to finding constructive ways of responding to the offence and its consequences as well as a willingness to support victim-survivor and offender reintegration is emphasized (Maxwell \& Lui, 2007).

A final point - the guidelines also state in principle four that the RJ process should only address the current offence. However, other offences may be simultaneously addressed in the RJ conference if they overlap with the current offence (i.e. offending was to get money to support drug dealing) or if they are considered "sufficiently serious", the police may be informed (MOJ, 2013, p. 15). Participants should be informed that this is a possibility if additional offending is disclosed. It was noted in the guidelines that FV offending is different than other forms of offending because rather than being incident focused, there is an "ongoing pattern of abuse" (MOJ, 2013, p. 22) - which would then imply that in the case of IPV, historical violence should be considered during a conference. It is said that IPV can be intergenerational as well as historical (within that couple), so it is important to address historical violence and abuse in order to give all parties "a more in-depth mutual understanding of the violence, its effects, and where it has come from" (Hayden, 2014, p. 214). It is apparent that the general RJ criteria in this particular area may not fit the 
framework of IPV due to the strong historical component of IPV that should be acknowledged and addressed.

\section{Principle five}

Principle five states, "flexibility and responsiveness are inherent characteristics of restorative justice process" (MOJ, 2013, p.16). The process of restorative justice practices tends to be relatively informal and private when compared to the criminal justice process of public rituals and legal jargon. In the conventional criminal justice system, both the offender and the victim-survivor are set outside of the formal, rule bound, rituals of the courts and are limited in the amount in which they can participate or even comprehend the proceedings (Maxwell \& Lui, 2007). There is little room for flexibility or responsiveness to individual needs. Conversely, in the restorative justice process, settings and procedures that are followed can be agreed upon by the stakeholders and the group facilitator, which allows for individual and cultural sensitivity and the stakeholders can "retain ownership of the process" (Bennett, 2008, p. 5).

The fifth principle (and is repeating throughout several of the other principles) stresses that RJ values such as physical and emotional safety of participants, respect and dignity for all involved, safeguarding offender and victim rights, balance and fairness, voluntariness, transparency (or process and outcomes), and empowerment of participants should underpin practice. Restorative justice is concerned with the protection of the human rights of the victim-survivor and the offender, endeavours to have sensitivity to cultural practices, and encourages cultural connectedness (Maxwell \& Lui, 2007). It is the responsibility of the facilitators to accommodate cultural practices when appropriate by, for example, consulting cultural advisers or kaumatua (respected Maori tribal elders) and utilizing interpreters when necessary (MOJ, 2013). In addition, it is said in the guidelines, that a way to reflect responsiveness to the culture of the participants, is to have facilitators who have the same ethnicity as the victim-survivor and the offender (MOJ, 2013). This will be discussed in later sections, however at this point it is important to acknowledge that this cultural matching is difficult to achieve in New Zealand as there was said to be an imbalance of particular IPV offender ethnic groups and enough RJ facilitators to accommodate this.

\section{Principle six}

The sixth principle states that, "emotional and physical safety of participants is an over-riding concern" (MOJ, 2013, p. 17). Potential risks for the victim-survivor and the offender need to be managed carefully. It has been found that minimization or denial of offending can increase psychological harm of the victim-survivor, and a criticism of RJ in the 
area of IPV has been the possibility that the abusive partner can have coercive control over the victim-survivor that is both overt and covert (Hayden, 2012). Trust between the victimsurvivor and the facilitator is key as well as physical and emotional safety for all stakeholders. Included within this idea it is said to be important that the victim-survivor is aware that trust develops over time, not everything is within their control, and the direction of the process is not precise or predictable (Jülich et al., 2010). In order for this process of restoration to work, the victim-survivor and offender must feel safe and an understanding of each of their motives to be involved in the restorative process must be carefully assessed and monitored (Jülich et al., 2010; MOJ, 2013).

This sixth principle of best practice regarding safety is particularly highlighted in the area of IPV and RJ. Victim-survivor safety, both during and after the conference, is potentially at risk and there is very often a fine balance between the consideration of safety and a future relationship with the offender (Hayden, 2012). As mentioned earlier, there are a number of reasons victim-survivors of IPV are often reluctant to leave or to end relationships with their abusive partners and it is important to acknowledge these and respect a woman's autonomy and power (Fernandez, 2010) as well as be aware of the intricacies of IPV and ongoing patterns of behaviour. This illustrates how skilled RJ facilitators need to be in the area of IPV as there are far more complexities than when thinking about the safety issues in a 'stranger' offence. Another point to consider is whether the process could potentially become too risk averse - where, due to a fear of harm, some assessors then assess most IPV cases as inappropriate. In that case, rather than focusing on healing, the process becomes focused on risk reduction.

Principle 6 also states that the privacy and confidentiality of all stakeholders participating in the conferences should be protected as much as possible. Attendance of conferences by non-stakeholders (i.e. media or researchers), and sharing of private information, can only occur with consent of the participants (MOJ, 2013). The state system no longer has a central role in the process other than establishing a restorative justice framework, enabling the necessary processes to occur, "providing for the implementation of the outcomes arrived at in this way, and monitoring the quality of the outcomes achieved" (Maxwell \& Lui, 2007, p. 9). What exactly this framework looks like and entails is questionable and unclear. Is restorative justice an intervention within the criminal justice framework? Does RJ sit along side or is the goal to have an overarching RJ framework in which all justice works?

Following the conference, if referred by the courts, the criminal justice authorities (i.e. the courts) should be informed of the outcomes agreed to but not the specifics of the 
conference (Shapland et al., 2011) or offences unrelated to the referred offence. Follow-up, in most cases will be required in order to monitor whether obligations are being carried out, whether victim-survivor and offender require further support or care from other agencies and for feedback on the restorative process. Provisions should be made regarding what should occur if the agreed to obligations are not met (MOJ, 2013). This is a repeat of many of the points that were addressed in the fourth principle.

\section{Principle seven}

The seventh best practice principle states, "restorative justice providers (and facilitators) must ensure the delivery of an effective process" (MOJ, 2013, p. 18). This is said to include choosing facilitators who are skilled in communication, conflict resolution, "managing strong emotion and conflict", and knowledgeable in local culture, the criminal justice system, gender issues, RJ practices, and specific victim-survivor and offender issues (MOJ, 2013, p. 18). Facilitators should be monitored to ensure performance standards are met as well as ensuring that ongoing training and peer and professional supervision occurs for these facilitators (MOJ, 2013). In addition, the guidelines suggest that there are certain personality characteristics such as accountability, honesty, openness, integrity, selfawareness, and objectivity that constitute a "high quality facilitator" (MOJ, 2013, p. 18-19). The effectiveness of a facilitator plays a key role in the RJ process, as a study by Armstrong (2012) showed, victim-survivors felt that, "the way the facilitator listens during the meetings and makes sure that you get anything that you may need, answering your questions does make a big difference, you feel like they are actually listening and trying to help you" (p. 46).

Principle 7 also notes that facilitators should not work for a justice sector agency (e.g. the police), not have a bias towards either the victim-survivor or the offender, and "respect should be had for people including those who are different" (MOJ, 2013, p. 19). It is said that facilitator performance should be monitored, regular supervision should be available, and appropriate facilitators should be chosen for particular case referrals. This is particularly relevant in the IPV area as facilitators not only need to be trained in RJ, but also in the area of $\mathrm{FV}$. This may mean that there is more than one facilitator present (one with RJ accreditation, one with FV accreditation ${ }^{3}$ ), someone from an external FV agency is present to work with the RJ facilitator, or that a single facilitator has experience/accreditation in both. Component 2

\footnotetext{
${ }^{3}$ The MOJ uses the term "accreditation" for FV, however, the Resolution Institute (https://www.resolution.institute) - which has the MOJ contract for accreditation training presently, think of this more as a FV "endorsement" as the process is not as comprehensive as an accreditation process for RJ.
} 
highlights this as an area that is lacking consistency and monitoring in some areas of the country. RJ facilitator training and selection for cases warrants attention and should not be overlooked as making an assumption that an RJ facilitator is appropriate for IPV cases would be at best doing a disservice to the stakeholders and at worst, creating a dangerous practice.

There appear to be a few gaps and areas left open for interpretation within this section - in particular, how the various qualities, skills and traits of a facilitator are assessed. There is no mention about accreditation although there is a footnote that directs the reader to the Ministry of Justice website (www.justice.govt.nz) (MOJ, 2013, p. 18) where it is mentioned that RJ accreditation (or in the process of achieving it) is required for all RJ facilitators. However, it is unclear what accreditation is required in terms of FV although it does mention that accredited facilitators are available. As will be discussed, this FV accreditation (or endorsement) is thought to be significantly less rigorous than the RJ accreditation process and is in need of further attention and analysis.

There is also mention in principle 7 that "formal evaluation of programmes should be supported and encouraged wherever possible [my emphasis] and RJ providers should monitor their own practice on an ongoing basis" (MOJ, 2013, p. 19). The question remains, who is ensuring that this occurs, that the evaluation is done properly and within certain guidelines, is performed by someone who is qualified, and there is consistency across evaluations? A discussion with an individual at the Resolution Institute (www.resolution.institute) revealed that a problem with the accreditation process is that many people will go through the RJ facilitator training, but the last portion that requires mentoring, on the job skill training, and supervision, is often lacking and not followed through with due to a number of reasons such as agency funding and time shortages. Additionally, it became evident after analysis of the policy, that further defining effective facilitator characteristics and traits is needed and is an integral part of creating an effective assessment process.

\section{Principle eight}

The eighth principle states, "restorative justice processes should only be undertaken in appropriate cases" (MOJ, 2013, p. 19). This refers to the type of offence, the willingness of stakeholders to be involved and the "participants suitability, including their maturity and ability to participate effectively and in a voluntary capacity" (MOJ, 2013, p. 19). In addition, the eighth principle introduces the concepts of FV and SV and emphasizes the cautious approach that professionals should have when considering these cases for RJ, due to the particular dynamics of power imbalances that are "inherent to this type of offending" (MOJ, 2013 , p. 20). It is mentioned that some of these cases may not be appropriate and can pose 
significant physical and emotional risks to the victim-survivor and facilitators need to be skilled and experienced in the areas of FV and SV in order to ensure safe practice. In addition, it is stated that "a one-off intervention may therefore not be effective or safe" (MOJ, 2013, p. 20). This seems to reflect a position that RJ is possibly considered a one-off intervention rather than part of a bigger picture or longer process. However, in the RJ for FV portion of the document, it is clearly stated that "a one-off restorative justice service is unlikely to achieve this degree of change [(change of deeply entrenched behaviours, abusive relationship transformed, significant and long standing harms repaired)] and will be one step only in a much longer process"(MOJ, 2013, p. 21). This seems to acknowledge that RJ for FV may be considered part of a much broader picture. This is another example of how there appears to be a lack of clarity in how policy views RJ in terms of a framework and the expectations of how/where it sits in the justice process.

This principle vaguely hints at the concept of readiness without clearly stating what this looks like and how facilitators would know if the offender or victim-survivor were in fact ready. The guidelines elaborate later about what offender characteristics should be considered, however, as will be pointed out, there are many gaps in those recommendations such as not discussing how to assess the characteristics that they recommend should be present such as genuine remorse, empathy or the ability to change.

\section{RJ and FV guidelines in NZ}

Within the Ministry of Justice restorative justice standards for family violence cases that were released in July 2013 (MOJ, 2013), two new principles were added that specifically focused on family violence. These were underpinned by certain restorative principles that reflect the specific needs of all of the stakeholders affected by family violence or sexual offending who are involved in RJ services (MOJ, 2013). This was an attempt to clarify and standardize the processes and principles of RJ for FV.

\section{Principle A}

The first principle is that the process is victim-survivor driven as it:

Respects the right of the victim to hold the offender accountable. It recognises rebalancing of power between the victim and the offender as a key to victim healing. (MOJ, 2013, p. 23)

What does it mean to be victim-survivor driven? According to the report (MOJ, 2013), this suggests that victim-survivor needs and capacities moderate the pace and procedures that occur and also implies that the victim-survivor is self motivated rather than being coerced by external parties such as the community, family or the offender. It is thought that the victim- 
survivor driven process will allow the victim-survivor to experience control and the ability to make choices, while having their needs met (MOJ, 2013).

Offender needs are also addressed and though the victim-survivor's needs and wishes are considered first, they do not take precedence over the respect and protection of the offender and cannot "cause harm beyond that which could be considered to be a consequence of the other person's behaviour" (MOJ, 2013, p. 23). It is not clear how the level of appropriate harm within a conference is measured and I suspect this might depend on many variables and subjective perspectives. Additionally, this runs the risk of RJ slipping into the retributive perspective of punishment and it is unclear how this line will be clearly navigated.

\section{Principle B}

The second principle states that the processes of RJ are "designed to maximise both the opportunity to experience a sense of justice and the chances for healing, and to minimise chances for harm.”(MOJ, 2013, p. 24). The document further elaborates this point by defining a safe and supportive environment as one where victim-survivors are able to express their experience of harm, where they receive a genuine apology, and where they are able to have a say in what reparations required of the offender would be restorative for them. It is not clear how to assess what would be a genuine apology and how the stakeholders would know if it was genuine or not.

Forgiveness and apologizing is an important aspect of restorative justice, and though this may not occur in every case, it has been said that the "principle objective of restorative outcomes is to reintegrate victim-survivors and offenders into their respective communities" (Maxwell \& Lui, 2007, p. 10) and forgiveness and apologizing are important elements in this process. However, it has been suggested by Coker (2002), that forgiveness should not be forced as this could be seen as coercive and only serve to reinforce the power imbalance that occurs in the relationship. In that case, it would become more of an act of compliance rather than true forgiveness.

The assessment and screening criteria outlined (MOJ, 2013) stipulates that the offender must have the "capacity and readiness to offer a meaningful apology" (p. 27). What is not mentioned is: What is a meaningful apology? How do we know if the apology is meaningful or not, to whom is it meaningful, and where is the evidence that an apology is required in order to have a successful RJ conference? As previously mentioned, an apology is far more than merely saying "I'm sorry" and is a far more nuanced concept that would require experienced and knowledgeable assessors to even begin to ascertain its genuineness. Additionally, later in the document it states that "an offender is not expected or required to 
offer an apology” (MOJ, 2013, p. 30) - which seems somewhat confusing. The MOJ also acknowledged that offenders should not expect forgiveness or "acceptance of the apology"(MOJ, 2013, p. 30) because this could be seen as coercive and put additional pressure on the victim-survivor. These inconsistencies make it unclear what place an apology takes in this process.

It was also mentioned that an offender should "understand impacts on victimsurvivors [and be aware of] offender's attitudes, [be able to] express remorse, and have insight into their own behaviour" (MOJ, 2013, p. 27). This is not only about readiness, but again, seems to be asking that during the pre-conference period, that the offenders show they are capable of empathy. Is this possible prior to treatment for many of the offenders? Many of the offenders may not have the skills to express empathy yet. What happens to those cases where the offenders (or other stakeholders) do not show readiness or the ability to show empathy - are RJ values still being upheld if the case is simply rejected? Is this implying that empathy is a key component of restorative justice and additionally, there is the question of whether empathy has been proven to be a marker of readiness to change for IPV offenders?

It has been said that empathy may help to motivate individuals to "take into account others' interests but... it is normatively detached and if it is to lead to pro-social outcomes it needs to be explicitly linked to justified ethical norms" (Ward \& Durrant, 2013, p. 7). As was previously mentioned is often the case in IPV, there are social norms that support the lack of balance and use of control over victim-survivors, so to have empathy leading to change, there needs to be a connection to a change in the accepted social norms. In addition, it has been suggested that it is possible to have an empathetic response towards a victim-survivor and still offend (Ward \& Durrant, 2013). This leads to a point that was made earlier - it is important to consider the difference between empathy and altruism and consider the implications of what is being assessed.

Healing and justice is said to be promoted for the offender by the ability to publically be accountable for "wrong-doing" by making reparations that are considered to be appropriate and by having the opportunity to "commit action to prevent any further abuse" (MOJ, 2013, p. 24). This leads to the question regarding offender needs and if RJ is meant to heal all stakeholders, how, without treatment, are some offenders able to heal from these actions?

This document notes, "the quality of the assessment and intervention pre-conferencing will mitigate risk for all parties and largely determine the potential for safe effective conferencing and successful outcomes" (MOJ, 2013, p. 23). This does not specify what is done and how this assessment quality is determined and what pre-conferencing intervention 
looks like. Given that this is a very heterogeneous population, the guidelines would need to be flexible to accommodate this, however, it seems as if some framework needs to be in place to ensure the best possible outcomes for all involved.

\section{Pre-conferencing assessment}

During this period of time, the victim-survivor's safety is paramount and is the focus of assessment and screening practices along with taking into consideration the seriousness of the offence and the likely future relationship/contact between the victim-survivor and the offender (MOJ, 2013). There is mention that when screening the offender, an assessor should look to see if he is taking "a high degree of responsibility for the harm they have caused through abuse"(MOJ, 2013, p. 27). In order to assess this, an offender should exhibit "some understanding of the cognitive distortions, minimisations and behaviour that have supported the offending" (MOJ, 2013, p. 27). In addition, they should be able to contain their emotions when with the victim and should have a "reasonable degree of empathy as this will impact on their ability to show remorse and provide genuine apologies" (MOJ, 2013, p. 27). Again, these guidelines do not specify how is this readiness assessed? There appears to be a lot of room for subjectivity by the assessor.

Other areas to be considered during the assessment are: the offender's history of participation in the RJ process; ongoing psychological needs; offender safety (for self and for others); offender capacity to understand his impact on the victim-survivor; his attitudes, expressions of remorse, insight into his own behaviour and his desire to put things right or repair the harm (MOJ, 2013). Again, if this assessment were occurring prior to any treatment program, how many offenders, at this point, would be considered "ready" - and then what

happens? Does this mean that they miss out on the opportunity to participate in the RJ process if not deemed as ready? Should this assessment occur in order to determine which intervention would be useful and then have procedures in place to deal with each stage of readiness, stage of change and motivation?

Another area to consider during the assessment process are, support people. The MOJ requires at least one support person to be present during FV conferences, although they do recognize how this can be challenging for some offenders due to lack of suitable support people or a desire to keep their offending private. The screening of support people in order to assess whether they may support the beliefs and behaviours that perpetuate the DV cycle of abuse, victim-survivor blame, or collaborate with offenders, was stressed (MOJ, 2013). This is a crucial point because it is well documented that abuse can be passed down through the generations (Erickson \& Hart, 1998) and through society and therefore support may be 
coming from someone who supports the violence or power imbalance. According to the guidelines, "the degree of societal myth and high rates of victimisation in the community" increases this risk, so screenings of support people must be done in order to further ensure safety and reduce risk of further violence (MOJ, 2013, p. 29).

A final point to consider in regards to the conference: the guidelines (MOJ, 2013) acknowledge that other stakeholders may have been affected by the abuse. They are referred to as "indirect victims" and "with victim permission, these indirect victims might [my emphasis] be acknowledged in the conference" (MOJ, 2013, 31). Looking at the literature, a "core value of RJ is centrality of community in addressing crime... it is this collective, relational process that most distinguishes RJ from standard criminal justice responses" (Frederick \& Lizdas, 2010, p. 43). This poses the question about how much the current policy addresses the effects of IPV offending on stakeholders other than the identified victimsurvivor and offender. In fact, the question also arises regarding how much the effect on the offender is acknowledged in policy.

After analysis of the RJ standards for family violence cases (MOJ, 2013), it is apparent that a lot of the policy is supported by the international literature on RJ, however there are still gaps in the policy that need clarification. In particular: how to assess readiness, genuine remorse, empathy, accountability, and the value of an apology. Additionally, it is unclear after closer inspection, how RJ sits in relation to the traditional criminal justice system or how the MOJ views RJ as a framework. These are areas that will be further explored in Component 2 in order to see how this cloudiness in policy manifests in practice. 


\section{CHAPTER 6 \\ COMPONENT 2: EMPIRICAL ANALYSIS}

Component 2 was an empirical analysis where a combination of $30 \mathrm{RJ}$ facilitators, judges, lawyers, police, and court coordinators, who were part of the RJ assessment process of IPV offenders, were interviewed in order to understand how assessment of readiness and suitability occurred. In particular, the concepts of how to assess genuineness and how to understand the information gathered in order to make an informed assessment were explored while also attempting to understand how the values of RJ were upheld/not upheld within practice. Additionally, this component aimed to understand how the framework of RJ manifested in practice.

Following analysis of the data, two main areas of focus immerged: Restorative justice intimate partner violence conceptualization and RJ practice (see Figure 1). RJ IPV conceptualization was found to be an umbrella category that gave an overarching view of RJ IPV theory and perspectives here in Aotearoa New Zealand. RJ practice was divided into three categories: effective RJ IPV assessor qualities, IPV offender assessment for RJ suitability/readiness, and RJ IPV practice issues. Each of the categories was then divided into a number of themes and sub-themes. Each category will be discussed in detail.

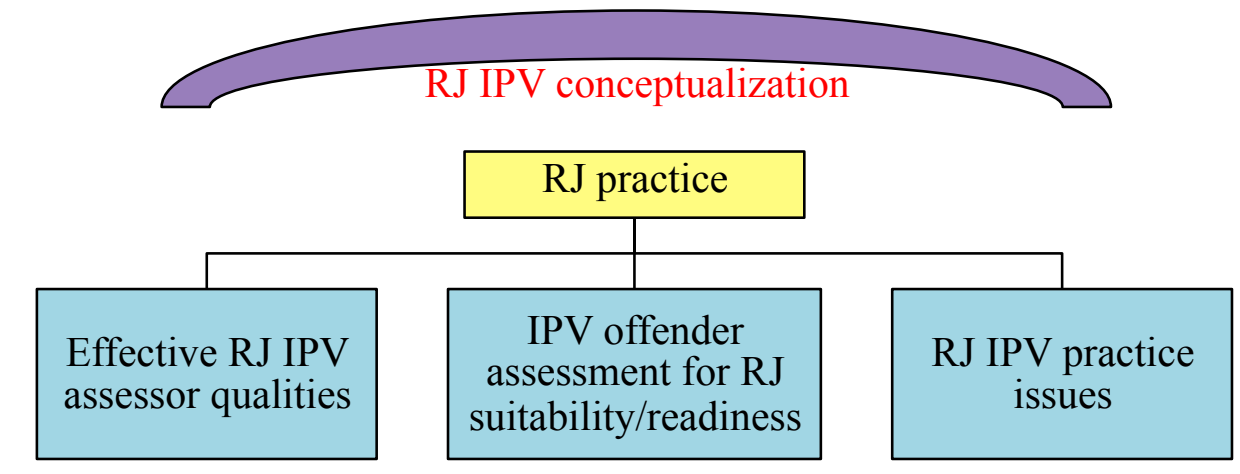

Figure 1. Conceptualization and practice map of the assessment of RJ in IPV case 


\section{RJ IPV Conceptualization in New Zealand}

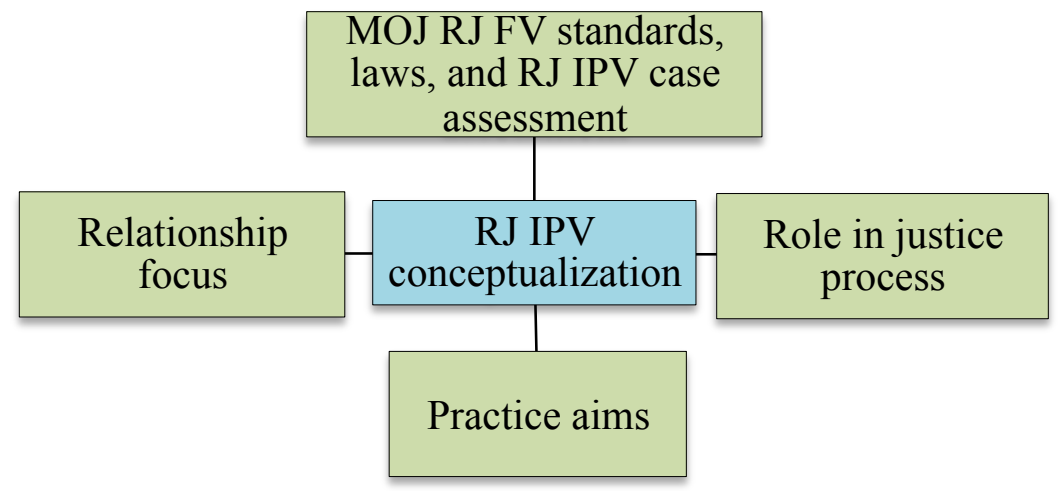

Category

Theme

Figure 2. RJ IPV conceptualization

$\mathrm{RJ}$ is not confined to the current MOJ contracts around providing RJ services that are pre-sentence, after the charge and the guilty plea. RJ is much wider then that. Then I think if you take justice off and you say a kind of restorative approach - that's even broader, so basically I think when people use the idea of a restorative approach or RJ, they have in mind the word restore...something's happened in a relationship between two people... (T13Lawyer, 13-18)

The first category found was RJ IPV conceptualization (see Figure 2). This is an umbrella category that is the over-arching viewpoint of RJ and IPV in New Zealand. This was found to be divided into four main themes: Relationship focus, practice aims, role in the justice process, and MOJ RJ FV standards, laws, and case assessment. These themes were further broken down into sub-themes that will be discussed in detail in each section.

\section{Relationship focus}

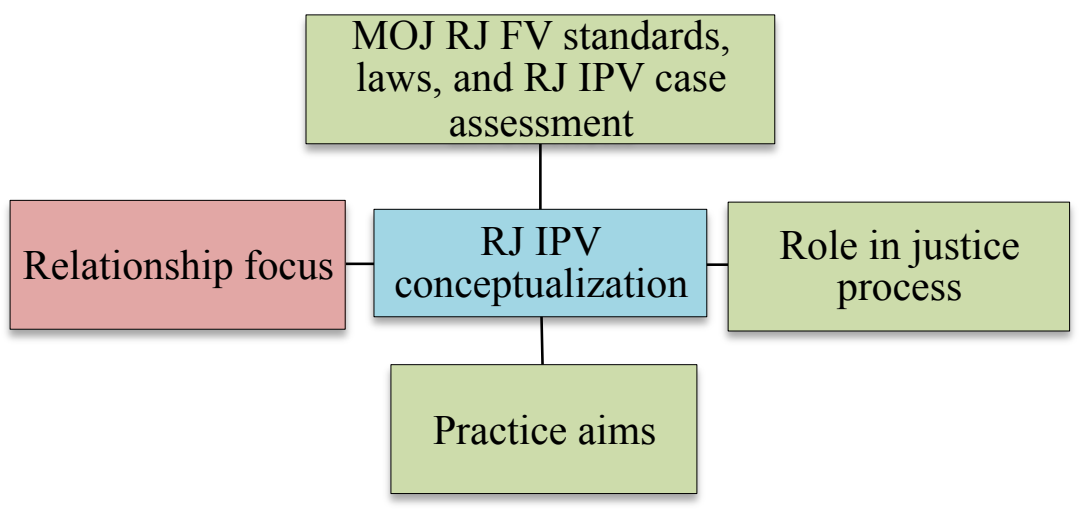

Figure 3. RJ IPV conceptualization: Relationship focus 
$\mathrm{RJ}$ is about supporting the right for the victims to get an appropriate and responsive justice process... that actually helps them, empowers them and restores their own mana and safety... because by intervening we are able to say straight away - what's happening now at home, how safe are you, what do you need... those sort of things... and then holding the offender accountable for the harm they caused but it also allowed that we could involve whanau... so it is about helping restore equilibrium in relationships and whanau because they're not going anywhere... they're all still here... (T27RJFacilitator, 317-324)

The first theme that emerged in the RJ IPV conceptualization category was that RJ practice for IPV is relational (see Figure 3). It focuses on the relationships between stakeholders (victim, perpetrator/offender, family, whanau, community) and the relationship between the facilitator and the stakeholders. It was said during the RJ FV Conference (2015) that RJ "is about helping people. It comes down to a simple thing. If we don't know who you are or have any knowledge of who you are / where you're from, then we can't engage with you. It's all about getting enough knowledge and skills to help the people sitting in front of you that are hurting." (Restorative Justice Conference, 2015, p 27). A common thought that was expressed throughout the interviews was that RJ for IPV is complex due to the fact that it is relational - that they are dealing with people that have a past and often a future together rather than a one off stranger offence. Therefore, this requires different considerations and knowledge than other RJ scenarios.

The simple cases that RJ does normally... that person A, that person B, and we just say it's about the intersection of two lives, and we put a little box around it and that's what we're here to talk about. Of course FV [draws picture of scribbled, crossing over lines] how do you put a box around that? And that to me is why there's something quite different about the FV stuff... (T22RJFacilitator, 479-484)

Because RJ for IPV it is not dealing with strangers, it has a strong family component and several interviewees stressed that there is a responsibility to society to help rebuild and strengthen individuals and families.

It is about allowing them to have the conversation they want and need... we are weighted towards the offence victim... but actually, we have a responsibility to all parties, including the offender ... and the more one goes into work on these things, the distinction becomes less clear ... they are all actually people that need to engage in a process to deal with something... (T22 RJFacilitator, 121-126) 
Although the idea of RJ encouraging couples to remain together is a point of tension that was mentioned by several participants. However, it was acknowledged by some interviewees that there are many different outcomes that may be focused on for healing to occur and during the RJ process, it may, in fact, be found that it is better for the family not to stay together.

The purpose of RJ is to strengthen the family, to look at what the issues are in that family, and to address the causes of the offending... and to look and see whether they can be addressed - whether it is better that that family actually does not continue as a unit... (T4Judge, 21-26)

\section{Offender and victim-survivor}

"A lot of women don't want their partner jailed or arrested - they just want the violence to stop...” (T15RJFacilitator, 90-91)

The first relationship that it was said should be addressed is the one between the offender and the victim-survivor. $\mathrm{RJ}$ is about bringing the offender and the victim-survivor together in order to heal or repair the harm that was done.

For us [RJ] was the only intervention that could get us with both people... get us in contact with both the victim and the offender... to bring whanau in, to look at what services needed to be wrapped around them, and start some of the work to change that behaviour... (T27RJFacilitator, 88-94)

As previously mentioned, a point of contention was what RJ means when talking about the relationship between the offender and the victim-survivor in terms of relationship repair. Does this mean relationship reconciliation or rupture? Or neither? A small fraction of the sample indicated that there was a concern from other non RJ agencies, that RJ's point was to keep a couple together and that there was an increased risk with RJ that unsuitable couples will stay together. Some interviewees felt that there are some agencies that seem to be philosophically against couples staying together, and are therefore skeptical of RJ.

Woman's refuge can't look after all victims especially they struggle if the woman says "I'm not leaving him" so [some victim-survivors] don't want a bar of Woman's Refuge because Woman's Refuge is more for the time when they've made the decision to leave...they get frustrated when the women come, use the service and then go back to [the offender]... (T23RJFacilitator, 19-25)

From the victim-survivor perspective, it was said that there could be a perception that women's refuge and other agencies do not want to work with them due to the victimsurvivor's desire to keep the relationship intact. Some say that this may be more a case of victim-survivor perception rather than reflective of the actual viewpoint of refuge. 
There are also many DV survivors that Refuge does not work and for some of these women this is because of a perceived hostility from the Refuge movement to the relationship remaining intact. So this is fraught in another way, as these women may be more likely to reach out to RJ as a response that fits their needs, but lack the specialist DV support because of barriers and perceived judgment. (T32RJFacilitator, 65-67)

Other interviewees made the point that these same agencies (i.e. Women's Refuge) do not turn victim-survivors away if they want to return to the offender - so perhaps RJ should not either.

In a women refuge type focus, they don't deny those women a bed or safe shelter based on whether or not they're going to go back. I don't know that we should deny a couple an opportunity to sort or talk this through in a safe environment with willing people if they want it. (T25RJFacilitator, 91-94)

Some pointed out that many of the couples want to stay together, and that most victimsurvivors of IPV want the abuse to end, but not necessarily the relationship. Therefore, it is the agency's/RJ facilitator's responsibility to address this desire rather than focus on their personal agendas or perspectives.

Unfortunately [some think RJ] also increases the risk of them staying together and can be seen as supporting them staying together... what I say to that is - we are not endorsing anything, at this point they refuse to separate and they're going to stay together and police aren't going to be able to do anything about that... however if that's the decision they've made and we can impact on that then we need to try and give them some skills to deal with that... no point in giving them nothing because they won't agree with us and break up... (T8Police, 326-333)

One interviewee pointed out that RJ may increase victim reporting of IPV because it may be seen as an option that is better than the court system.

It's part of a criminal prosecution process when we're talking about it in the way we are... it's also got a therapeutic benefit... It helps to encourage victims to come forward because they may see the consequences as less severe for someone who they don't necessarily want to see go to prison for instance... so you might flush out more IPV and have it addressed because $\mathrm{RJ}$ is there as an option rather than simply having the court process or nothing... we know the underreporting of IPV is a significant issue... so if RJ helps to increase the reporting and address IPV where it is prevalent in the 
community...well it's got a very beneficial factor in that regard as well... (T3Judge, 5564)

Others noted that the offender and the victim-survivor might not desire to be together, however there is still contact due to children being involved, or alternatively, the cyclical patterns of IPV come into play and the victim-survivor may return to an abusive situation. A final point was that the conference might illuminate the fact that the couple is better off separating and the conference is a space in which to decide how best to proceed from that point. Either way, healing the relationship is necessary regardless of whether they stay together or not.

In IPV you have this whole context where you've got both a past and a future... usually... not always... if a relationship is over the last thing they want is to see each other again but more often than not, there is likely to be future contact if only because there are shared children... and often a resumed relationship... the pattern where women return to abusive relationships... so you've got all these dynamics at work as well as a current criminal prosecution... (T3Judge, 26-31)

It became apparent that there are a wide variety of viewpoints on the offender/victimsurvivor relationship and what role RJ and external agencies should take depending on the varying configurations. However, a majority of the interviewees pointed out that RJ is not about reconciling or rupturing a relationship - it's about healing - regardless of whether they stay together in the long term or not.

\section{Family/whanau/wider community}

The relational aspect of RJ for IPV focuses a great deal on not only the relationship between the victim-survivor and the offender, but also their relationship with family, whanau and wider community. This is not only for support but also to break the secrecy that is often very prevalent in IPV.

So we're networking them in with support we're helping them be ready and to make the most of that support... we're bringing other whanau into the conversation so we're breaking the secrecy ... we're exposing the problem to the wider family group... (T17RJFacilitator, 344-347)

IPV abuse is something that is very often private and behind closed doors. It was acknowledged by most interviewees, that the conference is a place to make the abuse public to other members of the whanua, family and/or community. Having support people in the preconference and conference are not only there to support the victim and the offender, but are 
also there to witness the abuse, and to witness/hear promises and commitments made by the offender, which can help to hold him accountable post-conference.

For me accountability is not about this being a little private process or secret process.

$\mathrm{FV}$ is often about secrets and the antidote to that is, you know, throwing a whacking big search light on it and illuminating the situation... and what that means to me, in reality, is bringing other people into the circle. (T22RJFacilitator, 293-298)

This brings up an interesting balance that was spoken of - that of transparency and openness versus confidentiality and victim safety. Some noted that in IPV cases, it was thought that transparency between stakeholders might not be appropriate for safety reasons because it could endanger the victim-survivor. For example, facilitators will cross reference stories with other stakeholder stories, however, it was said to be important for victim-survivor safety not to be too transparent when speaking to the offender.

Sometimes we hear things from one party which mean we need to go back to the other...I would be doing very much informed consent working with the party. "Sounds like this is important to you, how would you feel about me going back to check this out... and how would I do that where it's going to be all right for you?"... Because often they'll know more about the risk in real terms then I ever would just as a stranger stepping into their lives... (T22RJFacilitator, 417-426)

In addition, specifics that are discussed in conference are not shared with the court and reasons for not proceeding with the conference are not shared with the stakeholders or the court. The only aspect that is shared with the courts is whether the conference proceeded and what agreements/commitments were made. However, an interviewee pointed out that though facilitators might be conscious of the hazards of transparency, in court, there have been times when others involved in the case may not be as mindful of their responses (i.e. might tell the court that the victim does not want to participate in $\mathrm{RJ}$ when the offender is there and willing) and could inadvertently add stress to the situation.

Our communication to court, which is vague and wears this as it is a "facilitator decision" is regarded by lawyers and some judges as "oh well the victim probably didn't want to do it" and that is literally how they talk about it in court.

(T32RJFacilitator, 42-43)

There were subtle differences in the degree in which the availability of support influenced the assessment of offender suitability. Few felt it was a factor that could disqualify someone if support was not available - most identified that support was often a problem in terms of availability, willingness, and/or perspectives that supported IPV. Several 
interviewees mentioned that the availability of support people supplied by the offender and victim should not be a suitability criterion held too stringently due to circumstances that may be out of the offender's control - or a reflection of the difficult and isolated context in which the couple exist rather than defiance.

[Support] is not a primary consideration at all because regrettably, whanau support of offenders in court is increasingly rare... they're on their own... maybe up to $1 / 3$ have whanau support in court... but once again, it can be very very powerful in a good way to get it... (T1Judge, 326-332)

Though, as previously mentioned, some interviewees noted that a lack of support could actually be a dangerous situation, and keeping the abuse private may increase the risk of harm.

If they were unable or unwilling to use that support, then I would be assisting them to get that other professional support... because there's some people that say they don't want to talk to anyone about it... and I think that's the danger in domestic situations for me - that it's kept in the closet... (T26RJFacilitator, 133-136)

This is countered with the perspective that an RJ facilitator should balance the needs and desires of the stakeholders and should acknowledge the request that wider family is not informed of the abuse.

It very much depends on their relationships with their wider family... some people don't want the wider family to know too much about what is going on and I have to respect that... (T29RJFacilitator, 245-247)

Another point that was discussed was the awareness that should be had in terms of support people (whanau or family) supporting the beliefs around power imbalances between men and women. It was said that an assessor should be mindful of this possibility.

[I often] involve people from the church, or elders from the community... talking respectfully to the kaumatua from the family... often you'll get letters from PI elders, especially in FV situations, and they're to be treated with a little bit of caution... unless you really know who they are or what they're involvement is... because while it's a sensible thing to look at...there is still a question mark over the role of the women as opposed to the role of the man... you've got to trust that there's not going to be inequality and the woman's not being forced to accept that, well, not that she's exactly a punching bag, but she has her place... (T4Judge, 230-237)

Additionally, when screening for appropriate support people, it is important to meet them in context (with the offender or victim-survivor), due to the fact that individually they 
may behave one way and seem very appropriate, and then when in the presence of the victimsurvivor or the offender, another dynamic may become evident (i.e. power and control over, or reinforcing anti-social ideas).

One of my learnings out of a case... I met with the support person of the offender... one to one... and he was great... he was a model support person by my estimation... what I had totally missed, was the dynamic that then existed between him and the offender because I didn't have them in the room at the same time... and so when they came together [in the conference] it was a really unhelpful dynamic... so I guess the learning for me is around it's not just about the individuals... it's how the individuals combine..." (T22RJFacilitator, 79-90)

\section{Victim-survivor focused}

At the end of the day, it's the victim that I'm concerned about. To be brutally honest, and showing my redneck tendencies, the offender can go jump. But if it's going to help the victim - I'm all ears... (T1Judge, 117-120)

Though RJ is relational, all interviewees agreed that RJ in IPV cases is clearly victimsurvivor focused. This central role during the assessment of case and offender suitability was found to be in terms of an assessor understanding/honouring victim-survivor expectations, needs, capacity, and safety before proceeding with a conference.

So when you talk about what determines if an offender is suitable, one of the absolute first questions you need to ask yourself is, "will this help the victim and is the victim ready?" I wouldn't even look at the offender first. If the answer is yes, then go back to the offender - is the offender ready for this? Can the offender accept responsibility? Does he address all the principles of the RJ process? The accountability, the flexibility, the process, fully informed... is this voluntary? So if they're addressed why would you not do it? (T28RJFacilitator, 37-48)

However, it was also pointed out by the majority of participants that despite being victim-survivor driven, if the victim-survivor expressed interest to participate in RJ and the offender was not interested or assessed as inappropriate (or vice versa) a conference would not occur. In fact, it was pointed out by all of the facilitators that the conference will not occur, despite both the victim-survivor and the offender expressing interest, if the RJ facilitator assesses the case as unsuitable. In the case of RJ for IPV - the facilitator has the final word on whether the case goes to conference or not.

In terms of being victim-survivor centred, victim-survivor safety and empowerment were emphasized by the majority of people. 
We're teaching it to be an offence victim centred - they are the most important person in the process...I guess what we are looking to do is to empower them through the processwhat ever that might mean for them... and to the extent that they want to... including empowerment to say "bugger off we are not interested in this"... and to me that's what is restorative is giving someone a choice. (T22RJFacilitator, 142-154)

However, a point was raised that a safety plan for the victim-survivor, and empowering the victim-survivor, may place too much responsibility and be stressful on her rather than place the focus on others (i.e. support services, whanau, family, offender). It was suggested that empowerment makes safety her issue rather than the offender or the system - ignoring systemic issues that made safety a challenge for the victim.

[Empowerment] is a term taken from civil rights movements and social and community empowerment and what we have done is individualise it, and hide the structural issues that affect people who experience violence. The misuse of empowerment focuses on what the victim is doing to keep herself and her children safe, and renders invisible the systemic barriers that impede her choices. It shifts responsibility and accountability to end the abusive partner's violence to the victim. (Family Violence, Restorative Justice and the Law Conference Day 1, 2015, p 3) In terms of goals, a number of people said that victim-survivor goals need to be assessed as realistic based on offender capacity, victim-survivor capacity, and parameters of the conference. This emphasizes the issue of timing of the pre-conference assessment being pre-treatment - and how ready are the victim-survivors and offenders to address issues? This will be discussed in depth in a following section. The capacity is referring to both internal capacity (cognitions, skills) and external (support, safety) factors. The capacity of victimsurvivors also referred to their needs and what is required to keep them safe, what support they need, and how to not risk re-traumatize them.

RJ has always been, as far as I know anyway, very victim focused, so it's more about the capacity of the victim to be able to benefit from this, and move through this process... if we thought someone was emotionally too young for this, or for example, someone might have been quite heavily involved in counselling after the incident, and as soon as we hear something like that, we want to talk to the counsellor to say "do you think this person is prepared?" (T13Lawyer, 255-266)

Informed consent has to be given before proceeding with pre-conference assessment and it was stressed by a majority of the interviewees, that it is important to understand that victim-survivor views may be skewed due to being coerced or there being an ongoing 
relationship. As mentioned, RJ is relational, and though RJ for IPV is clearly victim-survivor focused, it was stressed by a few of the interviewees that the relational aspect of RJ should not be forgotten, and that means that all parties should be taken into account.

It is about allowing them to have the conversation they want and need... we are weighted towards the offence victim... but actually, we have a responsibility to all parties, including the offender... and the more one goes into work in these things, the distinction becomes less clear... they are all actually people that need to engage in a process to deal with something... (T22RJFacilitator, 121-126)

A final point that was raised by a few of the interviewees in regard to being victimsurvivor focused is the very contentious issue regarding victim-survivor precipitation and multiple victims. Most interviewed said that in the case of RJ, though it is said to benefit all, there is a clear victim-survivor who was harmed, and an offender who should take responsibility for the harm. However, this was a point of tension for some because in IPV, it was said by a few of the interviewees, that there is often a situation when the offender has also been a victim-survivor and the victim-survivor has also been an offender. A point was made that the traditional criminal justice system does not allow this discussion of context and blurred lines.

We talk about in IPV, that it's usually not just a one way street - so we look at the poor victim and think poor victim but then turns out she cracked him over the head a couple of times with a bottle as well... so we need to put that bit in as well. Or he's a horrible person - he's done this blah blah blah... we need to put that out of our head. We need to look at the people as human beings that need help... (T28RJFacilitator, 275-281)

This is a very controversial point of view and it was emphasized that this is still not an excuse for violence or abuse for anyone.

"While almost everyone accepts there's two sides to most stories, there's still no excuse for smashing someone's head in." (T4Judge, 357-358)

\section{Facilitator/offender}

A final relationship that was found to be a focus when considering the relational aspect of RJ was that of the facilitator and the offender (and other stakeholders). It was mentioned by a few of the participants that building the relationship (rapport) between the facilitator and the offender is an important part of the assessment process. This helps to build trust and to allow a more honest flow of information. 
You're asking a person to trust you. You're asking them to open up their lives and arms and values, and trust you with some of the most intimate details they can explain to you. You have to work with those people and gain their trust... (T28RJFacilitator, 247-251)

The over riding message regarding assessment and the relational aspect of RJ for IPV, was that a holistic approach needs to be taken - looking at all of the relationships and the individuals within those relationships.

You need to deal with it in a holistic process as opposed to an isolated process between victim and offender and stuff like that. You are talking about whanau... wider communities and stuff like that. You need to be as broad as you possibly can be ... [this] isn't just the offender - it's the families and communities that condone the activities that go on in that environment... (T28RJFacilitator, 286-293)

\section{Practice Aims}

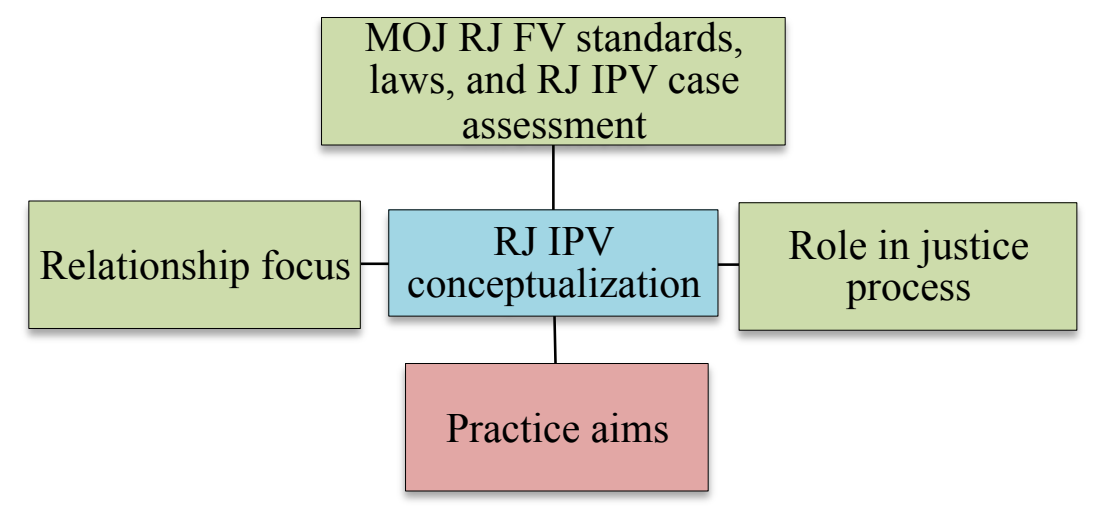

Figure 4. RJ IPV conceptualization: Practice aims

$\mathrm{RJ}$ is not about apologizing, it's not about being forgiven... it's not about any of that... the RJ conference is about the conversation... of people being heard, the meaning heard... listened to... and participating in the process where their voice is heard ... and provide our people with the opportunity to heal... provide people with the opportunity to get balance, restore hope - give them hope... all that sort of thing... it's not about the court. (T28RJFacilitator, 396-399; 416-418)

After considering who we are thinking about and their relationships, the next aspect found in the conceptualization of RJ IPV category was to think about what is trying to be achieved the practice aims (see Figure 4). There were two main subthemes that became apparent: Repair harm/restore mana, and evaluation of safety. 


\section{Repair harm, restore mana}

$[R J]$ is not about the reduction of crime, it's about healing harm and giving people an opportunity to be heard in a meaningful manner. If the people we work with walk away from the RJ conference and they say "they feel a hell of a lot better and listened to..." and victims can get up in the morning instead of hiding under their covers, and go to work in society... isn't that better? If the offender can say "I've had enough of this crap, I should have never done that... let's see what I can do to make a change..." isn't that better? (T28RJFacilitator, 377-389)

All participants agreed that RJ for IPV aims to repair psychological and moral harm, and some pointed out that it restored mana that was damaged as a result of the offending. It was mentioned by several interviewees that RJ allows a level of catharsis and insight for victim-survivors and offenders that the traditional criminal justice system does not provide. This is in terms of both the current episode of offending and the damage as a result of historical abuse. It was also stressed by a few individuals that in the case of IPV, the relationships are not exactly being restored - because they may have been damaged from the beginning. It is more a case that they are being repaired.

IPV is definitely not the same principle [as other RJ cases] - you're not restoring the relationship which was faulty anyway, you're trying to resurrect and improve...

(T4Judge, 13-15)

This addresses a point of tension that was raised in that the traditional criminal justice system deals in "incidents" - a current offence. An offender is in court for a particular crime that has occurred (an incident), and is referred to RJ for this event. However, the majority of people working in the RJ IPV field agreed that pre-conference assessment should be done holistically and look more broadly than the individual incident. Some suggested that it should be thought of as an "episode" (Smith, 2015) - taking in the cumulative pattern of harm.

We don't want people to be blinkered in incident focus when they go [on a IPV call out] - we want them to actually know the [offending] history, know the context, when were we last there, what did we do, what do we know about the family and often with offenders, they go from partner to partner to partner. The actually person's history is relevant too... (T6Police, 244-248)

In a sense, most interviewees acknowledged the idea that when healing harm, RJ takes into account the past, but also the present and the future. Healing and repairing the harm - but not necessarily restoring anything because the past may not be a healthy or positive place to return to. 
People need to find a way to not restore them where they were exactly before, because there's no way to rewind the clock, but just to find a way to begin to move forward... the relationships going to be ongoing [in IPV cases]... so I think there's a lot more hope put into the meeting about finding a way not only to carry on, but to be able to continue to interact in some way or another and hopefully in a positive way... (T13Lawyer, 2236)

\section{Evaluation of safety}

It's much wider than simply looking at the two primary parties... It's actually looking at how is this going to be safe for all of the participants, how is this going to work. (T22RJFacilitator, 97-100)

Interviewees expressed that not only was the pre-conference period used to evaluate relational issues such as offender distortions, reactivity, capacity in order to address harm and repair, but was also used to evaluate recidivism risk and safety.

$90 \%-99 \%$ is the pre-conference work. The conference is probably a single point where we are in a process... could be many meetings, could be one meeting, could be days, could be months... If you minimize or identify all the potential risk factors or what you consider a potential risk factor... is he remorseful, does he have access to weapons? Is he a violent character? Has this happened before? You add all the factors together, if you come out with a situation where you are unsure or you are uncertain, then you would err on the side of caution. You need to balance it up...

(T28RJFacilitator, 145-153)

More specifically - The safety costs versus the benefits of proceeding to conference are being evaluated (predominantly for the victim-survivor, but also the other stakeholders). It was noted by a number of participants that facilitators are constantly making decisions about where this balance point is between healing and risk and understanding what are realistic expectations.

The truth, painful as it is, is actually part of the healing journey... so to say someone is remorseful and they're not, is more harmful than to say they aren't when they aren't... while that's painful for the survivor to hear, that they actually didn't give a shit about them, that they actually just [behaved] out of their own selfishness... that helps them disengage from any taking responsibility themselves for anything that happened to them. That painful is a healing painful... we're still careful how we do it and we're monitoring the survivor's ability to hear information as well... (T17RJFacilitator, 325334) 
There was also an acknowledgement by several individuals that in this balance there is the consideration that doing nothing or doing nothing new, is not going facilitate change either.

Whatever you do you have to make sure there are safe guards. At the same time, if you don't do anything it's not going to help... it is tricky and it changes depending on who your provider group is and all that sort of thing... it's changeable. (T4Judge, 301307)

The safety that is being considered is not only present safety, but also future safety issues. RJ facilitators, in a sense, are being asked to be risk assessment experts. This will be further discussed in the "effective IPV RJ facilitator qualities" section, but it is important to stress how the evaluation of safety was found to be an over arching practice aim. In IPV cases, as previously mentioned, the RJ facilitator has the final word on whether the conference goes forward. Meaning, if the facilitator assesses the case as unsuitable - for any reason - the case will be referred back to court, without any reason given other than unsuitable regardless of the expressed interest by either the victim-survivor or the offender.

You have to have a line where the safety of the victim comes first... it's not worth simply trying something like this if it's going to put them at further risk or further victimization... (T6Police, 51-53)

This is in contrast to stranger sexual violence (SV) cases where the victim-survivor has the final say. An important distinction was noted that in non IPV SV, the risk is no longer current, where as in IPV cases - the risk may be current and ongoing.

It was noted by several facilitators that the assessment practice, in itself, could be risky for the victim because it was mentioned that the process is initially offender driven (the referral comes from the court) and therefore, the offender is aware of the referral. However, seeing as RJ is considered victim-survivor driven, it was found that in most cases that victimsurvivors were spoken to first - in order to determine if they were interested or not and to avoid re-traumatization by coercing them in any way due to the offender's desires for RJ. This set up the possibility that the offender, if not interviewed (due to the victim-survivor not wishing to proceed), might think the conference was cancelled due to the victim-survivor's wishes or as previously mentioned sometimes other individuals in court who, for whatever reason, are not mindful of the possible repercussions, will state outright that the victimsurvivor is not interested in RJ. This has the potential to anger the offender and cause him to blame the victim-survivor for not getting a reduced sentence from participation in RJ. When questioned about the possibility that this could endanger the victim-survivor, some of the 
facilitators acknowledged the imperfect system, but that they do their best to ensure the safety of the victim-survivor.

Yes, I certainly see that risk... I generally discuss the whole issue with the victim as they usually have a really good sense of safety... With IPV cases, we go to the victim first because they are generally aware of the possibility of RJ. If after that, we or they think it is unsafe we do not even proceed to meet the offender. In cases where we meet both parties, we are clear to all parties that for it to proceed to conference there needs to be three yeses - victim, offender and facilitators. If a decision not to proceed is made, we don't give reasons and the decision is "owned" by the facilitators... I don't think this is perfect and it is one we are constantly re-thinking. (T31RJFacilitator, 30, 15-18)

It was mentioned by a number of the interviewees that there is a concern about the ability of assessors to competently evaluate safety - and that if there were more confidence in the ability of making the right decisions regarding risk, then there would be more confidence in referring to RJ. However, it was acknowledged by many of the interviewees that making correct judgments and assessing genuineness is challenging, but at some point trust in the process and the assessor's ability to evaluate risk is needed in order to proceed - with caution.

If we could be sure the process is safe, if we could be sure both parties really want it really mean to give it a good go, I mean why wouldn't we do it? But it's the risk of it and how well do you assess [the genuineness]...so in terms of making that decision... I guess at a certain point you're just going to have to make that decision ... (T6Police, 173-183)

\section{Role in the justice process}

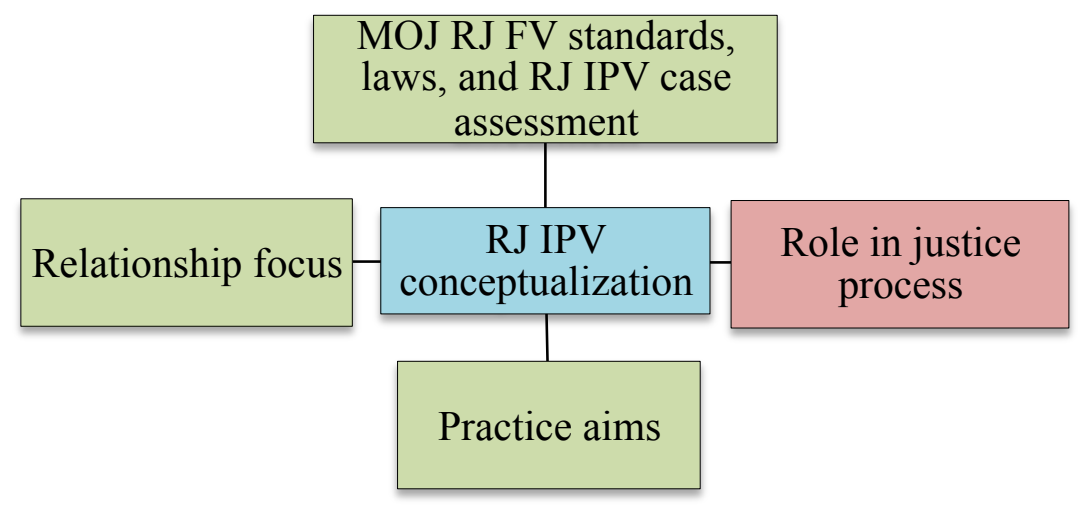

Figure 5. RJ IPV conceptualization: Role in justice process 
After considering who and what was the focus of RJ for IPV, it became apparent that understanding its role and position in the justice process was an important aspect in understanding the conceptualization of RJ for IPV (see Figure 5). This was found to have five main sub-themes: component vs. umbrella; intervention vs. just pathway; timing (pre/post treatment); offender sentencing; and punishment vs. moral repair vs. behavioural technology.

\section{Component vs. umbrella}

I look at RJ practice like the acupuncture of the medical world... it'd be nice to have out on the fringes. However with the legislative changes and what's happening in society... we're becoming mainstream... With that comes responsibility for standards, accreditation, volume and quantity stuff and quality stuff. Huge changes, short amount of time, we're running flat out but we need to make sure that we're doing it right because we are becoming mainstream... (T28RJFacilitator, 360-367)

It is important, when thinking about RJ, to understand its relationship to the traditional criminal justice system. When reviewing the data, it was not clear-cut whether RJ was considered a component of the traditional justice process, or an umbrella for a new way of thinking about justice. Some implied that RJ was something that fits within the criminal justice system (component) - part of a systemic response to FV, while others implied that RJ could be a new way of thinking about and approaching justice for FV that either sits outside of the traditional system, parallel to it, or perhaps overarching the system (umbrella).

In terms of it sitting within a traditional criminal justice system - [RJ] really doesn't... but as we try to get better responses to crime, and if we use that as our goal then it very much fits within a criminal justice system. It doesn't sit comfortably within a purely adversarial system... it sits rather more comfortably within a problem solving system. The modern trend in courts, certainly at this level, is that they should move further to a problem-solving model... (T1Judge, 3-6)

\section{Intervention vs. just pathway}

We know FV is intergeneration... so it's really complex issues to unpack... so ideally to have any enduring effect, it's not something that's going to happen with one meeting... it's got to be a sustained long term commitment and the right skills to get to the root of it... (T6Police, 253-256)

Regardless of where it sits relative to the traditional criminal justice system, there were questions raised regarding how it sits. After analysis of the interviews, it became apparent that there were some differing viewpoints regarding whether RJ is a "just pathway" 
towards justice, a one-off intervention, or therapy. Most RJ facilitators interviewed viewed RJ as part of a pathway to justice and rehabilitation - a catalyst for broad change rather than a therapy or a one-off intervention.

Our role and function there is not to stop the problems. Our role and function is to provide the appropriate support mechanisms or networks that do have the expertise to deal with that. Ours is a very very small process... ours is the process that can light the spark or fire of change... We might affect it - but we only do a part. We do this much [made small gesture] of that much [large gesture]. (T28RJFacilitator, 182-187) It was acknowledged that there may be therapeutic outcomes, but that is said to be a byproduct rather than a goal.

I think it's facilitating change... I don't see that we are doing therapeutic intervention... I think that's a by-product of the pre-conference interviews and stuff like that... I think that part of the process is therapeutic but I more describe the RJ process as facilitating change so that if someone needs counselling or is willing to go to counselling, that becomes a task from the RJ conference... (T26RJFacilitator, 244-251)

In addition, it was noted that there may also be reduced recidivism rates, but some said that this is also considered to be an incidental consequence rather than a goal of RJ. RJ is part of a much bigger picture of justice.

We are this tiny intervention in a much wider story. And therefore what I'm seeing as our role, or a core role, is to ensure that we're building an oversight for this going forward... (T22RJFacilitator, 466-471)

It was said by a number of people that RJ heals the system and should benefit all stakeholders in a non-coercive way - but is not to be confused with mediation, which does not necessarily have a clear victim-survivor and a clear offender. Either way, it was agreed by most interviewees, that RJ for IPV was part of a process to address the need for long-term change.

I like the idea of family violence being an episode and not just an incident, I'd like to go further to say restorative justice is also an episode - these episodes are made up of incidents, these are the conferences, the activities - these are the incidents that make up the episode of restorative justice, and that episode is but one chapter in a book, and that book is life, it's varied and its huge, and no one can tell you what your chapter is about. (Family Violence, Restorative Justice and the Law Conference Day 1, 2015, p 23) 
There were a small number of individuals interviewed who viewed RJ for IPV as a one off intervention in which other people or agencies will be involved in any future monitoring or processes. However, in a sense, this is still saying that RJ is part of a bigger picture - it is just a case of how big a part in that picture does RJ take.

I don't see our role as being much bigger than the meeting. Where as some of my colleagues think we might be in there for a while... I see RJ as an in out intervention from which comes some written notes, or a plan or some commitments that will be monitored by other people in an ongoing way to carry out. (T25RJFacilitator, 182188)

There was a very small portion of interviewees that suggested that not only is RJ one off, but there should be a zero tolerance policy if there is re-offending.

Does it mean the next time something happens you're going to get offered RJ again? ... There's nothing to stop that being offered again... which seems to me absolutely preposterous... if someone comes in and genuinely says all of this stuff and then doesn't do it, why would they get another chance at it... with the same relationship... unless there was some intervening reason - a compelling one... because it just seems that the victim carries all the risk and there's no accountability for the offender and it's just putting, usually her, in a very dangerous place where nothing's helping...

(T6Police, 194-203)

Whether it was considered "one-off" or not, it was stressed by all, that post-conference monitoring was necessary to keep the offender accountable to commitments made - to continue the process of change and accountability. This will be discussed later in another section on post conference monitoring.

\section{Punishment/adversarial vs. moral repair vs. behavioural technology}

For 2000 years we've been butting heads together. So we need to change [the way the traditional criminal justice system deals with FV]... because if we don't change we're just going to live in an adversarial society that's just going to marginalize people, and we will never deal with hurt or harm in a way that can restore balance and healing. It's time to change... that's the bottom line. (T28RJFacilitator, 16-19)

After thinking about where and how RJ sits in relation to the criminal justice system, the next question raised was about the underlying focus/purpose of RJ for IPV. Analysis found that RJ for IPV in New Zealand had three possible foci: punishment, moral repair, and behavioural technology. 
A small portion of the sample saw RJ as trying to fit into the adversarial position of traditional criminal justice system where punishment was the focus. A criticism of RJ from this perspective was that an offender is not held suitably accountable and does not satisfy the need for shared suffering.

I see a lot of problems with RJ... there's a lot of issues or risk around it being proportionate to the level of violence of what occurs... what measures that are put into place? $[\mathrm{RJ}]$ does not hold someone truly accountable for what they've done. (T8Police, 98-102)

The second position found was that of moral repair - where core relationships are addressed.

It's a very blunt instrument through the court system. The beauty with RJ process is that it personalizes the situation for both the victim and the offender... it actually gives them back some power. It very much gives the victim back some power, some support... somebody saying, "what you've been through is awful”. (T26RJFacilitator, 199-207)

These core relationships are not only between the offender and the victim, but include the community, family, and whanau as well.

If we take the metaphor from Chris Marshall... crime is about a tearing of the parchment of society, and RJ is about repairing that tear... (T1Judge, 104-106) As Walker (2006) points out - "wrongdoers and victims -- whether individuals or groups -are a natural focus for moral repair. It is less obvious but essential to see that moral repair is always at the same time a communal responsibility" (p. 29). Within this concept of moral repair is included the idea of moral censure where offenders and the community are asked to challenge their moral positions that are opposed to cultural or societal norms.

The final conception found was that of a behavioural technology where $\mathrm{RJ}$ is thought to primarily be about behaviour change - decreased recidivism, decreased abuse, and increased insight.

The traditional court system is really only set up to punish the offender. We've got the opportunity to leave things better off as opposed to neutral or worse. There's nothing in the court system that I can think of now, unless we believe that the opportunity for penance, prison or some sort of punishment actually works... I think we all know it doesn't actually do any good. Doesn't help anyone change necessarily or very seldom. 
Whereas it's possible we can help bring about change and betterment of some sort. (T25RJFacilitator, 151-157)

There was found to be some overlap between the perspectives - especially moral repair and behaviour technology, where not only were relationships addressed, but behaviours were thought to be changed as a result of the moral repair. There was also overlap between the adversarial and behavioural perspectives from one interviewee.

We don't allow alternative [approaches] or RJ as part of our [FV] processes. We come from a really hard-line approach where we are trying to change behaviour and culture around FV. FV is a crime. It's treated as a crime... (T6Police, 54-57)

Another point worth mentioning is that several interviewees pointed out how RJ might increase reporting rates of IPV because some victim-survivors think of RJ as a softer option. This crosses over between the adversarial perspective and moral repair.

It helps to encourage victims to come forward because they may see the consequences as less severe who they don't necessarily want to see go to prison for instance... so you might flush out more IPV and have it addressed because RJ is there as an option rather than simply having the court process or nothing... (T3Judge, 52-64)

\section{Timing}

Further tension existed between agencies dealing with IPV and policy regarding the best timing for RJ (pre versus post external IPV agency treatment). There was consistent agreement amongst most interviewees, that RJ was not a stand-alone practice and there was awareness that prior to treatment there are many potential offender limitations in terms of accessing language about their feelings, understanding cognitive distortions, alcohol and drug issues, and mental health issues. Many questioned the value and effectiveness of running a RJ IPV conference pre-treatment and a few individuals felt that some conferences might be running before the offender is ready.

If you err on the side of caution, say "listen mate we are not quite at the stage where we can do this, let's do these things first" - could be relationship counselling or anger management, alcohol addiction, could be a host of things because you just don't come into IPV with [no issues]... So if you start dealing with those issues that are behind them, then you can have a look at mitigating the risk. (T28RJFacilitator, 153-159) In addition, it was expressed that, given enough time and resources, most cases could become appropriate if the individuals could have time to go through programmes before going to conference. 
I think people can change. I have a huge belief in people's capacity to change. But I don't think it happens over night and certainly doesn't happen over one conversation, and it's certainly not a straight line. There's tons of relapse along the way... I think most cases could be done if you threw enough time and resource at it. Might take a year, 18 months, 2 years, before you build up to a conference but at the moment no ones' being funded to do that... (T22RJFacilitator, 516-538, 711-713)

However, one individual from the RJ Conference noted that not only is timing important, and attending a DV treatment program is important, but also proof that attending a DV program had results that would be considered successful. It is more than just a certificate of completion - offenders need to show that they have changed.

If we have a restorative justice process without the right steps it won't work. What does accountability mean? They can pick up a piece of paper and say I did the program and slide back into a family... we need to make this more meaningful. (Family Violence, Restorative Justice and the Law Conference, 2015, p 32)

This problem also extends to the victim-survivor in terms of their readiness and capacity to participate in a conference in a fulfilling and non-re-traumatizing way. The tension existed in that there was an acknowledgement that in many cases, due to time, funding and resources, offender and victim-survivors were being assessed for suitability prior to attending any programmes so potentially suitable people may be turned down due to not having a chance to start the change process.

\section{Offender sentencing}

In addition to RJ often occurring pre-treatment, at the moment, RJ in New Zealand exists pre-dominantly pre-sentence. If an offender participates in the RJ process, section 8 of the Sentencing Act (The Parliament of New Zealand, 2014) stipulates that outcomes of the process must be taken into account during sentencing - meaning a potentially reduced sentence. There was found to be tension around this issue because some view RJ as a softer option and that this reduction in sentence may hinder the assessment of genuine remorse due to offenders having an incentive, other than healing harm, to participate in RJ.

The criticism is often from people like the Sensible Sentencing Trust, is that if the defendant is often up for it because they're either told by their lawyer or they think it's going to help with their sentence, they'll be treated more leniently... and without doubt because our sentencing act has a provision which says that issues such as RJ must be taken into account in the sentencing process... so if someone has taken part in a conference, they will be given credit for that... (T4Judge, 206-217) 
A few individuals thought that offenders might be more genuine if RJ was offered post sentencing because of the lack of sentence reduction incentive. Others felt that it did not really matter if an offender feigns remorse in order to get a reduced sentence - in fact some commented that it was completely understandable that someone would want a reduced sentence. Several individuals expressed the view that this does not diminish the effectiveness and value of the RJ process and as long as the conference was deemed safe, then just getting the offender and victim to participate, and potentially experience positive outcomes - was worth overlooking the offender's incentive.

It doesn't really matter why an offender wants to participate in RJ... The literature suggests that even if you go in half-heartedly, the chances are you're going to benefit... (T4Judge, 218-219)

MOJ RJ FV standards, laws and RJ IPV case assessment

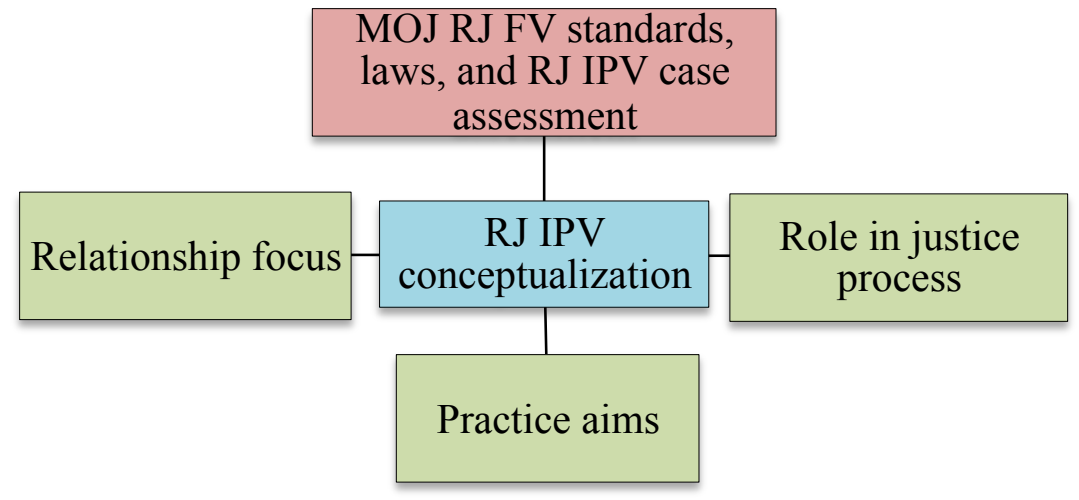

Figure 6. RJ IPV conceptualization: MOJ RJ FV standards, laws, and RJ IPV case assessment

"One of my concerns is we need to maintain our hearts and soul...the community we're coming from, the values that we have..." (T28RJFacilitator, 367-369)

Finally, when thinking about the conceptualization of RJ for IPV, it was found to be important to also think about how conceptualization is influenced by the Ministry of Justice (MOJ) (see Figure 6). Despite having a grass roots origin, it was found that the assessment of IPV case suitability was now driven by the MOJ restorative justice standards for family violence (MOJ, 2013). However, it was pointed out by a number of people that the MOJ standards were government rather than RJ industry initiated. Though these standards of 
practice are upheld, several interviewees expressed concern that with the new legislations, there is a risk that $\mathrm{RJ}$ will lose its core values and may become too regulated.

MOJ captured RJ really. I think for me, it belonged in the community. I think people who have got relationship difficulties but are wanting to sort things out, should be able to do that without having to commit an offence... (T27RJFacilitator, 459-464)

However, it was acknowledged that it is necessary to put standards around practice in order to increase rigor, reliability, and safe practice and flexibility can still be maintained within the practice implementation.

I think MOJ is rightly saying "so within this box here, you guys do your thing, and we're going to fund it or partly fund it at least...you guys do your best RJ work in there, get who you like, get the experience..." and MOJ are supporting that by the training that it offers for new facilitators, and also by running the accreditation... So if you want to be accredited as a facilitator you have to be accredited by the MOJ. They're making sure that this thing is good as well - especially around FV stuff... (T13Lawyer, 54-59)

In fact, most interviewees acknowledged that the MOJ is forward thinking in their inclusion of $\mathrm{RJ}$ in the FV justice process.

The MOJ is probably one of the leading government agencies in the world for dipping their toe in the water and having a go. I commend them for the standards for sexual offending and FV, but I think it's something that needs to be worked on constantly reviewed, updated, and not left on its laurels. (T28RJFacilitator, 329-332)

The focus of this thesis was on the section of offender suitability in the RJ FV guidelines. This specifies assessing the offender's ability to show remorse, give a meaningful apology, have insight into behaviour, the ability to change, and to show empathy. The standards do not say how to determine this - only what to look for. When participants were asked to clarify how they understood these behaviours, there were a variety of responses though all acknowledged in one way or another, that this was a difficult question to answer and there was a concern that assessment might become inflexible and too "tick box" if forced to stick too stringently to pre-set standards.

Another point of tension between policy and practice was that most interviewees said that during assessment, "sorry" was not the point and that saying "sorry" should not be confused with remorse when trying to determine genuineness. It was said that merely apologizing does not indicate genuineness nor is it an indication that further harm and offending is not a risk. As one interviewee stated: "Repeated offending makes a mockery of 
sorry" (T2Judge, 278-279). It was apparent across most of the interviews that though there are standards of practice and policy that did inform practice to a degree - the bigger question of how to assess readiness, was challenging and poorly defined.

In addition to the challenges with implementing the assessment standards, there were many participants who questioned the quality of the MOJ FV accreditation for RJ facilitators. My concern is that from the ministry perspective that's a tick box, project achieved, we now have an accreditation for FV, and it's not - it's a starting point... You've closed off a little bit of the risk that was there but it doesn't bear up to much more than a sniff test... (T22RJFacilitator, 825-828)

It was pointed out by a number of interviewees that prior to the new regulations, many RJ agencies/individuals would not accept IPV cases. Due to the new referral mandates, it was pointed out that there is now an increased assessment caseload with reduced resources and a limited number of trained/willing RJ facilitators to take the IPV cases - potentially creating risky situations with rushed or unskilled assessments being done, or cases being rejected due to lack of skill or resources rather than inappropriateness for RJ.

[RJ IPV assessment] is going to be in front of us in a much more direct way and we're going to have to deal with it and deal with the consequences in terms of churning cases through... meaning cases take longer to dispose of and we need more court hearing dates and court staff and more judges as well. That may be the consequence of the government passing a law that mandates RJ in so many cases. (T3, 241-246) The 2014 amendment to section 24A of the Sentencing Act 2002 (The Parliament of New Zealand, 2014) mandates if an offender appears in court, pleads guilty to a criminal charge, and no previous RJ has occurred in relation to this particular offence, the case will be adjourned to determine if an RJ process is appropriate. This directly affects the practice and implementation of RJ in IPV cases because numbers are increased and time and money pressures are then increased.

The way things are set up for the moment, for providers in NZ, is effectively - they're funded for a certain number of FV cases. Now, they're being examined on a quarterly basis - if they're not hitting their targets they're up to lose funding... the perceived threat from providers is very high... so the pressure to get cases and just to knock them off... is really high... And I don't think the MOJ has any idea around the systemic pressures that they're creating and setting people up to do stupid things... (T22RJFacilitator, 591-605) 
The amendment stipulates that the offender has not participated in RJ before. This implies a zero tolerance approach to RJ, which, as previously mentioned, was also a position held by a small portion of the interviewees. This point of view starts to suggest a leaning towards RJ being viewed as an intervention, where recidivism is viewed as a failure of the process and unlike the traditional criminal justice system where repeat imprisonment is utilized, offenders are given one chance to succeed.

\section{PRACTICE}

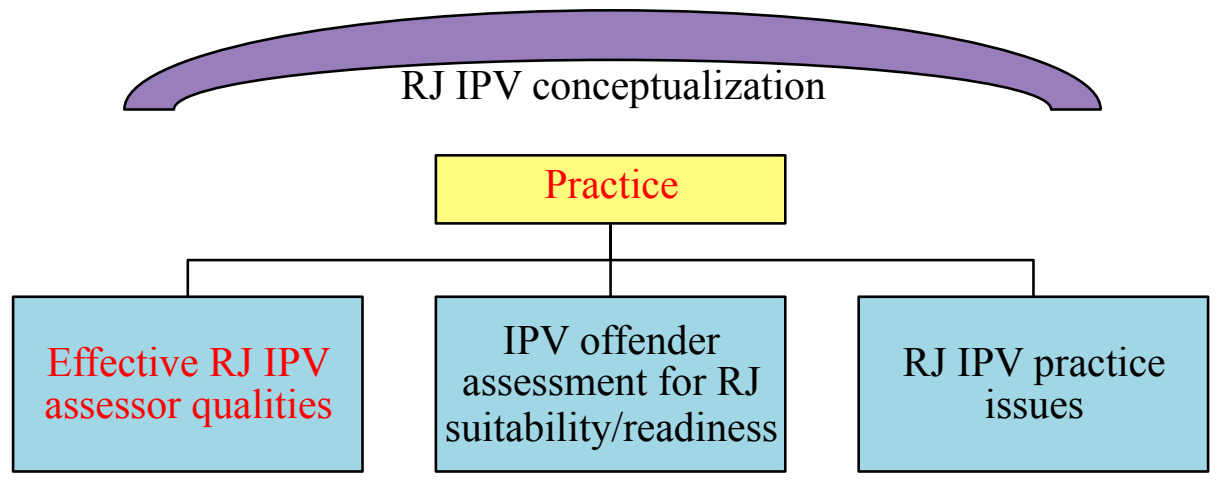

I think we don't have a good nation wide structure - we don't have the government support. The way forward ${ }^{4}$ says there needs to be a system... and saying there is no cohesive structure... if you take the funding out of [the issue of FV and RJ], then it's suitably trained people, robust processes and practices, across a range of agencies...so a training in skills and processes across the agencies... Everyone goes funding because it's not possible to do what we need to do with the resources we have... (T6Police, 290-297)

\footnotetext{
${ }^{4}$ Herbert \& Mackenzie (2014)
} 


\section{Effective RJ IPV assessor qualities}

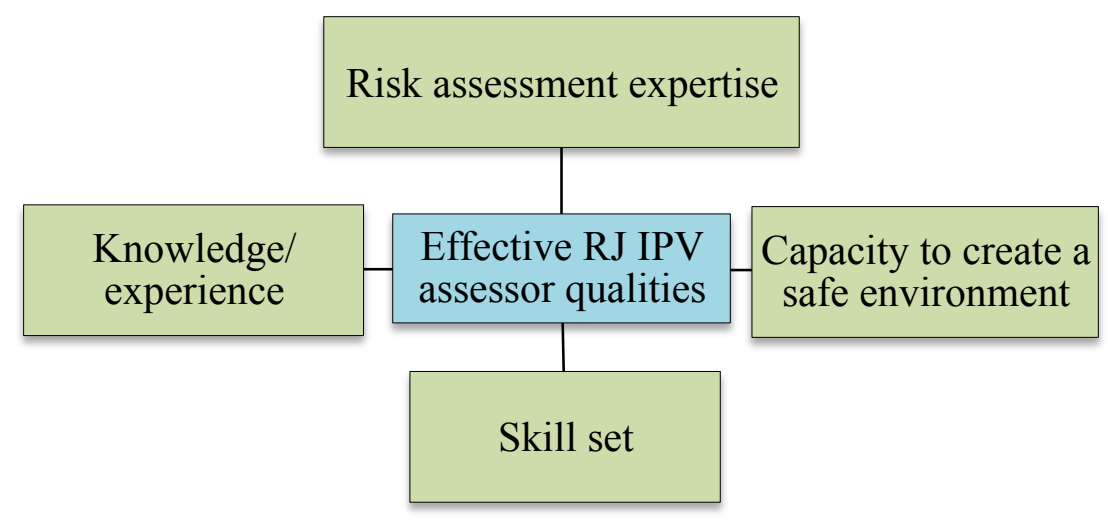

Category $\square$ Theme

Figure 7. Effective RJ IPV assessor qualities

After thinking about conceptualization of RJ for IPV, practice became the thematic focus. Practice includes both the assessment and the implementation of RJ. The first step in thinking about assessing offender/case suitability is to think about the qualities of an effective assessor (see Figure 7). This is crucial because without a knowledgeable and experienced assessor, the assessment becomes haphazard at best and dangerous at its worst due to the RJ IPV assessor being put in the position of a risk assessment expert. It was stated by a number of interviewees, that there is a lot of trust involved in the referral process and more IPV cases would have been referred to RJ if they had felt that there were suitable people available to do the assessment.

I am willing to accept that well run RJ conferences by well qualified people (as appears to be the case in Rotorua) is a very worthwhile and beneficial process... people alert to all the risks and really seem to deliver some benefits for both the offender and the victim. I just want to make sure that across the board everyone does it as carefully and as thoroughly as they do. I suspect it will take a while before we get to that stage. (T3Judge, 369-375) 


\section{Knowledge/experience}

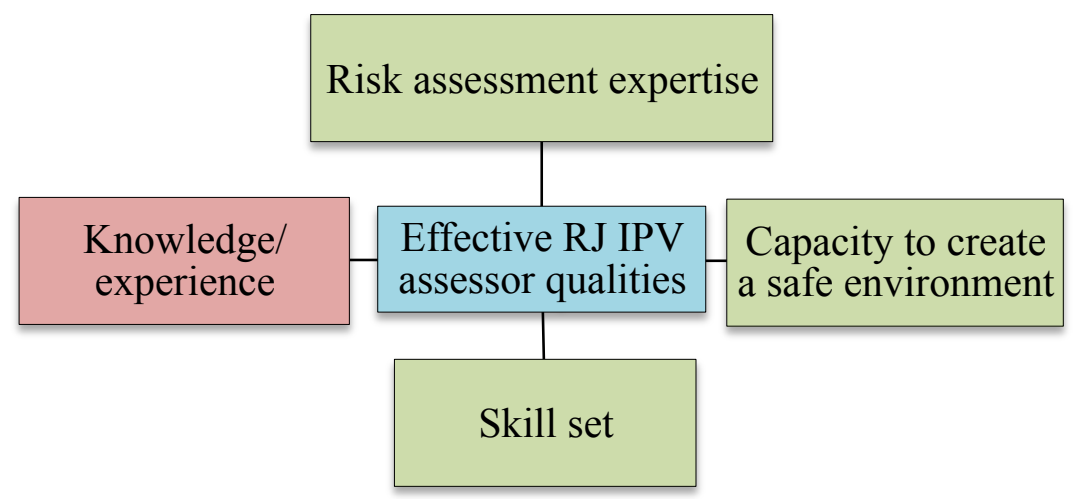

Figure 8. Effective RJ IPV assessor qualities: Knowledge/experience

Assessment of suitability happens in a variety of stages throughout the court process. With the law changes that have occurred recently (i.e. the amendments to the Sentencing Amendment Act 2007(The Parliament of NZ, 2014)), RJ facilitators now do the majority of assessments because there is a mandate about most cases being referred for assessment. Prior to this, initial assessment (to decide whether to refer to RJ for further assessment) was done by judges, lawyers, court coordinators, and at times, the police. It was pointed out by several interviewees that this initial assessment was not necessarily done in manner that was as informed or with enough time, as it should be and judges and lawyers needed to rely on the expertise of the RJ facilitators (see Figure 8). Others felt that the initial screening or "gate keeping" was helpful and informed.

What happens in court is the police prosecutors are very much the gate keepers...and I say that in a positive way - they will never recommend anything that is hideously violent... A lot of what might be considered the top ten FV offenders, I would never get to work with them... the police might be at their wits end, but they know that RJ is too pressured a process to put someone that just thumbs their finger to everything through... and that offender probably wouldn't get past me anyway. (T29RJFacilitator, 178-187)

In addition, a few of the interviewees commented that trust and familiarity amongst police, lawyers, judges and RJ facilitators helped during the initial referral and assessment process because they could discuss the cases and share their knowledge. 
It was found that RJ facilitators come from a variety of backgrounds, but regardless of this, it was said by most interviewees, that the RJ IPV assessor should be MOJ accredited in $\mathrm{RJ}$ and/or DV. The "or" option is due to the configuration of many preconference/conferences where more than one facilitator is present. At least one person is required to be RJ accredited and at least one is required to be FV accredited or have DV experience. There are a variety of conference/pre-conference configurations that will be discussed in a future section.

Often you work as a pair, where at least one of you will be family violence accredited. Personally I think they both should be... and actually I think that all RJ facilitators should have that background and training... (T22RJFacilitator, 27-29)

It was noted by a number of participants, that though accreditation requirements for RJ facilitators may be the policy for most agencies, there are still many people who are running RJ conferences throughout the country who are not accredited for RJ or DV. This is often due to the fact that RJ has grass roots origins and much of the work happens in isolated communities across New Zealand where monitoring of practice does not occur.

It's farcical to be honest. It's farcical on many different levels because for the main facilitator accreditation it's been going now [for a number of years] and it's still not mandatory for RJ facilitators to be accredited... and so a tiny proportion of them have been accredited because they don't have to be... and the notion of what's restorative justice is, I think, quite varied - I don't think there's huge consistency across the country... (T22RJFacilitator, 749-761)

In fact, it was said that there are people who have been doing RJ for a long time, who are not accredited, yet are training new facilitators. However, this was not viewed as a negative point - more as an acknowledgement of the value of experience.

Nobody told us how to do anything. Nobody trained us. So I don't have an MOJ qualification yet here I am training people and supervising them... (T27RJFacilitator, $327-438)$

Others noted that individual agencies have different policies on accreditation and protocols to decide whether there is enough experience there to work with IPV cases - or notand whether to perhaps bring in people who are more suitably qualified and knowledgeable. For example, it was noted that the MOJ SV accreditation was more rigorous than FV accreditation, and that the SV is considered acceptable for RJ facilitators working in FV however, it was said that just because someone is skilled in the complexities of SV, and SV is often a component of FV, additional up-skilling is needed. 
All of our facilitators have to have an accreditation for sexual violence and that's seen by the ministry as more robust than the accreditation for the FV and so they consider it to be enough... that actually isn't assessing FV skills so it's not really enough...

(T17RJFacilitator, 373-377)

Several interviewees were aware of the gaps in their knowledge (especially in the case of SV IPV cases) and noted that rather than take the cases, or automatically assess them as unsuitable, they refer them to other agencies better equipped to work with them.

We don't work with sexual violence cases... because I'm not interested in getting training or facilitator accreditation in that area. So any cases we just send them to Project Restore in Auckland... (T29RJFacilitator, 172-175)

When this research began, accreditation was run through the MOJ and there was concern raised by several of the participants about the lack of separation between policy and practice and there was a concern that the FV accreditation is only a paper accreditation which a few mention is not as robust, rigorous, and consistent as it should be. Currently, the MOJ contract for the accreditation and training of $\mathrm{RJ}$ facilitators had recently been given to Resolution Institute, in partnership with PACT Training Consultants (Resolution Institute, 2016).

The accreditation system I think is flawed, because it's never been required or mandated. The subsequent accreditation done for both FV and sexual violence...both of those accreditations are simply done on the papers... you're not interviewed. Effectively it's a questionnaire... you're providing a kind of CV. It could easily be plagiarized... I think it was a response to the fact that there had been creep into this area without any formal accreditation so as a short term measure I think it's a fine logical starting point... but to my mind it can only ever be a stop gap because just because someone's worked in a stopping violence agency for 5 years, 10 years, 15 years - it doesn't tell me what their skills and awareness really are and what's driving and motivating them. (T22RJFacilitator, 788-804)

Above and beyond the accreditation, it was said by the majority of the interviewees that knowledge and experience in RJ and IPV are vital - It was noted by a majority of individuals, that there is a concern regarding the lack of adequately knowledgeable and experienced RJ IPV facilitators across New Zealand.

I don't think there's anywhere near the expertise that there should be or the facilitators trained...how to approach a case, and how to do the pre-conferencing properly, where the supports might come from and just how to recognize the imbalance and power... 
most of them have a good deal of common sense but don't have the training yet. There's a lot of very experienced [RJ] facilitators... but they haven't historically been involved in IPV... (T4Judge, 67-75)

However, others noted that while some judges may feel reluctant to refer due to some of this inexperience, there are many knowledgeable and experienced RJ IPV facilitators in New Zealand.

There was an awareness by most interviewees that there are many RJ IPV facilitators who, due to this lack of IPV knowledge and experience, a grass roots approach that may not have been assessed by outside moderators (and perhaps may not be consistent with MOJ standards), and a lack of adequate skill set, are unable to ensure they run safe RJ IPV preconference assessments and conferences.

I don't think [the RJ organization that we work with] has the expertise and a danger obviously is that people think they have that expertise and they try to do things without building in safeguards which might include the appropriate supports for the violence... (T4Judge, 44-53)

The same interviewee made an interesting point that if there is trust in a RJ agency's IPV knowledge and expertise, cases that would ordinarily be considered inappropriate for RJ may be considered possible.

I suppose the more faith you have in the provider group's ability might allow you to be referring people who are slightly riskier? Without a doubt - If I had [XY] sitting in the back of the court on FV days, and knew that he had the facilities and supporting workers, it would be a completely different kettle of fish... (T4Judge, 310-312)

A final concern is regarding the tension surrounding RJ IPV agencies and which theories of IPV are supported, and what is the best practice in terms of addressing IPV and thinking about IPV. It was suggested by several participants, that amongst the agencies who work with IPV cases, there seems to be tension at times - in terms of the best way to address IPV. So the question of how and what RJ facilitators should be up skilled in, in the area of IPV, is unclear and ill-defined.

I think the value of that power/control analysis of FV has been incredibly important. Not least actually in educating people... I think that the problem became a sort of a stuckness which is having a sort of a single theory which almost became ideological as an explanation for all violence that occurs in families, as all being about power and control... there's a bunch of research now which actually shows that violence is a bit 
more complicated than that... different typologies... but it's not actually, to my knowledge, particularly mainstream knowledge here yet. (T22RJFacilitator, 215-242)

Skill set

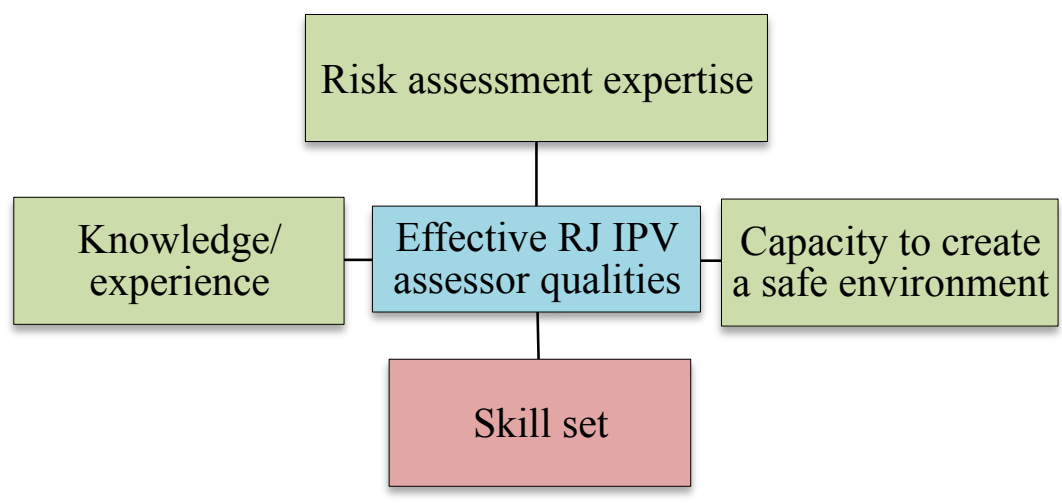

Figure 9. Effective RJ IPV assessor qualities: Skill set

Along with IPV and RJ knowledge, it was found that RJ IPV assessors were said to require certain skills and attributes in order to be considered more effective (see Figure 9). This skill set was broken down into 3 sub-themes: reflectiveness, assessment methods, and a tailored approach.

\section{Reflectiveness}

"If [RJ facilitators] don't understand their own limitations that's trouble." (T13Lawyer, 438)

Above and beyond IPV and RJ knowledge, it was found that a majority of interviewees felt that assessors should have reflectiveness of their own biases, perspectives, limitations, and practice as well as a reflectiveness of the RJ process.

We are reliant on our own perceptions and our own value systems and our own life experience ... you can't separate these out. We're asked to do a job and we do it as conscientiously as we can but we all have blind spots and we lack skills in a whole range of areas that ideally you'd have and be able to bring to bear in the decision making that we're asked to do but that's not the way it works. (T3Judge, 357-363) This includes awareness of any expectations they might have of the RJ process and of the stakeholders, and an ability to be non-judgmental.

I think a lot of facilitators find that notion of letting go quite difficult. It's not about us, 
it's not our result and sometimes people come up with outcomes and agreements that to me are surprising but that's the beauty of it - it's their agreement, not my agreement... I'm their servant to allow them to have that opportunity.

(T22RJFacilitator, 936-941)

In terms of limitations, this is referring not only to assessor skill set limitations, but also whether they are a "good fit" with the offender in terms of experience, culture, and facilitator personal history (e.g. may have a certain judgment about a particular offender due to personal experience with that type of offending). In addition, an awareness of preintervention offender limitations was also mentioned as important during pre-conference assessment.

Within self-reflection, many interviewees also spoke of the awareness of a "gut feeling". This is an intuitive response based on experience, and professional judgment and a level of trust in the word of the offender. Though many of the interviewees were not necessarily consciously aware of using gut feeling, they all spoke of it on reflection of how they knew if an offender was being genuine. This will be further explored in the section on offender assessment judgment practices.

[Assessment] is providing as much objectivity without subjectivity that you can. But it's also understanding that we're human beings. We will naturally have an explanation for this or that... and when we talk about gut feeling and stuff like that - $90 \%$ of the time it's right. It's just fact. Why? I don't know. You need to work at those strengths... work at identifying your own biases, identifying your gut feeling. Understanding what preconceptions that you might bring into this discussion about stuff like that...

(T28RJFacilitator, 268-275)

Reflectiveness of process was indicated by a number of participants and refers to an awareness of whether the RJ process is not only being run with integrity and best practice, but also an awareness of whether the process is right for the situation and the individuals. An additional point that was raised by a few of the participants that fits within the process reflectiveness, was facilitator courageousness - The courage to stop a conference when it is apparent that it is not appropriate to continue; the courage to admit a mistake in judgment; and the courage to take a chance on a risky IPV case; and the courage to learn from mistakes.

Things will happen and they will not always be right. But it's learning from those mistakes - not accepting those mistakes, but definitely not making them again... that will determine how strong we are as a culture. (T28RJFacilitator, 314-317)

\section{Assessment methods}


We're bringing in staff that already have [FV] skills... we haven't brought tools in ... It's more a relational assessment as opposed to a ROC*ROI [(Risk of re-conviction $\mathrm{x}$ Risk of re-imprisonment tool)] or other type of assessment that you might use for treatment purposes...we are working in the same skill set as motivation... assessing motivation and checking their thinking out, challenging distortions, seeing how they respond to being challenged and whether their response is safe... to be in the room with the other person. (T17RJFacilitator -359-368)

In addition to self and process reflectiveness there was found to be a number of skills that were suggested to be necessary for effective assessment. This refers to the specific ways in which it was said that an assessor most effectively gathers information.

The first feature is the ability to listen - listen to what is said and how it is said; listen for signs of whakama (shame); and listen for consistency, persistence, and emotional reactions contained in offender responses. In addition, a number of people mentioned the importance of listening rather than inputting one's own ideas, judgments, or expectations of what should be said or done. It was pointed out be a few of the interviewees that listening and good questioning skills are somewhat lacking in many RJ IPV facilitators.

What I consider some of the core skills which are around questioning and listening are actually relatively poor... and some of that is because their prior career, or current career... has nurtured a different style of questioning. So for instance a lawyer will have much great reliance on leading and closed questions because that's how they're taught to work... and also the judgment of how deep do you go and focusing on where do I need to go in order to get someone ready for this conference rather than into much deeper therapeutic journey which may take us a couple of years to achieve. (T22RJFacilitator, 869-878)

This ability to ask deep challenging questions was mentioned by most interviewees. These questions were used to find the meaning underneath statements, confirm stories, challenge beliefs, and as a means to observe reactions.

For a lot of men, they have never been asked by a woman "what do you think you were doing?"... That's sort of challenging and confronting... they'd never had to answer to anybody for what they've done... their wife or their partner never queried... never asked them anything... but here's [an RJ facilitator] saying "sooo what did you do - what sort of violence do you think you do?"... “I just tapped her"... "What do you mean tapped?"... “Show me how you tap...how come she's got a broken nose and a 
broken cheek? Is that a tap?"... Nobody has ever said that to them... (T27RJFacilitator, 117-127)

Most reported that this ability to observe reactions to challenging questions was a vital skill in assessment - Observe the offender's demeanour (e.g. the offender refuses to remove sunglasses or hat), body language, and question and challenge what is seen rather than assuming its meaning (e.g. clenched fists could mean nervousness rather than aggression, or tears might not be an indicator of genuine remorse); observe the offender's ability to contain their emotion when in a pressured or challenging situation; observe their ability to listen; observe outward appearance (e.g. stoned or drunk?); and observe any game playing.

We had a guy the other day who was so nervous... and that's alright, but maybe a clenched fist isn't so good... I think, “what's that about?"... so you ask... and they realize it's just tension, and say “ok, do you need a break so you can relax?”... And watching the jaw lines... seeing if there's a match between what's actually said and what the body is saying... the body betrays you... (T23RJFacilitator, 242-247)

It should be emphasized again that many interviewees stressed that assumptions should not be made regarding what is observed or heard, and that cultural knowledge and following up on hunches and observations is important in order to reduce the chances of misinterpretation.

In order to be able to challenge an offender, it was stressed by a large portion of interviewees, that an effective facilitator should possess the skills of rapport building. As previously mentioned, RJ is relational, and the ability to build rapport with stakeholders while remaining non-judgmental, encourages them to be open, honest and vulnerable with the facilitator.

I think it depends on the skills of the people working - are they able to do that in a non-threatening way. Trying to take the blame out and get to the "why is it happening?" (T6Police, 265-267)

Part of this rapport building was being pono (genuine, honest). It was pointed out, if a facilitator is expecting a stakeholder to be genuine and to engage with them, then they need to be genuine as well.

\section{Tailored approach}

If you say what you've done doesn't fit into my box or square of what a process should be... well this is not a process. Take process out of this. Deal with people. One of the principles of best practice is flexibility...and it's responsiveness to the participants in the conference... instead of "did we do this? - Tick... did we do that? Tick".... (T28RJFacilitator, 440-444) 
The final feature included within the skill set for effective assessor qualities was having a tailored approach that is responsive to individual and group needs. This was found to include stakeholder capabilities, goals, context, culture (i.e. race, sexuality, religion etc.), and safety issues. When thinking about goals, it was mentioned that it is important to think about whether the goals of the individuals and the conference are realistic and achievable in order to best ensure a successful outcome both during the conference and post-conference. It was stressed by a number of people that the focus is on the needs of the victim, and secondly, to the needs of the offender - and importantly, the focus is not on the needs/expectations of the facilitator or the RJ and IPV agency involved.

Every single person is different. Every single culture is different. Every single society is different. Every single relationship is unique... and until we stop putting people in pigeon holes, and say you need to do this, this, and this because this is what society thinks, we're not addressing these people. We need to address individuals as individuals... understand and celebrate their differences but also understand that their difference might not conform to what your idea or my idea of normal is... (T28RJFacilitator, 216-222)

Within this tailored approach is an awareness of culture. Culture means looking holistically at the individuals - physical health, mental health, spiritual health, cognitions, life experience, attitudes, criminal history, context of the offending, social norms, and community. It was mentioned that this might include having awareness that an interpreter with IPV and RJ jargon knowledge may be necessary to utilize.

In oral cultures, the writing down is important because we're going through a legal process [so] we still cross our "t" and dot our "i"... but it's the hearing of the commitments and the seeing of the follow through that's more culturally important and who attends, and who listens, who takes on what roles... if he's hooked into a church... who from the church comes... if he is hooked into an ainga - his extended family... what's their view of IPV? What commitment do they have to change or do they think it's perfectly ok to behave like that? ...Where's his brother? Where's his father? Where's his uncle, his priest, his minister? We need to explain in a preconference just as much to them as him and get an overall impression from his side as to what commitment they've got to domestic non-violence. (T25RJFacilitator, 217230)

It was noted in the Wellington FV and RJ Conference, that some of the agencies throughout New Zealand are making an effort (and many are already) to be bicultural and 
therefore, a knowledge of ti kanga (Maori customs and traditions) and an awareness of te whare tapa wha (one of the models of Maori health (New Zealand Ministry of Health, 2015)) is important in order to be responsive to the needs of the stakeholders who identify with Maori culture. As one individual said, "Matauranga ${ }^{5}$ - it has to be ongoing".

We're trying to use a co-leadership model with tangata whenua, and engage with kaupapa Maori services. So partly it's around getting the right skills mix, using te reo Maori and changing processes where needed. But that's an ongoing mission for [us] to put resources into doing things in a Maori way. (Family Violence, Restorative Justice and the Law Conference, 2015, p. 11)

A small portion of individuals expressed an opinion that "like" should work with "like" (i.e. Maori should work with Maori, Pacific Island should work with Pacific Island) - which was also reflected in the MOJ policy (MOJ, 2013).

[The facilitators are] predominantly wonderful Maori women. That gives them an awful lot of street cred too I think. This being a predominantly Maori part of the world, I don't think, to be quite frank, a Pakeha facilitator could be as effective. (T1Judge, 159-162)

However, it was also pointed out that this idea is not realistically a possibility in most cases because of the fact that there is a higher number of Maori and Pacific Island IPV cases than there are qualified Maori and Pacific Island RJ IPV facilitators. It was pointed out by most interviewees that in either case, cultural knowledge is essential in order to best address the needs of the individual stakeholders.

Maori make up 50\% of the number of inmates in the different prisons... and that's huge given that Maori only make up at best $15 \%$ of the population... so the current system, I don't think, is working well at all... I think one thing that we could be doing better is a way that we work with Maori and whanau and the RJ approach... I think $[\mathrm{RJ}]$ lends much more with traditional Maori principles and values... if it's run correctly. If it's run with facilitators who know nothing about Maori or how to work with Maori... then it wouldn't and could probably do some more damage... (T13Lawyer, 363-373)

\footnotetext{
${ }^{5}$ Matauranga Maori is a term often "used synonymously with wisdom. In the contemporary world, the definition is usually extended to include present-day, historic, local, and traditional knowledge, goals, aspirations and issues from an indigenous perspective." (Landcare Research - Manaaki whenua, 2016)
} 
It was resoundingly agreed upon that assessors should focus on the big picture of the offending rather than look at the referral incident in isolation. This included acknowledging the importance of understanding the culture and community of the offender and victim, rather than just working from the perspective of your own culture and having an awareness that their life experiences and perspective may not neatly fit into a "PC" system.

One of the first things I would say to a facilitator beginner is this - when we talk about $\mathrm{RJ}$ practice it's about understanding your community and family and whanau, but it's not your community.... it's the community of the people that you're engaging with that you need to know and have an understanding of... (T28RJFacilitator, 260-266)

Included in the idea of culture and a tailored approach is the understanding of the context in which the offending, the original referral, and the assessment is taking place. This will be discussed further in the section on context of assessment.

A final point - It was mentioned by a number of people that a key skill for the facilitator is to be mindful that they are there to support the offender and prepare him for the conference. The point is to empower - not to speak for him or to prompt him to behave in a particular way.

I get worried when I've seen facilitators prompting people and reminding them of something they said in pre-conference. I think it's really bad practice... our job is to do that preparing in the pre-conference... and also to be saying, "You may choose not to say the stuff you talked to me about today and that's absolutely fine"... that to me is the empowerment and not me having a neat little script of what this fairy tale meeting is going to look like. (T22RJFacilitator, 921-933)

\section{Capacity to create a safe environment}

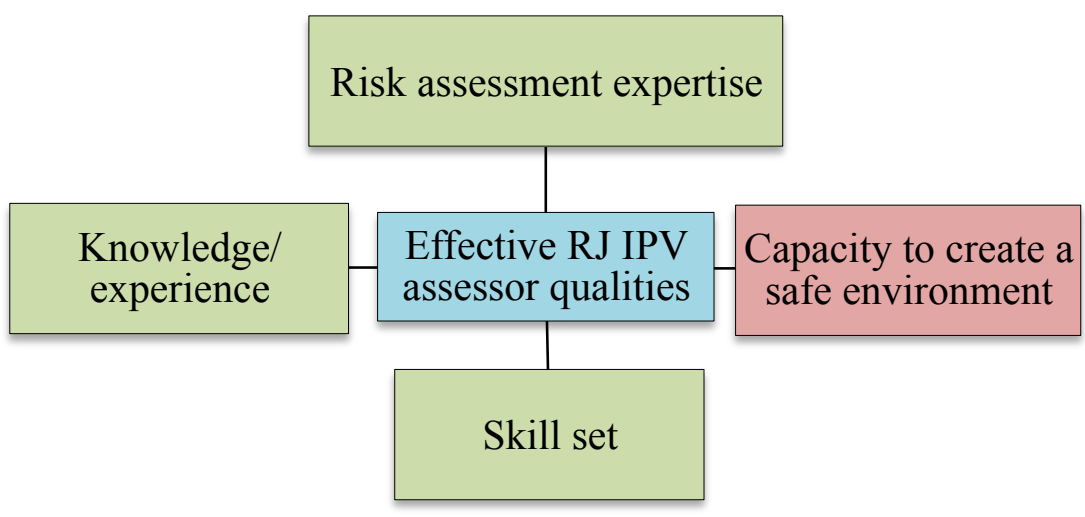

Figure 10. Effective RJ IPV assessor qualities: Capacity to create a safe environment 
$\mathrm{RJ}$ is not about me the facilitator or the system. $\mathrm{RJ}$ is about putting people at the heart of the process... providing a safe environment for people to have a conversation... [The role of an RJ facilitator] is to get the people together in the room to converse with each other so that they can understand - hear each other in a meaningful way...

(T28RJFacilitator, 81-88, 191)

Creating a safe environment (see Figure 10) was something almost everyone emphasized and is very closely tied to an assessor's knowledge and skill set. For example, taking a short two-week course in IPV and thinking an assessor has all of the skills and knowledge to be an expert in IPV would be dangerous. Conversely, having awareness of cultural protocols can help to create a safe environment for the stakeholders. This refers to both physically and emotionally safe for all parties. Creating a safe environment also means that a facilitator should be aware of his/her limitations and consults those who do have knowledge in that area and perhaps having them in the conference for guidance.

You wouldn't want to set up a cultural awareness program for two weeks and people think, "excellent I can go off and run this thing at a marae or I can run a very big conference with whanau up and down one side of the wall and the other whanau down the other side and know what I'm doing"...but what I do think you can do is provide kinds of courses where they say, "this is what's going on in this cultural environment, and when you go into this, you need to make sure that you are safe and mind you're competent" (T13Lawyer, 419-431)

Creating a safe environment was said to encourage meaningful conversation because people felt supported and enough time and space was available for victim-survivors and offenders to get their ideas across without feeling pressured or coerced.

Part of [an RJ facilitator's responsibility is] insuring that there is enough time for dialogue, open dialogue within the process for the offence victim to be able to ask questions and then feel strong enough and well enough, supported to ask and say what they want to say... (T22RJFacilitator, 354-357)

This not only allows meaningful conversation but also was said to reduce the risk of revictimization by testing during pre-conference meetings, how offenders respond or contain themselves when pressured. In this safe space they are able to respond and additionally, the offenders can be given strategies for managing themselves, more in service of a safe process rather than as a treatment goal.

It was mentioned by several interviewees that in creating an environment that is person specific, there are challenges when trying to balance needs, goals, and risks. This 
relates closely to the tailored approach that was spoken about earlier - because in order to create a space in which people can be vulnerable, open, and safe, the approach must be tailored to the particular individuals and circumstances.

There is a vulnerability in being person specific or situation specific and when [RJ facilitators] make a judgment call that is inappropriate... but there are as many safeguards that we can put in place to mitigate that as much as possible... and I think the RJ group process, is a very powerful process and I think that it is a healthy and safe process for the victim and the offender... (T26RJFacilitator, 185-189)

\section{Risk assessment experts}

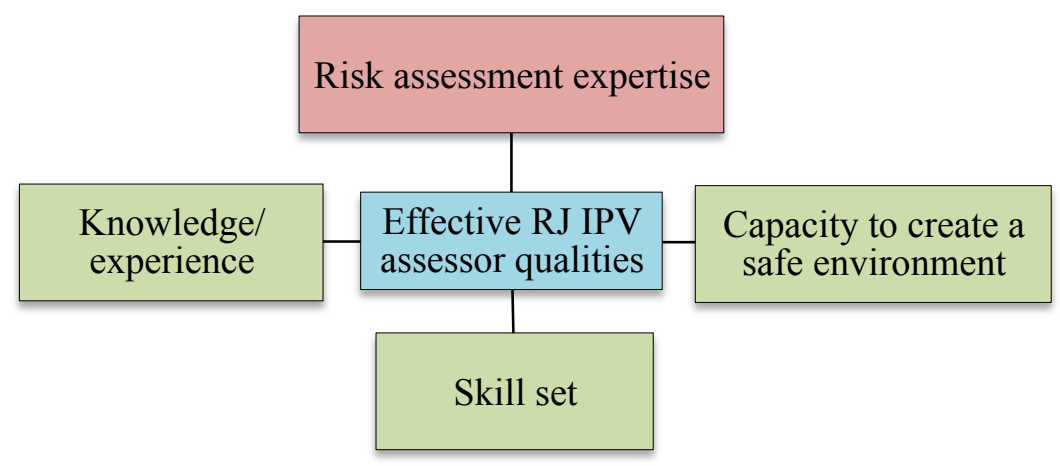

Figure 11. Effective RJ IPV assessor qualities: Risk assessment expertise

"The assessment is also about safety... is it safe to proceed? Is the conference going to be safe?" (T27RJFacilitator, 430-431)

Safety and risk is on a continuum and it was apparent throughout the interviews that the cut-offs are not clear-cut and RJ facilitators who do the pre-conference assessment of offenders and victim-survivors are put in the position of risk assessment experts (see Figure 11).

It's about managing that risk so the chance of him killing [her] is limited... and you look at every possible scenario of where the damage and hurt and harm can occur. And you need to balance it all up... (T28RJFacilitator, 130-141) This is assessing the present and future risk of harm and re-traumatization for the victim, offender, and/or whanau and community. This risk assessment was found to include understanding when and who to refer to externally, which support agencies are needed to be involved, determining if the case is outside of the skill base of the facilitator/RJ agency, and who may be better suited to work with the particular case if it is unsuitable for their agency. 
There was a while there where people were saying that RJ shouldn't touch [IPV] because it's too dangerous... and it is... it's full of possibility to cause further harm and things like that... we are mitigating that as much as we can... I don't think anything is not "restoritable justible", but it is still done with caution and nothing is predetermined until the process unfolds... (T26RJFacilitator, 223-233)

It was agreed by most interviewees that there is no particular risk assessment tool used or checklist per say - other than the Canadian risk assessment tool ODARA that is used by the police. However, it was suggested that this is an imperfect tool that is not really suitable for New Zealand.

The problem is there are very few risk assessment tools around...and certainly very few that seem to be effective... so I think the police looked at it like "we need something"... so they took the Canadian model... unfortunately there's been research, by the Canadians even, to say this is not fit for what NZ want it for... In my opinion, we're not seeing those risk assessments equating to real life future risk...in many cases... (T8Police, 7-24)
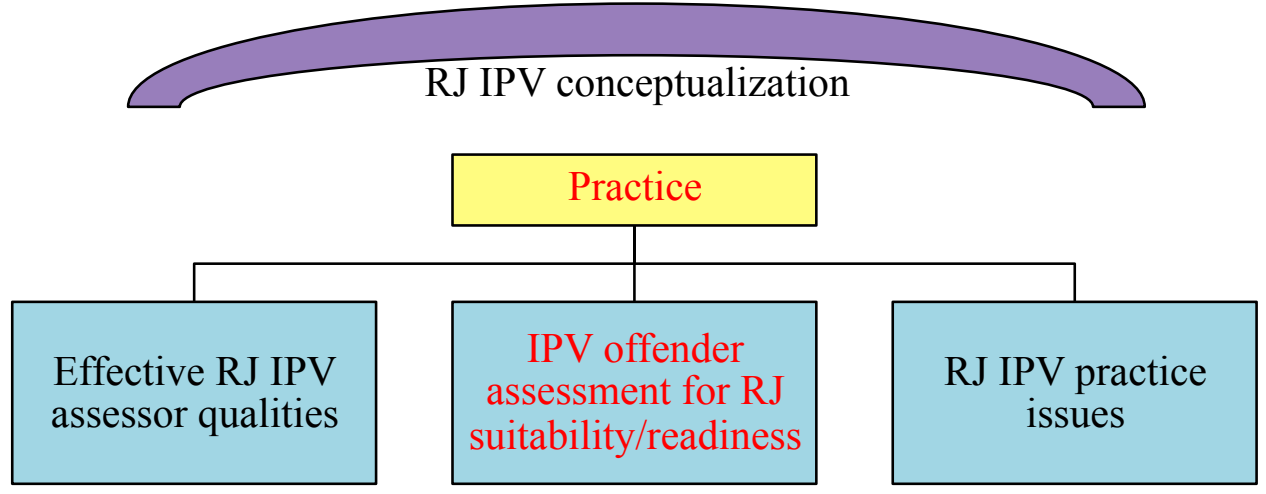


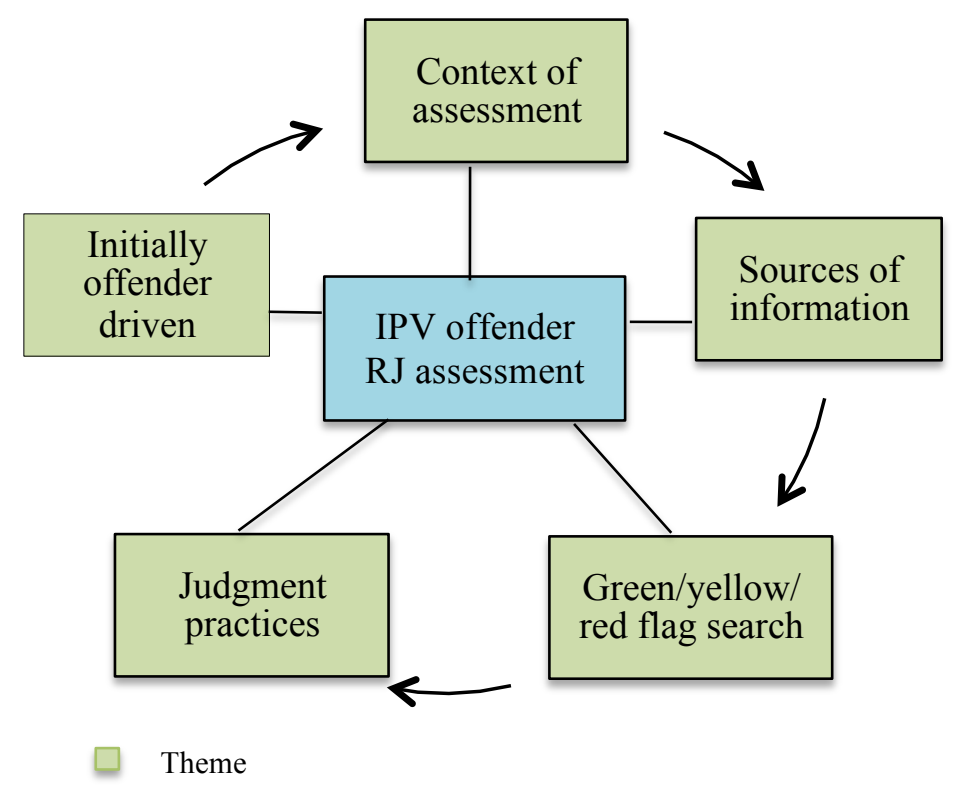

Figure 12. IPV offender RJ assessment

\section{IPV offender RJ assessment}

I think even after $[\mathrm{RJ}]$ assessment, who knows if we got if right or not? There's a Maori proverb, "he kokonga whare e kitea, e kore e kitea he toki huna" which translates to something like - you can see the four corners of a house but [the concealed weapons cannot be seen]" (Mead \& Grove, 2007, p. 86)... and I think that applies here. You can never know for sure, for example, what someone is holding in and what they might be very practiced at in terms of saying "I want to do this and give you everything you want to hear"... but I think that's partly why you have the experienced people at the table... (T13Lawyer, 142-151)

Once establishing the qualities that make an effective RJ IPV assessor the focus of the research steps into the next level of practice - the assessment IPV offender suitability (see Figure 12). This category reaches much further than merely discussing what RJ assessors are looking for during assessment. It addresses how they look for it, where they look for it, and how they understand and assess what is found in terms of readiness and suitability to take part in an RJ conference. There is another Maori proverb which states, "he piko rakau e tae te titiro, tena he piko ngakau e kore e kitea" which translates to "the crookedness of a tree can be seen but not that of the heart" (Mead \& Grove, 2007, p. 108). This also addresses the issues at hand - because an offender may appear a certain way from the outside, but until you delve to a deeper level, a facilitator cannot truly understand what is seen on the surface.

In terms of assessing genuine remorse, it was pointed out by a number of interviewees that honesty and accountability are on a continuum and can change. In fact, some mentioned that with enough time, space and silence, the offender can process what has occurred in the 
pre-conference period, and then present with a different perspective come conference time. However, all agreed that genuineness is difficult to assess and that "sorry" does not equal genuine remorse and that there is an important distinction to be made between accepting a charge (pleading guilty) and accepting responsibility.

Well I think the sort of cartoon version of RJ is probably saying... "Come along, he'll say sorry, you forgive him and we'll all move off into the sunset together..." And that's not going to be the reality of many situations... in terms of assessing...I think that it's one of the areas in NZ that we need to do a lot more work in... (T22RJFacilitator, 269271)

Five main themes were found in this category, which are addressed sequentially: Initially offender driven; context of assessment; sources of information; green/yellow/red flag search; and judgment practices.

\section{Initially offender driven}

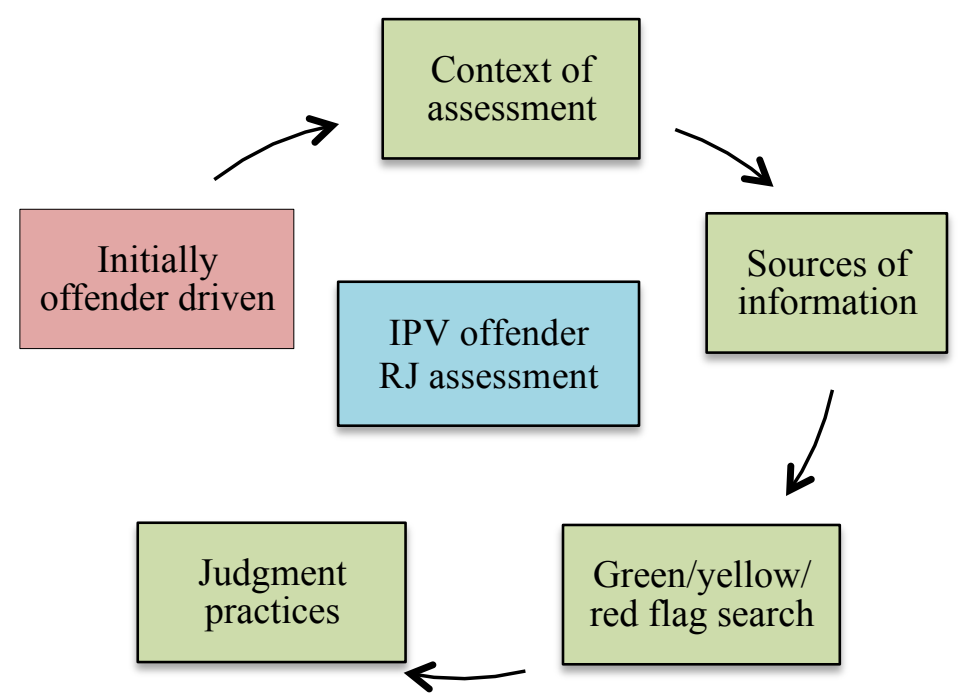

Figure 13. IPV offender RJ assessment: Initially offender driven

In many ways $[\mathrm{RJ}]$ is shaped by the offender actually because the case name will have the offenders name on it for a start... and that's where the judge is referring it out to RJ as part of the whole case load... (T22RJFacilitator, 137-140)

Though the RJ process is said to be victim-survivor focused, it was said that the RJ assessment is originally offender driven (see Figure 13) because cases are referred through court where the case is focused on the offence and the offender. Prior to changes in policy, judges, lawyers or court coordinators might flag that a case was suitable for RJ, and the offender would be spoken to at that time in order to start the assessment process. 
When a judge has a case, he would say he thinks that's a suitable case... [The court coordinator] could take [the offender] down to where ever the cells are and he'd get in and interview that person... "So what do you want to do, what's happening with the relationship... are you willing to acknowledge your responsibility for what has happened? Do you want some help to sort this out?"... All those sort of things... so he's already started a process then... (T27RJFacilitator, 275-281)

Following the changes in policy (the Sentencing Amendment Act 2014 section 24A in particular (New Zealand Parliament, 2014)), the cases became even more initially offender driven as the legislation criteria refer to the offender and the offence when stipulating if a case is appropriate to be adjourned for assessment.

There were differences amongst interviewees in terms of who was spoken to first during the pre-conference assessment period - some said it was the offender, others had a policy to speak with the victim-survivor first.

"I always interviewed the offender first to get his side and then do the victim and any whanau members...” (T27RJFacilitator, 243-245)

"We assess the survivor first... we do that on the presumption that if the offender has been referred to us by the court, then they've already agreed to participate."

(T17RJFacilitator, 50-52)

However, regardless of who drives the initial referral or who is spoken to first, it was clear that an offender was not assessed in isolation and that the victim-survivor assessment influences, and, in the end, drives the outcome of the pre-assessment period.

There was a small portion of those interviewed who expressed a position that a problem with RJ is that it has too much offender focus, but then acknowledged that there does need to be some focus on the offender in order to get to the root of the IPV problem.

I guess the sense of it is that it is offender focused but having said that we agree that you've got to work with the offender because that's where the root of the problem is usually... otherwise we're just being reactive and waiting at the bottom of the cliff and responding after... but if you can stop the violence from happening in the first place ... I don't think [the traditional criminal justice system] is good at that yet. (T6Police, 207-211)

It was stressed by most interviewees that the facilitators will make the final call on suitability after ascertaining whether there is informed and non-coerced consent of both 
parties, and both the offender and victim-survivor are found to be suitable and ready - with the victim-survivor's needs and safety at the centre of that process.

\section{Context of Assessment}

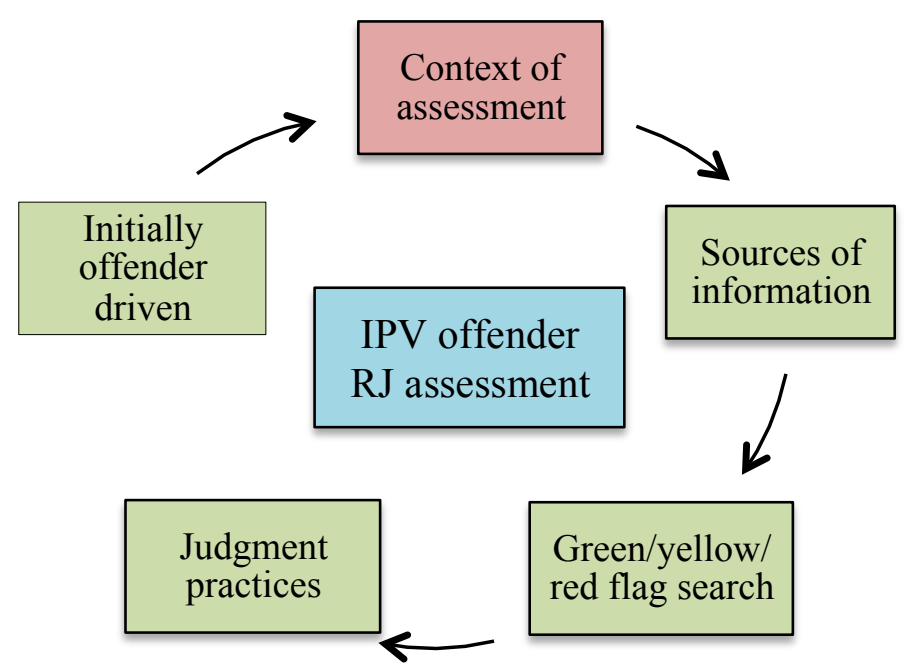

Figure 14. IPV offender RJ assessment: Context of assessment

We try to form views of people in the witness box or in the dock in the courtroom where there are all sorts of things going on... publicity, there's exposure to scrutiny by others, there's embarrassment, uncertainty, people might have had health issues, they might have physical or mental health factors at play... very hard, [with] just a little snap shot in a courtroom, to form a view about what's going on in a person's head and how you treat expressions of remorse or empathy and the like... (T3Judge, 348-356)

Context refers both to the context in which the assessment is occurring (i.e. court, by police, on a marae, in a neutral space, at the couple's house), and the context/culture of the offending (see Figure 14). Prior to the law changes, a lot of initial assessment of suitability for referral to RJ was done in the court setting. It was pointed out that within this context, it's important to be aware of the added pressures on the offender in that context (i.e. embarrassment, public scrutiny, whakama) that can manifest in a way that appears as if the offender is unremorseful, unresponsive, or has a negative attitude. Coupled with a lack of information supplied and time pressures, it was said by a number of interviewees, that assessors are often ill equipped to make truly informed decisions on suitability for referral to RJ.

You only operate in a short time span... RJ is managed by a court and you have a certain amount of time to contact both parties to do the pre-interviews, to allow them 
time to decide whether they want to go ahead, to come back and ask questions, to talk to whanau if that's what they want to do, to prepare them for the conference... and then have the conference and then report back before it's due back for sentencing... so everything is dependent on that time frame from the court which is quite a rushed process... how do you really know somebody when you've only seen them twice? You have to do the best you can... (T27RJFacilitator, 224-231)

If the police are doing the assessment, it was found that many of the interviewees felt there was a lack of adequate police IPV training, a lack of understanding of RJ and a thought that police were "gate-keepers" in terms of court referrals to RJ. Also, if police are doing the assessment, some victim-survivors (and offenders) might be hesitant to talk openly to them for a number of reasons such as fear of retaliation, threat of jail, or pre-conceived negative biases about police.

The most traumatized victims are often the hardest people to talk to and are often unwilling to talk to the police about their experiences... fear is a big one - particularly where the offender sees the victim engaging with police and makes all sorts of negative assumptions... (T6Police, 145-150)

As mentioned earlier, some interviewees thought that this "gate-keeping" in court was helpful because it ensured that the serious cases that were not appropriate for RJ would not be referred for assessment. This is reflecting an assumption that those offenders, based on the seriousness of the offence, would not be appropriate for RJ.

In addition to understanding the context of the assessment, understanding the culture and context of the offending was mentioned as vital.

Most RJ operates with one sort of focus... so they're looking at what happened in the summary of facts and they don't discuss anything else... in the context of [IPV] that's a waste of space, it's a waste of time, you might as well do nothing because there's always context... so we're always looking at the bigger picture and the bigger context and the relational issues that are behind what happened on that day... So there's a healing for the system and breaking the cycle... opportunities that the criminal justice system is just one slice of it... bang of the hammer approach. (T17RJFacilitator, 338344)

Included within this awareness is knowledge of ti kanga - especially when working with Maori clients who identify with their Maori culture. Additionally, having an awareness of whakama (shame), the power of being pono (real/honest), and the use of equal or superior 
mana by the facilitator are methods used to build rapport and understand offenders in the Maori context. This last point was interesting because it raises the question of whether enforcing this use of mana and hierarchy could also somehow be reinforcing the idea that it is appropriate to have a power imbalance and 'power over' someone else - which is prevalent in IPV. However, it is also said to build the concept of respect, so it is hard to say whether this could create a power struggle or not.

It was also pointed out that understanding the environment in which the individuals live is crucial - what area in NZ are they from? What is their education, socio-economic status, living conditions, and people they are surrounded by? All of these factors affect how stakeholders will present themselves and interact during an assessment and awareness of this was said to be an important part of an assessor's understanding of what is heard and observed during the pre-assessment period.

"Understand that each community is different... wherever you are you have to know those communities... understand the dynamics..." (T28RJFacilitator, 465-471)

\section{Sources of information}

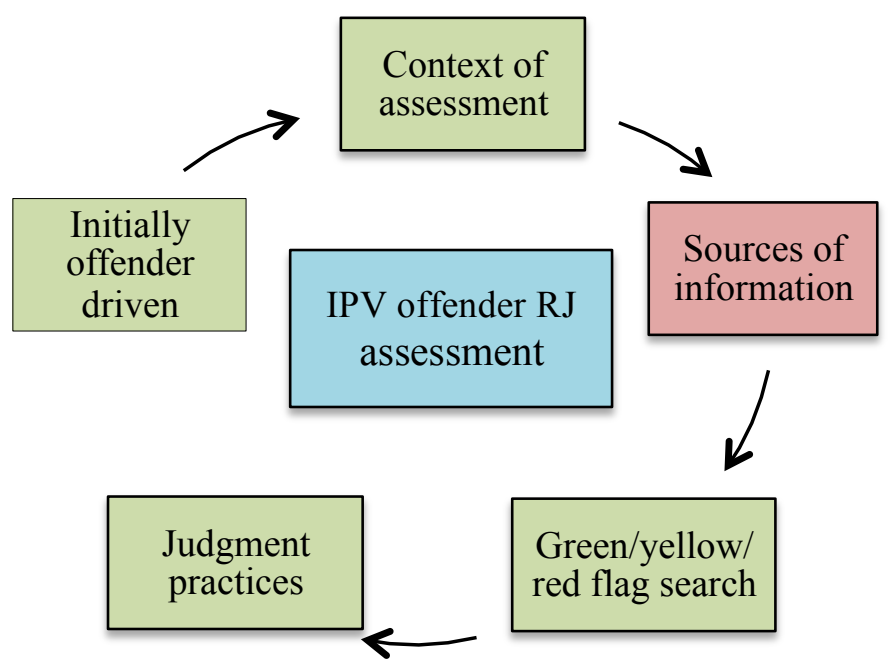

Figure 15. IPV offender RJ assessment: Sources of information

"Knowledge they say is power. It is also a fundamental prerequisite to be able to effectively intervene." (T1Judge, 27-28)

Thinking on a deeper level, in the various contexts in which assessment might be done, gathering information in order to make an informed assessment is essential (see Figure 15). When analysing the data on this, it became clear that this theme focuses on how information is gathered, what is gathered, and whom it is gathered from. It was strongly 
suggested by all of the participants that information for the assessment should be gathered from a wide variety of sources in the most holistic way possible, using a variety of techniques such as rapport building, motivational interviewing, challenging questions, listening and observation.

The fundamentals of risk assessment are getting your information from more than one source - and preferably from a number of different sources. If I've picked up anything from working in that FV area, is never to wholly believe one story... and in some ways that's what RJ does though. Is actually allows multiple stories and what it aims to do is bring stories together... (T22RJFacilitator, 276-285)

By hearing the offenders' stories, reviewing the summary of facts, and comparing this to information gathered from the victim-survivor, family, whanau and the community, it was said that an RJ facilitator could endeavour to establish validity of the information given. Interestingly a number of interviewees commented on the reliability of offender statements and how to proceed with interviewing and information gathering under the premise that people may not always be truthful.

T1: Offenders almost invariably don't share the truth...

Researcher: So the challenge is asking the right questions?

T1: Asking the right questions but also getting the right answers. (T1Judge, 27-30) This can also be said to mean that as an assessor, meaning/truth should not simply be taken from the surface of what people say - it is important to dig deeper and truly verify and understand what is being said and what the truth might be.

I wouldn't say I don't trust people, but I look deeper than what's being said to me... you get to the point where everyone is hiding something so you have to dig a little deeper and that's all the relationship building stuff... when you listen and give that empathy, then you're more likely to get stuff... (T8Police, 249-252)

Once informed consent is received from both parties, the pre-conference period begins and information is gathered. It was pointed out by the majority of interviewees, that a "checklist approach" is not used. There may be guidelines used (especially for new facilitators), but it was said that this should not be used as the definitive and narrow approach to information collecting. Assessors need to be able to think broadly and be able to understand how to not only collect, but to interpret the responses and observations and know when and how to dig further in order to establish an accurate picture.

I've seen a number of checklists. In themselves I don't think that they are particularly helpful beyond as a sort of steer to what to look for. I don't think it's necessarily 
formulaic... we'd be wanting to get a real understanding of the pattern of violence and that's where it links to typologies... and unless we understand that then we're not bound to make an accurate assessment whether they are a good candidate...

(T22RJFacilitator, 276-285, 393-399)

Most participants agreed that victim-survivors are great sources of information regarding the offender although many pointed out that assessors needed to be mindful that victim-survivors may still feel coerced or pressured by the offender to answer in particular ways or they may want to reduce the severity of the story in order to ensure that they can remain together with the offender, or the offender not receive as strong a sentence.

Initial information comes from the summary of facts from the police report. Accuracy of this report is relied upon and often, this report along with a report of historical charges, and what was seen in court, was all the judge may have had to go on for the consideration of referral. This referral portion of the process has now changed in terms of mandated adjournment for RJ assessment - but the lack of information initially available is still an issue. It was stressed by all of the participants that offender information supplied by the courts is often lacking, so assessors often have to rely on their own skills in collecting information as well as utilizing other sources that may have had contact with the couple such as external IPV agencies, community groups, or police.

"Sometimes you don't know as much as you need to know and that's a failure of the system to not provide a truckload of information..." (T29RJFacilitator, 294-296)

It was said by a number of participants, that combined with a lack of time, this lack of information available in the courts (and initially for the RJ facilitator) seriously limits the accurately and rigor in which an assessment can be done safely and fairly. In order to gather thorough information, time is needed and several participants stressed that time balance is important and that the pre-conference period should not be too rushed in order to best build relationships that are conducive to the sharing of information.

I have no right to demand someone reveal something that could be quite intimate, it's where the time thing comes in again and why I think a good pre-meeting is something you don't rush, and I think it's often what I see with people starting out in RJ work they try and rush through it... in a kind of prescriptive way like a recipe... You need to give time, enough silence, and leave pauses in the conversation for people to reflect on what they are saying and to gather their thoughts and to decide if they want to say more... (T22RJFacilitator, 894-902) 
As previously stated, all interviewees noted that information should be gathered holistically - looking at the offender's criminal history, life experiences, attitudes, context of offending and living situation, mental health and medical history, A\&D history, and the societal and cultural norms. This information should be gathered from a number of sources: whanau, family, community, DV agencies, victim-survivor statements, medical history, mental health information, A\&D information, and from the offenders themselves.

Interestingly, some interviewees noted that offenders and victim-survivors are more likely to open up to other individuals than they would to a judge, so it is important for judges to be open to utilizing information from outside sources whenever possible.

Rightly or wrongly, offenders open up to doctors far more often than they would to a judge. We tend to get a goldmine of information in psychiatric reports that we don't get anywhere else... (T1Judge, 10-13)

The information from the offender themselves is gathered through listening and observing what their cognitions and behaviours are in a number of circumstances such as, when telling and re-telling their stories, self reports, or as one interviewee mentioned observing to see if there are any ritual apologies is useful in understanding genuineness and readiness (e.g. the Samoan practice of ifoga).

Story telling is a source of information that most RJ facilitators reported utilizing. They asked the offender to tell their story - after listening to offender stories they can be crossed referenced with both the summary of facts, and the stories of the victim-survivor, family, whanau, and/or community (agencies, work, friends, etc) to check for accuracy and consistency. Challenging the stories and thinking, and reframing questions in a variety of ways, was said to be utilized in order to understand cognitions of the offender at a deeper level - in a way it was to cross check the offender's story within himself to see if there is consistency and persistence.

During the telling of the story I always say, "here is the summary of facts and you pleaded guilty to that but I know there is a back story"... so they tell me what is going on in their lives... I ask a lot of questions like "what were you thinking about at the time and what have you been thinking about since?"... And those questions are the kind of deep questions, especially “what have you been thinking about since?”... That will tell me if someone is a bit remorseful for what they've done... (T29RJFacilitator, 41-53)

It was said by most interviewees, that support people involved in the pre-conference and conference were also vital sources of information and it was reported that they are also 
useful in keeping the offender honest so to speak. Due to having personal knowledge of the offender, they are able to act as fact checkers and challenge the offender in ways in which the RJ facilitator may not be able to. As was previously mentioned, many interviewees pointed out that though support people can be great sources of information, it is important to assess their (the support people) own perspectives and interactions with the offender and victimsurvivor because they may, in fact, support and perpetuate abusive or anti-social cognitions and behaviours and the power imbalance that is characteristic in many IPV relationships.

Another source of information is the offence history of the offender. What this information means was a point of contention because some felt that this information could be a clear cut-off - indicating unsuitability if there is a long history of chronic violence or serious or significant harm to the victim. Others pointed out that if nothing else had worked, RJ might be worth trying if safety was guaranteed. This will be discussed further in the next section.

Again, it was emphasized by most of the participants that assessment is holistic and the methods of gathering information were not formulaic - If a checklist were used, it was only as a guideline and that information was more about the narrative rather than a tick box.

\section{Green flag (Go)/Yellow flags (Caution) / Red Flags (Stop) search}

Researcher. From your perspective, how do you know when an offender is appropriate... Or what would make them not appropriate?

T6. Well that's when you're getting into a grey area... (T6Police, 34-36)

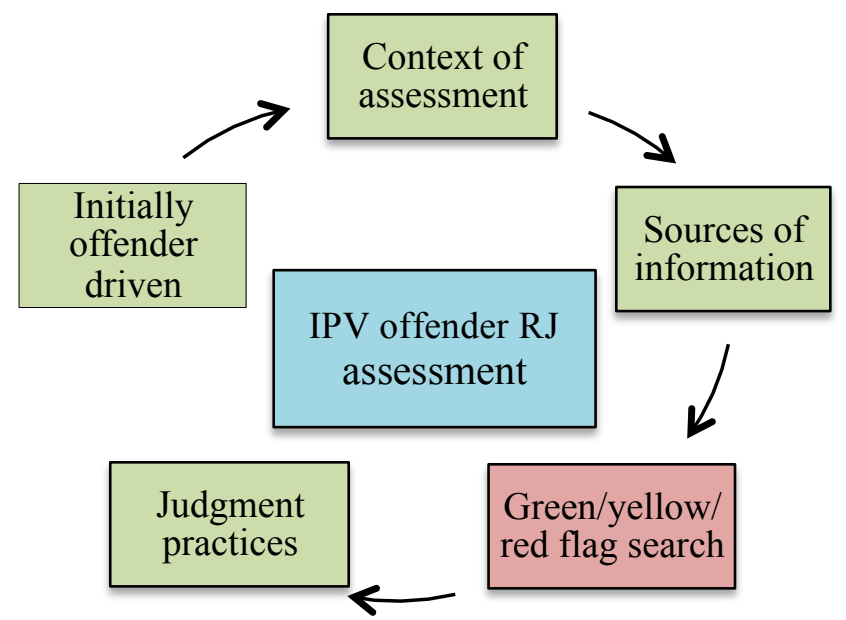

Figure 16. IPV offender RJ assessment: Green/yellow/red flag search

The various sources and methods used to gather information all serve the purpose of finding out information to inform the assessment of offender suitability. In a sense, assessors are looking for either green flags (go) that tell them someone is suitable and ready, and yellow 
(caution) or red (stop) flags that would alert them to the possibility that the IPV offender, and/or the case might be unsuitable to proceed to conference (see Figure 16). This research was focused on the offender, rather than the victim-survivor assessment, so this is the perspective that will be taken when discussing green, yellow and red flags. However, it is important to again highlight the fact that all interviewees emphasized that assessment of the victim-survivor's suitability and readiness is a vital part of the process of the case assessment and the offender is not assessed in isolation. To be clear, these are offender characteristics/traits that RJ assessors (either RJ facilitators, judges, lawyers, or police) have mentioned as things that grab their attention and along with other information about the case, will be used to determine suitability or readiness. It became apparent that the line or cut-off so to speak is very grey and depends not only on the offender and the victim-survivor being assessed, but who does the assessment. There were some similarities, but it became clear that individual assessors had their own cut-offs and criteria that they personally used to determine suitability.

$\mathrm{RJ}$ in the area of IPV is a very new area for many agencies throughout New Zealand. Many agencies and courts that had been working with or referring to RJ had not been covering IPV or FV cases. With the new legislation, this all changes, so everyone is being forced to re-think their stances and in many cases, either get training for their facilitators, utilize trained and experienced FV facilitators, refer cases to other RJ agencies that are better suited to handle the cases, or in some cases, reject or accept cases that they are unable/unskilled to assess properly.

We've only been doing FV referrals for the last couple of months... so we just trust those experienced eyes and the experienced facilitators who have been involved in this stuff for years to look at it on a case by case basis and say "yea" to this one or "no" to this one... where it's very serious I think there will be lots of red flags that are obvious and stand out... and unless those are provided for, I think we would say "no we're not doing this one"... and it's a very careful decision... (T13Lawyer, 226-233)

For a small portion of the interviewees, the simple fact that the case was an IPV case was enough to say that it was unsuitable for RJ.

T18: In terms of FV, I would never accept a case where IPV is the issue... where the actual crime is an actual IP crime... for me FV of any sort

Researcher: Why is that? 
T18: Because it's a crime, in my view it's non-negotiable and as soon as you allow negotiables around a crime, you get drawn into the IPV cycle really...

(T18RJFacilitator, 149-154)

For others, there were characteristics outside of the fact that it was an IPV case that gave an indication that the offender may not be suitable (a yellow flag) - or more specifically - that the case may not be safe to take to conference. For some, the characteristics were red flags and indicated to them that the conference should not proceed.

It was noted by many interviewees, that nothing is absolute and it is important to be mindful of how the information is being interpreted - this is further discussed in the "judgment practices" section, but is also relevant to note here that what may appear to be a yellow/red flag, may, upon further investigation, not be. For example, for some facilitators, having a support person is a requirement of attending an RJ conference. However, it was also pointed out by several of the facilitators that not having a support person, is not a clear-cut red flag and should not, in itself, be a sign of inappropriateness.

Researcher: If an offender decided, "I don't want anybody to come, I don't want any support people" - would that give you a red flag?

T29: Yup, that could be a red flag - why are they not asking anyone else to come? ... But it may also be that they don't have relations in this town that they can ask or friends that they feel are close that they want to bring. Family might all be working and the conference is at a time that doesn't suit... whilst ideally they should have a support person ... it's not as simple as everybody must have a support person... just because someone doesn't have a support person doesn't mean it won't be a successful meeting... (T29RJFacilitator, 255-264)

It was indicated that not bringing a support person could imply a number of things: a. the offender is being resistant; $b$. the offender does not want others to know about his offending; c. there are no support people available because of scheduling issues; $d$. there are no support people available due to isolation; or other reasons. Whatever the reason, it appears that not having a support person is an indication of how vulnerable and potentially risky the situation may be and this must be addressed in order to ensure safety not only in conference but postconference.

I think it's vital for a person to be connected, but to me it's an indication that I've got a more vulnerable and dangerous situation if that person doesn't have any of that support... I think it's a measure of how safe a person is, how connected they are, how 
many people are aware of what's happening in the situation... (T26RJFacilitator, 122128)

In addition, a key point that was pervasive was that it is the responsibility of the RJ facilitator to ensure that a support person is found before proceeding to conference. Whether this meant that they helped the offender identify a suitable person himself, or they contacted an external agency that would take on that role.

If there isn't good or available support for the offender and the victim, this is not enough to disqualify someone from attending an RJ conference. The question to ask is "where do we get it, what do they need, how can we help?" So I would make a really really serious effort to find it. If you can't find it then what are you doing in this business? (T28RJFacilitator, 202-204)

While discussing support people, it is important to reiterate what several interviewees pointed out that the support people must be screened as well as the offender and victimsurvivor because they may actually help to perpetuate beliefs and behaviours that support abuse and could actually be part of the problem. One interviewee pointed out that this screening should not be done solely in isolation (support person and facilitator) because it is the observation of the interaction between support people and victim-survivors or offenders that may illuminate the patterns.

\section{Green flags}

The MOJ RJ for FV assessment guidelines (MOJ, 2013) note a number of criteria that should be considered during pre-conference assessment: expressions of remorse, the ability to change, insight into their own behaviour, and the capacity to give a meaningful apology, capacity for empathy (understanding their impact on the victim-survivor), a level of responsibility and being accountable for their offending, safety for the offender and victimsurvivor, and a willingness to repair the harm done or to "put things right" (MOJ, 2013, p. 27). In a sense, these could all be considered the "green flags" - characteristics that let an assessor know that an offender is suitable and ready for RJ. However, an underlying message in the criteria is the understanding of the genuineness of all of those characteristics and most interviewees discussed the difficulties in determining genuineness. In addition, the guidelines do not mention how these green flags are identified - what lets an assessor understand that these qualities exist?

In the case of assessing an ability to give a "meaningful apology", it was stressed by many of the interviewees, that saying "sorry" was not the point of the pre-conference and conference period - healing harm and insuring safety was the point. 
Often you get someone coming into the room and sorry is the first thing they say... but it actually carries no weight, and as the facilitator I wouldn't make much of that...it's kind of where you get to at the end of the conversation that's more important...

(T22RJFacilitator, 327-331)

In addition, a couple of the interviewees pointed out that looking for "sorry" might be a problem because it may be an assumption that an offender understands the deeper meaning of sorry. It was said that some offenders don't really know what "sorry" is or know how to express that they are sorry due to lack of experience or perhaps cultural pressures that make saying sorry shameful or weak.

Accountability was an area that many interviewees discussed from the perspective of a green flag. When thinking about genuine accountability most interviewees spoke of offender attitudes that reflected a willingness to be responsible for their actions and to move forward. This included looking at the offence from their partner's perspective (which sounds a lot like the ability to have empathy) as well as speaking about the offence in terms of their actions and what they need to do to move forward rather than blaming the victim-survivor.

So first off [assessment] starts with ownership. Are they talking about stuff that they've done or are they talking about what provoked it from their point of view. So it's a basic step of accountability. What do they think is needed to move forward? What ability have they to move from one to two?... To look at it from their partner's perspective... (T22RJFacilitator, 545-549)

It was pointed out that when thinking about offender accountability, it is important not to mistake a guilty plea with accountability. An offender may agree to the charge, but may not agree with the summary of facts or feel that they are at fault - indicating that though they are accepting a guilty plea, in fact, they are not being accountable. This illustrates the perspective that rather than looking at what characteristics make a green flag, many people worked from the perspective of looking for characteristics that were indicative that a case was not suitable and was not a green flag. Rather than being able to explain what, for example, accountability looks like, interviewees would explain what it was not or how it would appear that someone was not accountable.

There are two aspects - the charge and that's often the easy bit... yes they agreed that a male assaulted a female etcetera. The hard part is usually the summary of facts - the story that sits behind the charge. The person may agree with the charge but they say I never did that I never did that... yes I shoved her once and the summary of facts says he kicked her in the head a number of times... that's not the sort of thing where I would 
think RJ would be appropriate at all ... just simply because the summary is so disputed that there's no point in sending that person along just to argue. (T12Lawyer, 106-113)

This was a recurrent pattern amongst the interviewees - when discussing the MOJ assessment recommendations and green flags, it became apparent that, for the most part, rather than answering what characteristics indicated green flags, interviewees very often answered the question from the perspective of signs (yellow and red flags) that indicated a case might be (or was) inappropriate. In reality, the perspective was very often a mixture of the two.

I just interviewed someone an hour ago and in the summary of facts it said when he spoke to the police he'd said to his partner, "now look what you've made me do"...that's such a red flag to a bull as far as him not taking ownership... it very much could have been said in the heat of the moment or whatever, but I've got to make sure that isn't what they're thinking... taking ownership for what they've done... and acknowledgement of what has happened... that they made the choice, it's not anything that the other parties forced them into or anything like that... (T26RJFacilitator, 30-40)

\section{Yellow and red flags}

Yellow and red flags were found to be characteristics that interviewees said could indicate that an IPV offender was inappropriate for RJ or at the very least, some caution should be taken before proceeding. This caution could mean that they had to investigate further, or resources needed to be utilized (i.e. external DV agencies, treatment programmes).

It became apparent that the yellow and red flag characteristics could be divided into five basic subthemes: Behavioural, psychological, cognitive/motivational, cultural, and victim-survivor. However, it is important to note that there was often some crossover between the subthemes because there is often a close link between them. For example, at times, a certain behaviour was said to be indicative of a particular cognition.

\section{Behavioural characteristics}

Included within behavioural characteristics are those traits that describe what offenders historically did prior to the offence, during the current offence, or were doing at the time of assessment. First, chronic or historical violence (especially with the same victimsurvivor), having a protection order, and a history of anti-social behaviour was said to suggest unchangeable views and chronic behaviours, and was mentioned by many of the interviewees as a potential red flag.

If you see certain people with anti-social behaviour and they've lived a life of crime and it's all they know and violence is a big part of that... especially if violence extends 
outside of the family, then it's going to be very hard for there to be any ability to actually change that... and so you can involve people like that in this type of thing but really they're people that know systems and processes - they know how to abuse them they know how to prolong them they know how to work the court and if they see this as an opportunity to not get a conviction, not be imprisoned and to show their partner that they really are in control - they'll just carry on regardless... (T6Police, 42-50) However, others pointed out that chronic anti-social behaviours and violence in itself might not be enough to find an offender unsuitable because it is important to look holistically at the case - i.e. the circumstances, context, what interventions occurred/have not occurred, what has changed or has not changed since the offending, and the experience/perspective of the victim-survivor(s). In addition, it is thought that if there is a history of violence and a particular way of reacting to it from a systemic point of view, perhaps, since that has not worked, RJ might be a good alternative - trying a new approach. Additionally, it seems to be suggested that what on the surface might appear to disqualify someone, may appear differently if a full assessment is done and to automatically decide someone as unsuitable for RJ before undertaking a full assessment, may be doing a disservice.

If someone's got a history of numerous FV convictions or offences, you might say this person's propensity for violence or manipulation is so extensive, you would doubt that whether they would be able to take a different view in the context of this charge but then again people can change ... virtually no one is completely un-reformable and the offending can occur in one context with a certain group of friends or relationships... I wouldn't say it should be ruled out... I'd be reluctant to draw lines and say, "even without an assessment for suitability we won't consider this or that person or this or that offence"... (T3Judge, 124-134)

In addition to past violence, current violence, stalking behaviours, and serious or recent significant harm to a victim-survivor were mentioned by a number of people as red flags because of the potential re-traumatizing for victims to meet with the offender and could also be indicative of potential for future violence. It was expressed by several interviewees that the potential risk would be too great and therefore not worth the gamble - illustrating the uncertain nature of assessment in this area and how much of the risk assessment could really be thought of as "erring on the side of caution."

You'd see the word throttle and grabbed her by the neck and you'd think "well... how serious was that? How did he grab her by the neck? When did he let go? There was no record of strangulation"... now it's been highlighted... I would think - "What if he 
progresses? What would be the end result of that?" That's not for me to take that chance... (T27RJFacilitator, 191-196)

For some this violence was seen as something that the system was not adequately skilled to address yet. This seemed to indicate that the door was open for possibility assuming developments in practice and procedures occurred that better addressed IPV issues.

It's fair to say that for the really violent cases where there are moderately serious to serious injuries, we tended not to go there. That's just presently anyway, a bit of a bridge too far... (T1Judge, 66-68)

However, the cut-off was unclear and most said that assessment should be on a caseby-case basis - not strictly based on severity. One interviewee pointed out that perhaps the line for judgment of violence is moving - and what was once considered too violent, is now less shocking and perhaps perceived as possible for RJ.

Even after nearly 17 years, one is still shocked by people's capacity to hurt their fellow man... and so I suppose it's the initial sort of revulsion at the behaviour that tends to contraindicate RJ... But as time goes by, we are getting more comfortable with perhaps, pushing that boundary a bit further out. However, the last thing that of course we want to happen, is for a victim to be re-victimized... (T1Judge, 71-76)

Along with historical violence and violence in the current episode, aggression towards the assessor was stated by a number of interviewees as a red/yellow flag. This could be overt or covert aggression and it appeared as if assessor experience and knowledge comes into effect here in order to detect the subtler forms of aggression. This would be particularly relevant in IPV cases involving psychological abuse or with grooming.

Researcher: What would make you think, when you are interviewing or looking at an offender, "No, this IPV offender is not appropriate"?

T29: If someone is aggressive toward me, and if they are really negative. That aggression can be subtle but you can see it... (T29RJFacilitator, 162-166)

\section{Psychological characteristics}

In addition to behaviours, many interviewees pointed out that there are psychological characteristics and/or traits that could be considered yellow or red flags. Certain personality styles such as those with narcissistic features, "pit bull" or "cobra" types ${ }^{6}$, misogynistic tendencies, and coercive interpersonal approaches or engaging in power and control

\footnotetext{
${ }^{6}$ See Jacobson and Gottman (1998), in particular, chapters 4 and 5 for more information on suggested "cobra" and "pitbull" offender classification.
} 
strategies ${ }^{7}$ were mentioned throughout the interviews as red flags. There were a variety of reasons given such as the various personality types reflect an inability to be genuinely accountable, a deep seeded desire to continue to punish or harm the victim-survivor, or a power imbalance that contributes to the victim-survivor being coerced into accepting the behaviours and mindset.

The classic stereotype of power and control male violence - where there are really stuck, misogynistic mindsets, it's probably not going to be a good candidate for restorative justice... because I think there is no degree of victim empathy - there's actually no accountability. (T22RJFacilitator, 247-253)

Some mentioned untreated alcohol and/or drug (A\&D) issues and untreated mental illness as areas that are warning signs for a number of reasons. They felt that for some people, IPV only occurred under the influence of $A \& D$, so treating the offender without treating the trigger was not useful and in fact, treating the A\&D problem may eradicate the IPV. This point of view reflects the underlying notion that RJ's purpose is to reduce recidivism rather than being focused on repairing the harm that was caused as a result of the offending. For others it was thought that without treating A\&D issues, the offender might not be able to engage properly or follow through on commitments made during the conference due to recurring A\&D problems.

Researcher: What if they haven't had the drug and alcohol counselling?

T29: You might say, "Why are we doing this? Is it going to make a difference?"

(T29RJFacilitator, 308-309)

In the case of untreated mental illness, the reason for this being a red flag seemed to be more a case of facilitator inexperience - dealing with mental illness was out of the scope of their knowledge and training rather than untreated mental illness in itself indicating offender inappropriateness. Although, like the untreated A\&D issues, this may also reflect a perspective that treating the underlying problem might stop the violence - and that is the goal. This is not the primary intention of $\mathrm{RJ}$ - this is more a reflection of a traditional criminal justice point of view.

If there are mental health issues... it's hard to find a balance for them and their realities are not the normal realities... so you just have to be very careful... often the problems aren't identified... you're only asking, "so what have you had help with?" and then you discover a whole raft of mental health workers behind them, medication, drugs...

\footnotetext{
${ }^{7}$ See the Duluth Model and The Power and Control wheel (DAIP, 2011)
} 
there's a whole range of things that I don't think people are trained to consider... (T27RJFacilitator, 19-26)

One interviewee suggested that having a developmental or intelligence mismatch between the victim and offender could indicate an unsuitable case - for example, if the offender is more intelligent or developmentally advanced than the victim-survivor, he may continue to manipulate and take advantage of the victim-survivor because this imbalance is the nature of their relationship.

Another of "you don't do RJ with this pair" would be those who are developmentally very disparate. That might be a big age gap, but not all of those will be bad for RJ - it might be... it might be the kind of relationship of a very unintelligent woman and a quite bright controlling man...and there aren't so many of those these days, but they are there....and it might be your highly diligent plodding along bloke with a manipulative developmentally toxic but never the less quite clever at it woman. Those mismatch have great capacity to be abusive as another process. (T5Judge, 689-697) An area that was said to strongly influence psychological functioning was offender physical health. It was said by several interviewees that physical health issues such as undetected hearing problems, dental issues, and head injuries should be taken into consideration because these can influence how able/willing an offender may be to participate effectively (i.e. How distorted are their realities? How cognitively flexible are they? Is there jealousy? How much have they misunderstood over the years due to not hearing things properly?). It was mentioned that this is an area that is often over-looked, yet can be a strong influence on behavioural, psychological and cognitive functioning.

\section{Cognitive/Motivational}

Across the various personality types, there were a number of cognitive patterns that were mentioned. These cognitions were not always connected to a particular personality type, but were indicative of red or yellow flags when combined with other factors. For example, if an offender behaves in a particularly staunch or blaming way, this was said to be an indication of unchanging attitudes and suggested unsuitability for RJ. Although as mentioned earlier, context and other factors should be taken into consideration, as some of the staunchness could, for example, be shame masking itself when in front of other people or when feeling under pressure.

If they come in very staunch... "Well she got what she deserves... she's the problem"... and looking to blame it on alcohol or drugs or a crap day at work... or argument with 
neighbour... or if they are using "I" statements and actually owning their behaviour... That's what I am listening for... (T23RJFacilitator, 188-193)

Others mentioned that claiming that he (the offender) was the victim was an indication of unsuitability. This again, reflects a position of blame rather than taking responsibility for the offence. This is not to say that his history is not acknowledged and that there may be abuse that he has experienced, however, interviewees made it clear that he needs to take ownership of his part of the abuse.

I know the perpetrator isn't suitable for RJ [when] he's just not in the place of readiness for it. He's the victim and she's the problem... and he's not owning his behaviours and still putting the blame on everybody and everything, and "I've had a hard childhood" and all the things like that... (T23RJFacilitator, 61-66)

However, as one interviewee pointed out, this may not be a red flag from the victimsurvivor's perspective - it depends on what the victim-survivor wants and if the assessor decides that the conference would still be safe to proceed. If the victim-survivor is aware that the offender is not willing to be accountable, but has the resources and capacity to face this and wants an opportunity to safely tell her story - the RJ facilitator may allow the conference to occur (assuming safety and no re-traumatization can be ensured as much as possible).

If [the offender's] story was full of blame...I might not be going into a conference without having challenged that really heavily... I'm deliberately not being absolute here because it depends what the offence victim wants...[if] the offence victim says "I know he's just going to blame me, I don't care about that" and the woman might have been supported, might have been through a woman's education program, had a certain amount of therapeutic strengthening and stuff, and got to a point where it's almost a unilateral message... and "I just want to go in there and tell him what my life's been like..." (T22RJFacilitator, 360-372)

As previously mentioned, others pointed out that in many cases the picture is often muddy in terms of a clear-cut victim-survivor and offender. This is a very controversial position that must be tread very carefully as there has been a history of victim-survivor blaming in the area of IPV and the participants did not want to insinuate that this was their position. Rather, it was a point of view that acknowledged the complexity of the relationships they deal with.

Another point that was raised was if an offender is found to want to attend RJ for a reduced sentence - is that a disqualifier? Many thought that in many cases, this motivation would not be a disqualifier in its self - Other cognitions, behaviours, characteristics, and traits 
would have to be taken into account in order to make a fully informed decision. In fact, some pointed out that this was a very natural part of human nature - to see a potentially easier road and to want to take it so to speak.

We'd be naive to think that offenders who go into a RJ process don't expect to get some credit for it in criminal prosecution and the law says [judges] have to take account of RJ processes and by that I mean, I guess, successful ones where there seems to be a genuine engagement by the offender... so you give credit for it... so you have to be constantly alert to what's motivating the offender and what seems to be a genuine wish to take responsibility for his actions - isn't... (T3Judge, 31-37)

However, it was noted that depending on the offender's stage of motivation to change (Prochaska, DiClemente, \& Norcross, 1992), this can make a difference in whether wanting to attend $\mathrm{RJ}$ for a reduced sentence is a red flag or not. As one interviewee pointed out, if an offender was in the pre-contemplative stage, there would be no point in working with them because there is no sense of accountability, no sense that there is a problem in their thinking, and may be no awareness that there is a behaviour that needs to change.

The huge challenge with rehabilitation, and you will know all the psychological buzz words like pre-contemplative stage and the contemplative stage and so on... we don't go ahead with those who are in the pre-contemplative stage. They haven't got their head in the right space to acknowledge that what they've done is wrong and to see any need to do anything about it... (T1Judge, 84-89)

How the offenders tell their stories and what is said was also indicated as a factor that contributes to the assessment of suitability. Is there an indication of shame or accountability? As previously mentioned in the assessor skills section, listening for what is being said and how it is being said, can be indicators of deep seeded cognitions.

It's the way they tell their story. Whether they are just there going through the motions or not... when you start talking about shame, I don't think anyone can go through the motions of that. Shame is a deep thing. I ask them what's going on inside...

(T29RJFacilitator, 83-87)

\section{Cultural}

From a cultural perspective it was said you want to ask, "how balanced is the offender?" in terms of their physical, psychological, spiritual, and family health. This is from the standpoint of te whare tapa wha (New Zealand Ministry of Health, 2015), which acknowledges the Maori perspective, and the bicultural nature of a lot of the RJ IPV work that 
happens in New Zealand. It appears as if imbalance was not so much a red flag as a yellow flag - an indication that attention is needed in certain areas.

I have a worldview that's Maori... when I'm assessing a client it's the more holistic view of assessing a person. Is his life in balance? Obviously not if he's in court... what else have you got in there - alcohol, drugs, illness, can he hear, can he see? Many men have got hearing problems ... I think a lot suffer poor health... they don't always heal well... I think many of the older ones haven't had a good education, so they struggle to understand things... and I would say when there's teeth involved.... those are some of the cultural things I look at... it the Te Whare Tapa Wha model of - how balanced is this person? (T27RJFacilitator, 4-11)

\section{Victim-survivor}

This is not so much an area where flags will be discussed, but rather, a point to be made in regards to cases being victim-survivor centred. This reiterates the idea that was consistently spoken about - if the victim-survivor was assessed as ready and deemed to have the required capabilities, and the risk could be managed, and as long as the victim is aware of the position of the offender (i.e. his cognitions), the case may be suitable to go to conference.

For very serious violence where prison is inevitable, RJ may still be appropriate ... in fact some victims, I guess, may feel more comfortable knowing the offender is in custody at the time and is going to be in custody for a while so the risk of revictimization are reduced... (T3Judge, 165-168)

As previously stated, it was emphasized by most individuals, that holistic assessment is vital as is the acknowledgment of the influence that the context of assessment (i.e. in court, the culture, police) because this can affect the presentation of the offender and in turn, the assessment and conclusions drawn. 


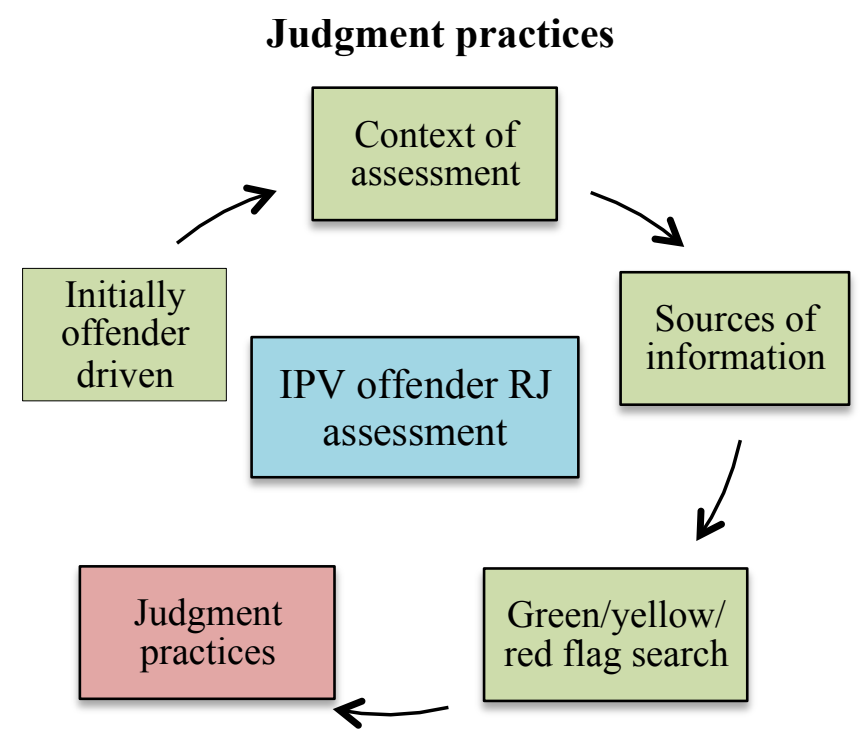

Figure 17. IPV offender RJ assessment: Judgment practices

I don't think the way RJ is being developed now, rules in or out any particular case. It starts off on the case that any person charged with any offence has to go through the screening process, where there is an identified victim, to see if $\mathrm{RJ}$ is appropriate... and it may be as time develops, there will be some protocols put in place that would suggest that RJ shouldn't be or is unlikely to be appropriate in this that or the other case, but [cases] vary so much in their nature... different charges tend to reflect the different nature of the assault and the seriousness of it but there are nuances of each case... it's really hard to categorize one particular kind of case as necessarily suitable or unsuitable for a process or predict an outcome... (T3Judge, 304-319)

After gathering information and looking for the green, yellow, and red flags, assessors make final judgments on offender suitability to participate in RJ. The final theme found was judgment practices (see Figure 17) and refers to what assessors do to understand the information gathered and how assessors draw their conclusions and understand this information. Judgment practices were expressed in two different ways: Practices that inform judgment, and methods of judgment

\section{Practices that inform judgment}

When assessing whether an IPV offender is appropriate for RJ, and whether they are being genuine, there are techniques, methods, and practices that were utilized. Some of these practices were mentioned previously under the theme "skills that make an effective RJ assessor," however, it is important to highlight them in this section in order to understand them from the perspective of implementation. 
There were a number of techniques mentioned that were used to gather information to inform judgment. This information was then processed, using experience, knowledge and gut feelings, to make a judgment. The first method used was observation - looking for signs in an offender's behaviour such as tears in their eyes, and body language. Tears were said to be important to observe in the context of other body language and speech as it may or may not indicate genuine remorse. Body language may include the way in which someone is holding their head, facial expressions, eye contact, body posture, hand and feet gestures to name a few.

I'm watching and listening and taking notes as well and just thinking is this person just going through the motions or is there some emotion here? People will tell me about their own backgrounds and they voluntarily do that... and they're not justifying anything - it's just explaining who they are and what happened for them... Signs of remorse can be the emotional thing - eyes filling up with tears but not actually crying... talking in depth about an understanding of the hurt and the harm they have caused other people...We talk about shame and see where that sits in that persons psyche...we talk about mana if the person's Maori. (T29RJFacilitator, 53-60, 67-75) In addition to the actions that are observed when face-to-face, there are also actions in the broader commitment sense that are observable such as attending counselling or treatment sessions they agreed to attend. This willingness was said to indicate a more genuine commitment to the process than someone who does not participate in agreed tasks and could therefore indicate genuineness.

As previously mentioned, assessors noted that caution should be taken in making assumptions about what certain behaviours mean as it is also easy to misinterpret. There is also a cultural perspective when thinking about what body language means - for example, in some cultures, it is considered rude to make direct eye contact with someone (especially someone of authority), in other cultures it is rude not to. Some mentioned that due to these challenges, interpreting body language is low on their list of judgment practices.

In addition to observing behaviours, listening to the way in which someone tells their story and what they are saying is another technique found to assisted judgment.

It's not an exact science ... I don't have a "tic this box"... it's trying to think around some of the actuals behind what you're feeling... a lot of that comes down to where you've been in life and what you think... I think it's listening... a big part of the preconference process is listening to how they're telling the story... as they tell the story you get quite a sense by the way they tell the story as to where it's at... not a specific 
science... if they use this word here... it's very much listening to the story and how it's told and the language that's used, and the attitude that's used in the telling of the story... (T26RJFacilitator, 156-161, 44-48)

When listening to the stories, interviewees mentioned that in-depth questioning was utilized to understand offender perceptions and beliefs at a deeper level. This includes asking the same challenging questions in a variety of ways. Doing so was said to assist in exposing offender thinking, enables observation of consistency and persistence in answers, highlights inconsistencies, and allows a deeper understanding of the offender's perspective and true point of view. In addition, when listening to the offender's responses, it was said that it is important to discern whether the answers are too practiced and/or perhaps coached. It was said that by following up their responses with questions that come from an unexpected angle, an assessor could test an offender's true perspectives.

We would always challenge anything that we didn't feel genuine... so that "woe is me" stuff which you see all the time, is challenged and not just accepted at face value... [Offenders] often expose their distortions and shortcomings in the process of trying to manipulate us... it kind of works against them if their motivations aren't genuine and they're trying to play games... We trip them up in a sense, through our challenging and their responses... (T17RJFacilitator, 204-218, 281-288)

It was noted that caution should to be taken during that time as challenging an offender could lead to an increased risk for victims if the offender became defensive or angry. This highlights the importance of a skilled and knowledgeable assessor who understands the risks involved in IPV case assessment.

Another technique that is used to understand genuineness is assessor story telling. In a roundabout way, it was said that by building rapport, through the assessor telling a relevant story of say, a similar circumstance or scenario, the offender can feel more at ease, and will tend to be more genuine in his responses and perhaps gain insight into his cognitions or behaviours.

The genuineness is difficult, but I think if you can crack through the emotional barriers with someone or tell them a story about someone else I've worked with... then they can sometimes recognize things. (T29RJFacilitator, 86-95)

When making a judgment as to whether an offender is being genuine, one interviewee made a point that it is important to remember that the showing remorse is for the victimsurvivor. If she feels it is genuine, then that is good enough - it is not about how the assessor feels, it is about how the victim-survivor feels (while also ensuring safety). 
If the offenders say they are sorry, it's not about being sorry to me, it's about being sorry to the victim. If I think in the conference, for example, that the apology is so pathetic, but the victim is accepting of it in a real way... then it's fine... because it's not about me, it's not my judgment, it's what does that person think about what has been said... while I might want to say "yeahhhh right"... and sometimes I do, I say "my god, look at her, or look at him they are accepting this it just seems so veiled."

(T29RJFacilitator, 86-95)

This is a point of view that has some tension around it. As stated earlier, offender responses are often cross-referenced with other stakeholders - and the victim-survivor in particular. As another interviewee pointed out, victim-survivors may be coerced or have ulterior motives when saying they accept the remorse as genuine, so caution needs to be taken in order to ensure safety and reduced risk for the victim. In addition, as previously stated, "sorry" can be hollow and meaningless and was stated by a number of interviewees that though it may heal a victim by hearing this, it is important to understand the full picture and depth of meaning so that safety inside and outside of the conference can be ensured (as much as possible).

It's hard to know [if offender remorse is genuine]... Even a victim might say "I accept remorse as genuine"... well victims, especially where there are ongoing or potentially ongoing relationships, might want to find remorse where someone else might say it's very shallow and insincere... it's a very fraught area. (T3Judge, 330-339)

Interestingly, though there was a lot of discussion about offender genuineness and honesty throughout the interviews and in policy, one interviewee pointed out that some assessors do not expect offenders to initially be completely honest or to disclose everything that comes over time and as long as victim-survivor needs and goals are met, then that may be good enough for now.

We're also looking for inconsistencies in their stories... where they say one thing and then say something else... we don't expect them to be fully honest. So we're not expecting that they will be telling us everything... we understand that that's a journey of taking responsibility, and that they'll be on that continuum. As long as they are far enough on the continuum for the survivor to get what they want of the process in a safe way... (T17RJFacilitator, 123-135)

It was also noted that there should to be a level of trust in the offender's word when making a judgment of genuineness. In a sense - a leap of faith because it is difficult to discern with complete confidence, whether or not an offender is being genuine or has the skills to 
follow through on what he wants to happen. This raises the question of whether offender genuineness should be a criterion in order to participate in the RJ process. One interviewee suggested as long as the offender expresses a desire to meet, whether they are deemed genuinely remorseful or not, they should be allowed to proceed to conference if it is assessed as safe for the victim.

I don't think you can know 100\% [if an offender is genuinely ready]... it's part of building the relationship... you have to give them a certain amount of trust and faith... if they say they're ready and they want to ... there's got to be a little of give and take... if it works out then its hugely beneficial... if it doesn't you learn from it... (T8Police, 256260)

\section{Methods of judgment}

Underlying all of these practices that inform judgment was something that was said to help the RJ assessor understand the information collected - a gut instinct, "a vibe", or a sense. This was informed by personal knowledge and experience with IPV and RJ cases. This combination of experience and gut feeling was utilized to interpret what was observed or heard in order to differentiate between genuineness and an act - between "crocodile tears" and genuine remorse.

All I can really say about that is... having been on the job close on 17 years, you get a gut feeling when you're getting close to honestly. It's in body language, often it's those who have hit rock bottom and you can see it by the way they're standing there... they have run out of options, they don't know what to do next. Their whole demeanour says it all... (T1Judge, 33-37)

Some interviewees pointed out they had been trained in specific techniques such as Cognitive Behavioural Therapy, or have a checklist that can act as a framework along side gut feelings, experience, and professional judgment.

Gut feeling [based on] experience, understanding, and a checklist... And the checklist that most of the providers will go through is: Does this person demonstrate remorse? Are they accepting accountability, are they accepting of change? Will they, in say sexual offending process... will they go to treatment? Do they want to address the hurt and the harm they've caused, do they want to address the problems that caused this hurt and harm? (T28RJFacilitator, 49-67)

It was noted that when utilizing informed gut feelings and professional judgment, caution should be taken and it is important to be as objective as possible. Personal biases and perspectives can influence judgment therefore, as stated earlier, personal reflectiveness is 
vital. Additionally, though many interviewees admitted that they trust their instincts to make accurate decisions, they are not completely clear why it works, and some admitted that judgment could really be considered a very imprecise practice.

Researcher: How do you know [offenders] are being genuine?

T4: Oh you don't... you base it on what they're saying, what the experience is, and also their history. History is huge... but obviously you don't know... you have to have an understanding of people and how they work... that is certainly a criticism... a valid criticism by [a politician] who was very critical of our FV court. Believed we had no idea of what we are doing... (T4Judge, 168-174)

A point that was reiterated throughout the interviews was that the judgment needed to utilize information from multiple sources in order to cross-reference and help to verify genuineness.

If I've picked up anything from working in the IPV area, is never to wholly believe one story... we are validating that story by speaking to the other people, the other side of that equation... So at some level we're looking to triangulate that... do these pieces fit together and is that a consistent story? Partly I guess I judge it by how much they want to tell me... (T22RJFacilitator, 281-282, 883-893)

\section{Cultural perspective}

From a cultural perspective, there were various methods that helped with the judgment of suitability. It was pointed out that within the Maori context, the status of the assessor was an important component of the assessment process because with greater status, a level of respect would customarily be given. This differing level of status can be used to challenge offenders who have not, in the past, experienced this power difference. If the respect was not given, it was said that this could indicate unsuitability. As stated earlier, the question of whether this power difference that is being utilized is actually further reinforcing the idea that a power imbalance is acceptable within a relationship, is unclear.

I'm older... I hold a different status to younger offenders... I'm Maori... and that would show up with offenders being a bit more respectful and attentive...and able to be challenged. Younger ones won't challenge or confront... the older facilitator carries a different sort of mana or status... you can see it... you can hear it... (T27RJFacilitator, 199-217)

If an offender has connections to a marae, the elders on that marae can be used to confirm information about the offender because there is a good chance that they will know the offender better than the assessor and have the know-how in terms of understanding contextual 
and cultural issues that may be present. However, it was also emphasized that caution should be taken in terms of investigating whether there was support from the elders and the community that perhaps perpetuated behaviours and cognitions associated with IPV.

It is clear that the assessment process, methods, and practice are challenging and ill defined and that an integral part of the offender assessment of suitability is the assessment of the victim-survivor. It is really a case assessment that should be done in a case-by-case fashion that is flexible, holistic and accommodating to individual factors. However, it is also apparent that there is a lot of subjectivity within the present practice, which leaves a lot of room for inconsistencies across facilitators and across agencies.

Researcher: have you ever been fooled?

T28: I've done a lot of conferences....and all that means is I've made a lot more mistakes than most people... just reality... (T28RJFacilitator, 435-437)

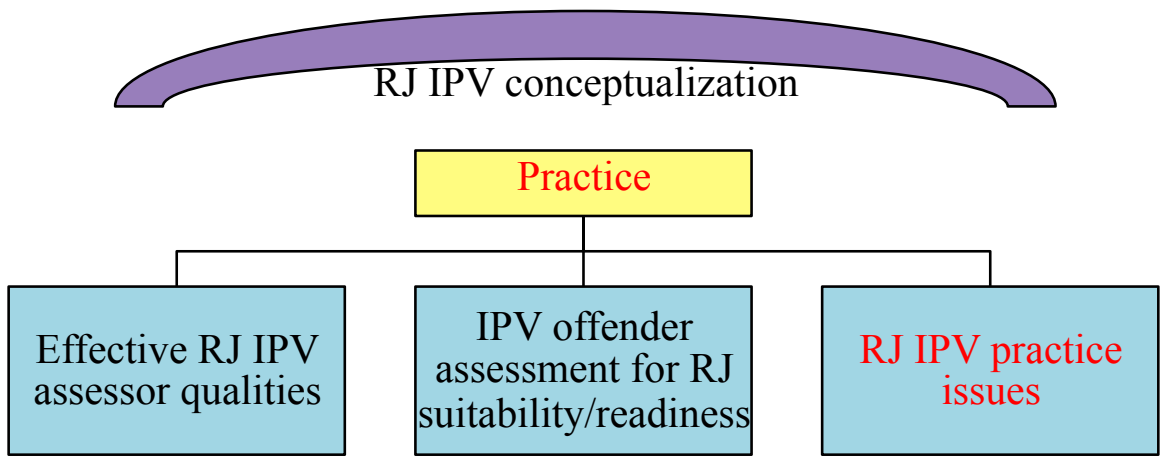

\section{RJ IPV practice issues}

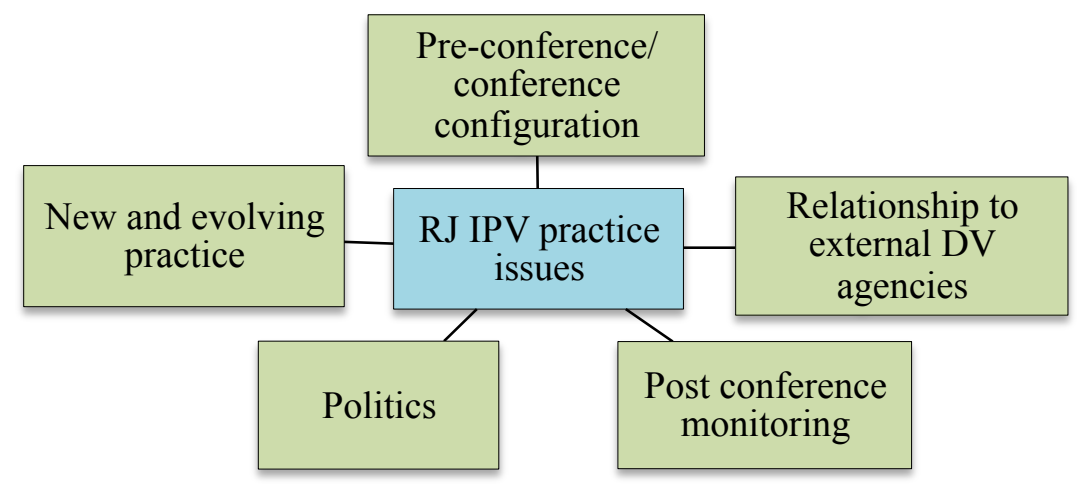

Category

Theme

Figure 18. RJ IPV practice issues 
Researcher: Do you have a sense what would make a good referral process?

T4. There's often delays as far as trying to get permission to get the address, phone, emails etcetera... and there's a lot of things lost... and also just making sure that there is continuity... and all that process is put into place quickly and efficiently...because it's not now - not as good as it could be... (T4Judge, 320-328)

After considering what qualities make an effective RJ IPV assessor and how to assess IPV offender suitability, the final stage to consider was the practice issues involved in the implementation of RJ within IPV (see Figure 18). Within this there were five main themes found: New and evolving practice, pre-conference/conference configuration, relationship to external DV agencies, post conference modelling, and politics.

\section{New and evolving practice}

"I think what I would say right up front is that this is very much work in progress... the model is very much evolving" (T22RJFacilitator, 4, 10)

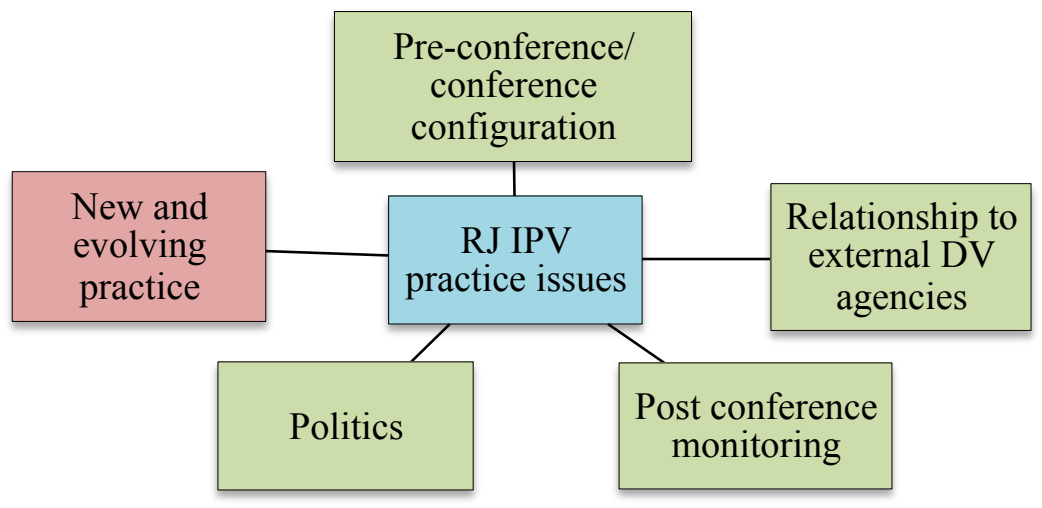

Figure 19. RJ IPV practice issues: New and evolving practice

To be honest, I haven't really thought about this a lot because it's new ground this IPV thing. I can recall countless times lawyers and myself arguing before a judge about RJ and the judge would say it's not appropriate... and in terms of a frame work, it's still developing. (T12Lawyer, 87-90)

As mentioned earlier, $\mathrm{RJ}$ has a strong history of a grassroots origin and a connection to the indigenous practices of New Zealand. It was pointed out by a few of the interviewees that this was considered to be a strength of RJ because rather than being part of a separate and at times intimidating criminal justice system, RJ was approachable and made the offending and the process to deal with the offending a matter of community and relationships. 
It's a grass roots organization, it's the community... it's not the police, it's not the angry old judge, it's not probations... the offender quickly has to understand A. that this is the community that he is offending against as well as offending against the victim and B. it's us - we are not the police we are [your iwi and whanau], so you're offending against us and that's the reason you should do something about it. (T1Judge, 162-169) Though RJ has been in practice for a long time in one form or another throughout New Zealand, it was noted by many of the interviewees that RJ for IPV is a relatively new practice in many parts of New Zealand (see Figure 19). However, it was also pointed out that there are some agencies in the country that have been working with FV cases for over 15 years due to the demand of the particular area where they are located.

Some RJ agencies work from a Maori perspective and most others consider themselves bi-cultural. It was noted by a number of interviewees that there is now a push for more RJ agencies to become more bicultural - utilizing the principles of te whare tapa wha (New Zealand Ministry of Health, 2015). This is in recognition of not only the bi-cultural nature of New Zealand but also the influence and underlying principles of indigenous practices in RJ practice here. Some interviewees pointed out that unlike the traditional criminal justice system, indigenous practices (i.e. Maori culture) helps to inform the RJ process - in turn making a more effective practice when compared to the more traditional criminal justice processes or even non-Maori run/influenced RJ processes.

Maori culture leaves Pakeha culture for dead....and that I think, helps to inform the RJ process... the starting and finishing with a karakea... if that were a Pakeha construct, who would we offend if we start with a prayer or a song? In a purely Pakeha construct, you're dancing around on the head of a pin, trying to be politically correct, culturally sensitive, and frankly getting nowhere...it elevates the process to something where everyone thinks "oh I better behave myself - this is quite serious, this is quite important, I need to focus on what is happening, this is not just another meeting by a probation officer or something... (T1Judge, 353-365)

In fact, some see the Maori approach to justice as being inherently restorative and therefore feel that RJ really existed in New Zealand, in a way, long before the traditional criminal justice system recognized and put a name to it.

I think what the MOJ is doing- it's RJ. But I don't think you can put a box around that and say, "this is the only way RJ is done" - so indigenous people including Maori have their own particular way of a restorative approach. My view is that indigenous people often have a more restorative way of dealing with damage than say the Westminster 
system has or our criminal justice system has. It's not as restorative. I don't think that is its goal - at least that's not one of its main goals... (T13Lawyer, 39-45)

Regardless of these indigenous roots, it was acknowledged that RJ for IPV is a new and evolving practice in New Zealand in terms of becoming more mainstream due to the release of standards by the MOJ (MOJ, 2013) and changes in the Sentencing Law section 24A (The Parliament of New Zealand, 2014) that mandated that if an offender appears in court and pleads guilty to a criminal charge, and there has not been any previous RJ used, the case must be adjourned to determine if an RJ process is appropriate. There were restorative justice standards for family violence cases released by the MOJ (MOJ, 2013) that stipulated various offender assessment guidelines, however, it was pointed out by a number of people that these did not necessarily disqualify any case as there are a lot of individual differences between cases.

I don't think the way RJ is being developed now, rules in or out any particular case. It starts off on the case that any person charged with any offence has to go through the screening process, where there is an identified victim, to see if $\mathrm{RJ}$ is appropriate... that's the starting point... and it may be as time develops there will be some protocols put in place that would suggest that RJ shouldn't be or is unlikely to be appropriate in this that or the other case, but they vary so much in their nature... (T3Judge, 304-309) It was said that these law changes have many implications - primarily in terms of increasing the number of IPV cases that need assessment and placing pressure on the entire system in terms of quantity and quality of qualified RJ IPV assessors throughout the country.

When you've got a huge list of cases to get through in a day and to stop and spend a few minutes talking about the possibility of RJ or adjourning a case... adding to another list... churning cases through the court...there are process issues which weigh against that... that dynamic around a heavily loaded criminal court calendar that we have to balance - we want to try and do justice in every case... so competing pressures at play... (T3Judge, 205-209, 237-239)

A majority of interviewees agreed that a great deal of the pressure from the changes in legislation comes from a lack of confidence about the skill level, knowledge and experience of many RJ IPV assessors throughout the country leading to a hesitancy from the courts to refer cases. This is because part of the legislation stipulates that an "appropriate" restorative justice should be accessible (The Parliament of New Zealand, 2014). It was said that some courts/judges feel torn between a willingness to adjourn a case for RJ assessment, and reluctance due to a lack of skilled/qualified IPV RJ assessors available. 
I am willing to accept that well run RJ conferences by well qualified people is a very worth while and beneficial process... people alert to all the risks and like really seem to deliver some benefits for both the offender and the victim then I applaud the process if it is carried out as they are doing it. I just want to make sure that across the board everyone does it carefully and thoroughly. I suspect it will take a while before we get to that stage. (T3Judge, 369-375)

In addition, there were many RJ providers throughout the country that had refused to take IPV cases, but with the new law change, may be forced to face them. Add to that the acknowledgment by the majority of interviewees that there was generally a lack of government funding for $\mathrm{RJ}$ (both for training and for implementation) and there is a problem. Because of this increased volume, lack of adequate time due to pressures of the courts system, and reduced funding and resources, it was unanimously agreed amongst interviewees that this can increase the potential for risky practice and/or the increase in a more conservative/risk averse approach that may disqualify cases that could be suitable if assessed by experienced facilitators

It was suggested that many of the problems with the current system, in some way, could be linked to the grass roots origins because there are many RJ practitioners who practice in isolation. This was said to lead to a lack of checks and balances so to speak, and potentially risky practice - which can lead to a lack of confidence in RJ facilitators. It was acknowledged that in the majority of cases, best intentions were at the heart of the practice, however practice might still be risky.

If you're working in isolation, over time your view does become sort of... it can become warped. It's like Pitcairn Island - you're sitting there in the middle of the sea values get shifted over time and it becomes normalized... and I don't think there's enough challenge and oversight ... many of them won't have been through the standard training, they've just been doing it for a long times... these are good people... it's been led with incredibly good intentions. Often characterized by some sort of religious drive underneath it... and a desire to do good by people... but that's different to being professional, to being ethical, to having a really clear set of operating principles... (T22RJFacilitator, 770-786)

This isolation was also said to contribute to a general lack of consistency across RJ programmes and RJ facilitators throughout the country. RJ, in some ways, has become very site specific because it was said that the programmes were set up in response to community demands, not necessarily with particular guidelines in mind. In addition, there may be 
guidelines, but depending on who is delivering the program, the practice may occur differently.

There's person variations, site variations... it's like if you try to get a good coffee... with the same coffee machine, people can make different coffees...some taste revolting... it's just because it's an individual running that process and I think RJ is the same... so reliant on the individuals... (T26RJFacilitator, 271-272, 282-289)

Included within this differing practice picture, were differences noted on how integrated agencies were with other services. Some interviewees noted that there are agencies that have implemented agency policies and integrated services with outside agencies (such as the police and women's refuge) in order to address the new demands and to accommodate the more complex assessment demands. There were a few agencies in New Zealand that already had support systems build into their practice model, however it was noted that throughout the country there were inconsistencies in the amount of support and integration between government agencies, non-government organisations (NGOs), and RJ organizations - a lot of siloing occurs. For example, in some jurisdictions the judges and police all support and refer to RJ and are said to have a "shared ethos" - in other areas, not at all.

I think police aren't ready for RJ and IPV just yet... I think they're getting there and will dabble in stuff soon and I think we are in silos... From my perspective there is a lack of trust around the management of the RJ process... I think we may not have the resource to run it ourselves and [there is a] reliance on other agencies to do that and we're not seeing these other agencies stepping up to do their job at the level they should be now... (T8Police, 309-318)

This relationship to external agencies will be discussed further in the "relationship to external DV agencies" theme section that follows.

There were some questions raised by a number of people in terms of measurement of the effectiveness because RJ does not fit into the traditional justice model of success (i.e. reduced recidivism rates). One suggested that RJ measures things like happiness, which they felt was not as measureable or as accepted an outcome in the criminal justice system as reduced offending. It was said that due to this, some agencies question RJ's validity with IPV cases. In addition, it was also mentioned that the way the system is set up now, the government seems to be measuring the success of RJ for FV by numbers of cases utilizing RJ - and that is dangerous. Due to agencies wanting to keep their funding, they may be inclined to push cases through either faster than they should be, or when they should not have been accepted due to either unsuitability or facilitator inexperience. 
You then superimpose onto [the isolated and unprofessional/unsafe practice], the pressure of a system that kind of pays by cases ... I think the ministry is naive in that sense... or pressured so much by the government minister to see a result, a return on their investment...there are not good measures, evaluative measures of success, and particularly in terms of quality... and if quantity is your only measure, well this is what you're going to get... (T22RJFacilitator, 770-786)

However, it was expressed by most people interviewed, that tension exists between the fact that the traditional criminal justice system is widely agreed to be ineffectual for IPV, and the concerns regarding the safety of RJ. There is a sense that the traditional criminal justice system does not protect victim-survivors from further harm, the justice process can often be re-traumatizing, and studies show that it does not reduce offending. This knowledge led some to think that RJ should be utilized because "nothing else works."

If we look at their criminal history, that will often give you some clues as to whether you should be working with this person or not... if it's the same victim and this is the third time well hello what's going on? And that doesn't mean to say you can't do RJ because sometimes the police have tried everything and they have been involved, corrections has been involved, etcetera, and nothing has worked... so why don't we give RJ a go? Sometimes it is an opportunity for people to engage in a different way... (T29RJFacilitator, 126-140)

However, it was also stressed by several interviewees, that RJ for IPV is imperfect and is a work in progress. An important note - It was emphasized by most interviewees that regardless of the lack of funding and time, RJ IPV practice should be done effectively and safely and as a culture, RJ needs to be open to learning from its mistakes in order to move forward. Now in the RJ world, the shit will hit the fan one day. We're assuming that will happen. If we stuff up, something will happen. It's not the stuff up that will be the telling thing, it's how we deal with it and move forward from that. Things will happen and they will not always be right. But it's learning from those mistakes - not accepting those mistakes, but definitely not making them again... that will determine how strong we are as a culture. (T28RJFacilitator, 301-317) 


\section{Pre-conference/conference configuration}

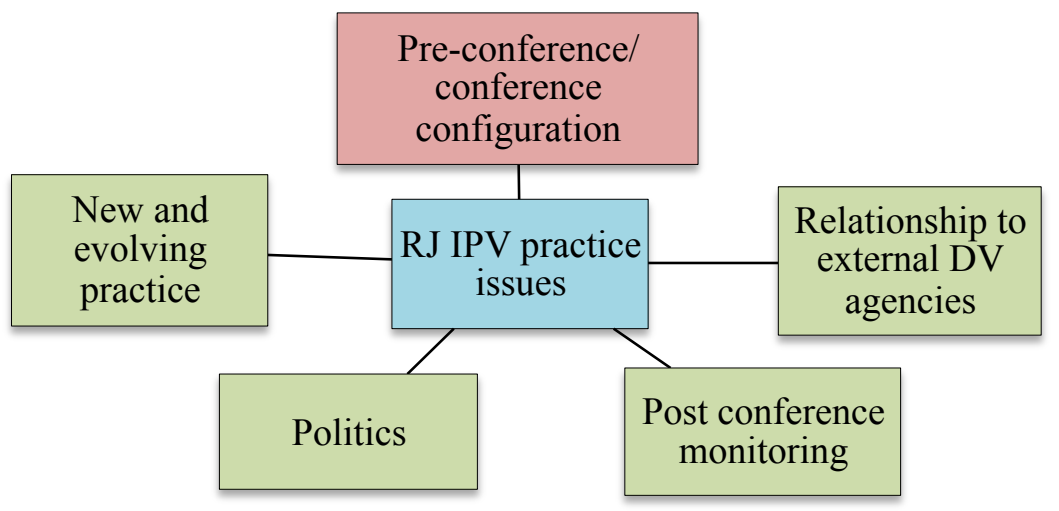

Figure 20. RJ IPV practice issues: Pre-conference/conference configuration

During this time of development and legislative changes, there are a number of variations across RJ agencies. Amongst these variations, one area that stood out in the transcripts was the pre-conference and conference configuration (see Figure 20). There were found to be many variations in RJ IPV pre-conference and conference configurations throughout the country, and varying standards and rules used although, in terms of MOJ requirements, it was said that at least one facilitator should be RJ accredited.

The ministry requires that at least one of the facilitators has to be accredited... so usually you work as a pair... or often you work as a pair, where at least one of you will be family violence accredited. Personally I think they both should be... and actually I think that all RJ facilitators should have that background and training. (T22RJFacilitator, 2229)

Some interviewees noted that there are RJ conferences occurring in New Zealand by facilitators who are not MOJ accredited, however, though most are adhering to that requirement for the most part, there were many variations in configuration. For example, some agencies required two facilitators, one with at least FV accreditation and the other with at least RJ accreditation. Other agencies had only one facilitator with both accreditations (or sometimes only RJ) and they work with volunteers. Others worked alone during the preconference period.

I'm the sole facilitator... I have a group of volunteers, 30-35, I choose 2 of my volunteers that have FV training to come in and support me in this work... some of them work in the area of FV but others might be just, some man who lives down whatever suburb and has been working with me for yonks and has done this training. (T29RJFacilitator, 8-16) 
"Researcher: When you're doing pre-conference work, do you do that alone? T26: yup (T26RJFacilitator, 98-118)"

Some facilitators required the offender and victim to have support people present - others did not. All interviewees said that having a support person is the ideal but acknowledged that sometimes this was easier said than done. Some had community volunteers present, others had external DV agency representative present, others - did not.

One person in the room and the skills they bring are the FV experience... the second facilitator who is in the room is an RJ experienced person, so they should be accredited as well as experienced... what our best practice means is we want another set of externalized [people] to also consider this referral... at the moment, our externalized end are made up by, Presbyterian support, Relationship Aotearoa and also Ko Kite Marae... (T13Lawyer, 108-115) ${ }^{8}$

Another agency used one RJ facilitator with SV/FV and RJ accreditation, an offender specialist, a victim-survivor specialist, and a clinical psychologist (clinical consultant). They meet pre-conference between 3 and 10 times in order to establish suitability and to prepare the stakeholders for conference. It was noted that this particular agency has about four times as much funding as other RJ providers, which allows for this configuration and process to occur. This configuration was pointed out to be unrealistic for most other agencies due to this funding difference.

They have what you call the three legged stool model... and the three work together and it's much longer time scales and the entry into more of a therapeutic relationships certainly with the offender and survivor specialists... we wouldn't do that. I think we have to be realistic about it... it's not to say that we wouldn't want to do it - it's just that we're not resourced to do that. (T22RJFacilitator, 443-451)

Several of the participants spoke about the importance of gender balance between RJ facilitators and victim-survivors and offenders in the pre-conference and conference. This was to help with understanding the different gender perspectives, safety, to model pro-social gendered behaviour (i.e. a male can interact with a female, (or two same sex facilitators in the case of same sex IPV) in a non-coercive or power position), as well as helping the victimsurvivor and the offender feel as if they have someone they may be able to relate/talk to.

\footnotetext{
${ }^{8}$ Since this interview occurred, Relationship Aotearoa has shut down.
} 
However it was generally agreed that this is often difficult to achieve due to a lack of trained RJ IPV facilitators and a gender imbalance of RJ facilitators in general (more women).

One of the things also, is having two facilitators - one male and one female... That's very important if it's two gendered... the guy could possibly recognize things in the man... and that's important in your assessment. (T15RJFacilitator, 130-132)

As previously mentioned in the assessor skills section, cultural balance is another area that is important and at times difficult to achieve. In particular, it was noted that there is a lack of trained Maori and Pacific Island RJ IPV facilitators throughout the country, which is a problem considering it was said that a high percentage of the IPV offenders referred for assessment are found to be of Maori or Pacific Island descent.

I asked [an RJ facilitator from Aotearoa Family Violence in South Auckland] how many people come to your organization that are Maori? She said quite a high percent, maybe $70 \%$. I said: that's great, but let's say it was just 50 , why isn't $50 \%$ of this room Maori? Or why haven't we got engagement with Maori? This is not a slight on anyone in this room - it's a challenge to us as a society... (Family Violence, Restorative Justice and the Law Conference, 2015, p. 22)

\section{Relationship to external DV agencies}

Dealing with FV has come at us by surprise and so we haven't figured out how to go about that, except for the fact that we're wanting to connect in with FV agencies to build on their resource. (T17RJFacilitator, 357-359)

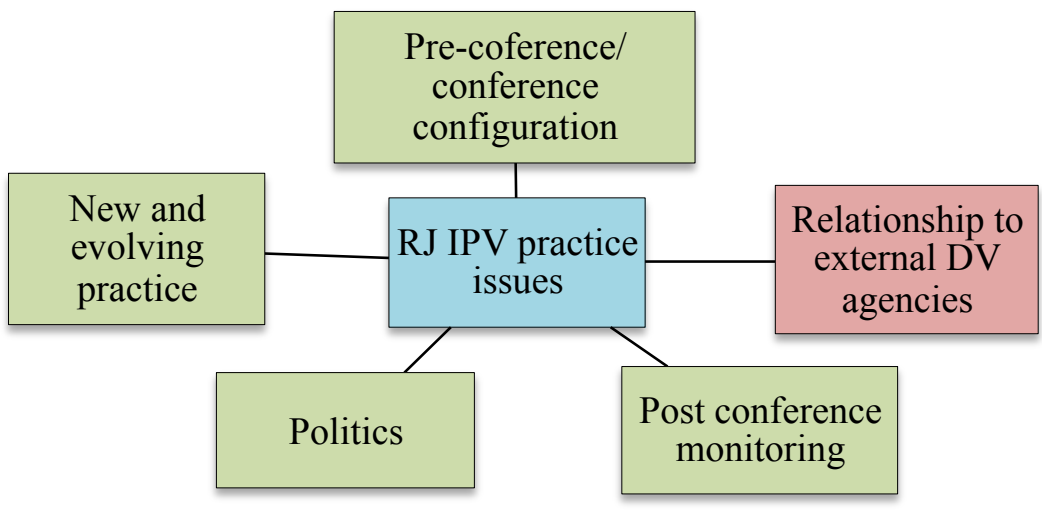

Figure 21. RJ IPV practice issues: Relationship to external DV agencies

In addition to the inconsistencies and variations with the pre-conference/conference configurations, lack of adequate time, resources, information access, and measurements of effectiveness, it was emphasized that relationships to external agencies were important yet at times flawed because interaction with the agencies was often post RJ referral and there were 
at times a misunderstanding or misperception of what RJ actually is (see Figure 21). Time restraints refer to the courts and how there is often a time restriction on how long the case can be adjourned or perhaps a client/lawyer desire to not delay sentencing - so the case is pushed through the system before allowing time for a program to occur prior to $\mathrm{RJ}$ or prior to sentencing.

If you're going to practice RJ in a FV context, it needs to be done in the context of a whole range of services... so you've got those set up already and there's a partnership of the RJ group with Stopping Violence and clinical psychotherapists who are specialists in that field... a team approach... slowing the process, involving more people in the assessments, take it right out of the context of pre-sentencing or anything like that... and also probably require a Stopping Violence course prior to the conference which adds another 12 weeks... (T18RJFacilitator, 358-367)

Throughout the interviews it was noted that siloing of agencies is a consistent problem which not only affects the RJ agencies, but also the victim-survivors and offenders.

[Offenders and victim-survivors] have agencies for Africa telling them what to do... and each time an agency turns up they have to tell their story again so there's a lack of cohesiveness or cooperation between the agencies. (T8Police, 275-277)

However, it was also noted that in certain areas of New Zealand, RJ agencies and external agencies have a much more integrated system with a "shared ethos" between judges, police, defence counsel, probation officers, mental health professionals, and RJ coordinators.

It was found that this siloing of the agencies contributed to a tension between balancing the awareness that the traditional criminal justice system approach to IPV is, for the most part, ineffectual, and concerns about the safety of using RJ for IPV. Some even suggested that prior to the legislative changes, because of the aversion to risk, some judges would not make a referral to RJ or an external agency process unless approached by one of them first.

Some judges in particular are more risk adverse and believe it's not for the courts to manipulate relationships and what the court needs to do is say no contact and if there's an agency in the community that can do something with that couple then maybe they can make an application to the court. (T4Judge, 272-275)

It was pointed out by a number of interviewees that this problem of siloing was not only an agency policy problem, but also a problem of the individual - individuals might not consider utilizing resources outside of their own agency thereby creating a lack of communication between the different silos that are all potentially working on or could be 
working on a case. This was thought to be due to lack of experience, lack of information on RJ, or at times, a sort of "turf protection" that was exacerbated by lack of funding. It was pointed out that it is not necessarily that agencies do not want to work together or do a proper job - but it becomes a case of "it's not my job" when determining which service should take responsibility for certain aspects of the justice and therapeutic process because of a lack of funding.

In terms of neat little packages tied up with bows, [RJ for IPV] is fairly messy... but that is the nature of the people that we are involved with... and particularly these days where everything has a cost and you have to justify every dollar you spend on RJ... [Someone might say, "the offender is] going to counselling for drug and alcohol abuse or anger management...that's normally done by the probation services... so shouldn't they be doing that rather than the RJ people who are primarily in the business of RJ?" ... well... yes... but my experience of life is that there is no one fix that fixes all... and there will be overlaps... and some of this will actually depend on the expertise, the experience, the mana, the ability, of the RJ facilitator... (T1Judge, 301-311)

It was noted that part of the RJ IPV assessment was to determine not only which agencies to refer to, but also, if RJ adds anything to the wrap around system that may already be in place. It was acknowledged that DV agencies could assist in case assessment because they may already have a relationship with the stakeholders, so can add information and insight into the assessment. It was said that a good partnership was needed between the DV and RJ agencies in order to best address the issues at hand but again, due to lack of funding, resources, a lack of information/knowledge about what RJ actually is, territorial lines are often drawn, and some DV agencies do not utilize or work in partnership with RJ.

I think there's a role and place for all of the organizations. I think we understand we need to build a better society and we stop worrying about where the money comes from... If we look at and knocked the silos and the government we'd work better - we'd work across sector... a lot closer than the bullshit they say they're doing now. If the NGO sectors worked together and didn't have to worry about where they're going to get their loaf of bread every week it'd be different... and one part of it is often driven by fear. The fear is not knowing what we do... (T28RJFacilitator, 301-317)

In terms of being properly informed about RJ, some interviewees pointed out that a negative viewpoint by external agencies can be influenced by "bad news stories" in the press about RJ and IPV as well as experiences of being "burnt" by other DV interventions that the government has supported in the past, that have not worked and were run by inexperienced 
and unspecialized practitioners. It was said that in some ways, it has been a slow process to educate and inform providers about what $\mathrm{RJ}$ is, how it is not the same as other past practices (such as mediation), and how accountability, victim-survivor safety, and facilitator knowledge are central to the RJ IPV practice. It was said by a number of interviewees that this gap in information regarding $\mathrm{RJ}$ has at times led to DV agencies and $\mathrm{RJ}$ agencies working in parallel rather than together due to the external agencies believing the goals were at odds rather than similar.

We work in a field not in conflict with groups like Stopping Violence and groups like that, or Woman's groups... we don't work in conflict with them, what people need to understand, is that we actually work in an area that supports their work, but we look at it differently because Woman's Refuge and Shine are still in this adversarial conflict mode. We're not. We're saying, "here is an issue - how can we help?" - it's not you're right, and you're wrong. (T28RJFacilitator, 164-170)

It also became apparent across several interviews that there are also cultural response differences within agencies such as Women's Refuge, non-refuge DV agencies, and even RJ facilitators. It appeared as if those coming from a more Maori perspective were more open to working with RJ agencies, and with IPV. That is not to say they were less cautious or safety focused - just more open to the possibilities.

Important to note however that this very risk-averse, power-and-control analysis, can be quite specific to the tauiwi [(non Maori)] Refuges. Maori women's refuges have generally shown more support [for RJ], as have non-refuge DV agencies and others with a broader and more holistic cultural focus (i.e. Pacifica community agencies). (T32RJFacilitator, 59-61)

As previously mentioned, lack of funding is a major problem - not only for RJ agencies, but other support agencies. Some agencies were actually closing and it was suggested this was due to lack of government support. In addition, one interviewee noted that there was the problem of funding from both the DV and the RJ agency sides and asking representatives from agencies to be involved in the pre-conference or conference period without adequate funds to pay them was a pervasive problem - many people volunteer their time or attend conferences in order to support the process, but it was noted that it is unacceptable practice to assume that facilitators or IPV experts should be volunteering their time rather than be adequately compensated.

As practitioners of justice it does sometimes feel like we are saying ' $\mathrm{Hi}$, we don't have any money but we need you... we really want you in this circle.' This is unfunded 
work for the people you are asking to come in. How sustainable is it for me to ring up people who I know are great for this case, but also next week's case and next month's case? (Family Violence, Restorative Justice and the Law Conference, 2015, p. 8)

A final point - it was expressed that this relationship and breaking down of the silos is not only a funding issue. It is a structural issue that points to a lack of cohesion and strategic vision from the government sector.

We need resources, and not just money - we need to be supported to do this properly and to do it well. I think we lack the strategic vision, to say where [RJ for FV] fits in the overall system. At the moment it feels to me that the judicial system has no idea what to do with a family, who has perhaps been involved with CYFS, NGOs, so they pass it off to the hot new thing, RJ, and RJ is trying to [work with] government departments to get information and join dots and get it done, but at the moment there is no system and from a provider perspective it's like 'we've given you the rules now give us the system' This is absurd... (Family Violence, Restorative Justice and the Law Conference Day 1, 2015, p. 26)

\section{Post conference monitoring}

Unless we can ensure that the shadow of the conference continues going forward, then I don't think we should be doing it. (T22RJFacilitator, 500-501)

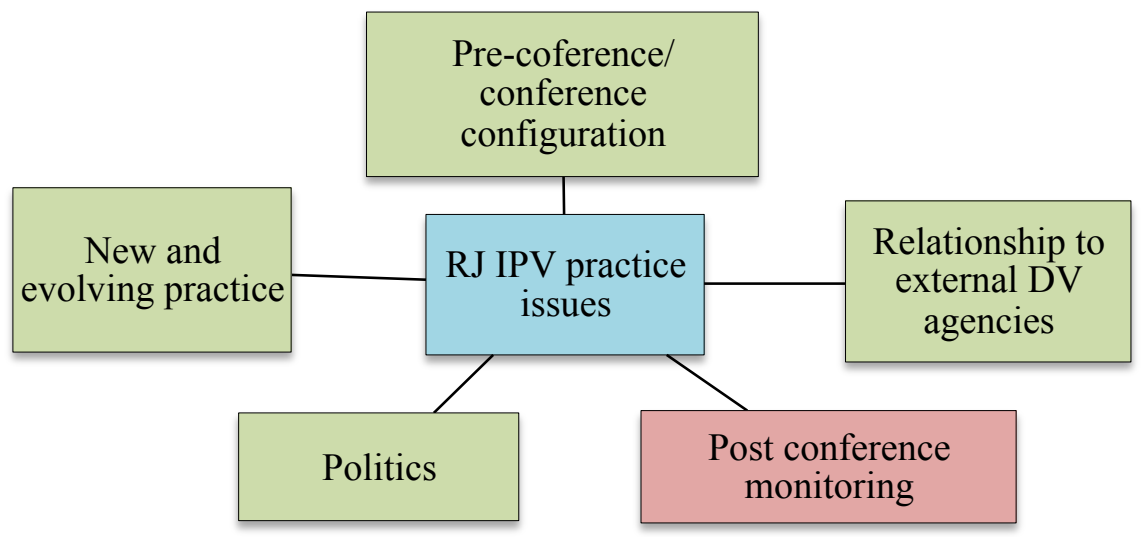

Figure 22. RJ IPV practice issues: Post conference monitoring

Looking at the relationships to external agencies not only highlighted a siloing issue, but it also brought to light the question - who is responsible for monitoring progress post conference (see Figure 22)? It was evident in the interviews, that there was lack of clear understanding regarding who is responsible for post conference monitoring and conference 
accountability. However, all agreed that monitoring needed to be done by someone in order to ensure continuity of commitments made in the conference and safety for all involved.

Some thought it was the RJ facilitator's job to follow up or to ensure that there is support post conference - this suggests a perspective that RJ is not just a "one-off" intervention where responsibility stops when the conference is over.

The facilitator should, I think, be trying to find ways to make sure the support doesn't stop after the two hours or three hours of the RJ conference. This isn't any kind of medicine where you can inject people with three hours of discussion and everyone walks off. (T13Lawyer, 174-180)

It appeared as if some of the practices were individually based and others were at the agency level. Some individuals had a personal policy of following up conferences with phone calls or text messages to check on stakeholders and to see if any further support was needed.

You can never control what happens outside this environment...but I always follow up with a text message or a phone call to see how people are... just to see if people are ok... I do a follow-up for a year with all FV people I meet with and I track what is happening, how people were - every month... (T29RJFacilitator, 113-122, 265-267) Other RJ agencies have follow-up built into their conference plan and agency policy which includes getting treatment feedback from treatment providers - part of the agreed outcome is that the agencies must be given the opportunity to get all the necessary feedback if/when required.

Others noted that there were judges that practiced therapeutic jurisprudence and followed up with offenders in court, while others saw some of the responsibility lying with external agencies or it was the support peoples' responsibility to follow up on commitments made.

[Assessment of case suitability] will include such things as... the continuity factor who's going to be the oversight on this afterwards. I think the evidence we have from other jurisdiction is that the safety in this comes from extending your circle and not limiting your circle... and that means having other professionals that will have ongoing connection with those people... but also family, whanau, community. That can be the watchful oversight going forward... (T22RJFacilitator, 657-662)

The point that was emphasized by most people was the idea that the monitoring was not only to help guarantee that commitments were kept, but also to ensure that risk was being managed safely and effectively. Overall, it was unclear who was to take responsibility for post 
conference monitoring, however it was clear that conference continuity was an issue that concerned the majority of the interviewees.

We are this tiny intervention in a much wider story. And therefore what I'm seeing as our role, or a core role, is to ensure that we're building an oversight for this going forward. I think if we are not able to do that then I think we have really missed the boat and we've left people exposed. (T22RJFacilitator, 467-472)

\section{Politics}

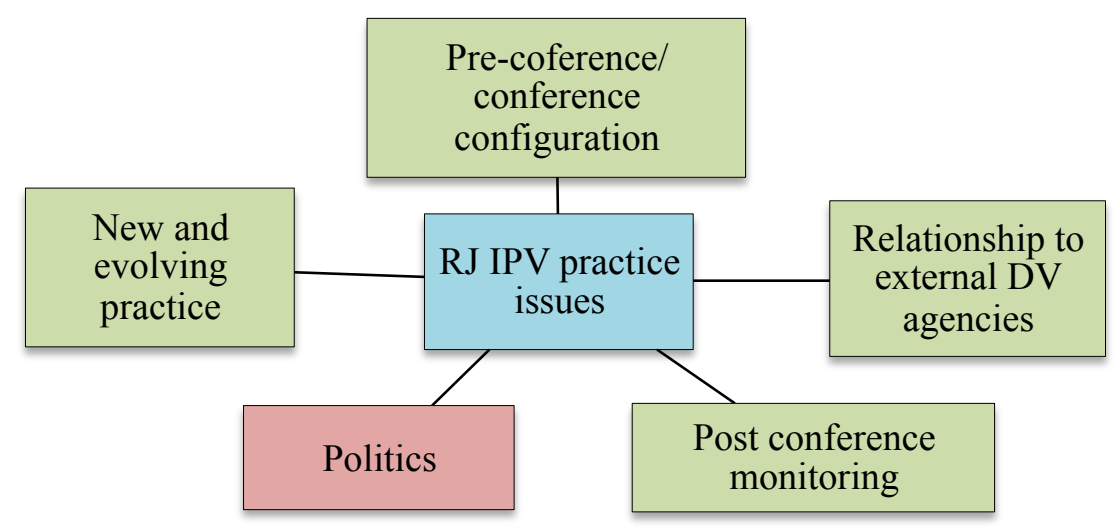

Figure 23. RJ IPV practice issues: Politics

As the previous sections illustrate, there are a lot of practice issues that are coming to light in the RJ IPV arena. Due to the Sentencing Amendment Act (The Parliament of New Zealand, 2014), RJ for IPV has now moved from the fringe and is more visible in the criminal justice system and there are therefore, more issues that are being illuminated (see Figure 23). The fact that $\mathrm{RJ}$ is becoming more regulated by the government has raised some concerns with many of the interviewees. For example, some pointed out that the policy and operations were very intertwined with the Ministry of Justice (MOJ) and there was concern that the core principles of RJ may be under threat if too regulated by the government. There were questions raised about how to guard against this and how best to proceed so that the government values do not influence RJ practice adversely.

I was really concerned when the MOJ brought out "this is how you do DV" guidelines because under the law it becomes a rule... and it sort of becomes inflexible, and I was confused when they brought out the DV stuff, that there isn't the flexibility to be more person specific rather than sausage machine stuff... (T26RJFacilitator, 180-185)

Another issue raised was that lack of understanding about RJ for IPV in both the government and the private sector. Some pointed out that RJ is often considered a "soft" alternative and seemingly offender focused and therefore is best not used for IPV. In addition, 
some agencies do not want to be viewed as being offender focused because this would be a politically incorrect stance. However, this just further accentuates the lack of understanding around RJ for IPV.

I guess the sense of it is that $[\mathrm{RJ}]$ is offender focused but having said that we agree that you've got to work with the offender because that's where the root of the problem is usually... (T6Police, 207-209)

Additionally, the perspective that RJ is a "soft" option assumes that RJ is an alternative to the criminal justice system or that is a replacement form of punishment. There is a fear by some that by supporting RJ, they will be seen as not making the offender accountable. Politically, it was said that it is not a straightforward decision and some agencies feel stuck between knowing that something has to be done to better address IPV, and a fear that $\mathrm{RJ}$ for IPV is too risky.

In the [IPV] environment, you have to be so damn careful... There are some in the political spectrum who think RJ should never be used for [FV] ever... and then there would be some who would say "maybe it's the only way forward"... we take a middle course... and that middle course is yes we can do it, but not for FV and the reason is because of the political considerations... (T9Police, 111-128)

However, it was acknowledged by a majority of the interviewees, that the way the traditional criminal justice system is presently dealing with IPV is flawed - and that something needs to change - and perhaps RJ is the way forward.

Researcher: Do you think the way the system is now is successful for addressing FV? T8: Uh, no. [laughter] I think we don't have a good nationwide structure, we don't have the government support... what is the best way to address [IPV]? RJ is one of those things potentially... the shoddy system we have at the moment where we don't even do the basics right, we're looking at something that's quite a complex thing requiring a lot of skill, my levels of confidence in how well that will be done aren't very high... but if there was a conference that would be done right I'd be into it... (T6Police, 289-297, 303-308) 


\section{CHAPTER 7 \\ DISCUSSION}

This research set out to explore the international literature on RJ and IPV, study the New Zealand policy, and to answer questions that arose in the policy regarding the assessment of IPV offenders' suitability and readiness to participate in RJ. Thirty-one semistructured interviews were conducted with RJ facilitators, judges, lawyers, police, and court coordinators who are involved in the RJ referral process of IPV offenders. A number of questions drove this research originally, and a number of questions evolved during the process. When examining the restorative justice standards for family violence cases (MOJ, 2013) the first question that arose was in the area of offender pre-conference assessment. Throughout the document there were several principles that guided practice, highlighting values of RJ that needed to be upheld, and some characteristics of facilitators, victimsurvivors, and offenders, which should or should not be present. However, what was not obvious was how to assess some of these criteria, and what became apparent during analysis, was that there were some discrepancies not only within the policy but also between policy and international literature and between policy and practice.

This latter point regarding how to assess appropriateness brought up another much broader issue upon reflection and analysis: while analysing the policy and practice data it was very unclear what perspective and what frame or lens RJ for IPV is being viewed through. By having criteria that excluded or included anyone from RJ assumes a perspective that rather than being an overarching theory for justice, RJ for IPV was perhaps a specific intervention for specific individuals meeting certain criteria. For example, if viewing RJ as a broad framework in which to view justice, the need for determining who is appropriate for RJ should not enter the picture because RJ becomes a way of thinking about crime and its values should permeate through all practice. In that case, would it be necessary to understand green/yellow/red flags or appropriateness criteria? They may in fact only be useful in order to discover the areas in which more caution should be taken or the areas that require more attention in a particular case versus another case. If RJ for IPV were viewed as an approach to justice, then theoretically, all individuals would be considered appropriate because there is nothing to be excluded from - there is no appropriate or not appropriate because everyone would be dealt with from the RJ perspective.

When focusing on red or yellow flags, this suggests that practice (and really policy) is buying into a risk management perspective that echoes the viewpoint of a punishment or 
consequential viewpoint to justice. What it really appears to be saying is "this particular person or case is too risky to be worked with." Is this ok? Is this what RJ is about? Is the fact that the assessment is for IPV cases enough to change the rules so to speak, of RJ? I discuss later in this section the finding that there is a strong focus on risk assessment during the preconference period in IPV cases, and that it is implied that this is necessary in order to ensure the safety and reduced risk of re-traumatization. The question remains - Is it possible that RJ values can act as a framework in which to address any IPV case and that assessment is more about understanding what measures need to be put into place in order for healing to occur? This may include postponing the conference until treatment or other interventions have occurred in order to address the areas that need more attention or having safeguards in place. However, this takes time, and often, time is at a premium for a number of reasons such as the individuals wanting to settle the case quickly, lack of resources, and financial restrictions.

What begins to emerge is that RJ for IPV is actually sitting within a system that is risk averse, and that is what drives a lot of the perspectives, practice, and policy for RJ. This brings up another issue within this problem - is RJ for IPV actually considered to be an intervention model that reflects RJ principles rather than an over-arching framework? As with other interventions, the need to assess appropriateness to take part in the intervention becomes relevant to RJ for IPV cases because there would be more of an expected outcome and risk management. Intervention can be defined as: "the systematic process of assessment and planning employed to remediate or prevent a social, educational or developmental problem" (American heritage dictionary of the english language, 2011). Applying this to RJ for IPV, it would look like the focus was to "fix" the problem of abuse rather than to focus on healing the harm. Rather than thinking that all people "fit" and the framework accommodates those individual needs - an intervention then becomes focused on whether it is too risky to do this particular process and whether it will reduce recidivism rather than thinking from an overall perspective of healing and upholding all of the other values that are meant to be intrinsic to RJ.

With these overarching points in mind, the specific points of tension found throughout the analysis of policy and practice will now be addressed. It will become apparent throughout the next sections, that the question of whether RJ for IPV is sitting within or alongside the traditional criminal justice system, or is an overarching framework, is unclear but starts to lean towards the risk management perspective which leaves it vulnerable to losing its core essence of healing.

\section{Tension between RJ FV policy and RJ IPV practice}


There is a long history of RJ and RJ type processes in New Zealand at an indigenous and grass roots level and at a government policy level since 1989 when family group conferences were introduced into legislation (Hayden, Gelsthorpe, Kingi, \& Morris, 2014). However, it is only in recent years that the policy in New Zealand has included RJ standards for family violence cases (MOJ, 2013) as well as mandating, through the Sentencing Amendment Act of 2014 (The Parliament of New Zealand, 2014), that all court cases, if fitting criteria, should be adjourned for assessment for restorative justice. The grass roots nature of RJ is a point of tension because policy is stipulating that there should be monitoring and "high-quality" practitioners - however, due to the way in which RJ has developed, this is not always the case.

The legislative changes have added new pressures to a system that had in the past, often not considered FV appropriate for RJ. In addition, because of the grassroots origin, there has been concern from practitioners throughout the interviews that perhaps becoming government regulated may lead to a "this is how you do DV" perspective, a lack of flexibility, and a threatening of the core values of RJ. However, in the best practice guidelines this tension and point of concern was acknowledged by discussing the dynamic and evolutionary nature of restorative justice practice as well as the need to uphold fundamental RJ principles in order to ensure a safe response to offending (MOJ, 2011).

\section{Convergences and divergences between RJ literature, FV RJ Policy, and practice}

When comparing NZ policy and the literature, it was evident that a large portion of the New Zealand policy (MOJ, 2013) reflected RJ internationally recognized normative values of empowerment, accountability, participation, voluntariness, interconnectedness, respect, repair of harm, victim-survivor driven, safety, and flexibility (see Table 1). Within these principles there are some very strong implicit assumptions that are made as well (see Table 2). After assessing the congruence of the best practice standards and the two new principles that underpin the standards that are focused on FV and SV, it was apparent that there were several areas that were of particular interest in this research. Only those principles that contain a point of tension will be discussed as some principles were found to reflect the international literature and were also reflected in practice.

\section{Principle 1}

Principle 1 focuses on the required voluntary nature of RJ and that informed consent is needed - and specifically, no coercion. This reflects the core value of RJ in the literature of voluntariness and was also reflected in practice. However there is the possibility that with the new amendments to the sentencing act (see Appendix C) (The Parliament of New Zealand, 
2014), many more cases will be adjourned for RJ assessment without being initially requested by the victim-survivor. This may open the door to potentially coercive situations because the victim-survivor may feel added pressure to consent to the process than in the past, especially if there is an ongoing relationship with the offender. As mentioned previously, in some ways, the case is initially offender driven, and without careful management of not only the case, but other professionals working with the case, the victim-survivor could potentially be unintentionally implicated as the reason the case was not accepted for RJ if they decide they do not want to proceed - and be at risk of further harm as a result.

\section{Principle 4}

Principle 4 states that, "restorative justice processes must hold the offender accountable" (MOJ, 2013, p. 14). This appears to support the core value of accountability however there is a contestable line within this section stating, "a plea of guilty, which may [my emphasis] be accompanied by an agreed statement of facts, will provide the clearest indication of an offender's acknowledgement of responsibility" (p. 14). In practice, it was pointed out by most individuals that a guilty plea is not the same thing as being accountable In fact, the Statement of Facts that is presented in court is often the most contested part. In addition, the MOJ (2013) states, "providers and facilitators should be aware of the additional risks to the victim and offender when RJ processes are undertaken in cases where a guilty plea has not been entered or when there has been a change in plea." (p. 14). This goes directly against the previous statement regarding accountability and in practice there was a very strong emphasis on accountability (in addition to a guilty plea). Several interviewees voiced concern over RJ IPV cases that occur without a guilty plea and one pointed out that this is still occurring in practice, which suggests that there is still a long way to go for the RJ community as a whole, to have a unified picture of best practice for IPV cases. Additionally, the Sentencing Amendment Act 2014 (The Parliament of New Zealand, 2014) stipulates that an offender must plead guilty in order for the case to be adjourned for RJ assessment, which is in contrast to the statement within the standards.

Another point to mention in principle 4 is that "the RJ process should only respond to the offence(s) that is the subject of the original referral" (MOJ, 2014, p15). However, in the case of IPV, there is often a far broader offence story than just the current offence and all interviewees pointed out that assessment needs to be holistic and take into account historical violence. This raises a point of tension that was raised in that the traditional criminal justice system deals in "incidents" - a current offence. An offender is in court for a particular crime that has occurred, and is referred to RJ for this event. However, the majority of people 
working in the RJ DV field agreed that pre-conference assessment needs to be done broadly and look outside of the individual incident. In the case of IPV there is agreement that not only is the violence often ongoing, but can also be intergenerational and this information can be useful in helping both parties "gain a more in-depth mutual understanding of the violence, its effects, and where it has come from" (Hayden et al., 2014, p. 214). Some suggested that it should be thought of as an "episode" (Smith, 2015) - taking in the cumulative pattern of harm and the idea that the IPV case that is in front of court at that moment, is often only one "episode" of a much larger story of abuse/offending that needs to be discussed. The intent is not to re-punish someone for crimes they may have already "paid" for, but rather to create a broader picture and understanding of the abuse in order to promote healing for all stakeholders.

This brings up another interesting point that arose during analysis - the concept of zero-tolerance. This leans towards the punitive outlook on justice rather than restorative and illustrates how "the criminal justice lens is much narrower than restorative justice processes" (Hayden et al., 2014, p. 214). Within section 24A of the Sentencing Amendment Act (The Parliament of New Zealand, 2014) it states among the criterion for RJ adjournment that "no RJ process has previously occurred in relation to the offending" (p. 2). Which sounds like they are saying that if RJ occurred, and was (assumingly) unsuccessful (due to recidivism), a case should not have the chance to go through the RJ process again. This raises issues about how RJ is viewed within the traditional criminal justice system. In many ways this seems to imply RJ is viewed as an intervention that is only given one chance to work. In addition, in the case of IPV, it is rare that the presenting offence is an isolated incident, so to say that no RJ has occurred in relation to the offending is first of all a rather grey statement - does this refer only to the present offence or IPV offending that has occurred over time with this particular offender? Secondly, it seems to put RJ in the same basket as punishment - or more specifically, the act of "double jeopardy." In the New Zealand Bill of Rights Act 1990 (MOJ, 2013a) section 26 states that "no one who has been finally acquitted or convicted of, or pardoned for, an offence shall be tried or punished for it again" (p. 9). However, in this case what is the reasoning behind not allowing the RJ process to occur again if $\mathrm{RJ}$ is not part of the conviction or punishment process but rather part of the rehabilitation and healing process? Or is it?

A final point - in Principle 4 there was mention that outcomes should be monitored. This is consistent with the literature, and is a point that is agreed to by the interviewees. 
However, in practice, it is unclear who is responsible for this monitoring and varies greatly from provider to provider, facilitator to facilitator.

\section{Principle 5}

Principle 5 states, that "flexibility and responsiveness are inherent characteristics of restorative justice process" (MOJ, 2013, p.16). This too is reflected in the literature, however the point of tension here was with facilitators because there is concern that by legislating practice, this might affect the principle of flexibility. This is more a point to be aware of and consider how to uphold this RJ value while also creating consistent and safe practice across $\mathrm{RJ}$ practitioners and RJ agencies. It is understandable that this is a point of concern because the question that remains is, "where is the line drawn between enough legislation and too much legislation?"

\section{Principle 7}

Principle 7 states that "restorative justice providers (and facilitators) must ensure the delivery of an effective process" and "high quality facilitators are critical to an effective RJ process" (MOJ, 2013, p. 18). While initially endeavouring to clarify how assessment of readiness and suitability was accomplished, it became apparent that amongst the interviewees, the importance of skilled and knowledgeable facilitators was crucial to an effective process. Additionally, it was also very apparent that there was not a high level of confidence in the existence of enough of these skilled IPV RJ facilitators and that this was a point of concern for many of the interviewees. This creates further tension because looking further into policy, the Sentencing Amendment Act 2014 (The Parliament of New Zealand, 2014) stipulates that a case is only to be adjourned for RJ assessment if an appropriate RJ process can be accessed. Therefore, if there is concern amongst the courts that there is not a suitable RJ process to refer to, IPV cases which may have been assessed as suitable for RJ in some parts of the country, may be found inappropriate in other parts due to the lack of skilled facilitation to refer to rather than case unsuitability. Additionally, there seems to be a great inconsistency across facilitators so even with a referral for assessment, there is potential for great variation in suitability assessment outcome depending on who is doing the assessment.

While there was found to be an agreement between what was said to be ideal practice and policy in terms of what skills and knowledge are desired - there was noted to be a gap in what was actually occurring across RJ facilities in New Zealand and there were areas in which practice further clarified policy. Additionally, issues with accreditation became apparent. This will be discussed further in a later section on facilitator issues however it is worth mentioning here that amongst the interviewees it was noted that most felt that RJ and 
FV accreditation should be required for at least one of the facilitators and though it appears as if the MOJ states that accredited RJ facilitators working in FV are specially trained in FV as well - it is unclear whether this accreditation is officially a requirement. It appears as if there is a lot of greyness across agencies, individuals, and policy in this particular area.

There was also mention in the standards that "formal evaluation of programmes should [my emphasis] be supported and encouraged wherever possible [and] restorative justice providers should also monitor their own practice on an ongoing basis..." (MOJ, 2013, p. 19). This line suggests that the monitoring is not a requirement, and the fact that this evaluation is not monitored by anyone particular (i.e. an appointed official from either the RJ community or the MOJ), leaves a lot of room for interpretation of competency and also the potential for unsafe practice to occur. Who is doing the monitoring? Is there consistency in this monitoring across the country? Is there a way in which this monitoring is monitored so to speak? (i.e. when is it done, how often, by whom, to what standards). This was not clarified in the interviews and answers varied.

This research was able to define more explicitly and in depth the skills and knowledge that was referred to in the policy. For example, within the skills needed, policy stipulates "highly developed communication skills including an ability to maintain and encourage dialogue with a wide variety of people" (MOJ, 2013, p.18). In Component 2 it became apparent that a lot of that encouragement is not only through communication skills (such as listening rather than just their ability to talk to a variety of clients) but also the ability to create a safe environment in which to encourage this conversation. A lot of the information found not only clarified areas that were already mentioned (e.g. self and process reflectiveness), but shed light on a few areas that were not discussed in policy such as the problems with the accreditation and monitoring.

\section{Principle 8}

Principle 8 states, "restorative justice processes should only be undertaken in appropriate cases" (MOJ, 2013, p. 19). In addition, the service design portion of the standards mentioned various factors to consider during the pre-conference assessment and screen of the offender. Both of these sections raised many questions that drove much of empirical research in component 2. For example, though it is stated that appropriateness of RJ was based on factors such as type of offence, it does not specify what type of offence would be considered inappropriate for RJ. Principle 8 also specifies that a factor to consider in assessment of appropriate cases is the suitability of participants, "including their maturity and ability to participate effectively" (MOJ, 2013, p. 19). How this suitability is assessed is not mentioned. 
For example, how do you assess genuine remorse or a genuine apology? Also - what exactly does "maturity" mean? This is not specified. During the service design portion, the assessment considerations do elaborate further on what to look for, but again, do not really mention how to assess things such as the ability to give a meaningful apology, empathy for the victim, offender capacity to understand their distortions. Additionally - what exactly is being assessed in terms of readiness? Is it the readiness to heal or is it a readiness not to cause further harm? Also, does this ability to heal address both the victim-survivor and the offender, or is more weighted towards the victim-survivor?

It became apparent during analysis of the 31 interviews, that though the principles were reflected in practice, when looking at the area of IPV offender assessment, there were some areas of contention and the implementation of the assessment of readiness and suitability had, as predicted, a subjective element. Clarification of what many interviewees considered "readiness and suitability" occurred, however, the variation seemed to predominantly appear where lines were drawn so to speak. For example, the offence severity - individuals varied in terms of what offence was the cut-off in terms of what was considered too serious to proceed. As seen in the literature (or not seen), the interviewees did not seem to base many of these decisions on empirical evidence, but rather on their gut feelings and their experience.

In response to the question "Is the focus of RJ practice on the readiness to heal or is it a readiness not to cause further harm?" it appeared as if the focus was actually focused initially on the readiness/likelihood not to cause further harm - which gave the individual assessors the first cut-off points in a sense, and then the next area they focused on was readiness to heal. Additionally, it became apparent that the assessment of the ability/readiness to heal was predominantly focused on the victim-survivor and the ability/likelihood to harm assessment was predominantly focused on the offender. This really illustrates how, of the interviewees spoken to, the RJ practice in New Zealand reflects an overlap in the encounter/process and reparation/outcome focus.

This section also acknowledges that in cases of FV or SV there is often a cycle of offending that occurs and "reflects deeply entrenched attitudes and beliefs [where] offenders may be more manipulative and have offended seriously and repeatedly therefore a one-off intervention may not be effective or safe" (MOJ, 2013, p. 20). This seems to reflect many assumptions - that perhaps RJ (for other forms of offending) has been considered a one-off intervention, and that a FV or SV offender with deeply entrenched attitudes or who has seriously or repeatedly offended may not be suitable for RJ. A question that arises from this 
and also has become apparent in Component 2, is in regards to repeat offending - does this illustrate that an offender is unchangeable or is it more a case that his behaviour has been unchanging? This will be discussed further in a later section.

These issues were addressed in the green/yellow/red flag and judgment practices of the empirical Component 2. In this section it became apparent that there were many different ways of thinking about IPV offender suitability and that assessment is very individually based. As previously mentioned, it became apparent that there was a strong subjective feel to assessment because, though many people had specific characteristics they looked for, the final decisions were often based on gut feelings that were informed by personal experience and knowledge.

\section{FV portion of policy}

\section{Principle A}

Principle A "respects the right of the victim to hold the offender accountable. It recognises re-balancing of power between the victim and the offender as a key to victim healing" (MOJ, 2013, p. 23). This is said to be driven by victim-survivor motivation rather than external pressures such as the justice system however, as with the first principle of the best practice guidelines (MOJ, 2013), this raises a question regarding the effect of the new legislations which greatly increases the number of cases that are adjourned for assessment Does this now put added pressure on the victim-survivor to agree to RJ? Additionally, this principle adds that victim-survivor wishes prevail but not "where such prevailing would cause harm which beyond that which could be considered to be a consequence of the other person's behaviour" (p.23). It is unclear who decides what is considered an appropriate consequence and sounds like it may reflect more of a punishment perspective rather than a healing perspective. The line can be very blurry and this again highlights the need for experienced and effective assessors who understand the nuances and intricacies of IPV RJ work. Additionally, it is important to remember that though there is emphasis on the needs of the victim-survivor, this does not pose their rights and needs over or in opposition to those of the offender or the community (Bazemore, 1998).

\section{Principle B}

Principle B states that part of a victim-survivor's experience of healing and justice occurs through the receipt of a "genuine apology" (MOJ, 2013, p. 24) and in the preconference assessment of offenders portion, it states that the assessment must consider "the capacity and readiness of offender to give a meaningful apology" (MOJ, 2013, p. 27). As previously discussed, though there seems to be an implicit assumption as to the power of a 
genuine apology, the guidelines do not mention how a meaningful or genuine apology is assessed. What is a meaningful apology, and to whom is it meant to be meaningful? A point to consider, as a lot of the literature points out, perhaps "apologies are a form of treatment rather than a cure... we should view initial apologetic gestures as beginnings rather than conclusions [and] one of the most substantive aspects of just about any apology lies in its relationship to the offender's future behaviour" (Smith, 2014, p. 21). Others acknowledge the healing power of apologies and without thinking about the genuineness, note that an apology is "a powerful ritual for offenders, victims, and communities that would teach offenders lessons, vindicate victims, and encourage communities to welcome wrongdoers back into the fold" (Bibas \& Bierschback, 2004, p. 90). It was found that in a lot of the literature on apologies, there is often a blind spot in the area of reparation for harm done and little mention about the importance of commitment to future reform. Principle B (MOJ, 2013) does mention that healing for the victim-survivor can occur not only if they receive a genuine apology, but also if there were negotiations for commitments that they (the victim-survivor) would find restorative. This does imply that there is thought about not only the words but also the behaviours attached to an apology. However, the guidelines do not state that healing occurs because the genuine apology is backed up by behaviour - only that there is negotiation. In addition, policy does not specify how a facilitator would know if an apology was genuine or not.

When examining this aspect of the policy in the interviews, there was some clarification regarding what to look for in order to determine genuineness of remorse and an apology. However, there was a subjective slant to this and it also became apparent that most interviewees felt that apologies and saying "sorry" was not the point of RJ and that an apology can often be empty and practised. It was pointed at that this "practised apology" was something to keep an eye out for during assessment in order to help ascertain whether an apology was genuine or not. There were also differing opinions regarding the value of determining the genuineness of an apology. Some interviewees felt that as long as the victimsurvivor felt it was genuine, then that was what mattered. However others implied that the RJ facilitator has a responsibility to ensure safety as much as possible, and if the apology is not genuine (but the victim-survivor is lulled into a false sense of security because she thinks it is genuine), this could create a dangerous situation. Regardless, most facilitators indicated that the focus of the conferences should not be on apology, but rather healing - and to them, expecting healing to come from receiving an apology is fraught. 
Principle B also states that healing for the offender occurs through the opportunity to be publicly accountable, to "commit to action to prevent any further abuse [and] to make appropriate reparations for the harm caused" (MOJ, 2013, p. 24). What this neglects to mention is any needs that the offender may have and how this process may also address these needs in order to promote long term healing of the relationship and the individuals. What about offender needs? How does this model address what each individual offender needs for healing and for reintegration into a prosocial life? As Ward and Laws (2010) note, "rather than moral strangers, offenders are people like us who have made bad choices and acted upon them in ways that unacceptably harm others" (p. 11). Perhaps healing of the offender (and the victim-survivor) could take guidance from the Good Lives Model (GLM; Ward \& Laws, 2010). As previously mentioned, the GLM is a model that understands that programmes need to go beyond treatment and increasing empathy or stress management skills. Offender needs should be taken into consideration, and understanding their social and psychological shortfalls should happen - while plans for treatment and reintegration should be both "personally meaningful and socially acceptable" (Ward \& Laws, p. 21).

Another assumption that was seen in policy service design was that the offender should exhibit some level of empathy by being able to understand his impact on the victimsurvivor. Again, the policy is not clear how to assess the genuine nature of this. Additionally, caution should be taken, as there is not strong empirical evidence that having empathy promotes reduced recidivism in offenders (Mann \& Barnett, 2012). Another point to consider, as previously mentioned, the literature suggests that perhaps it is altruism that needs to be assessed rather than just empathy and one could deduce the next step is then to consider the motivation of the offender.

However, motivation was spoken about in the interviews in terms of what motivates the offender to attend RJ conference and does it matter if he is originally attending in order to get a reduced sentence? Most conceded that it does not necessarily matter why offenders want to attend. As long as the case is assessed as safe, getting offenders in the door so to speak allows for the possibility of healing (for both the victim-survivor AND the offender). This reflects a focus on offender healing that was not really reflected in the policy. In fact, it was really the only area in which there was a suggestion about RJ being about the healing of both the victim-survivor and the offender. Most other findings were focused on the healing of the victim-survivor and the assessment of risk when looking at the offender.

Additionally, it is also stated in the policy that "when these processes are followed, the chances of harm will be minimalized" (MOJ, 2013, p. 24) and is reiterated in the service 
design section: "the quality of the assessment and intervention pre-conferencing will mitigate risk for all parties and largely determine the potential for safe effective conferencing and successful outcomes" (MOJ, 2013, p. 25). This leads me to question again, the underlying purpose of this RJ process and what is used to measure successful outcomes - is the goal to minimize harm and reduce recidivism or is it to promote healing? Obviously, in the case of IPV, safety must be considered, however, rather than being a pivot point on which to decide to proceed or not, perhaps as stated earlier, assessment should be in place in order to understand how to proceed with RJ in all cases and assist in determining what measures need to be in place to ensure a safe and healing process for all stakeholders.

Another point to think about is that the core RJ values of healing and relationships are not specifically about either reconciling or rupturing these relationships - only healing them. This may mean reconciliation or rupture but that is not the primary focus. The focus is on the individuals in the relationship rather than what form that relationship takes. As stated in the results section, a misconception regarding RJ and IPV is that it is all about keeping the couples together. A point to consider is that justice is not "a detached exercise involving breaches of law, judgment and punishment. It embraces the whole fabric of social relationships and inter-relationships - individuals, families, communities, nations [and] is about us living with one another and nourishing and supporting the individual and social wellbeing of all people" (Workman, 2012a, p. 8). Therefore, when thinking about this relationship and the individuals who were affected by the IPV, it is important to not only think about the victim-survivor, but also the other stakeholders in order to create a broader picture of healing that will support the victim-survivor and offender in their process of restoration.

\section{Translating RJ principles and MOJ guidelines in practice: Flashpoints}

\section{Risk management vs. healing of harm}

The focus of this research was on understanding IPV offender assessment of readiness and suitability to participate in RJ. Since the release of FV RJ standards by the Ministry of Justice in 2013 (MOJ, 2013), a lot of the assessment has been, in theory, driven by these guidelines. The guidelines were established to supplement the original principles of best practice for restorative justice in criminal cases that were first published in 2004 (MOJ, 2004) by adding "additional safeguards [that] are necessary when dealing with harm which has had complex or chronic impacts such as family or sexual violence" (MOJ, 2013, p. 4). It became apparent throughout the interviews, that the assessments were very much focused on whether or not it was safe to proceed to conference and not necessarily about the healing of harm although these ideas are closely intertwined when working in the area of IPV. The focus was 
on safety in terms of recidivism risk and re-traumatization during and following the RJ process - so in a way, while thinking about the risk of further harm, assessors are also asking whether the conditions are conducive to healing because in the absence of threat, there may be greater potential for healing to occur.

This raises the question of whether healing of harm and risk management are both actually the main goals for RJ in IPV cases. Safety of stakeholders is a core value of RJ and present and future safety are key issues when dealing with IPV cases and is often an area that is focused on when it is said that RJ is not appropriate for IPV cases. Keeping this in mind, it is perhaps understandable, reasonable, and necessary that in both policy and in the interviews, risk assessment was a focal point. It seems that in this context, being exclusively about healing harm would be naïve and potentially harmful for the stakeholders. However, it is also easy to get drawn into focusing on reducing recidivism when thinking about RJ for IPV, and that would be straying too far from the traditional RJ values and moving too close to a traditional criminal justice perspective. This will be discussed in further depth shortly.

\section{Pre-conference treatment vs. post-conference treatment vs. readiness}

Along these lines of safety, in the service design section of the RJ Standards for FV Cases (MOJ, 2013) there is mention that "the quality of the assessment and intervention [my emphasis] pre-conferencing will mitigate risk for all parties and largely determine the potential for safe effective conferencing and successful outcomes" (p. 25). This states that one of the factors that can reduce conference and post-conference risk is intervention - can we assume this refers to treatment programmes? If this is the case, this is a point of tension for many of the interviewees because due to RJ timing (pre-sentencing) and time restraints, treatment often occurs post-conference which frustrated many of the interviewees and individuals at the RJ and FV conference (Family Violence, Restorative Justice and the Law Conference, 2015). They all expressed the viewpoint that this meant that many offenders and victim-survivors were either under prepared for an effective conference or were assessed as inappropriate without having had the chance to change or address issues. If this assessment occurs prior to any treatment program, how many offenders, at this point, would be considered "ready" - and then what happens? Does this mean that they miss out on the opportunity to participate in the RJ process if not assessed as ready? Instead, should this assessment occur in order to determine which intervention would be useful and then have procedures in place to deal with each stage of readiness, stage of change, and motivation (Prochaska, DiClemente, \& Norcross, 1992)? Then, the conference could occur after the offender and/or the victim-survivor have attended treatment programmes. Many interviewees 
expressed concern that to not have pre-conference treatment meant that there would be cases that could have benefited from RJ, however they were not assessed as safe to proceed because assessment, in a sense, was occurring too early in the process. However, as previously mentioned, there are constraints such as time and resource pressures that some interviewees mentioned might make this model unrealistic. However, it was also said to be the ideal and would be the best way to effectively utilize RJ, and provide the best possible service for all stakeholders.

\section{Punishment vs. rehabilitation/dualism of courts}

Within this greyness, there was also concern expressed by some individuals about whether RJ in IPV cases adequately addressed the punishment that was thought, by some, to be warranted as a result of the particular offence. A question to be considered is whether there is a way that an offender can be held accountable for their behaviours while also supporting the needs of the victim-survivor, the community and the offender, in order to allow for positive reintegration process and restoration. Something else to consider is that a lot of the criticism aimed at the conventional criminal justice system by restorative justice supporters appears to have an underlying assumption that the conventional criminal justice system should be restorative (of relationships) and it is failing to do so. In the past, the aim of the conventional criminal justice system appeared to be more risk management and retribution focused, with increasingly more attention on rehabilitation and positive reintegration (which is still focused on reducing the risk to the community) - however the underlying aim does not appear to be that of restoration of relationships that were damaged as a result of offending. This tension between risk management and rehabilitation leads to the issue of dualism in the courts. The criminal justice courts are focused on state interests of risk management and reduced recidivism. However, with the introduction of RJ into legislation, this should, in theory, introduce a restorative, healing aspect to the courts, which some interviewees mentioned existed through therapeutic jurisprudence ${ }^{9}$.

RJ can be viewed from the perspective of the Police Adult Diversion Scheme (New Zealand Police, 2013), which includes RJ as a possible option in some cases. Diversion is an initiative that allows offenders who have been initially charged in court, to be dealt with outside of the courts. Within this scheme, an offender must complete conditions that were agreed upon such as apologizing to the victim, reparation, referral to a treatment of counselling program, community service, and/or a referral to RJ. As a result, the charges may

\footnotetext{
${ }^{9}$ See Wexler, D. (2006). Therapeutic jurisprudence. In A. Taylor, Justice as a basic human need (pp. 61-69). New York: Nova Science Publishers.
} 
be dismissed and the offence may not be recorded (New Zealand Police, 2013). However, DV is one of the offences that is rarely considered appropriate for diversion due to being considered "too serious an offence" (Morris \& Edwards, 2015) and in turn, several interviewees suggested that DV should not be considered appropriate for RJ referral for this reason. In a recent DV case in New Zealand where diversion was used, it was suggested that diversion should not have been appropriate for this case because it did not send a "clear message that domestic violence is not acceptable in our society" (Morris \& Edwards, 2015). This seems to imply that RJ is seen by some, as some kind of replacement for punishment and gives a 'soft' message so to speak. What is not talked about is how RJ is not about punishment, is not a replacement for punishment, and points to the tension that exists between punishment and restoration for IPV offences. It highlights the misperception that they are mutually exclusive concepts or approaches to dealing with IPV and the misinformation about RJ. Within other legislation outside of the Police adult diversion scheme (New Zealand Police, 2013), RJ is part of the court process - not instead of the court process. Therefore, punishment/imprisonment can occur regardless of whether RJ has occurred because RJ is not about replacing the court process (at this point in time), it is about healing relationships regardless of whether the offender will eventually be imprisoned or not.

\section{Where does RJ sit in relation to the traditional criminal justice system?}

This leads to the question - how does RJ sit within the traditional criminal justice system? The traditional system has a punishment and recidivism risk focus. It became apparent while going through the interviews that while many are afraid that the government involvement will adversely affect RJ, many interviewees were also placing a lot of the energy and attention into risk assessment. This is likely a reflection of the fact that this research was focused on IPV, where safety plays a much larger role than for other non-FV cases where contact between the offender and victim-survivor will most likely have been a one-off incident.

As was previously stated, it was very apparent across many of the interviews, that there was a fine line with RJ IPV cases, between the goal of repairing harm/healing, and the goal of preventing further harm from occurring and reducing recidivism. In theory, when looking for yellow or red flags, the RJ IPV assessor is trying to establish the risk in proceeding with the conference. In other instances, it was a case of looking for the skills that the offender and victim-survivor might have in order to promote healing, but for the most part, when assessing suitability and readiness, it was found that assessors were looking for reasons not to proceed. It not only appeared that a lot of the assessment was focused on risk 
management, but the question arose whether there was also an underlying thread that suggested that there was a goal of reducing recidivism - aligning with the traditional criminal justice perspective. For example, it was said that untreated A\&D issues might be an indication of unsuitability because without treating them, offenders may not be able to engage properly but also by treating A\&D, the offending might stop. However, this was not overtly what was said to be the point of RJ - RJ was said to be about healing harm. Many suggested that reduced recidivism was not the goal but was a secondary gain of the process. It is also important to consider that since funding comes from the government, and RJ for FV is now a government legislated process, RJ may have become forced to be viewed with the lens of traditional criminal justice's measure of success - reduced recidivism.

Nonetheless, in the case of IPV, the primary goals seem to be to heal harm and for the abuse to stop - but again, is the second goal the job of the RJ conference? However, in the case of IPV, is it possible to separate the two goals? Is it possible to heal past or present harm while not also focusing on prevention of future harm? Where is the line drawn? This again illustrates the problem with understanding the lens in which RJ for IPV is viewed - as a framework of justice, or as an intervention. So what place does RJ for IPV sit within traditional system? Is it meant to sit within the system, along side, or is it viewed as a framework of justice that should be the overarching perspective of our justice system? There appears to be some tension around this issue because the government has released standards and guidelines for FV RJ cases (MOJ, 2013) - which would lead us to view RJ as something that is to sit within the traditional system. However, there appear to be different underlying aims (i.e. healing versus risk management and reduced recidivism). RJ is part of the criminal justice process, which runs the risk that $\mathrm{RJ}$ is evaluated with the same measuring stick as the traditional system - punishment and reduced recidivism rates. However, the intention behind holding offenders accountable in the RJ process is to achieve reparation of the relationships and the individuals, rather than to cause suffering (Ward \& Salmon, 2009). Part of the reparation of the relationships is a commitment to makes steps to "prevent further abuse" (MOJ, 2013, p. 24) which would reduce recidivism rates, but within traditional RJ literature, the point is less about reducing recidivism rates and more about promoting healing. However, if trying to sit RJ within a traditional system there is a risk that the focus becomes more about risk assessment and recidivism reduction rather than healing. The distinction between RJ and the formal criminal justice system rests in whether the aim is to repair or to punish. When looking at the relationship between RJ and the theories of punishment in the traditional criminal justice system, $\mathrm{RJ}$ appears to theoretically fit into a communication theory of 
punishment. As previously stated, the communication theory justifies punishment as a way for society to communicate censure and the primary aims are that the offender acknowledges wrongdoing, can understand why it was wrong, and can understand the impact of offending on the victim (Duff, 2003). However, clarifying the relationship between the theories of criminal justice and $\mathrm{RJ}$ is not that straightforward and appears to be confused in practice in a number of ways. Some felt RJ was a "soft" option, which implies a retribution perspective of RJ where the offending violated the law and the offender should be adequately and appropriately punished (Ward, 2009). In other ways, it appeared that by requiring reduced recidivism rates, a consequential perspective of $\mathrm{RJ}$ was being taken in the hopes that it should prevent future offending (Ward, 2009). So is RJ in NZ a reflection of a combined theory of justice? Not exactly, because assessors are looking for evidence of a more internalized desire to be accountable rather than a way to either avoid punishment or as a way to pay for offending - which implies a communication theory despite in practice, interviewees indicating that many offenders are involved in RJ in order to get a reduced sentence. However, perhaps from an RJ perspective, the idea is to transform the criminal justice system by reorienting [its] goals away from retributive and towards restorative ones" (Zernova \& Wright, 2007, p. 93). Again, in a sense, if working from a restorative framework, is there a need for assessing suitability at all? Should anyone be excluded? Perhaps assessment, from an RJ perspective should be asking the question how do we make a case safe to proceed, rather then assessing how to assess whether to exclude a case or not.

\section{Siloing}

Another area that was emphasized not only throughout the interviews but during the recent FV RJ conference that was held in Wellington (Family Violence, Restorative Justice and the Law Conference, 2015) and the recent publication, The Way Forward (Herbert \& Mackenzie, 2014) was the problem of siloing and a need for a more integrated system. Within the policy there was only a brief mention of this integration for IPV cases stating that RJ providers that are wanting to accept IPV referrals must have "established links with local community FV and sexual offending specialist agencies" (MOJ, 2013, p. 26). However, an issue that was repeatedly emphasized throughout the interviews was the fact that this link was often fraught with misunderstanding and tension due to lack of resources, funding and information. Analysis of the interviews illuminated an interesting trend which was that there were a few pockets of RJ around New Zealand, in smaller, familiar courts/areas, where there was support from judges, police, and the community for RJ and IPV. This seemed to contribute to the process running more smoothly and cohesively because RJ was not only 
better supported, but individuals were more accurately informed about the merits of RJ for IPV. In these communities there was more of an alliance between agencies and individuals regarding RJ and IPV rather than at odds with each other or running parallel, which seems to be the case in many other parts of New Zealand.

\section{Funding and measures of success}

Funding and lack of resources were issues that were consistently raised throughout the interviews as a factor that not only contributed to siloing, but to under resourced agencies and low numbers of suitably trained RJ FV facilitators. This is echoed in the literature as well:

Another impediment is that successive governments have restricted the amount of funding available for restorative justice. This is frustrating, because reduced reoffending rates, and reduced use of imprisonment in restorative justice cases, make the economics compelling. In New Zealand, [there seems to be] an unholy alliance between the media and most politicians promot[ing] the illusion that punitive reactions promote community safety - despite all the evidence to the contrary (Workman, 2012b, p. 20).

Interestingly, this quote again reflects that grey line between the measurement of success used by the traditional criminal justice system and the measures of RJ success. In order for RJ to receive more funding, it is thought that there needs to be evidence of success - which is considered to be reduced recidivism rates from the traditional criminal justice perspective. However, as one interviewee mentioned, the success of RJ if often measured in happiness, which is not an outcome that necessarily attracts government funding or eases the mind of the safety conscious/risk averse community. So the question remains - how to measure the success of RJ in terms that are both true to the values of RJ and understandable and valuable within the traditional criminal justice system and community concern.

\section{Findings for facilitators that differ or clarify policy}

A concern that was expressed across most of the interviewees was a lack of adequately trained IPV RJ facilitators. This includes a lack of faith in the skill level and knowledge of the existing facilitators, as well as an acknowledgement that more facilitators were needed to handle the increased influx of IPV cases that will potentially be referred for RJ assessment. These concerns then led to a reluctance to refer or utilize RJ. There were some criteria in the guidelines regarding "high-quality" facilitators (MOJ, 2013, p. 18). Throughout the interviews, there were several subthemes that emerged that either clarified points regarding facilitator traits mentioned in the policy or added additional points that seemed to better 
define what was meant by a "high-quality" facilitator. To begin with, rather than use the term "high-quality", a better term would be "effective" because these are qualities that allow an RJ IPV facilitator to do their job well - to make an accurate assessment and to run a preconference and conference in a way that best addresses the needs of the situation and the stakeholders. In other words, be effective.

The first criterion that many of the interviewees spoke of was that at least one of the facilitators should be MOJ accredited in RJ and/or DV. The "or" is in case there is more than one facilitator present, in which case, as long as each person has at least RJ and the other has FV accreditation, then it is good practice. The MOJ requires that all RJ facilitators need to either be RJ accredited or working towards their accreditation (MOJ, 2013b), though it is unclear if FV accreditation is explicitly required by the MOJ at this point. On the MOJ website page on specialist services for family violence cases (MOJ, 2013c) it states that "specialist RJ facilitators for FV cases are now available and facilitators are accredited by the MOJ and work to new FV practice standards", however, it is unclear if this means that they are accredited in FV or just in RJ and are aware of the standards, or whether this accreditation is required. Regardless, there was tension around the issue of FV accreditation because though it was felt that this would help to standardize practice requirements across the country, and in theory, make for more informed, safer practice, it was noted that since FV was only a "paper accreditation", it was not very robust, rigorous or consistent.

This opens up the challenging question of how knowledge is assessed. In the policy it is stated that facilitators need to have an "understanding of the criminal justice system and RJ processes, and of victim and offender issues" (MOJ, 2013, p. 19). In terms of RJ knowledge, it was acknowledged throughout the interviews that the $\mathrm{RJ}$ accreditation is a rigorous process - therefore one could assume that this is an area that could be assessed with some confidence. However, the FV accreditation does not promote as much confidence across the interviewees. As was previously mentioned, the requirement for FV accreditation is less clear than the RJ accreditation, and the agency that currently holds the contract for accreditation (www.resolution.institute), mentions that rather than an being an "accreditation", FV facilitator training at this point should be considered more of an "endorsement". This endorsement is meant to be a reflection of FV experience, though it was felt by some that rather than assessing actual practice, it only assessed how well you could fill out an application or how long you have worked in are area - more about quantity than quality.

There were a number of points from this section of the policy that were elaborated on/clarified in Component 2. Many were discussed in the results section, but there are a few 
that are particularly noteworthy. Self-awareness was mentioned in the guidelines in terms of identifying if RJ facilitators are being impartial and a way to critique their own performance. In Component 2 it was found that this awareness should also include an understanding of any expectations of the RJ process the facilitator may have, and limitations in terms of their skill set and experience, culture, and personal history. This awareness also includes an awareness of process - whether the process is being run with integrity and true to the values of RJ and whether the process or facilitator and the offender are a "good fit". This involves having an understanding of the limitations pre-intervention that may be present for the offender or victim-survivor and the courage to stop a conference if and when it becomes apparent that it is not appropriate to continue, to admit a mistake has been made, to take a chance on a risky IPV case, and the courage to learn from mistakes.

Policy mentions there should be highly developed communications skills that encourage communication between individuals from different classes, genders, and cultures (MOJ, 2013). Component 2 uncovered deeper levels of understanding that were necessary and skills that were used to make an effective assessment process. To begin with, because RJ is considered relational, it was stressed by all interviewees how important rapport building was. As policy stated, personal qualities such as honesty, openness, accountability, integrity and respect for [all] people" (MOJ, 2013, p. 19) contribute to an effective facilitator. Additionally it was found that being genuine was also important to this rapport building - in a sense if a facilitator is expecting stakeholders to be honest and genuine, then the facilitator needs to model this behaviour.

A particular quality that was emphasized throughout was that rather than inputting ideas or expectations, the facilitator had the ability to listen to not only what was said (content, persistence, consistency), but also how it was said (emotion, behaviours). In conjunction with listening, observation was said to be utilized in order to add more information to the picture - looking at demeanour, body language, and ability to contain emotion/or not. However, it was noted that assumptions should not be made and questioning should occur in order to understand what is really being observed.

Asking challenging questions was also said to be used in order to find deeper meanings, confirm stories or challenge beliefs. It was said that meaning/truth should not simply be taken for surface value, however, others noted that in some ways, there is a sense of having to take a leap of faith on some levels and trust what is being said (i.e. using a gut feelings). It was stressed by many of the interviewees that there is a balance between 
listening, observing, challenging, and gut feelings that are used throughout the assessment period to ascertain suitability.

A point that became apparent throughout the interviews was that RJ assessors needed to be able to think broadly when collecting information on the offender and other stakeholders, as the information that is supplied by the courts is often lacking. This means gathering information from offenders (i.e. historical offending, mental health, physical health, A\&D issues, context of offending, cultural norms), victim-survivors, support people, church groups, IPV agencies, community groups, police, or anyone else who has had contact with the offender. The effective facilitator not only understands how/where to collect information, but understand how to interpret what they gather. Additionally, it was important to remember that the point is to prepare and empower the offender to speak for himself rather than coaching him or prompting him throughout the conference.

Policy discusses the importance of a facilitator to be able to work with diversity and have an understanding of local cultures and communities. To expand on this, it was found that having a tailored approach that was responsive to individual and group needs was crucial. This not only included stakeholder culture and community, but also their abilities, goals, context of offending, and safety issues. As was noted in the policy, these goals need to be assessed as reasonable and fair. Additionally, culture was said to be a holistic issue and should address physical health, mental health, spiritual health, cognitions, life experience, attitudes, criminal history, context of offending, social norms, and the community. Particularly relevant to the New Zealand bi-cultural context, was an acknowledgement that knowledge of ti kanga was important in order to be responsive to Maori stakeholders. What was also alluded to was that whatever race, religion, culture, gender, or sexual orientation was being worked with, the RJ facilitator should endeavour to understood them on some level and provide/acquire support if necessary (e.g. translator familiar with RJ jargon, religious elder).

What was rather interesting was the idea that "like should work with like" that was expressed by a few of the Maori interviewees. This seemed to be in order to provide the support and understanding that was just discussed, however, it came across as rather exclusive in some ways and was also not a very realistic perspective at this point because there is an imbalance in numbers of Pacific Island and Maori offenders (high) and Maori and Pacific Island RJ IPV facilitators (low). Additionally, another interesting point that started to surface was a suggested power imbalance that occurred between Maori elder facilitators and younger offenders. In a sense, it was suggested that the use of an older Maori facilitator might work because of the respect that is culturally emphasized between youth and older Maori because 
they carry a different mana or status. However, something to ponder is whether this could be dangerous if not carefully watched. Could this just reinforce the concept that it is ok for there to be a power imbalance between people? Secondly, if an elder is a support person, is it possible that this power may just be perpetuating the violence cycle rather than being a respectful position that is not abusive? However, I am aware, as a researcher coming from a different culture, that this point of view may be highlighting the fact that I come from a more individualistic background and am unaccustomed to the hierarchal nature of other cultures.

Another effective facilitator quality that was discussed throughout the interviews that is closely related to skill and knowledge set was the ability to create a safe environment referring to both physical and emotional safety. The interviews teased out a more in depth description of safety than was presented in policy. For example, safety was illustrated through a variety of perspectives such as understanding cultural protocols can create a safe environment, and conversely a facilitator thinking that a short course in cultural awareness gives him/her the understanding of an expert can be dangerous. Creating a safe environment also encourages meaningful conversation and communication by creating space, time, and support for the stakeholders and reducing the risk of further harm. Implied within the concept of the ability to create a safe environment was that an effective facilitator must also be a risk assessment expert. This includes understanding not only the immediate and future risk of harm but also who may need to be referred to externally in terms of support agencies or therapeutic interventions, whether the case is outside of their (the facilitator's) skill set, and who might be better suited for the case. Considering that there is no risk assessment tool used (other than the ODARA ${ }^{10}$ used by the police - which was considered imperfect), it seems as if it is a rather ill defined practice to be a risk assessment expert without a risk assessment tool or guideline. However, as will be discussed in the next section, risk assessment is usually a job associated with criminal behaviour rather than thinking about restoration - though safety is a value of $\mathrm{RJ}$; can it be taken too far or become too prohibitive? It became apparent from the interviews that there was a pervasive perspective reflecting the value of healing harm that is central to RJ rather than only focusing on reduced recidivism. Within that perspective was the desire to prevent further harm (i.e. risk assessment experts), which could easily start sliding into a risk management approach to RJ rather than a healing approach. However, within the context of IPV, it would be very difficult and potentially dangerous to think that they should be mutually exclusive, so the challenge comes in understanding how to balance

${ }^{10}$ Ontario Domestic Assault Risk Assessment (Waypoint Centre for Mental Health Care, 2016) 
those to perspectives within a clear framework of justice (which is not very clear at this point).

\section{Findings regarding assessment that differ from or clarify policy}

As discussed in the results section, this particular area was found to be somewhat lacking in clarity in the policy, and was further clarified through analysis of the interviews. The major findings and differences have already been discussed in the results section and are not necessary to repeat here. However, there are some important issues that should be discussed at this point.

The first finding was that IPV cases that are adjourned for RJ assessment are through the criminal courts and are therefore based on the offence that occurred - rather than a request by the victim-survivor. Therefore they are in some ways initially offender driven. This is important to think about because policy states that cases are victim-survivor driven, which is true of the actual conference, but not of the initial referral. The idea that a case is only referred because it has come through the criminal court, and therefore is referred because of the offender being charged, brings up the question of whether the system neglects the needs of the IPV victim-survivor whose case is not taken to court? What about the cases where an offender is in court for a particular offence, but there are past victim-survivors who are not part of this particular case who need/want healing? What about their healing? If cases are only suitable for RJ if the offender pleads guilty (as per legislation) or charges are placed, does that not put the offender in a place of power again?

The pre-conference portion of the RJ for FV guidelines (MOJ, 2013) comes from a very "green flag" perspective for the most part. It speaks of what the offender should do in order to be considered appropriate such as have a capacity and readiness to give a meaningful apology, maturity, understand his impact on the victim-survivor, have empathy for the victim, express remorse, and have insight into his behaviour (MOJ, 2013). However, as mentioned, what is not discussed is how this is understood and also what would be some of the disqualifying characteristics and traits? There is a lot of ambiguity in the policy - for example, how does one assess maturity or genuine remorse? This was a focus of study 2 and many interesting findings were discovered.

Component 2 uncovered a number of yellow (take caution) and red (stop) flags that helped to clarify what let RJ assessors understand what might be an indication that an IPV offender was inappropriate for RJ due to a number of reasons but most were indicators that it would be too risky to proceed or that unchanging behaviour (i.e. violence) indicated unchangeable attitudes/behaviours. The first thing to consider is whether these behaviours are 
considered unchangeable or unchanging? This may seem like a fine line, but actually, there is a large point of difference in terms of perspective and treatment. How would someone know that an offender's behaviour is unchangeable? Unchangeable suggests that regardless of what intervention is done, or path of justice, behaviours will not change. However, unchanging suggests that perhaps something new could be done that may affect behaviour and cognitions. It was suggested by many interviewees, if the violence had historically been dealt with in the same way in the past, it might be an indication that it is time to try a different approach or to consider what treatment has or could occur to facilitate change. Perhaps repeat offending more illustrates that a new approach is needed rather than evidence that "nothing will change him."

This again highlights the treatment versus framework cloudiness that exists within RJ because thinking that "something new" should be tried indicates that RJ is not an overall framework in which to think about justice and could easily slip into the treatment perspective. The fact that the distinction exists and is a point of tension raises the question again about the focus of RJ and whether RJ is becoming another intervention in which to address IPV.

The issue of thinking about historical violence also ties in closely to the discussion regarding episodes and incidents. As discussed earlier, the traditional system presents cases in as incidents. However, in the case of IPV, it was found that it is far more episodic - the present offence is most often a single event in a much longer story. When thinking about a case that is adjourned for assessment, the only way to fully understand the offence and the offender, is to look at the full picture of offending and to determine whether the behaviour and cognitions are not only unchanging but unchangeable. Though the question still remains is that the job/goal of RJ? Is RJ an intervention that is meant to change behaviour or cognitions or is it about healing - and are these concepts mutually exclusive?

A reduction in sentence was mentioned as a driving force for many of the IPV offenders expressing interest in RJ. The question raised was whether this should disqualify someone or was an indication of the "wrong" motives for attending RJ. Most indicated that after taking into consideration other factors such as offender cognitions, behaviours, characteristics and traits, this motivation, in its self would not be a red flag. In fact, some felt that just getting someone "in the door" so to speak would help facilitate a change - it does not necessarily matter why they are there (note the implied intervention perspective of change). Just a note, many interviewees did say that therapeutic change was not their specific intention, however it was often a secondary outcome. Additionally, many thought that RJ was more of a pathway to justice rather than a specific intervention. However, when an assessor is thinking 
about motivation, or red/yellow flags, does this not implicitly suggest that RJ is being considered an intervention where there are individuals who are more suited or ready than others?

Others noted that it was still important to think about the offender's stage of change and if they were in the "pre-contemplative stage" (Prochaska, DiClemente, \& Norcross, 1992), this was said to possibly indicate a red flag as the offender does not see their behaviour or cognitions as a problem and may not be at the point of being accountable. This is interesting because accountability is one of the core values of RJ and in the case of IPV this was emphasized as a crucial element during assessment of suitability for RJ. This all seems to be focused around risk management in the service of healing. Though many interviewees pointed out, if the victim-survivor is aware of the lack of accountability but is assessed as ready for conference and is well supported and wants to proceed, the conference may occur - if deemed safe. This aspect does seem to primarily focus on the value of healing rather than on risk or reduced recidivism. Perhaps all of these aspects are often in the mix and being considered, but which goal is the frontrunner determines which value is driving the process (ie. healing, risk management, reduced recidivism).

An additional point about victim-survivor healing; Though the victim-survivor was not directly the focus of analysis, it is important to reiterate that RJ for IPV is victim-survivor centred. A lot of the case suitability was based on the capabilities, needs, and desires of the victim-survivor, regardless of what the offender wanted or needed. It is important to note that in IPV cases, if the RJ facilitator were to assess the case as unsuitable, they have the final say - regardless of the victim-survivor or offender's wishes. This was said to ensure safety for all stakeholders. However, interestingly, it was also suggested by one interviewee that perhaps it is not up to the facilitator to determine whether the remorse is genuine. Perhaps it is only important that the victim-survivor believes the remorse is genuine, which allows them to experience healing. However, this was a point of tension for a number of reasons. First, the victim-survivors may be coerced into accepting any form of an apology from the offender, which further enforces the power imbalance that may already exist. Secondly, this addresses the deeper level question of the purpose of RJ for IPV. Is this strictly for the healing of harm or is the conference about protection and risk reduction as well? If the latter is the case, then accepting an obviously shallow presentation of remorse could be dangerous and could result in future harm.

This raises another interesting point of tension - the relational value of RJ. If one of the core values of $\mathrm{RJ}$ is that it is relational, it seems as if the power imbalance that is trying to 
be addressed is perhaps still somewhat imbalanced by focusing predominantly on the victimsurvivor. If all power is shifted to the victim-survivor, to the detriment of the offender and his needs, is this healing or is this punishment? It was suggested that RJ is about healing and empowerment (as previously mentioned, the term empowerment might also imply that a victim-survivor is being asked to stand strong without acknowledging the responsibility of others for support and safety, but this was discussed in another section so will not be addressed now). What does this empowerment look like and are all RJ IPV facilitators skilled enough to hold and direct this delicate balance in order for healing to occur and the offender to feel accountable and even shameful, but not feel stigmatized ${ }^{11}$. Harms are said to be healed, however it is important not to risk slipping into the retributive perspective of punishment when implementing RJ by using it as a forum to further punish the offender.

\section{Concluding comments}

It became clear that the assessment process is challenging and ill defined. Though there were trends and common threads across the interviews in terms of techniques for judgment, it became apparent that the bottom line is a rather subjective one due to the fact that gut feelings play such a central role in the process. Additionally, an integral part of the offender assessment of suitability is the assessment of the victim-survivor. Therefore, it is really a case assessment that should be done in a case-by-case fashion that is flexible, holistic and accommodating to individual factors. However, this leaves room for a lot of inconsistencies within practice and without a very stringent and rigorous FV facilitator/assessor accreditation and monitoring system, the great work of many experienced RJ IPV facilitators could be jeopardized. Due to the law changes, there is an increase in the number of IPV cases that are being adjourned for RJ assessment, and without the resources to up-skill existing RJ facilitators, or others who are experienced in IPV, there will be RJ facilitators who are unprepared to work in this area who are at risk of making mistakes, oversights, or being overly conservative because they are driven by fear, lack of knowledge, and inexperience.

Above and beyond these findings, the question regarding whether assessment for suitability was actually relevant in the RJ arena began to surface upon reflection and analysis. If $\mathrm{RJ}$ is considered a relational construct whose aim is to heal the harms that occurred as a result of a crime, then perhaps assessment should be more about ascertaining what practices, interventions, treatments, and safeguards are needed in order to proceed rather than assessing

\footnotetext{
${ }^{11}$ See Braithwaite (2010) for more information on reintegrative shaming and stigmatization
} 
if an IPV offender or a case is suitable for RJ. If RJ is to truly be viewed from the perspective of a 'healing of harms practice' (or framework), then it follows that the assessment should theoretically be to ascertain what is needed in order for the RJ process to occur in a safe and effective manner in order to achieve that goal of healing. By excluding anyone seems to run contrary to the core values of RJ. Safety is a core value in IPV, but is it possible that the fear of harm (a very valid concern) in IPV cases and the need to fit into the traditional criminal justice system's measure of success (reduced recidivism), has overridden all other core values? Perhaps there is a way to have a safe environment and allow all parties an opportunity to heal, repair, and be empowered. By finding an offender inappropriate, the system is not only depriving the offender of this opportunity, but also the victim-survivor and the community. In a sense - perhaps no one wins and the same system that historically has not worked will most likely continue to not work.

Though there are some changes in the mindset of the government, which are expressed by the legislative amendments that now integrate RJ into the court process for adults, it became clear that many RJ agencies across the country are still under-resourced and/or underskilled to handle this new influx of cases and to run safe and effective processes for IPV. Add to this the seemingly unclear lens in which RJ for IPV is viewed and implemented and we are left with many unanswered questions in terms of intervention/versus framework for justice, timing of other interventions, timing of RJ, whether the focus should be on healing, risk management, or both, and the position RJ is taking within the justice system.

The New Zealand government is said to be very progressive in its policies around RJ for IPV (and FV) and this research does not deny that claim. It does, however, acknowledge the need for clarification of intention, theory, and perspective in order to prevent a haphazard (and at times potentially dangerous) implementation of RJ for IPV. Further research, funding, education, and training in the area of RJ for IPV is needed in order to ensure effective and safe implementation of RJ consistently throughout the country, while acknowledging the core value of flexibility that is also inherent in RJ practice. As a country, New Zealand is stepping towards a criminal justice system that acknowledges the benefits of RJ for IPV, and it is crucial to not get lost trying to fit RJ for IPV within a traditional system that looks primarily at laws, punishment, and recidivism rates. It is imperative to think about RJ and IPV from not only a healing perspective, but also keeping the present and future safety of all stakeholders in mind. However, it is also important to not get lost by being so risk averse that justice forgets about the core intention of healing - Healing individuals and healing relationships. This is a 
chance to look at the people - the relationships, and look at justice through a new, clearer, restorative lens.

\section{Limitations}

The findings of this study must be considered in light of some limitations that exist. The sample was relatively small due to the level of detail and rich data that was collected, and an awareness that this level of analysis can realistically only occur with a smaller sample size (Smith \& Osborn, 2003). Additionally, due to difficultly with access, the variety of RJ IPV professionals sampled was not as diverse as would have been desired (both culturally, geographically, and professionally). Future studies would benefit form a broader range of participants. Due to this, there is not "empirical generalizability but the power of this type of study is judged by the light it sheds within [a] broader context" (Smith \& Osborn, 2003, p. 56). As stated earlier, this study aimed to open up the conversation around RJ and IPV and highlight gaps in policy in order to give voice to an area in the RJ process that has, up to this point, been virtually silent. 


\section{VICTORIA UNIVERSITY OF WELLINGTON \\ Te Whare Wānanga o te Ūpoko o te Ika a Māui}

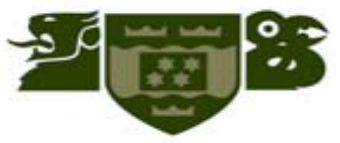

\section{Research: Assessing intimate partner violence offender suitability and readiness to participate in the process of restorative justice}

\section{Researcher:}

Melissa Garber, School of Psychology, Victoria University of Wellington

Email: Melissa.Garber@vuw.ac.nz

Ph: 0272005927

\section{Supervisor:}

Professor Tony Ward, Clinical Director, School of Psychology, Victoria University of Wellington

Email: Tony.Ward@vuw.ac.nz

Ph: (04) 4634724

Kia ora,

I am a PhD student at Victoria University School of Psychology in Wellington, doing research in the area of intimate partner violence and restorative justice. The focus of this research is the policy and practice of restorative justice (RJ) in the area of intimate partner violence (IPV). This research project has three major aims. The first is to identify the underlying practice assumptions and values evident in the New Zealand Ministry of Justice standards for restorative justice interventions with perpetrators and victims of intimate partner violence. The intention is to compare these assumptions and values with restorative justice international theory and practice. The second aim is to clarify the processes and criteria used to determine/assess intimate partner violence offender suitability and readiness for restorative justice interventions, and ascertain the ways in which these practices are theoretically justified. The third aim is to examine the way in which restorative justice 
practitioners implement these policies and procedures of assessment and readiness, and to see in which ways they explicitly follow RJ guidelines and theory-and why they make the choices they do.

I am inviting judges, lawyers, community advocates, and restorative justice facilitators who are involved in the RJ referral and facilitation process of IPV offenders to participate in this PhD research project. I will be conducting 45 minute-1 hour interviews in person or via Skype (or other internet based communication device) and they can occur at a time and place that is convenient to you. Interviews will be recorded and all material collected will be kept confidential, and only grouped responses will be presented in the final report. No other person besides me, my supervisor, Professor Tony Ward, and possibly a professional transcriber (who will sign a confidentiality agreement), will see the anonymous interview transcripts. Examples of potential questions are enclosed.

The thesis will be submitted for marking to the School of Psychology and deposited in the University library. The information collected in this study will be used only for research purposes, academic conferences, for publication in academic and/or professional journals.

If you are interested in knowing more about this research please return the reply slip which follows or contact me at Melissa.Garber@vuw.ac.nz, or on 0272005927.

Thank you for your time.

Kind regards,

Melissa Garber 


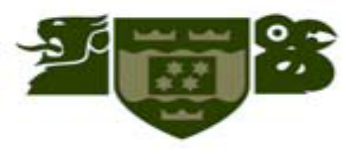

\section{Research: Assessing intimate partner violence offender suitability and readiness to participate in the process of restorative justice}

\section{Researcher:}

Melissa Garber, School of Psychology, Victoria University of Wellington

Email: Melissa.Garber@vuw.ac.nz

Ph: 0272005927

\section{Supervisor:}

Professor Tony Ward, Clinical Director, School of Psychology, Victoria University of Wellington

Email: Tony.Ward@vuw.ac.nz

Ph: (04) 4634724

\section{Reply Slip}

If you wish to take part in this study or learn more about it, please return this form to me via email or post (see contact details below). If you do not wish to take part there is no need to reply. If you express interest, I will be in touch with more information and to answer any questions you may have. This is not an official consent form, only a show of interest. You are free to withdrawal your interest at any point until September 30, 2014.

I am interested in taking part in this study and understand the researcher will be in contact with me with further information.

Name (please print):

Signature:

Best way to contact you: email:

Phone:

Skype:

Researcher details:

Melissa.Garber@vuw.ac.nz Ph: 0272005927

5 Mutu Rd., Paekakariki, 5034 


\section{VICTORIA UNIVERSITY OF WELLINGTON \\ Te Whare Wānanga o te Ūpoko o te Ika a Māui}

\section{Information sheet for research about assessing intimate partner violence offender suitability and readiness to participate in the process of restorative justice}

\section{Researcher:}

Melissa Garber, School of Psychology, Victoria University of Wellington

Email: Melissa.Garber@vuw.ac.nz

Ph: 0272005927

\section{Supervisor:}

Professor Tony Ward, Clinical Director, School of Psychology, Victoria University of Wellington Email: Tony.Ward@vuw.ac.nz

Ph: (04) 4634724

\section{What is the purpose of this research?}

- This research is about discovering the process and values associated with assessing intimate partner violence offender suitability and readiness to participate in the process of restorative justice.

Who is conducting the research?

- I am a PhD student and I am also undertaking a post-graduate diploma in Clinical Psychology at the School of Psychology at Victoria University of Wellington.

- This research has been approved by the School of Psychology Human Ethics Committee (SOPHEC) under delegated authority of VUW's Human Ethics Committee.

What is involved if you agree to participate?

- I will be conducting interviews with all participants.

- Interviews will occur either in person, the phone, or using Skype.

- Interviews will last for approximately 1 hour and will be recorded

- I may need to contact you once more for clarification after listening to the recording of the interview

- During this research, it is your right to refuse to answer any question, or to withdrawal from the study at any time before October 31, 2014. 


\section{Privacy and Confidentiality}

- Your consent forms and anonymised transcription of the interview will be kept for up to 20 years following publication in a locked file cabinet in a locked office of my supervisor, Professor Tony Ward, at Victoria University.

- You will never be identified in my research project or in any other publication or presentation. The transcripts will be coded by number and non identifying letter only.

- Your coded data may be used in other, related studies or shared with other competent researchers.

\section{What happens to the information that you provide?}

- The information collected in this study will be used only for research purposes, academic conferences, for publication in academic and/or professional journals.

- The overall findings will form part of my PhD thesis that will be submitted for assessment to the School of Psychology and be deposited in the University library.

\section{VICTORIA UNIVERSITY OF WELLINGTON Te Whare Wānanga o te Ūpoko o te Ika a Māui}

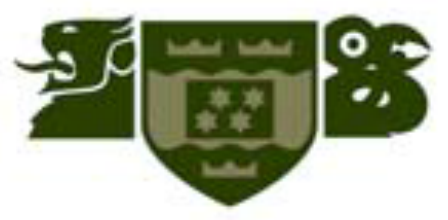

\section{CONSENT TO PARTICIPATE IN RESEARCH}

Title of project: Assessing intimate partner violence offender suitability and readiness to participate in the process of restorative justice

Researcher: Melissa Garber, School of Psychology, Victoria University of Wellington Email: Melissa.Garber@vuw.ac.nz

Ph: 0272005927

\section{Supervisor:}

Professor Tony Ward, Clinical Director, School of Psychology, Victoria University of Wellington Email: Tony.Ward@vuw.ac.nz

Ph: (04) 4634724 
The researcher has explained to me the purpose of the research and I have had the opportunity to ask questions and have them answered to my satisfaction. I understand that I may withdraw myself (or any information I have provided) from this project before October 31, 2015 without having to give reasons.

I understand that all information will be kept confidential by the researcher (Melissa Garber), the supervisor (Professor Tony Ward), and the person who transcribes the tape recordings of our interview. I understand that the information will be used only for research purposes, academic conferences, or for publication in academic and/or professional journals, that the published results will not use my name, and that no opinions will be attributed to me in any way that will identify me. I understand that the tape recording of interviews will be wiped at the end of the project and that anonymised transcripts of our interview will be kept for twenty years in a locked file in Professor Tony Ward's office at Victoria University.

I agree to participate in this research

Signature:

Name (Please print):

Date:

Please return this form to Melissa Garber at:

Melissa.Garber@vuw.ac.nz

Or

5 Mutu Rd

Paekakariki, 5034 New Zealand 


\section{APPENDIX B \\ SEMI STRUCTURED INTERVIEW FRAMEWORK}

\section{Semi-structured interview questions for RJ facilitators working with Intimate Partner Violence offenders}

1. In your opinion, what is Restorative Justice?

2. What values does RJ hold/ what do RJ programmes do that is different from the traditional criminal justice system?

3. How does RJ compare to the Maori model of intervention?

4. How does an offender come to you? (who refers?)

5. At what stage in the criminal justice process does the assessment occur for suitability to be involved in RJ? (ie. usually before sentencing?). How does the idea of a "right time" get addressed? Are you ever involved in post sentencing work?

6. How much of your work has involved IPV?

7. Are you accredited by the MOJ to work in RJ and family violence?

8. What types of IPV offences do you typically work with/come in contact with?

9. What are your expectations regarding RJ and offenders? What are the expectations you have of an offender's ability to participate in RJ?

10. What do you aim to achieve through the RJ process with and IPV offender?

11. What are the specific characteristics you look for in an offender that lets you know the offender is appropriate for participation in the RJ process? ... And lend to a more "successful outcome?"

12. How do you know this?

13. When assessing the suitability of an offender, what part does the victim and the whanau take?

14. Do you believe RJ would suit all IPV offenders? Why/why not?

15. What characteristics would make an offender unsuitable?

16. What place does risk assessment take? Do you consider your approach conservative or not?

17. HOW do you assess the suitability of IPV offenders to be involved in RJ? Specific guidelines used, specific assessment tools/measures 
18. How do you assess whether there is genuine remorse/apology,

19. empathy, and

20. offender insight?

21. How do you assess whether the offender is just "telling you what you want to hear?"

22. What is your sense/experience regarding offender expectations from involvement in RJ?

23. What are your thoughts about interventions before conferences? ...how does this influence your assessment?

24. Is the conference central or do you ever recommend that an IPV offender is referred to other programmes or services? If so, what is the reason for this and where to?

\section{Semi-structured interview questions: Judges, lawyers, police}

1. In your opinion, what is RJ? Values? Purpose?

2. How do you see RJ and the traditional criminal justice system - Overlapping? Different? Running parallel? One part of the other?

3. In what way are you involved in the referral process of IPV offenders to RJ programmes? At what point in the process are you?

4. How does an offender come to be referred to RJ? Do you suggest RJ to particular offenders, are they referred to you, or do they request involvement - or other means?

5. What are your expectations regarding RJ and offenders? What are the expectations you have of an offender's ability to participate in RJ?

6. What are the specific characteristics you look for in an offender that lets you know the offender is appropriate for participation in the RJ process? Do you look for different/other characteristics in a IPV case?

7. Do you believe that RJ is an appropriate option for IPV cases?

8. What do you aim to achieve through referral of an IPV offender to RJ?

9. How does this effect decision making/assessment regarding suitability of an offender?

10. In what way is a particular IPV offence (un)suitable for referral to RJ? (Or is it more individually based?)

11. How do you know this makes a (un)suitable/ready referral? Based on what? (research, gut, experience...) 
12. To what extent do you take into account the victim, the circumstances, the whanau etc...? The relationships...

13. HOW do you assess the suitability of IPV offenders to be involved in RJ? Specific guidelines used, specific assessment tools/measures

14. How do you assess whether there is genuine remorse/apology,

15. and offender insight/empathy?

16. How do you assess whether offender is telling you what you want to hear or if he/she is being genuine?

17. How does culture and ethnicity play a part in the referral process of IPV offenders to $\mathrm{RJ}$ ? 


\section{APPENDIX C}

SENTENCING AMENDMENT ACT (section 4) (The Parliament of New Zealand, 2014)

\section{Commencement}

This Act comes into force 6 months after the date on which it receives the Royal assent.

3 Principal Act amended

This Act amends the Sentencing Act 2002.

4 New section 24A inserted

The following section is inserted before section 25:

"24A Adjournment for restorative justice process in certain cases

“(1) This section applies if-

“(a) an offender appears before a District Court at any time before sentencing; and

"(b) the offender has pleaded guilty to the offence; and

"(c) there are 1 or more victims of the offence; and

“(d) no restorative justice process has previously occurred in relation to the offending; and

“(e) the Registrar has informed the court that an appropriate restorative justice process can be accessed.

“(2) The court must adjourn the proceedings to-

"(a) enable inquiries to be made by a suitable person to determine whether a restorative justice process is appropriate in the circumstances of the case, taking into account the wishes of the victims; and

“(b) enable a restorative justice process to occur if the inquiries made under paragraph (a) reveal that a restorative justice process is appropriate in the circumstances of the case."

5 Power of adjournment for inquiries as to suitable punishment

(1) Section 25(1)(b) is amended by omitting "occur" and substituting "occur, or to be completed".

(2) Section 25(2) is amended by omitting "section 10(4)" and substituting "section $10(4)$ or $24 \mathrm{~A}$ ". 


\section{APPENDIX D \\ DOMESTIC VIOLENCE ACT OF 1995 (Part 1 sections 3-4) (MOJ, 2014)}

3 Meaning of domestic violence

(1) In this Act, domestic violence, in relation to any person, means violence against that person by any other person with whom that person is, or has been, in a domestic relationship.

(2) In this section, violence means-

(a) physical abuse:

(b) sexual abuse:

(c) psychological abuse, including, but not limited to,-

14

(i) intimidation:

(ii) harassment:

(iii) damage to property:

(iv) threats of physical abuse, sexual abuse, or psychological abuse:

(iva) financial or economic abuse (for example, denying or limiting access to financial resources, or preventing or restricting employment opportunities or access to education):

(v) in relation to a child, abuse of the kind set out in subsection (3).

(3) Without limiting subsection (2)(c), a person psychologically abuses a child if that person-

(a) causes or allows the child to see or hear the physical, sexual, or psychological abuse of a person with whom the child has a domestic relationship; or

(b) puts the child, or allows the child to be put, at real risk of seeing or hearing that abuse occurring; -

but the person who suffers that abuse is not regarded, for the 
purposes of this subsection, as having caused or allowed the child to see or hear the abuse, or, as the case may be, as having put the child, or allowed the child to be put, at risk of seeing or hearing the abuse.

(4) Without limiting subsection (2),-

(a) a single act may amount to abuse for the purposes of that subsection:

(b) a number of acts that form part of a pattern of behaviour may amount to abuse for that purpose, even though some or all of those acts, when viewed in isolation, may appear to be minor or trivial.

(5) Behaviour may be psychological abuse for the purposes of subsection (2)(c) which does not involve actual or threatened physical or sexual abuse.

Section 3(2)(c)(iva): inserted, on 25 September 2013, by section 5 of the Domestic Violence Amendment Act 2013 (2013 No 77).

\section{$4 \quad$ Meaning of domestic relationship}

(1) For the purposes of this Act, a person is in a domestic relationship with another person if the person-
(a) is a spouse or partner of the other person; or
(b) is a family member of the other person; or
(c) ordinarily shares a household with the other person; or
(d) has a close personal relationship with the other person.

(2) For the purposes of subsection (1)(c), a person is not regarded as sharing a household with another person by reason only of the fact that-

(a) the person has-

(i) a landlord-tenant relationship; or 
(ii) an employer-employee relationship; or

(iii) an employee-employee relationshipwith that other person; and

(b) they occupy a common dwellinghouse (whether or not other people also occupy that dwellinghouse).

(3) For the purposes of subsection (1)(d), a person is not regarded as having a close personal relationship with another person by reason only of the fact that the person has-

(a) an employer-employee relationship; or

(b) an employee-employee relationshipwith that other person.

(4) Without limiting the matters to which a court may have regard in determining, for the purposes of subsection (1)(d), whether a person has a close personal relationship with another person, the court must have regard to-

(a) the nature and intensity of the relationship, and in particular-

(i) the amount of time the persons spend together:

(ii) the place or places where that time is ordinarily spent:

(iii) the manner in which that time is ordinarily spent; but it is not necessary for there to be a sexual relationship between the persons:

(b) the duration of the relationship.

Section 4(1)(a): amended, on 26 April 2005, by section 7 of the Relationships (Statutory References) Act 2005 (2005 No 3). 


\section{REFERENCES}

Abramson, L., Seligman, M., \& Teasdale, J. (1978). Learned helplessness in humans: Critique and reformulation. Journal of Abnormal Psychology, 87 (1), 49-74. http://dx.doi.org/10.1037/0021-843X.87.1.49

Ahmed, E., \& Braithwaite, J. (2005). Forgiveness, shaming, shame and bullying. Australian and New Zealand Journal of Criminology, 38 (3), 298-323. http://dx.doi.org/10.1375/acri.38.3.298

American heritage dictionary of the English language. (2011). American heritage dictionary of the English language (Vol. 5th edition). Houghton Mifflin Harcourt.

Andrews, D., \& Bonta, J. (2010). The psychology of criminal conduct. New Providence, NJ: Anderson Publishing.

Angel, C. (2005). Crime victims meet their offenders: Testing the impact of restorative justice conferences on victims' post-traumatic stress symptoms. University of Pennsylvania, Health Sciences. Dissertations available from ProQuest.

Applies Voices LLC. (2014). HT Professional Recorder (version 7.40) [Mobile application software]. Retrieved from Retrieved from http://itunes.apple.com

Archer, J. (2000a). Sex differences in aggression between heterosexual partners: a metaanalytic review. Psychological Bullitin, 126 (5), 651-680. doi: 10.1037MJ0332909.I26.5.651.

Archer, J. (2000b). Sex differences in physical aggression to partners: A reply to Frieze (2000), O'Leary (2000), and White, Smith, Koss, and Figueredo (2000). Psychological Bulletin, 126 (5), 697-702. doi: 10.1037//0033-2909.126.5.697.

Armstrong, J. (2012). Factors contributing to victims' satisfaction with restorative justice practice: A qualitative examination. British Journal of Community Justice, 10 (2), 3954.

Avolia, B., \& Hannah, S. (2008). Developmental readiness: Accelerating leader development. Consulting Psychology Journal: Practice and Research, 60 (4), 331-347. doi: 10.1037/1065-9293.60.4.331

Aziz, S. (2010). Should restorative justice be used for cases of domestic violence? International Journal of Restorative Justice, 16 (1), 1-49. 
Babcock, J., Green, C., \& Robie, C. (2004). Does batterers' treatment work? A meta-analysis of domestic violence treatment. Clinical Psychology Review, 23, 1023-1053.

Bailey, K. (2010). Lost in translation: Domestic violence, "the personal is political," and the criminal justice system. The Journal of Criminal Law \& Criminology, 1255-1301.

Barnett, G., \& Mann, R. (2013). Empathy deficits and sexual offending: A model of obstacles to empathy. Aggression and Violent Behavior, 18 (2), 228-239. http://dx.doi.org/10.1016/j.avb.2012.11.010

Batson, D., O'Quin, K., Fultz, J., Vanderplas, M., \& Isen, A. (1983). Influence of selfreported distress and empathy on egoistic versus altruistic motivation to help. Journal of Personality and Social Psychology, 45 (3), 706-718. http://dx.doi.org/10.1037/0022-3514.45.3.706

Bazemore, G. (1998). Restorative justice and earned redemption: Communities, victims and offender reintegration. American Behavioural Scientist, 41 (6), 768-813. http://dx.doi.org/10.1177/0002764298041006003

Bazemore, G., \& Earle, T. (2002). Balance in the response to family violence: Challenging restorative principles. In H. Strang, \& J. Braithwaite, Restorative justice and family violence (pp. 153-176). New York: Cambridge University Press.

Becroft, A., \& Thompson, R. (2006, August). Youth offending: Factors that contribute and how the system responds. Retrieved June 19, 2013, from Ministry of Justice: http://www.justice.govt.nz/courts/youth/publications-and-media/speeches/youthoffending-factors-that-contribute-and-how-the-system-responds

Bennett, C. (2008). The apology ritual: A philosophical theory of punishment. Cambridge, UK: Cambridge University Press. http://dx.doi.org/10.1017/CBO9780511487477

Berger, J. (2012). Changing on the job. Stanford, Ca: Stanford University Press.

Bibas, S., \& Bierschbach, R. (2004). Integrating remorse and apology into criminal procedure. The Yale Law Journal, 114 (1), 85-148. http://dx.doi.org/10.2307/4135717

Black, M., Basile, K., Breiding, M., Smith, S., Walters, M., Merrick, M., et al. (2011). The national intimate partner and sexual violence survey(NISVS): 2010 summary report. Atlanta: National Center for Injury Prevention and Control, Centers for Disease Control and Prevention.

Bograd, M., \& Mederos, F. (1999). Battering and couples therapy: Universal screening and selection of treatment modality. Journal of Marital and Family Therapy, 25 (3), 291312. http://dx.doi.org/10.1111/j.1752-0606.1999.tb00249.x 
Bowen, H., Boyack, J., \& Calder-Watson, J. (2011, September). Recent developments within restorative justice in Aotearoa/New Zealand. Retrieved June 19, 2013, from Restorative Justice Victim, Offender, Community: http://www.restorativejustice.org.nz/cms/BlogandNews/tabid/73/Default.aspx Braithwaite, J. (1989). Crime, shame, and reintegration. Cambridge: Cambridge University Press.

Braithwaite, J. (2003). Principles of restorative justice. In A. Von Hirsch, J. Roberts, A. Bottoms, K. Roach, \& M. Schiff, Restorative Justice and Criminal Justice: Competing or reconcilable paradigms? (pp. 1-20). Portland: Hart Publishing.

Braithwaite, J. (2007). Building legitimacy through restorative justice. In T. R. Tyler (Ed.), Legitimacy and Criminal Justice (pp. 146-162). New York: Russell Sage Foundation.

Braun, V. C. (2006). Using thematic analysis in psychology. Qualitative Research in Psychology, 3 (2), 77-101.

Brody, J. (1998, March 17). Science. Retrieved October 20, 2015, from The New York Times: http://www.nytimes.com/1998/03/17/science/battered-women-face-pit-bullsand-cobras.html?pagewanted=all

Charmaz, K. (1996). The search for meanings - Grounded theory. In J. Smith, R. Harre, \& L. Van Langenhove (Eds.), Rethinking Methods in Psychology (pp. 27-49). London: Sage Publications.

Charmaz, K., \& Bryant, A. (2008). Grounded Theory. In L. Given (Ed.), The SAGE Encyclopedia of Qualitative Research Methods (pp. 375-377). London: Sage. doi.org/10.4135/9781412963909.n189

Coker, D. (2002). Transformative justice: Anti-subordination processes in cases of domestic violence. In H. Strang, \& J. Braithwaite, Restorative justice and family violence (pp. 128-152). New York: Cambridge University Press.

Corlett, J. (2006). Forgiveness, apology, and retributive punishment. American Philosophical Quarterly , 43 (1), 25-42. http://dx.doi.org/10.1007/1-4020-4148-9_6

Corvo, K., Dutton, D., \& Chen, W. (2009). Do Duluth model interventions with perpetrators of domestic violence violate mental health professional ethics? Ethics \& Behaviour, 19 (4), 323-340. http://dx.doi.org/10.1080/10508420903035323

Creswell, J. (2013). Qualitative inquiry and research design: Choosing among five approaches. Los Angeles: Sage. 
Curtis-Fawley, S., \& Daly, K. (2005). Gendered violence and restorative justice: The views of victim advocates. Violence Against Women, 11, 603-638. doi: $10.1177 / 1077801205274488$

Day, A., Casey, S., Ward, T., Howells, K., \& Vess, J. (2010). Transitions to better lives: Offender readiness and rehabilitation. Devon: Willan Publishing.

Dennis, T. (2014). Time to tackle domestic violence: Identifying and supporting families. Community Practitioner , 87 (9), 29-32.

Department of Economic and Social Affairs/Division for the Advancement of Women (DAW/DESA). (2009). Handbook for legislation on violence against women. New York: United Nations.

Dixon, L., \& Graham-Kevan, N. (2010). Spouse abuse. In B. Fisher, \& S. Lab (Eds.), Encyclopaedia of victomology and crime prevention (pp 1-10).

Dixon, L., \& Graham-Kevan, N. (2011). Understanding the nature and etiology of intimate partner violence and implications for practice and policy. Clinical Psychology Review , 31, 1145-1155. http://dx.doi.org/10.1016/j.cpr.2011.07.001

DOJ\&CD. (2009). Truth \& Reconciliation Commission. Retrieved June 21, 2013, from Department of Justice and Constitutional Development, Republic of South Africa: http://www.justice.gov.za/trc/

Domestic Abuse Intervention Programmes. (2011). Wheel Gallery. Retrieved July 4, 2013, from domestic abuse intervention programmes (DAIP): http://www.theduluthmodel.org/training/wheels.html

Dow, B., \& Wood, J. (2006). The SAGE handbook of gender and communication. London: Sage.

Duff, R. (2001). Punishment, communication, and community. New York: Oxford Press.

Duff, R. (2003). Punishment. In H. LaFollette, The oxford handbook of practical ethics (pp. 331-357). Oxford: Oxford University Press.

Duff, R. (2011). Restorative punishment and punitive restoration. In M. Tonry, Why punish? how much? A reader on punishment (pp. 367-386). Oxford: Oxford Press.

Eccleston, L., \& Ward, T. (2006). Criminal justice and good lives. In A. Taylor, Justice as a basic human need (pp. 49-60). New York: Nova Science Publishers.

Eckhardt, C., Samper, R., \& Murphy, C. (2008). Anger disturbances among perpetrators of intimate partner violence, clinical characteristics and outcome of court-mandated treatment. Journal of Interpersonal Violence, 23 (11), 1600-1617. http://dx.doi.org/10.1177/0886260508314322 
Eckhardt, C., \& Schram, J. (2009). Cognitive behavioral interventions for partner-abusive men. In P. Lehmann, \& C. Simmons, Strengths-based batterer intervention. New York: Springer.

Elizabeth, V. (2003). Separating from violent male partners: A resistant act in the midst of power relations. Journal of International Women's Studies, 4 (3), 62-81.

Erickson, R., \& Hart, S. (1998). Domestic violence: Legal, practice, and educational issues. Medsurg Nursing , 7 (3), 142-147.

Esquivel-Santovena, E., \& Dixon, L. (2012). Investigating the true rate of physical intimate partner violence: A review of nationally representative surveys. Aggression and Violent Behavior , 17, 208-219. http://dx.doi.org/10.1016/j.avb.2012.02.002

Family Violence Death Review Committee. (2014). Fourth annual report: January 2013 to December 2013. Retrieved 2016, from Wellington, Health Quality and Safety Commission: http://www.hqsc.govt.nz/our-programmes/mrc/fvdrc/publications-andresources/publication/1600/

Family Violence, Restorative Justice and the Law Conference Day 1. (2015). Family Violence, Restorative Justice and the Law Conference. (pp. 1-30). Wellington: Victoria University School of Government.

Family Violence, Restorative Justice and the Law Conference. (2015). Family Violence, Restorative Justice and the Law Conference Day 2. Restorative Justice Conference (pp. 1-36). Wellington: Victoria University School of Government.

Fanslow, J., \& Robinson, E. (2010). Help-seeking behaviors and reasons for help seeking reported by a representative sample of women victims of intimate partner violence in New Zealand. Journal of Interpersonal Violence, 25 (5), 929-953. http://dx.doi.org/10.1177/0886260509336963

Feder, L., \& Dugan, L. (2002). A test of the efficacy of court-mandated counselling for domestic violence offenders: The Broward experiment. Justice Quarterly, 19 (2), 343-376.

Ferguson, K., \& Becroft, A. (2013). Family group conference. Retrieved February 24, 2016, from The youth court of New Zealand: http://www.justice.govt.nz/courts/youth/aboutthe-youth-court/family-group-conference\#footnotes

Fernandez, M. (2010). Restorative justice for domestic violence victims: An integrated approach to their hunger for healing. Plymouth, UK: Lexington Books.

Forrester, M. (2010). Doing Qualitative Research in Psychology: A Practical Guide. London: Sage. 
Frederick, L., \& Lizdas, K. (2010). The role of restorative justice in the battered women's movement. In J. Ptacek, Restorative justice and violence against women (pp. 39-59). Oxford: Oxford University Press.

Gavrielides, T., \& Artinopoulou, V. (2013). Restorative justice and violence against women: Comparing Greece and the United Kingdom. Asian Criminology, 8, 25-40. doi: $10.1007 / \mathrm{s} 11417-011-9123-\mathrm{x}$

Gerber, M., \& Jackson, J. (2013). Retribution as revenge and retribution as just deserts. Social Justice Research , 61-80. doi: 10.1007/s11211-012-0174-7

Glaze, L., \& Parks, E. (2012, November). Correctional Populations in the United States, 2011. Retrieved February 23, 2016, from Bureau of Justice Statistics: http://www.bjs.gov/index.cfm?ty=pbdetail\&iid $=4537$

Goodmark, L. (2015, October 15). Mandatory domestic violence prosecution may traumatize victims. Retrieved December 29, 2015, from The Baltimore Sun: http://www.baltimoresun.com/news/opinion/oped/bs-ed-dv-judge-20151017story.html

Gondolf, E. (2002). Batterer intervention systems: Issues, outcomes, and recommendations. London: Sage.

Gondolf, E. (2004). Evaluating batterer counselling programmes: A difficult task showing some effects and implications. Aggression and Violent Behavior, 9, 605-631. http://dx.doi.org/10.1016/j.avb.2003.06.001

Graham-Kevan, N., \& Archer, J. (2003). Intimate terrorism and common couple violence: A test of Johnson's predictions in four British samples. Journal of Interpersonal Violence , 18 (11), 1247-1270. http://dx.doi.org/10.1177/0886260503256656

Hamel, J. (2009). Toward and gender inclusive conception of intimate partner violence research and theory: Part 2 - New directions. International Journal of Men's Health , 8 (2), 41-59. http://dx.doi.org/10.3149/jmh.0801.41

Hartley, C., \& Ryan, R. (2002). Prosecution strategies in domestic violence felonies: Telling the story of domestic violence, executive summary. Rockville: National Criminal Justice Reference Services (NCJRS).

Hayden, A. (2010). Why rock the boat? Non-reporting of intimate partner violence. Auckland: Institute of Public Policy, AUT.

Hayden, A. (2012). Safety issues associated with using restorative justice for intimate partner violence. Women's Studies Journal, 26 (2), 4-16. 
Hayden, A. (2014). Reflections on family violence and restorative justice: Addressing the critique. In A. Hayden, L. Gelsthorpe, V. Kingi, \& A. Morris, A restorative approach to family violence (pp. 211-220). Farnham: Ashgate.

Hayden, A., Gelsthorpe, L., Kingi, V., \& Morris, A. (2014). A restorative approach to family violence: Changing tack. Farnham: Ashgate.

Held, V. (2006). The ethic of care: Personal, political and global. New York: Oxford University Press.

Henare, H., \& Hannifin, K. (2011). Cost of domestic violence. In G. Maxwell (Ed.), The costs of crime - Towards fiscal responsibility (pp. 75-79). Wellington: Institute of Policy Studies.

Herbert, R., \& Mackenzie, D. (2014). The way forward: An integrated system for intimate partner violence and child abuse and neglect in New Zealand. Wellington: The Impact Collective.

Herman, J. (2005). Justice from the victim's perspective. Violence Against Women, 11 (5), 571-602. http://dx.doi.org/10.1177/1077801205274450

Higgenbottom, G. (2004). Sampling issues in qualitative research. Nurse Researcher (through 2013), 12(1), 7-19. Retrieved from http://search.proquest.com.helicon.vuw.ac.nz/docview/200776754?accountid=14782.

Holtzworth-Munroe, A., \& Stuart, G. (1994). Typologies of male batters: Three subtypes and the differences among them. Psychological Bulletin , 116 (3), 476-497.

Holtzworth-Munroe, A., Meehan, J., Herron, K., Rehman, U., \& Stuart, G. (2000). Testing the Holtzworth-Munroe and Stuart (1994) batterer typology. Journal of Consulting and Clinical Psychology, 68 (6), 1000-1019.

Honderich, T. (2006). Punishment: The supposed justifications. London: Pluto Press.

Hooper, S., \& Busch, R. (1996). Domestic violence and restorative justice initiatives: The risks of a new panacea. Waikato Law Review, 4, 101-130.

Hudson, B. (2002). Restorative justice and gendered violence: diversion or effective justice? The British Journal of Criminology, 42 (3), 616-634. doi:10.1093/bjc/42.3.616

Institute for Economics and Peace (IEP). (2015). Global peace index 2015: Measuring peace, its causes, and its economic value. IEP.

Jackson, A. (2009). The impact of restorative justice on the development of guilt, shame, and empathy among participants in a victim impact training program. Victims \& Offenders: An International Journal of Evidence-based Research, Policy, and Practice, 4 (1), 1-24. http://dx.doi.org/10.1080/15564880801938185 
Jacobson, N., \& Gottman, J. (1998). When men batter women. New York: Simon \& Schuster. Johnson, M., \& Leone, J. (2005). The differential effects of intimate terrorism and situational couple violence: Findigs from the national violence against women survey. Journal of Family Issues, 26 (3), 322-349. doi: 10.1177/0192513X04270345.

Johnson, M. (2014). Distinguishing among types of intimate partner violence: Intimate terrorism, violent resistance, and situational couple violence. In M. Rinfret-Raynor, E. Lesieux, M. Cousineau, S. Gauthier, \& E. Harper (Eds.), Violence against women: Complex realities and new issues in a changing world (pp. 15-31). Quebec: Presses Universitaires de L'Universite du Quebec.

Johnson, S. (2007). Physical abusers and sexual offenders: Forensic and clinical strategies. Boca Raton: Taylor \& Francis.

Johnstone, G., \& Van Ness, D. (2007). Handbook of restorative justice. Devon: Willan Publishing.

Jülich, S. (2001). Breaking the silence: Restorative justice and child sexual abuse (PhD thesis). Albany: Massey University.

Jülich, S., Buttle, J., Cummins, C., \& Freeborn, E. (2010). Project restore: An exploratory study of restorative justice and sexual violence. Auckland: AUT University.

Justice Sector Strategy Group. (2009). New Zealand crime and safety survey (NZCASS). Wellington: Ministry of Justice.

Karmen, A. (2007). Crime victims. Belmont, CA: Thomson Wadsworth.

Kim, H., \& Gerber, J. (2010). Evaluating the process of a restorative justice conference: An examination of factors that lead to reintegrative shaming. Asia Pacific Journal of Police \& Criminal Studies, 8 (2), 1-20.

King, R., Mauer, M., \& Young, M. (2005). Incarceration and crime: A complex relationship. Washington, DC: The Sentencing Project.

Kingi, V., Paulin, J., \& Porima, L. (2008). Review of the delivery of restorative justice in family violence cases by providers funded by the ministry of justice. Victoria University, Crime and Justice Research Centre. Wellington: Ministry of Justice.

Kiro, C. (2009). Children, parenting and education: addressing the causes of offending. In G. Maxwell, Addressing the causes of offending: What is the evidence? (pp. 13-23). Wellington: Institute of Policy Studies.

Kitcher, P. (2010). Varieties of altruism. Economics and Philosophy, 26, 121-148. http://dx.doi.org/10.1017/S0266267110000167 
Koss, M., \& Achilles, M. (2008, February). Restorative justice responses to sexual assault. Retrieved June 28, 2013, from Applies Research Forum, National online resource center on violence against women: http://www.vawnet.org/Assoc_Files_VAWnet/AR_RestorativeJustice.pdf

Labriola, M., Rempel, M., \& Davis, R. (2005). Test the effectiveness of batterer programmes and judicial monitoring. Center for Court Innovation. New York: National Institute of Justice.

Laing, L., \& Humphreys, C. (2013). Social work \& domestic violence. London: Sage.

Landcare Research - Manaaki whenua. (2016). What is matauranga maori? Retrieved 21 , 2016, from Landcare Research:

http://www.landcareresearch.co.nz/about/sustainability/voices/mataurangamaori/what-is-matauranga-maori

Lang, S. (2002). Sulha Peacemaking and the politics of persuasion. Journal of Palestine Studies, 31 (3), 52-67. http://dx.doi.org/10.1525/jps.2002.31.3.52

Laroche, D. (2008). Context and consequences of domestic violence against men and women in Canada in 2014. Retrieved 02 1, 2016, from DesLibris: http://www.deslibris.ca/ID/252522

Lehmann, P., \& Simmons, C. (2009). Strengths-based batterer interventions. New York: Springer Publishing Company.

Lewis, R., Dobash, R., Dobash, R., \& Cavanagh, K. (2000). Protection, prevention, rehabilitation or justice? Women's use of the law to challenge domestic violence. International Review of Victimology, 7, 179-205. http://dx.doi.org/10.1177/026975800000700310

Lui, J. (2007). Social and historical contexts for restorative and retributive justice: Te ao po te ao marama (worlds of dark and light). In G. Maxwell, \& J. Lui, Restorative justice and practices in New Zealand (pp. 29-39). Wellington: Institute of Policy Studies.

MacDowell, E. (2011). When courts collide: Integrated domestic violence courts and court pluralism. Texas Journal of Women and the Law, 20 (2), 95-131.

Mahoney, M. (1991). Legal images of battered women: Redefining the issue of separation. Michigan Law Review , 90 (1), 1-94.

Mann, R., \& Barnett, G. (2012). Victim empathy intervention with sexual offenders: Rehabilitation, punishment, or correctional quackery? Sexual Abuse: A Journal of Research and Treatment, 25 (3), 282-301. 
Marks, D., \& Yardley, L. (Eds.). (2004). Research methods for clinical and health psychology. London: Sage.

Maxwell, G. (1994). Children and family violence: The unnoticed victims. Office of the Commissioner for Children. Wellington: Office of the Commissioner for Children.

Maxwell, G., \& Hayes, H. (2006). Restorative justice developments in the Pacific region: A comprehensive survey. Contemporary Justice Review, 9 (2), 127-154. http://dx.doi.org/10.1080/10282580600784929

Maxwell, G., \& Lui, J. (2007). Restorative justice and practices in New Zealand. Wellington: Institute of Policy Studies.

Maxwell, G., \& Morris, A. (2001). Restorative justice and reoffending. In H. Strang, \& J. Braithwaite (Eds.), Restorative Justice: Philosophy and Practice (pp. 93- 103). Burlington, VT: Ashgate Publishing.

McCold, P. (2000). Toward a holistic vision of restorative juvenile justice: A reply to the maximalist model. Contemporary Justice Review, 3, 357-414.

McCold, P. (2008). Protocols for evaluating restorative justice programmes. British Journal of Community Justice, 6.2, 9-28.

McMaster, K. (2012). Family violence series: Course 2. Retrieved October 19, 2015, from Pathways into violence: http://pwiv.weebly.com/uploads/1/0/5/4/10547270/learn_it__act_3_-_looking_deeper_into_pathways.pdf.

Mead, H., \& Grove, N. (2007). Nga pepeha a nga Tipuna: The sayings of the ancestors. Wellington: Victoria University Press.

Miller, W., \& Rollnick, S. (2002). Motivational interviewing preparing people for change. New York: The Guilford Press.

Millon, T., \& Grossman, S. (2006). MCMI-III. Retrieved 2013, from www.pearsonassessments.com: www.pearsonassessments.com

Ministry of Justice. (2011). Restorative justice best practice in New Zealand. Wellington: The Ministry of Justice.

Ministry of Justice. (2013). Restorative justice standards for family violence cases. Wellington: Ministry of Justice.

Ministry of Justice. (2013a, July). NZ Bill of Rights Act 1990, Section 26 Retroactive penalties and double jeopardy. Retrieved October 27, 2015, from Ministry of Justice: http://www.legislation.govt.nz/act/public/1990/0109/latest/DLM225528.html Ministry of Justice. (2013b). Restorative justice information for providers. Retrieved December 21, 2015, from Ministry of Justice: 
http://www.justice.govt.nz/policy/criminal-justice/restorative-justice/restorativejustice-information-for-providers.

Ministry of Justice. (2013c). Specialist services in restorative justice. Retrieved December 21, 2015, from http://www.justice.govt.nz/policy/criminal-justice/restorativejustice/specialist-services-in-restorative-justice

Ministry of Justice. (2014). Domestic Violence Act 1995. Wellington: The Ministry of Justice. Ministry of Justice. (2014a). New Zealand crime and safety survey (NZCASS). Wellington: The Ministry of Justice.

Ministry of Justice. (2015a). The district courts of New Zealand. Retrieved January 02, 2016, from Courts of New Zealand: https://www.courtsofnz.govt.nz/district/district/thejudges/judges

Ministry of Justice. (2015b). Sentencing Act 2002. Wellington: The Ministry of Justice.

Moffitt, T., \& Caspi, A. (2001). Childhood predictors differentiate life-course persistent and adolescence-limited antisocial pathways among males and females. Development and Psychopathology, 13, 355-375. http://dx.doi.org/10.1017/S0954579401002097

Moorfield, J. (2015). Maori dictionary. Retrieved October 20, 2015, from Te Aka online Maori dictionary: http://www.maoridictionary.co.nz

Morris, D., \& Edwards, J. (2015, October 30). The Dominion Post. Retrieved November 03, 2015, from Stuff.co.nz: http://www.stuff.co.nz/dominionpost/news/wellington/73533863/Wellington-law-firm-partner-slammed-after-gettingrare-diversion-for-kicking-wife

Murphy, C., \& Eckhardt, C. (2005). Treating the abusive partner: An individualized cognitive-behavioural approach. New York: Guilford.

National Collective of Independent Women's Refuges (NCIWR). (2013). The challenges of leaving an abuser. Retrieved 2013, from Women's Refuge: https://womensrefuge.org.nz/WR/Domestic-violence/Why-doesnt-she-leave.htm

NCH Software. (2014). Express Scribe v 5.50 Intel [Computer software]. Retrieved from http://nch.com.au/scribe/index.html.

New Zealand Ministry of Health. (2015, July). Maori health models- Te Whare Tapa Wha. Retrieved September 30, 2015, from Ministry of Health: http://www.health.govt.nz/our-work/populations/maori-health/maori-healthmodels/maori-health-models-te-whare-tapa-wha

New Zealand Police. (2013). Police adult diversion scheme. Wellington: New Zealand Government. 
Nikkel, R. (2011). Justice from the dark side. Conversatio Morum , 1-3.

Office of Women's Health, U.S. Department of Health and Human Services. (2015, September). Violence against women. Retrieved February 23, 2016, from Women's health.gov: http://womenshealth.gov/violence-against-women/types-ofviolence/domestic-intimate-partner-violence.html

Olson, L. (2002). Exploring "common couple violence" in heterosexual romantic relationships. Western Journal of Communication, 66, 104-128. http://dx.doi.org/10.1080/10570310209374727

Oxford Dictionaries Pro. (2013). Dictionary/thesaurus. Retrieved July 10, 2013, from Oxford Dictionaries Pro: http://www.english.oxforddictionaries.com.helicon.vuw.ac.nz/definition/justice

Oxford University Press. (2014). Dictionary. Retrieved May 14, 2014, from Oxford Dictionaries: http://www.oxforddictionaries.com

Oxley, J. (2011). The moral dimensions of empathy: Limits and applications in ethical theory and practice. London: Palgrave Macmillan. http://dx.doi.org/10.1057/9780230347809

Park, L., Jordan, D., \& Maner, J. (2011). Egoistic versus altruistic concerns in communal relationships. Journal of Social and Personal Relationships, 28 (3), 315-335. doi: http://dx.doi.org.helicon.vuw.ac.nz/10.1177/0265407510382178

Pence, E., \& Paymar, M. (1993). Education groups for men who batter: The Duluth model. New York: Springer.

Polaschek, D. (2006). Violent offender programmes: Concept, theory, and practice. In C. Hollin, \& E. Palmer, Offending behaviour programmes: Application and controversies (pp. 113-154). Chichester, England: John Wiley \& Sons Ltd. http://dx.doi.org/10.1002/9780470713341

Pranis, K. (2007). Restorative values. In G. Johnstone, \& D.Van Ness, Handbook of Restorative Justice (pp. 59-74). Devon: Willan Publishing.

Prison Fellowship International. (2009). Sycamore Tree Project. Retrieved June 24, 2013, from Prison Fellowship International, beyond crime and punishment: http://www.pfi.org/cjr/stp.

Prochaska, J., DiClemente, C., \& Norcross, J. (1992). In search of how people change. American Psychologist , 1102-1115. http://dx.doi.org/10.1037/0003-066X.47.9.1102

Ptacek, J. (2009). Restorative justice and violence against women. New York: Oxford University Press. http://dx.doi.org/10.1093/acprof:oso/9780195335484.001.0001 
Resolution Institute. (2016). Accreditation. Retrieved February 18, 2016, from Resolution Institute: http://www.resolution.institute/accreditation/rj

Sanders, M., Markie-Dadds, C., Tully, L., \& Bor, W. (2000). The triple p- positive parenting program: A comparison of enhanced standard, and self-directed behavioural family intervention for parents of children with early onset conduct problems. Journal of Consulting and Clinical Psychology, 4, 624-640. http://dx.doi.org/10.1037/0022006X.68.4.624

Saunders, D. (1992). A typology of men who batter: Three types derived from cluster analysis. American Journal of Orthopsychiatry , 62 (2), 264-276. http://dx.doi.org/10.1037/h0079333

Sawatsky, J. (2008). Justpeace ethics: A guide to restorative justice and peacebuilding. Eugene: Cascade Books.

Schacht, R., Dimidjian, S., George, W., \& Berns, S. (2009). Domestic violence assessment procedures among couple therapists. Journal of Marital and Family Therapy, 35 (1), 47-59. http://dx.doi.org/10.1111/j.1752-0606.2008.00095.x

Serin, R., Kennedy, S., Mailloux, D., \& Hanby, L. (2010). The origins of treatment readiness. In A. Day, S. Casey, T. Ward, K. Howells, \& J. Vess, Transitions to better lives: Offender readiness and rehabilitation (pp. 12-26). Devon: Willan Publishing.

Shapiro, A. (Producer), \& Shapiro, A. (Director). (1978). Scared Straight! [Motion Picture].

Shapland, J., Robinson, G., \& Sorsby, A. (2011). Restorative justice in practice-Evaluating what works for victims and offenders. New York: Routledge.

Sharpe, S. (2007). The idea of reparation. In G. Johnstone, \& D. Van Ness, Handbook of Restorative Justice (pp. 24-40). Devon: Willan Publishing.

Smith, N. (2008). I Was Wrong: The Meanings of Apologies. Cambridge: Cambridge University Press.

Smith, J., \& Osborn, M. (2003). Interpretative phenomenological analysis. In J. Smith (Ed.), Qualitative Psychology: A Practical Guide to Methods. London: Sage.

Smith, N. (2014). Justice through Apologies: Remorse, Reform, and Punishment. NY: Cambridge University Press. http://dx.doi.org/10.1017/CBO9780511843969

Smith, P., Goggin, C., \& Gendreau, P. (2002). The effects of prison sentences and intermediate sanctions of recidivism: General effects and individual differences. University of New Brunswick, Saint John, Psychology and Centre for Criminal Justice Studies. Canada: Public Works and Government Services. 
Stith, S., Smith, D., Penn, C., Ward, D., \& and Tritt, D. (2004). Intimate partner physical abuse perpetration and victimization risk factors: A meta-analytic review. Aggression and Violent Behavior, 10 (1), 65-98. doi:10.1016/j.avb.2003.09.001.

Strauss, A., \& Corbin, J. (1994). Grounded theory methodology: An overview. In N. Denzin, \& Y. Lincoln (Eds.), Handbook of qualitative research (pp. 273-286). London: Sage.

Stubbs, J. (2007). Beyond apology? Domestic violence and critical questions for restorative justice. Criminology \& Criminal Justice, 7 (2), 169-187. http://dx.doi.org/10.1177/1748895807075570

Taizi, S. (2007). Jirga System in Tribal Life. Peshawar: Area Study Centre (Russia, China and Central Asia).

Taylor, A. (2006). Doing Justice to Justice. In A.Taylor, Justice as a basic human need (pp. 1-12). New York: Nova Science Publishers.

ten Brinke, L., MacDonald, S., Porter, S., \& O'Connor, B. (2012). Crocodile tears: Facial, verbal and body language behaviours associated with genuine and fabricated remorse. Law and Human Behaviour, 36 (1), 51-59. doi: 10.1037/h0093950

The Courts Service Dublin. (2013). Brehon law. Retrieved May 11, 2013, from An tSeirbhis Chuirteanna Courts Service: http://www.courts.ie/Courts.ie/library3.nsf/pagecurrent/3CBAE4FE856E917B80256D F800494ED9

The National Collective of Independent Women's Refuges. (2015). The challenges of leaving an abuser. Retrieved 2015, from The National Collective of Independent Women's Refuges: https://womensrefuge.org.nz/WR/Domestic\%20violence/Why\%20doesnt\%20s he\%20leave.htm

The Parliament of New Zealand. (2014). Sentencing act amendment act 2014. Wellington: New Zealand Government.

Tifft, L. (2002). Crime and peace: A walk with Richard Quinney. Crime \& Delinquency, 48, 243-264. doi: 10.1177/0011287002048002004

Timmermans, S., \& Tavory, I. (2012). Theory construction in qualitative research: From grounded theory to abductive analysis. Sociological Theory, 30 (3), 167-186. doi: $10.1177 / 0735275112457914$

Tolman, C. (2006). Being human and the need for justice. In A. Taylor, Justice as a basic human need (pp. 13-23). New York: Nova Science Publishers. 
U.S. Attorney General's Task Force on Family Violence. (1998). Attorney General Mike Fisher's family violence task force: Final action plan, a coordinated, communitybased response to family violence. Harrisburg: U.S. Department of Justice.

Umbreit, M., \& Armour, J. (2010). Restorative justice dialogue. NY, NY: Springer Publishing Company.

United States Sentencing Commission. (2011). 2011 Federal Sentencing guidelines: Part E Acceptance of Responsibility. Retrieved May 14, 2014, from United States Sentencing Commission: http://www.ussc.gov/guidelines-manual/2011/2011-chapter3.

Walgrave, L. (2001). On restoration and punishment: Favourable similarities and fortunate differences. In A. Morris, \& G. Maxwell, Restorative Justice for Juveniles (pp. 1737). Portland: Hart Publishing.

Walker, C. (2004). Change readiness: A construct to explain health and life transitions. Journal of Theory Construction \& Testing, 26-34.

Walker, L. (2009). The battered woman syndrome. New York: Springer Publishing Company. Ward, T. (2009). Punishment and correctional practice: Ethical and clinical implications. In G. Maxwell, Addressing the causes of offending - What is the evidence? (pp. 219226). Wellington: Institute of Policy Studies Victoria University of Wellington.

Ward, T., \& Durrant, R. (2013). Altruism, empathy, and sex offender treatment. International Journal of Behavioural Consultation and Therapy, 1-50. http://dx.doi.org/10.1037/h0100986

Ward, T., \& Langlands, R. (2008). Restorative justice and the human rights of offenders: Convergences and divergences. Aggression and Violent Behavior, 13, 355-372. doi:10.1016/j.avb.2008.06.001.

Ward, T., \& Langlands, R. (2009). Repairing the rupture: Restorative justice and the rehabilitation of offenders. Aggression and Violent Behavior, 14, 205-214. http://dx.doi.org/10.1016/j.avb.2009.03.001

Ward, T., \& Laws, R. (2010). Desistance from sex offending: Motivating change, enriching practice. International Journal of Forensic Mental Health, 9 (1), 11-23. http://dx.doi.org/10.1080/14999011003791598

Ward, T., Mann, R., \& Gannon, T. (2007). The good lives model of offender rehabilitation: Clinical implications. Aggression and Violent Behavior, 12, 87-107. http://dx.doi.org/10.1016/j.avb.2006.03.004 
Ward, T., \& Salmon, K. (2009). The ethics of punishment: Implications for correctional practice. Aggression and Violent Behavior, 14, 239-247. http://dx.doi.org/10.1016/j.avb.2009.03.009

Ward, T., \& Salmon, K. (2011). The ethics of care and treatment of sex offenders. Sex Abuse, 23, 397-416. doi: 10.1177/1079063210382049

Waypoint Centre for Mental Health Care. (2016). ODARA. Retrieved March 16, 2016, from Waypoint: http://odara.waypointcentre.ca/

Wexler, D. (2006). Therapeutic jurisprudence. In A. Taylor, Justice as a basic human need (pp. 61-69). New York: Nova Science Publishers.

Willig, C. (2008). Introducing Qualitative Research in Psychology. New York: Open University Press.

Workman, K. (2012a). Justice Matters. Rethinking crime and punishment (pp. 1-14). Mt Eden: Third Space Trust.

Workman, K. (2012b). Restorative justice: Victims, violators and community - the path to acceptance. International Conference and Workshops on Restorative Justice, Human Rights and Peace Education (pp. 1-33). Taiwan: Restorativejustice.org.

Zehr, H. (2008). Doing justice, healing trauma - The role of restorative justice in peacebuilding. South Asian Journal of Peacebuilding , 1 (1), 1-16.

Zehr, H. (1989). Justice: Stumbling toward a restorative ideal. New Perspectives on Crime and Justice, Occasional Papers of the MCC Canada Victim Offender Ministries Program. 7, pp. 1-13. Elkart: MCC U.S. Office of Criminal Justice.

Zehr, H. (2002). The little book of restorative justice. Intercourse, PA: Good Books.

Zehr, H., \& Mika, H. (2003). Fundamental concepts of restorative justice. In E. McLaughlin, R. Fergusson, G. Hughes, \& L. Westmarland, Restorative justice critical issues (pp. 40-43). London: Sage.

Zehr, H., \& Toews, B. (2004). Critical Issues in Restorative Justice. New York: Willan Publishing.

Zernova, M., \& Wright, M. (2007). Alternative visions of restorative justice. In G. Johnstone, \& D. Van Ness (Eds.), Handbook of restorative justice (pp. 91-108). Portland: Willan Publishing. 